DOE/CS/40178.000-01

Volume 2 (of 2 Volumes)

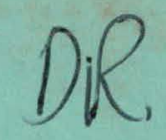

\title{
Relevance of the Second Law of Thermodynamics to Energy Conservation
}

January 1980

\author{
MASTER
}

Prepared for:

U.S. Department of Energy

Assistant Secretary for

Conservation and Solar Energy

Office of Industrial Programs

Purchase Request No 01-79 CS40178.000 


\section{DISCLAIMER}

This report was prepared as an account of work sponsored by an agency of the United States Government. Neither the United States Government nor any agency Thereof, nor any of their employees, makes any warranty, express or implied, or assumes any legal liability or responsibility for the accuracy, completeness, or usefulness of any information, apparatus, product, or process disclosed, or represents that its use would not infringe privately owned rights. Reference herein to any specific commercial product, process, or service by trade name, trademark, manufacturer, or otherwise does not necessarily constitute or imply its endorsement, recommendation, or favoring by the United States Government or any agency thereof. The views and opinions of authors expressed herein do not necessarily state or reflect those of the United States Government or any agency thereof. 


\section{DISCLAIMER}

Portions of this document may be illegible in electronic image products. Images are produced from the best available original document. 


\section{Available from:}

National Technical Information Service (NTIS) U.S. Department of Commerce 5285 Port Ruyal Road Springfield, Virginia 22161

Printed Copy: $\$ 15,00$

Microfiche: $\quad \$ 3.00^{50}$ 


\section{Relevance of the Second Law of Thermodynamics to Energy Conservation 将}

January 1980

MASTER

Prepared by:

National Bureau of Standards

General Energy Associates Inc.

$44^{9} 90^{\circ}$

Cherry Hill New Jersey

Purchase Request No 01-79CS40178.000

Prepared for:

U.S. Department of Energy

Assistant Secretary for

Conservation and Solar Energy

Office of Industrial Programs

Washington, DC 20545

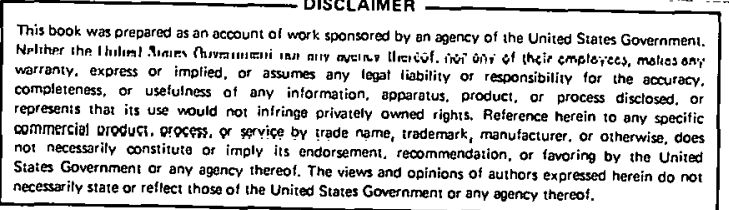


I. Introduction and Summary $\ldots \ldots \ldots \ldots \ldots \ldots \ldots \ldots \ldots \ldots \ldots$

II. Thermodynamic Availability and Effectiveness Definitions . 13

III. Evaluation of Monitoring Applications .............. 23

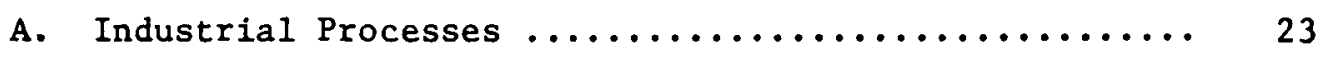

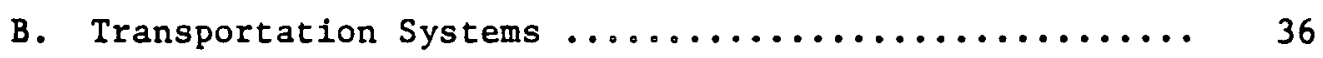

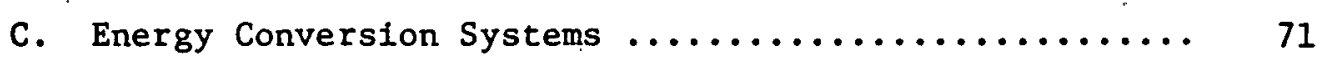

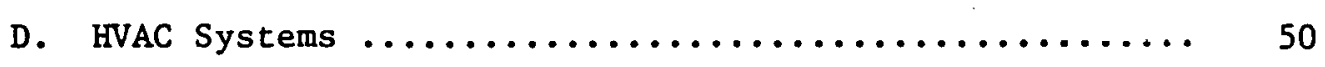

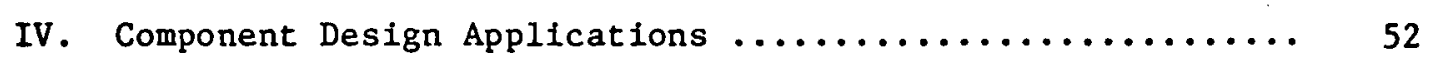

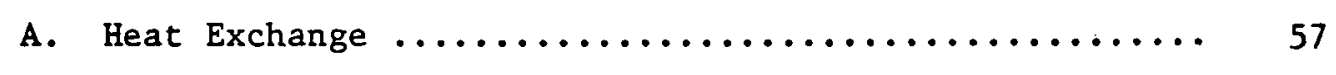

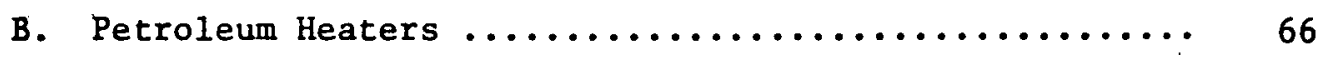

C. Multi-Effect Evaporators ................... 80

D. Distillation .................................. 99

v. Process Design and Modification Applications .......... 111

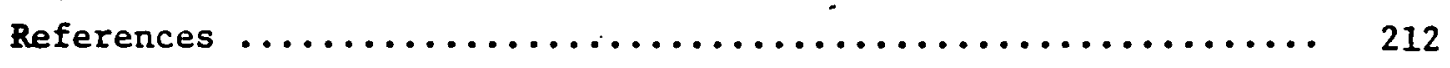

\section{Appendices}

A. Industrial Process Flow Diagrams $\ldots \ldots \ldots \ldots \ldots \ldots \ldots \ldots 214$

B. Available Energy Analysis for HVAC ............. 235

C. Transportation System Analysis ............... 255 


\section{Introduction and Summary}

In this report the use of the Second (2nd) Law of Thermodynamic concepts In energy system analysis is assessed. The basic advantages of using the 2nd law and availability concepts is that while the First (1st) Law of Thermodynamics considers all energy quantities with equal weight, the 2nd law (and the entropy concept) distinguishes a grade or quality of the energy. being considered as well as quantity. From this distinction flow two important considerations:

1. The losses at each point in a system can be assessed and measured in units that are directly proportional to input * or purchased fuel energy.

2. The minimum energy required to perform a given function or process is ascertainable as well as the maximum energy available from a given source.

These considerations represent valuable analysis tools and compei consideration of the 2 nd law in the analysis of energy systems. The use of 2nd law concepts is certainly not new or neglected. Practioners in the energy field make implicit use of these ideas in the design and operation of most contemporary energy systems. We address here the question of whether explicit use of these ideas can provide any new or overlooked benefits, in the design, operation, and reporting of energy using systems.

To address the expllcil use of 2 nd law concepts we have rhosen three areas of concern:

(1) energy monitoring: The use of avallability as an efficiency measure for comparing systems with different end functions or products.

* The terms input or purchased energy are used interchangeably to connotate energy used by the system or process elther from sources external to the process or internally generated fuel. 
(11) Process and System Design and Modification: The ut1lity of availability in the design and research phases of energy system development.

(111) Component Design and Modification: The ability to measure component performance and redesign for higher efficiency.

These three areas of concern provide a framework for making a meaningful inquiry into the use of 2nd law concepts in energy, system analysis. A larger concern of this study, is of course, the legislative mandate to investigate the relevance of 2 nd law concepts to the variety of federal energy conservation programs and legislation. In this regard the three areas addressed here are broad enough to encompass these programmatic concerns.

The basic conclusions we have reached here are that the 2 nd law is most appropriate in the process and system design and modification area and for component design. In the monitoring and reporting of energy systems we find the. use of 2nd law concepts generally inappropriate. Below we present in sumary form the basic conclusions (which are also presented in summary form in Table I):

- Energy Monftoring: The basic conclusion we have reached here is that it is inappropriate to use an availability mcosure to sumpre proccsses or systems whose products or end functions are different. In fact, when the functions or products are different, the realilles of economics, societal factors, etc. make these thermodynamic comparisons difficult if not futile. Where the product or function is the same, present efficiency measures are quite adequate. The most useful ranking criterium is generally purchased energy per unit function, where the function can be quantified in units 
that are appropriate to the function. For a comparable function this parameter serves as sultable ranking criteria.

To probe the use of monitoring we have explored the industrial sector in greatest depth. The rationale for this is that the unit function (eg. unit of production) is most explicitly defined in the industrial sector so that the application of 2 nd law here can be most reasonably applied. Twenty diverse Industrial processes have been examined and various availability measures have been used to establish some ranking procedure for efficiency. We have been unable to distinguish any inherent advantage afforded by any of these measures relative to others, and have been unable to observe any intrinsic insights these measures afforded in comparing different processes. Below we describe. the conclusions drawn from these comparisons and also describe our conclusio: 3 with regard to monitoring in the other sectors.

- Industrial Processes: Availability efficiencies for processes. have been defined and twenty processes have been analyzed in depth, a set of ranking procedures have been attempted. In general we have concluded that the various availability measures do not provide a consistent and meaningful ranklue of industrial processc3, (Table II). In fact, the only correlating parameter appears to be process temperature. Generally high temperature processes have higher availability efficiencies than lower temperature processes. This can of course be expected from the nature of the availability definitions and is reflective of the desirability of cogeneration and heat pumps in energy supply technology.

- Transportation Systems: We have concluded here that the measures of efficiency such as passenger miles/energy, etc. are not easily quantifiable In 2nd law terms and that other significant mitigating factors are present (political, sociological, etc.), and so the methods now in use to measure energy efficiency are quite sultable. We discuss this in Section IiIB. 
- HVAC Systems: Here, if one attempts to compare existing HVAC systems In different, existing buildings, one must first isolate the differences due to the building heating and cooling loads. The availability measure can then be constructed by: 1solating three areas of loss: conversion of fuel to thermal energy, delivery of thermal energy to room or space boundaries, and delivery of thermal energy to the space itself. If vile nuw cumpares different buildinge, the loopco mny be concentrated in out ur several of these areas owing to considerations of building design.

Therefore, a conclusion that a given building is more efficient than another ignores the mitigating considerations of function of the space. As before, for a given building, the availability measure may be helpful in redesign or system modification of a single system but should not be useful in comparing building, energy efficiency. Again this is discussed at greater length in Section IIID.

- Power Conversion Systems - With the output of different conversiou systems easily representahle hy a single parameter, entery/clme, availability may have some role in monitoring. Where the output of the conversinn systom 13 mechanical work, of course, the thermal efficiency now plays a role. comparable to any new 2 nd law measure. However, for cogeneration systems where the output can be mechanical work and thermal energy, thermal ffflclency now is difficult to apply.

In this case an availability measure may be valuable in comparing dissimllar systems. Here again mitigating factors such as economies of scale of various prime movers may dictate the nature of the system employed. This is discussed at greater length in Section IIIC. (Table III). 
- Process \& System Design \& Modification - The 1mplicit use of 2nd law concepts in process design and modification has been widespread in industry. Generally a checklist of some kind exists in design to guide the designer. We belleve that an explicit, computerized design tool which subjects each design to an availability analysis may be quite useful. In Section IV we have chosen six processes for detailed analysis. These analyses clearly indicate the system losses and inefficiences. All losses throughout the system may now be represented by a single unit of work or energy called availability which can be directly attributable to the fuel penalty exacted by the loss. This may suggest a new optimization procedure that begins with component optimization and then proceeds with some overall system matching of components. While no new drastic or radical energy efficiencies are likely with this tool, it may make energy efficiency tradeoffs more explicit, easier to conduct and reduce the number of calculations necessary. The major reservation we have in recommending such an approach is the requirement for a thermodynamic property data base of a scope and accuracy that does

not now exist or could be brought into existence with any reasonable effort. In order to explore this point, it would be neressary to examine fully the cost/benefits to the industrial process resulting from the application of a 2nd law based computer analysis to existing or new processes. This kind of analysis would require the development of the appropriate thermodynamic property data base and iriclude a detalled examination of the sensitivity of the 2 nd law results to the accuracy of these thermodynamic properties. 
Another important area is in the reexamination of processes for more drastic or radical conceptual changes in the processing pattern. As pointed out by Berg (1979) 2nd law concepts may point the way to a new method of processing for which both capital and energy costs are lower. This is not to say the 2nd law can by itself facilitate or bring about new invention - it can however help focus on new ways of thinking about processes.

- Component Design and Comparison: Here again, it may be dangerous or misleading to compare components with differing functions (e.g. compressors and heat exchangers) with a single availability measure in the hope of determining which components are more efficient than others. However, in the design and development of a single component, availability measures may be of value in isolating the Inefficiencies. While most designers now use 2nd law concepts implicitly, an explicit computer model based on availability may allow a rapid and accurate tradeoff of capital expenditure and energy efficiency in design. This is especially true for components for which it is difficult to determine the fuel or purchased energy penalty exacted by a 10ss. Gaggioli (1976) has given an excellent discussion of this in his examination of feedwater heater replacement in power plants. In Section IV representative components were chosen for pvaluation, and the nature of the capital/energy tradeoff is clearly exhibited. Tn Fig. I we see thia tradeoff for a heat exchanger in terms of Lost Work/unit area vs. heat exchanger surface area. One can now perform the necessary tradeoff directly on this component in isolation of the rest of the system and then perform a matching procedure to integrate the component to the other systems constraints and components. The earlier caveats about thermodynamic properties apply here with equal validity. These points are , discussed more fully in Section $V$. 
Table I: Summary of 2nd Law Applications

\begin{tabular}{|c|c|c|c|c|}
\hline \multirow[b]{2}{*}{ Industrial } & Monitoring & $\begin{array}{l}\text { Sys tem/Process } \\
\text { Change }\end{array}$ & $\begin{array}{l}\text { Component } \\
\text { Analysis }\end{array}$ & Comments \\
\hline & C & A & A & $\begin{array}{l}\text { Limitations here } \\
\text { are property } \\
\text { data base and } \\
\text { suitable computer } \\
\text { tools }\end{array}$ \\
\hline 'Transportation & C & C & B & $\begin{array}{l}\text { Social and } \\
\text { Economic factors } \\
\text { cannot be } \\
\text { quantified into } \\
\text { an availability } \\
\text { framework. }\end{array}$ \\
\hline $\begin{array}{l}\text { HVAC Resid/ } \\
\text { Commercial }\end{array}$ & C & B & B & $\begin{array}{l}\text { Comfort factors } \\
\text { as well as } \\
\text { architectural } \\
\text { and aesthetic } \\
\text { factors confound } \\
\text { attempts at } \\
\text { quantification. }\end{array}$ \\
\hline Energy Conversion & 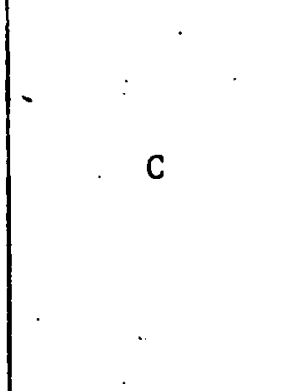 & B &. & $\begin{array}{l}\text { Thermal efficien- } \\
\text { cy is quite suit- } \\
\text { able except for } \\
\text { cogeneration } \\
\text { system. Avail- } \\
\text { ability does pin- } \\
\text { point losses with- } \\
\text { in convergion } \\
\text { systems. }\end{array}$ \\
\hline \multirow[b]{3}{*}{. } & \multirow[t]{3}{*}{$\begin{array}{l}\text { Generally not } \\
\text { useful - } \\
\text { present } \\
\text { seandards of } \\
\text { evaluation } \\
\text { suffice. }\end{array}$} & \multirow{3}{*}{$\begin{array}{l}\text { 2nd law most } \\
\text { suitable for } \\
\text { Industrial } \\
\text { process modl- } \\
\text { fication since } \\
\text { availability } \\
\text { losses are } \\
\text { proportional to } \\
\text { Input fuel. } \\
\text { Those energy } \\
\text { systems with } \\
\text { elements far } \\
\text { removed from } \\
\text { polnt of fuel } \\
\text { use are prob- } \\
\text { ably most } \\
\text { suitable }\end{array}$} & $\begin{array}{l}\text { For component } \\
\text { analysis, avail- } \\
\text { ability losses } \\
\text { help pinpoint } \\
\text { the losses in the } \\
\text { system. }\end{array}$ & \\
\hline & & & \multicolumn{2}{|c|}{ KEY } \\
\hline & & & $\begin{array}{l}\text { A. Potential App } \\
\text { B. Limited Appli } \\
\text { C. Application A }\end{array}$ & $\begin{array}{l}\text { Lication } \\
\text { ation } \\
\text { pears Poor }\end{array}$ \\
\hline
\end{tabular}


Table II: Comparison of Industrial processes

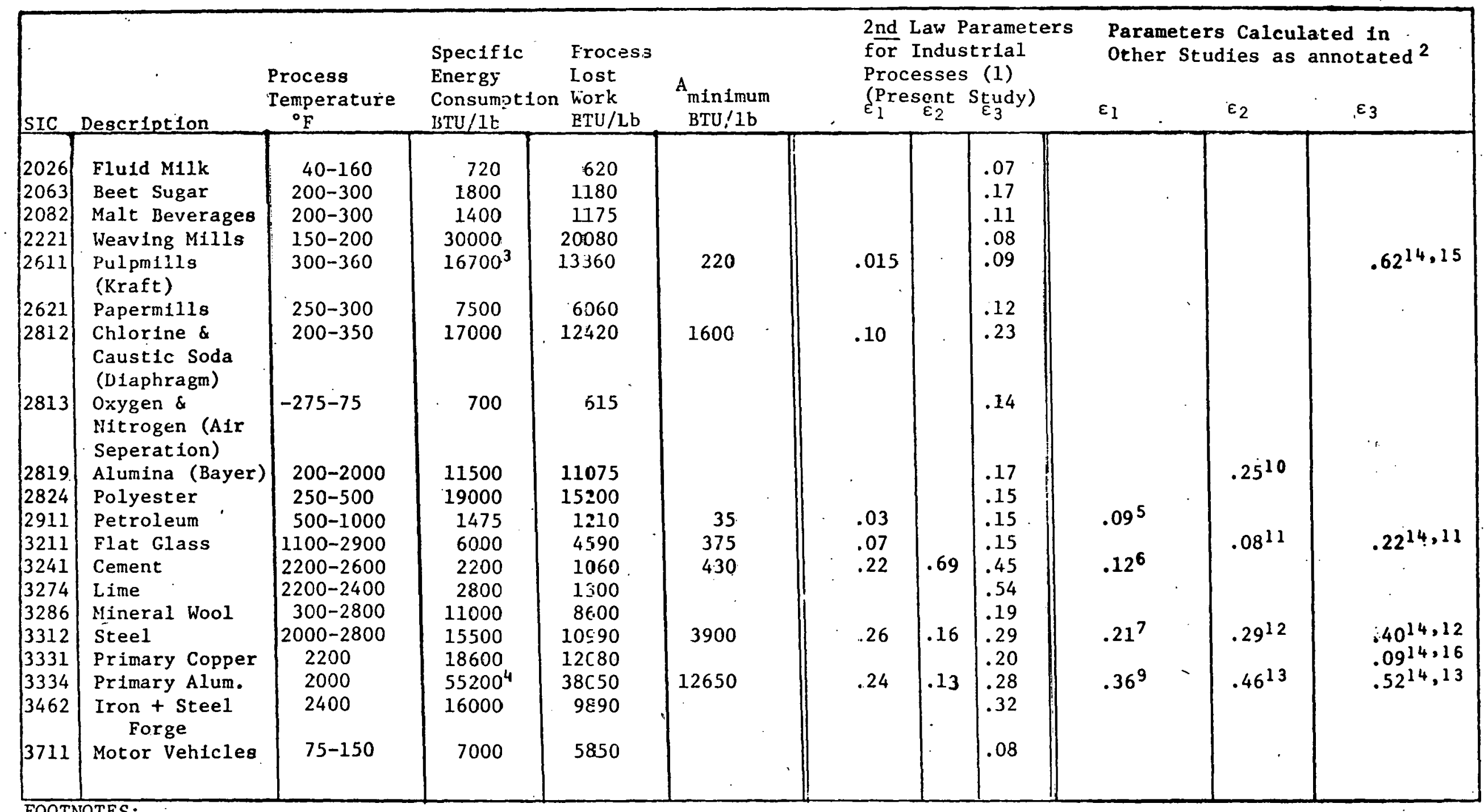

FOOTNOTES:

These parameters represent the entire tndustrlal process from feedstock to final product. Both converters and process unit operations are included.

${ }^{2}$ These parameters represent the pork of other investigations. The parameters cover either part or all the appropriate industries. They are all annotated.

${ }^{3}$ Includes waste products. consumed as fuel.

${ }^{4}$ Includes energy content of carbon anode. 


\section{FOOTNOTES (Continued)}

${ }^{5}$ Thermoelectron report (reference 5): Based on actual refinery data, product mix and operations different from national average.

6

Calculated from data in Thermoelectron study (reference 5).

7 Thermoelectron study (reference 5). Includes available energy of scrap input in denominator.

${ }^{8}$ Calculated from avallable energy estimates in Gordian Assocs. Study (reference 6). Represents a dry process kiln only - no crushing, grinding, milling, or clinker cooler operations.

${ }^{9}$ Calculated from data in thermoelectron study (reference 5 ).

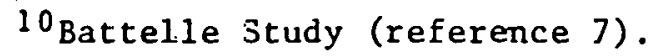

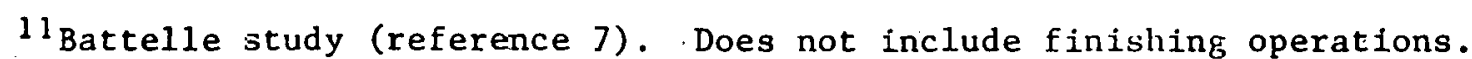

12 Battelle study (reference 7). Does not include complete finishing or heat treating operations.

13 Battelle study (reference 7). This parameter represents electrolysis operation only and does not include anode manifacturing or finishing operations.

${ }^{14} \varepsilon_{3}$ is equal to the ratio of available energy leaving an cperation to the available energy entering. In the Battelle study (reference 7) feedstock and product chemical availabilities are included directly in the numerator and denominator. In processes where feedsto:k and product avallability is large, this parameter tends to be high regardless of the losses in fuel vtilization.

15 Large chemical availability assoclated with wood and pulp. Parameter calculated by Battelle (reference 7) for, kraft digestion and liquor recovery only and does not include bleaching or drying operations.

16 Battelle study (reference 7 ) includes ore concentration step. Large availability associated with input ore. 


\section{Conversion Process}

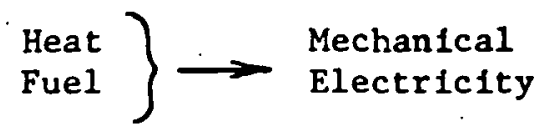

Chemical $\longrightarrow$ Electricity

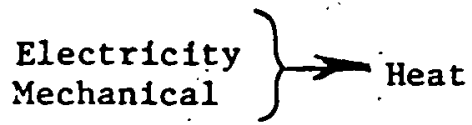

Fuel

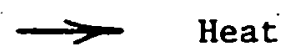

Fue1

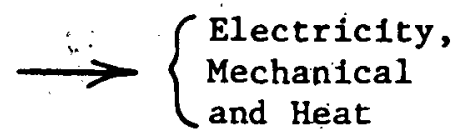

Equifment

Engir.əs

Fuel Cell

Heat pumf

Botler

Hot air Furnace

Cogezeration

Syst $\geqq m$

\section{Present Measures}

of Efficiency

Therma:

Ëficiency

Ilectricity

Chemical Energy

C.o.P.

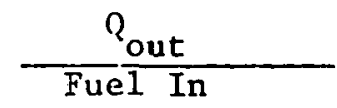

First Law Efficiency

\section{2nd Law Measures}

Uses Avallable

Energy in Fuel, Similar to Thermal Efficiency

Similar to Present Measure

Similar to Present Measure

Availability Efficiency is much Lower

Avatlability Efficiency is able to Reduce Work and Heat Output To Common Units

\section{Comments}

Present Measure

is Adequate

11

For Comparing Converters at

a similar Temperature Output, Present Measure is Adequate

May Provide a More Suitable Measure than is Presently Used. 
P1gure 1. Tradeoff of Lost Work/Unit Area v8. Heat Exchanger Surface Area

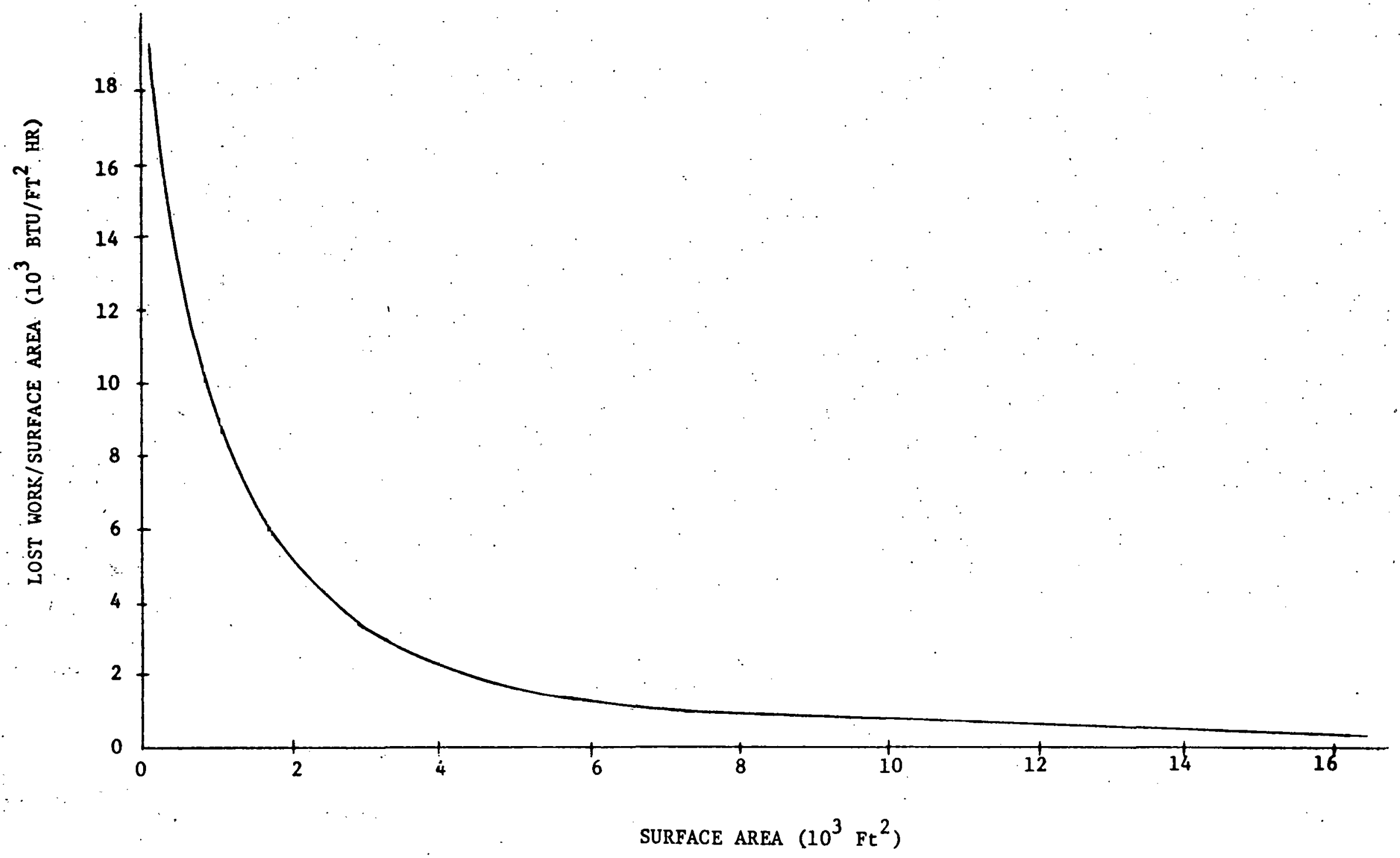


Summary Recomrendations

- The use of avallability measures in the modification and design of processes and components should be pursued. The explicit use of 2nd law concepts in the research and development process may be useful in facilitating the invention and discovery of new process approaches. In the modification and design process explicit use of availahility may reduce the time and effort in design optimization and may possibly lead to optimal design points that are different then present designs. We need to thoroughly evaluate the cost/benefit of availability in design/ modification procedures. To evaluate the benefits:

- a computer package must be developed that can' subject the design to availability analysis and can be used as another loop in the design and development process. This should then be applied to a representative process to determine the actual benefits that occur.

To determine the costs:

- The sensitivity of the results to a detailed knowledge of thermodynamic properties must be done and the effort to put in place this new property capability must be assessed.

- The difficulties that engineers and designers would experience in using availability must be assessed. What kinds of workshops and educational mechanisms would be required, and again are the benefits commensuratc with the effort necessary. 
II. Thermodynamic Availability and Effectiveness Definitions

Thermodynamics suggests that an analysis of the avallable work or available energy consumption of a given process can provide an additional measure of energy utilization. Available energy is defined as the maximum work that can be provided by a system as it proceeds to a specified finai state in thermodynamic equilibrium with the atmosphere (1).

The thermodynamic availability may be determined for each process stream by the following equation:

$$
a=h-T_{D} s
$$

where

$$
\begin{aligned}
& a=\text { specific thermodynamic availability, } \\
& (B T U / 1 b) \\
& h=\text { stream enthalpy }(B T U / 1 b) \\
& s=\text { stream entropy }\left(B T U / 1 b{ }^{\circ} R\right) \\
& T_{D}=\text { dead state temperature }\left({ }^{\circ} \mathrm{R}\right)
\end{aligned}
$$

The total thermodynamic availability for a stream is then determined thus:

$$
A_{i}=w_{i} a_{i}
$$

where

$$
\begin{gathered}
A_{1}=\begin{array}{c}
\text { total stream thermodynamic availability } \\
(B T U / h r) .
\end{array} \\
w_{1}=\text { stream flow rate }(\mathrm{lb} / \mathrm{hr})
\end{gathered}
$$

The thermodynamic availability for electricity is taken as the direct conversion of power to BTU/hr because electrical energy can be utilized to generate any practical temperature, hence electricity is totally available. 
The selection of the dead state temperature is normally taken as the average amblent temperature to which the process rejects heat. The dead state temperature should be selected as that temperature to which the process system will be rejecting heat on a long term basis. In this analysis the following dead state conditions are generally used:

$$
\begin{aligned}
& T_{D}=535^{\circ} R\left(75^{\circ} \mathrm{F}\right) \\
& P_{j}=1 \text { atmosphere }
\end{aligned}
$$

for single component streams with constant specific heats (and pressure $=\mathrm{P}_{0}$ ). The following form of availability is used relative to dead state.

$$
A_{1}=w_{1} c_{p}\left(T-T_{D}-T_{D} \ell n \frac{T}{T_{D}}\right)
$$

where

$$
\begin{aligned}
& \quad c_{\mathbf{p}}=\text { specific heat }\left(\frac{\mathrm{BTU}}{1 \mathrm{~b}^{\circ} \mathrm{R}}\right) \\
& \quad \mathrm{T}=\text { Process stream temperature }\left({ }^{\circ}\right)
\end{aligned}
$$

Several second law efficiencies, effectiveness or performance parameters have been presented in the literature $(1,2,3)$ and are summarized in Table IV. As shown in this table there are a significant number of variations and formulations for what is considered by many to be the same parameter. Because of data availability or lack thereof, absence of detailed information for industrial process, and lack of uniformity of definition, the literature contains 2nd law performance calculations for the same process which vary over a wide range. In this study we have attempted to use a limited number of parameters for investigation.

The parameter formulations investigated in this study to ascertain the usefulness of 2nd Law Analysis as a means to monitor system performance are defined below: 
Table IV

Formulations of 2nd Law Performance Parameters

\section{A minimum \\ Aactual}

A Increase

A out

A In

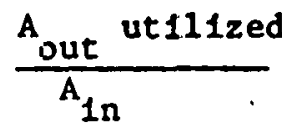

$\frac{\text { Aut }_{\text {ot } 111 z e d}}{\text { Aut }^{\text {total }}}$
Radio of the theoretical

minfmum amount of avallable

energy required to perform

a given function to the

actual avallable energy used.

Ratio of the avallability

increases of the destred

outputs of a system to

the availability decreases

that were required to pro-

duce the outputs.

Radio of available energy

out of the system to ava11-

able energy into the system.

The numerator includes both

ut1lized and wasted streams.

Ratio of utilized avallable energy out of the system

to avallable energy supplied

the system.

Fraction of the available

energy leaving the system

which is actually utilized.
Ross, Reference 1

Refistad, Reference 2

Hall, Reference 7

Ha11, Reference 7

Reistad, Reference 2

Streb, Reference 25 


$\frac{A_{\text {min }} \text { practical }}{A_{\text {in }}}$
$\frac{A_{\text {cut }}}{A_{\text {nin }} \text { pratical }}$
$\frac{A_{\text {out }}}{E_{\text {in }} .}$

Ratio of the minimum ava11atility reçuired to run the process in given configurations frdgement c.f practical $1 \mathrm{im}$ itations on the system to the actual availability input.

Rat lo of the avallability output from a process to the practical minfmum avallability required to run the process.

Ratlo of the avallable energy out of the system to the energy input to the system.
Streb, Reference 25

Hame1, Brown, Reference 8,9

Streb, Reference 25

Hal1, Reference 7 


$$
\begin{aligned}
& \varepsilon_{1}=\frac{A_{M I N}}{A_{I N}}, \frac{\text { minimum availability required to perform process function }}{\text { availability of incoming streams or supply }} \\
& \varepsilon_{2}=\frac{A_{I N C}}{A_{\text {DEC }}}, \frac{\text { availability increase of process streams }}{\text { availability decrease of energy supply streams }} \\
& \varepsilon_{3}=\frac{A_{\text {OUT }}}{A_{I N}}, \frac{\text { total available energy of outflow streams }}{\text { total available energy of inflow streams }} \\
& w=A_{\text {IN }}-A_{\text {OUT }} \text {, the process lost work. }
\end{aligned}
$$

This is a measure of the destruction of the availability in the process. The availability associated with an endothermic reaction is subtracted out, that associated with an exothermic reaction is added.

The first thermodynamic performance parameter, $\varepsilon_{1}$, represents the absolute minimum amount of available energy which must be expended to accomplish the desired transformation of feedstock (material or flow stream) to an end product. $A_{\min }$ is usualiy very small and represents a reversible path from beginning to end state and therefore is an ideal or theoretical level.

All real processes require an amounit of thermodynamic work greater than the ideal work to accomplish the desired state transformations since real processes represent irreversibilities which rosult in lost work. (see the following sketch).

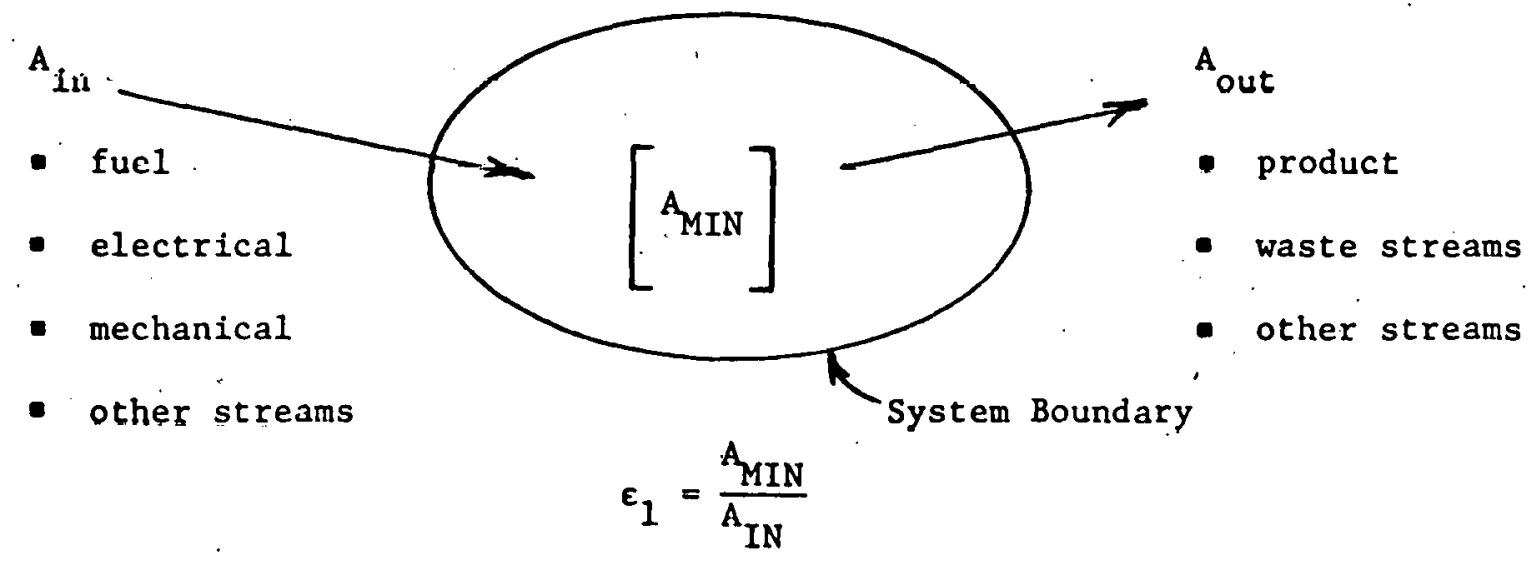

Total Lost Work $=A_{\text {IN }}-A_{\text {OUT }}>A_{\text {MIN }}$ 
Th1s lost work, $W$, may be defined for each untt operation or piece of equipment as follows:

$$
\begin{gathered}
A_{1} \text { (Incoming streams) }-A_{1} \text { (outgoing streams) }=\dot{W}_{i} \text { (lost work of } \\
\text { unit operation) }
\end{gathered}
$$

such that the total lost work is,

$$
\text { - }
$$

$$
w=\sum_{i} w_{i}(i=1, n)
$$

where $\mathrm{n}=$ total number of process unit operations or pieces of equipment

The second performance parameter, $\varepsilon_{2}$, is that generally defined as the "Gaggioli" efficiency (4). This parameter defines the increases in the availability of the product streams; that is outlet minus inlet conditions. The denominator defines the decrease in availability of the source streams which supply the availability to perform the specified function. This parameter is amply demonstrated in converter or power. systems as shown in the following sketch.

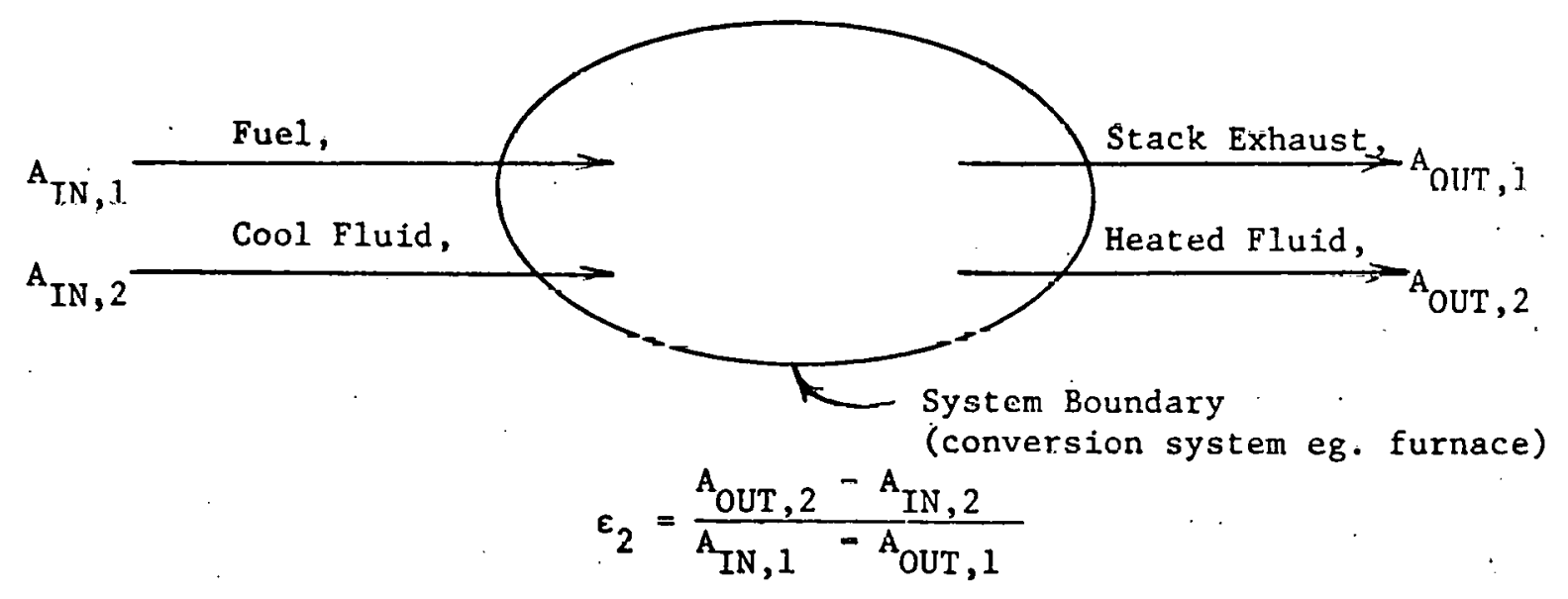

This is often reduced to: ${ }^{2}$

$$
\varepsilon_{2}=\frac{A_{\text {OUT, 2 }}-A_{\text {IN , 2 }}}{A_{\text {Fuel }}}
$$


The third parameter, $\varepsilon_{3}$, designated effectiveness, considers the maximum avallability of all the flow streams leaving a process, whether the avallability of these streams is used or not.

In order to explicitly define this last term a generalized process or system is presented below:

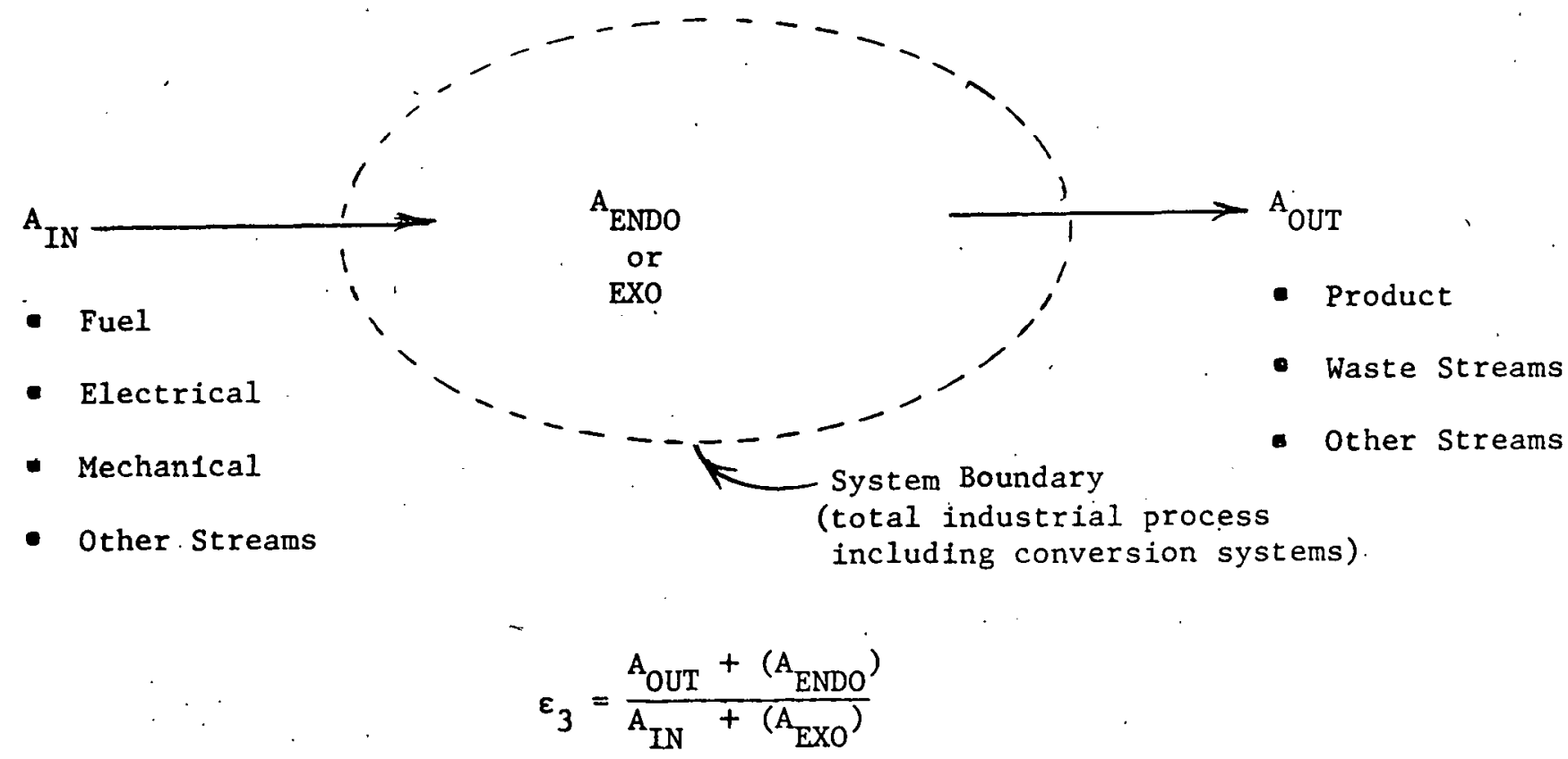

The available energies of endothermic and exothermic heats of reaction are estimated by the difference in Gibbs' free energy between the reactants and products. Electricity is considered equivalent to $3413 \cdot \frac{\mathrm{BTU}}{\mathrm{KWh}}$.

Although availability analysis may be applied. to any system, the . application of second law efficiencies to the industrial sector has been examined in significant detail. In order to perform the analysis, industrial processes have been subdivided into unit operations and converters as shown below. 


\section{Industrial Process}
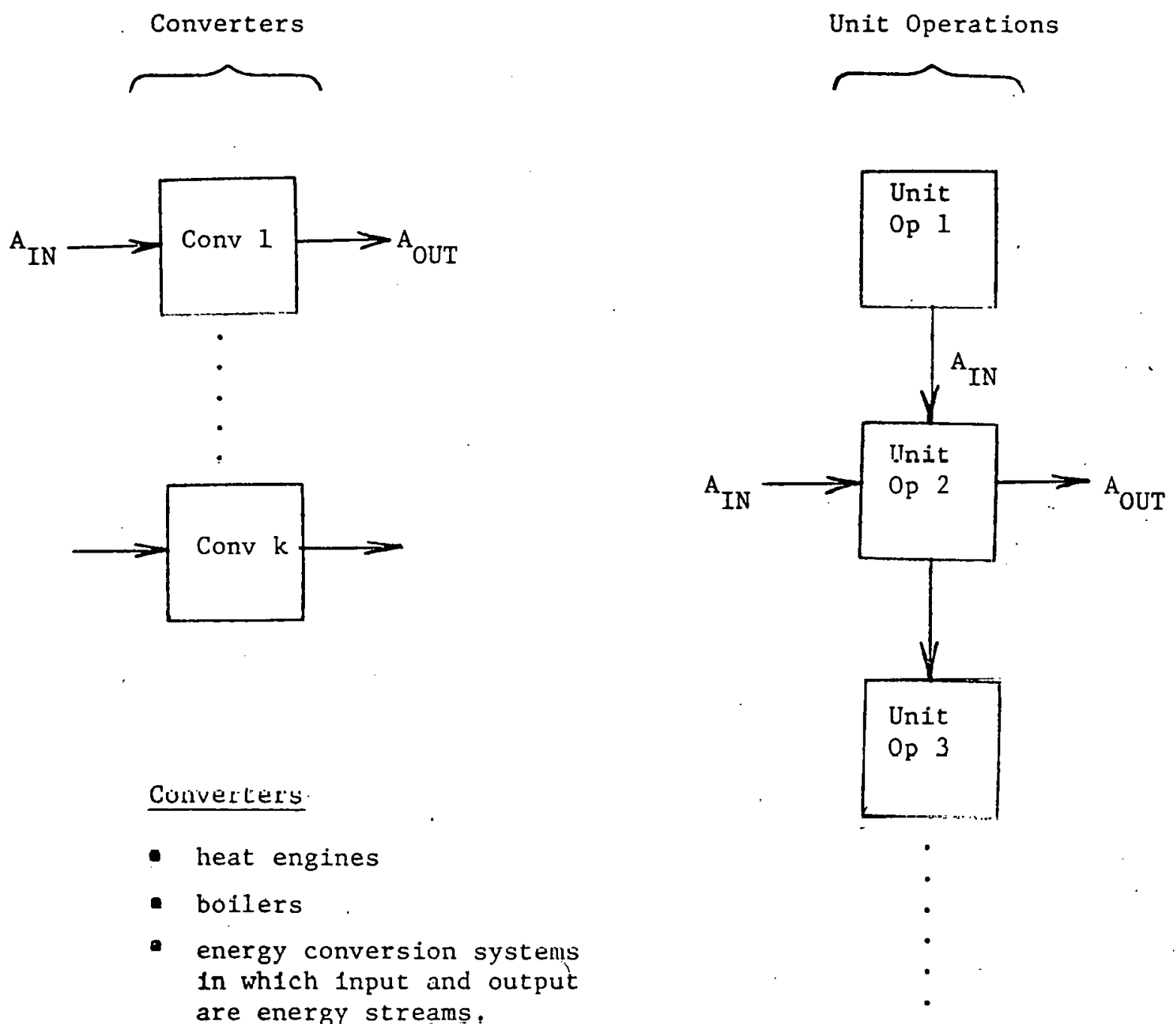

- heat engines

- boilers

- energy conversion systems in which input and output are energy streams.

\section{Unit Op i}

Unit Operations

- Any operation which transforms the product stream.

(i.e. changes the the rmodynamic state of the process fluid using a unique amount of avallability to accomplish the transformation). 
In order to determine 2 nd law performance parameters or effectiveness of the Industrial process including unit operations only and not converters, a system boundary is drawn around the entire configuration of unit operations. In the case below $A_{\text {IN }}$ comes only from converters or external sources, not other unit operations.

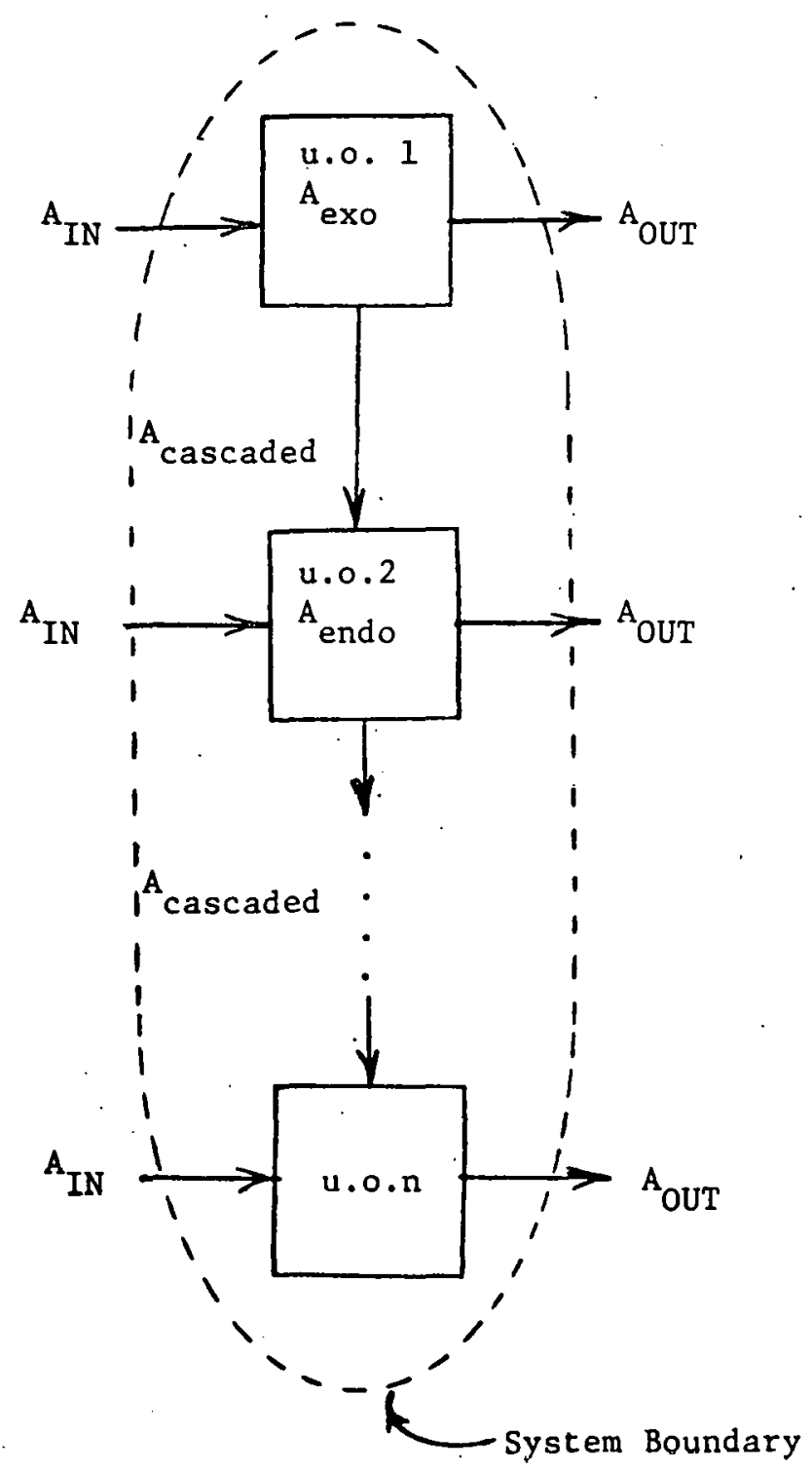


22

For each of the unit operations, the lost work may be defined as previously stated:

$$
\begin{aligned}
\mathrm{W}_{1} \text { (lost work of unit operation) } & =\mathrm{A}_{\mathrm{IN}} \text { (incoming streams) }-\mathrm{A}_{\text {OUT }} \text { (outgoing streams) } \\
\mathrm{W} & =\sum \mathrm{W}_{i}
\end{aligned}
$$

The lost work may be defined for coach operation and for the total process and represents another parameter which may be utilized to evaluate systems. 
III. Evaluation of Monitoring Applications

Summary

A major area of investigation in this study is the use of availability as an efficiency measure or an energy monitor for comparing systems with different end functions or products. As a result of this analysis, presented in Sections III A, B, C and D, the basic conclusion reached is that it is not appropriate to use an availability measure or 2nd Law parameter to compare processes or systems whose products or end functions are different.

To examine the use of monitoring, the industrial sector was investigated in greatest depth. Twenty industrial processes were examined and the various availability performance measures have been used to establish some ranking procedure for efficiency. The most useful parameter to rank processes is purchased energy per unit production or per unit function, which can be quantified.

To attempt a camparison of energy efficiency for different processes using the 2nd Law parameter is unrealistic since the different losses may be due to the inherent nature of the process: low operating temperature, rate of production, product quality, etc.

\section{A. Industrial Process}

As indicated in Section II, a number of performance parameters have been selected to investigate the usefulness in monitoring industrial processes. In order to evaluate this application a wide. range of industrial processes, have been examined. These cover a broad spectrum of temperatures, energy Intensiveness (BTU/1b), types of unit operations, feedstocks and complexity. Over 20 different processes were considered and are listed in Table V. The process flow sheets are shown in Appendix A. We conclude from this that 2nd law measures are inappropriate in the monitoring and reporting of energy use. 
Table v. Comparlem of ruluatrinl proconsca

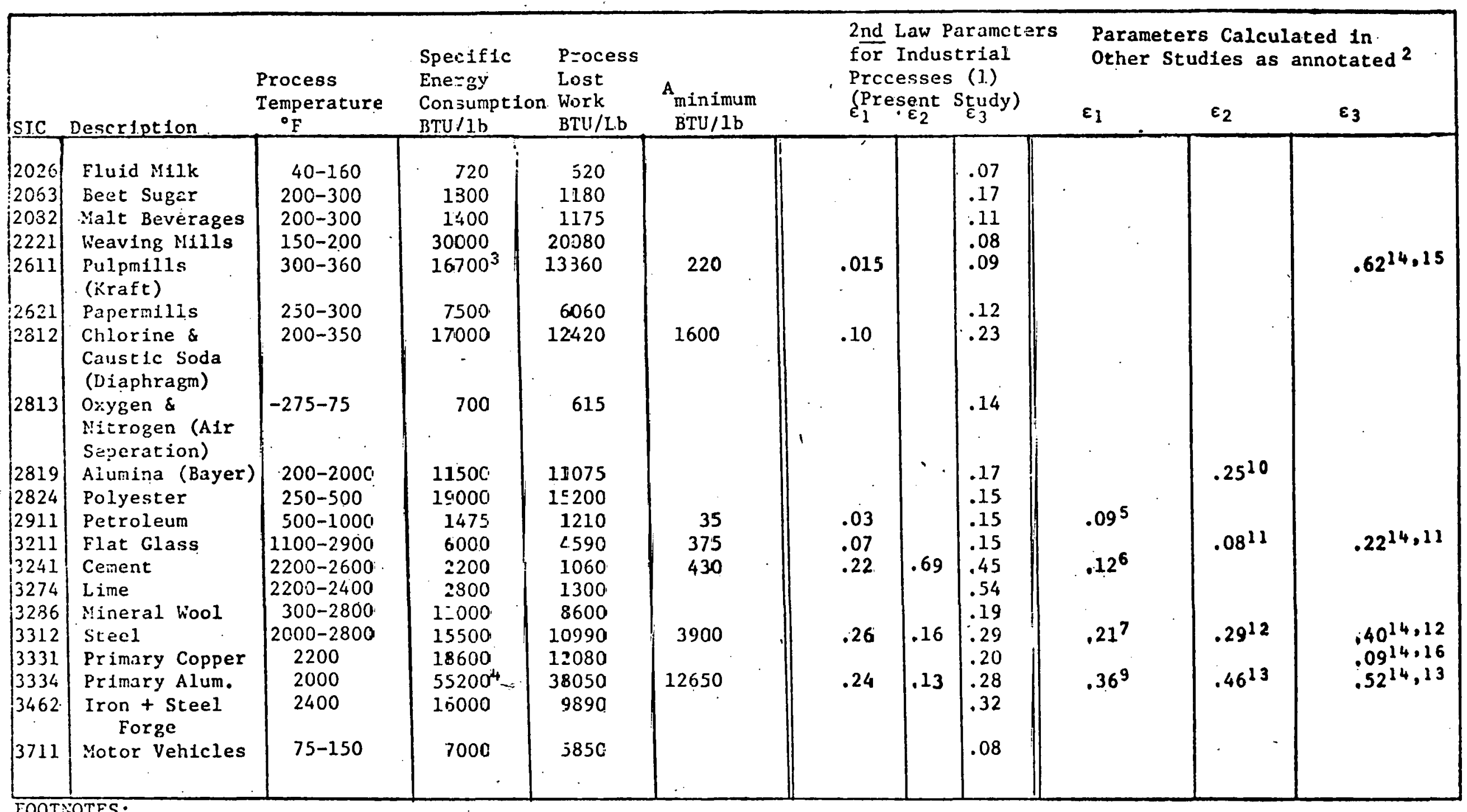

IThese parameters represent the entire 1-distrial process from feedstock to final product. Both converters and process unit opcritions are included.

${ }^{2}$ These parameters represent the work of other investigations. The parameters cover either part or all the appropiate industries. They are all annotated.

${ }^{3}$ Includes waste products consumed as fuel.

${ }^{4}$ Includes $e$ jy content of carbcn anode. 


\section{FOOTNDTES (Continued)}

5 Thermoelectron report, (reference 5). Based on actual refinery data, product mix and operations different from national average.

6

Calculated from data in Thermoelectron study (reference 5).

${ }^{7}$ Thermoelectron study (reference 5). Includes available energy of scrap input in denominator.

${ }^{8}$ Calculated from available energy estimates in Gordian Assccs. Study (reference 6). Represents a dry process kiln cnly - no crushing, grinding, milling, or clinker cooler operations.

${ }^{9}$ Calculated from data in thermoelectron stidy (reference 5).

10 Battelle Study (reference 7 ).

1 Battelle study (reference 7). Does not include finishing operations.

12 Battelle study (reference 7). Does not include complete finishing or heat treating operations.

${ }^{13}$ Battelle study (reference 7 ). This parameter represents electrolysis operation only and does not include anode manufacturing or finishing operations.

${ }^{14} \varepsilon_{3}$ is equal to the ratio of available energy leaving an operation to the available energy entering. In the Battelle study (reference 7) feedstock and product chemical availabilities are included directly in the numerator and denominator. In processes where feedstock and product availability is large, this parameter tends to be high regardless of the losses in fuel vtilization.

15 Large chemical avallability assoclated with wood and pulp. Parameter calculated by Battelle (reference 7) for kraft digestion ard liquor recovery only and does not include bleaching or drying operations.

16 Battelle study (reference 7) includes ore concentration step. Large availability assoclated with input ore. 
The industrial area was examined in this depth since it offers great diversity for analysis with fewest external factors (e.g. social, political, architectural, institutional, etc.).

The most useful and traditional ranking criterion in the industrial sector is generally purchased energy per unit production or unit function where the function can be quantified in units that are appropriate. In this study, the 2nd Law performance parameters selected in Section II were applied to each of the processes and are tabulated in Table $V$.

Using these parameters for each of the prucesses, correlations and ranking procedures were attempted as shown in Figures $2,3,4$ and 5 . In Figure 2, the lost work of the industrial process is plocted as a funcliui of the conventional parameter, BTU/1b. As shown there is reasonable linear correlation which points to the conclusion that the process lost work is directly proportinal to the energy consumed in the process. Thus, the energy intensity (BTU/1b) appears adequate añd suffices for comparative analysis; the lost work in this application appears to offer no new insight. However, the lost work analysis of components and systems appears to have potential in the design application as indicated in Section IV. and V.

In Figure 3, a correlation of 2 nd Law effectiveness, $\varepsilon_{3}$, with the characteristic process temperature indicaces Increasluy tifectivenesg with increasing temperature. This points to the potential for cogeneration type systems in conjunction with the low temperature processes. This is apparent because of the large $\Delta \mathrm{T}$ between the flame temperature and the process tomperature.

In Figures 4 and 5 various 2nd law parameters were examined for possible correlations and ranking criteria.

From these analyses no criteria suggests 1tself as a significant parameter to be used to rank or monitor industrial processes. 
Figure 2:

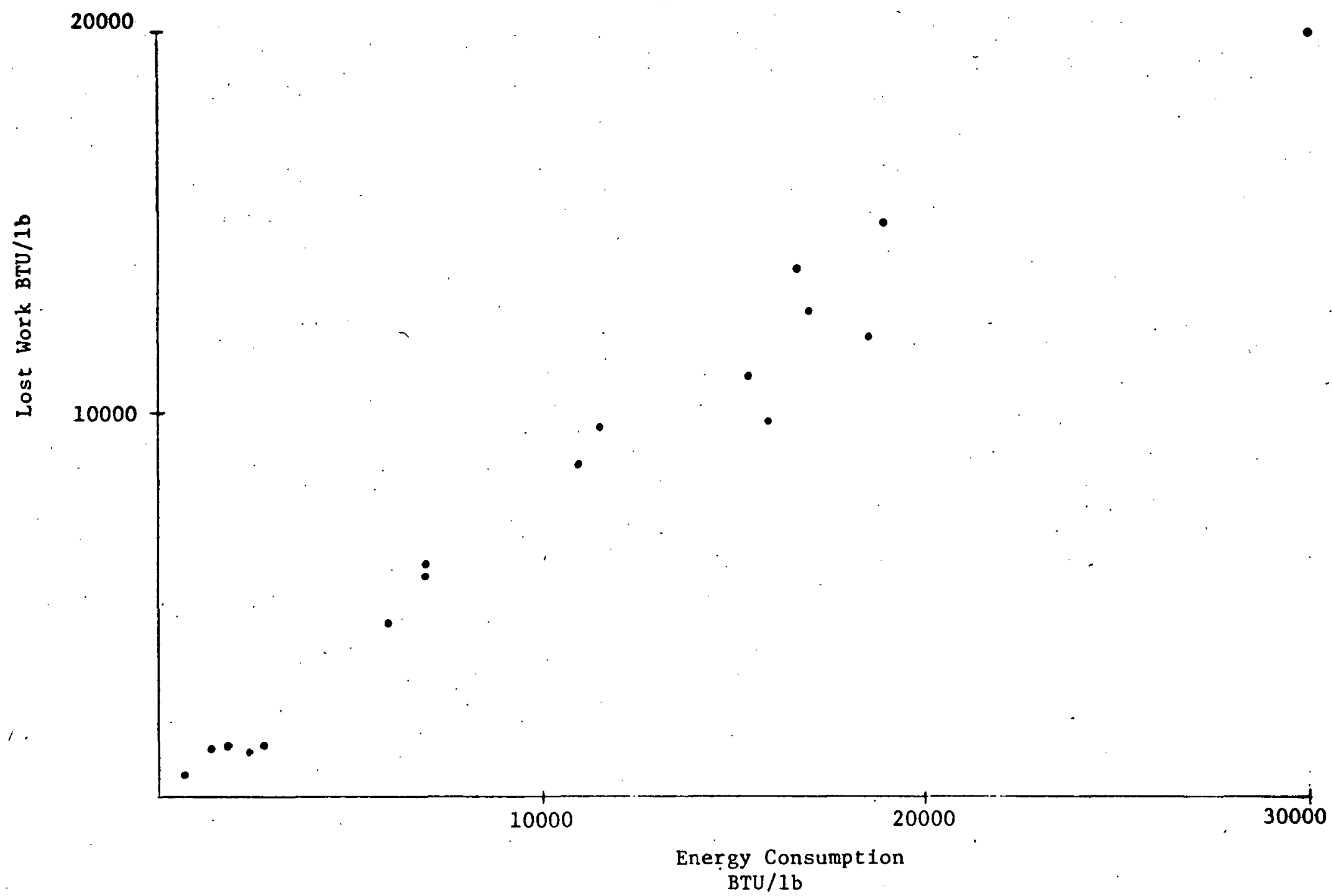


Figure 3.

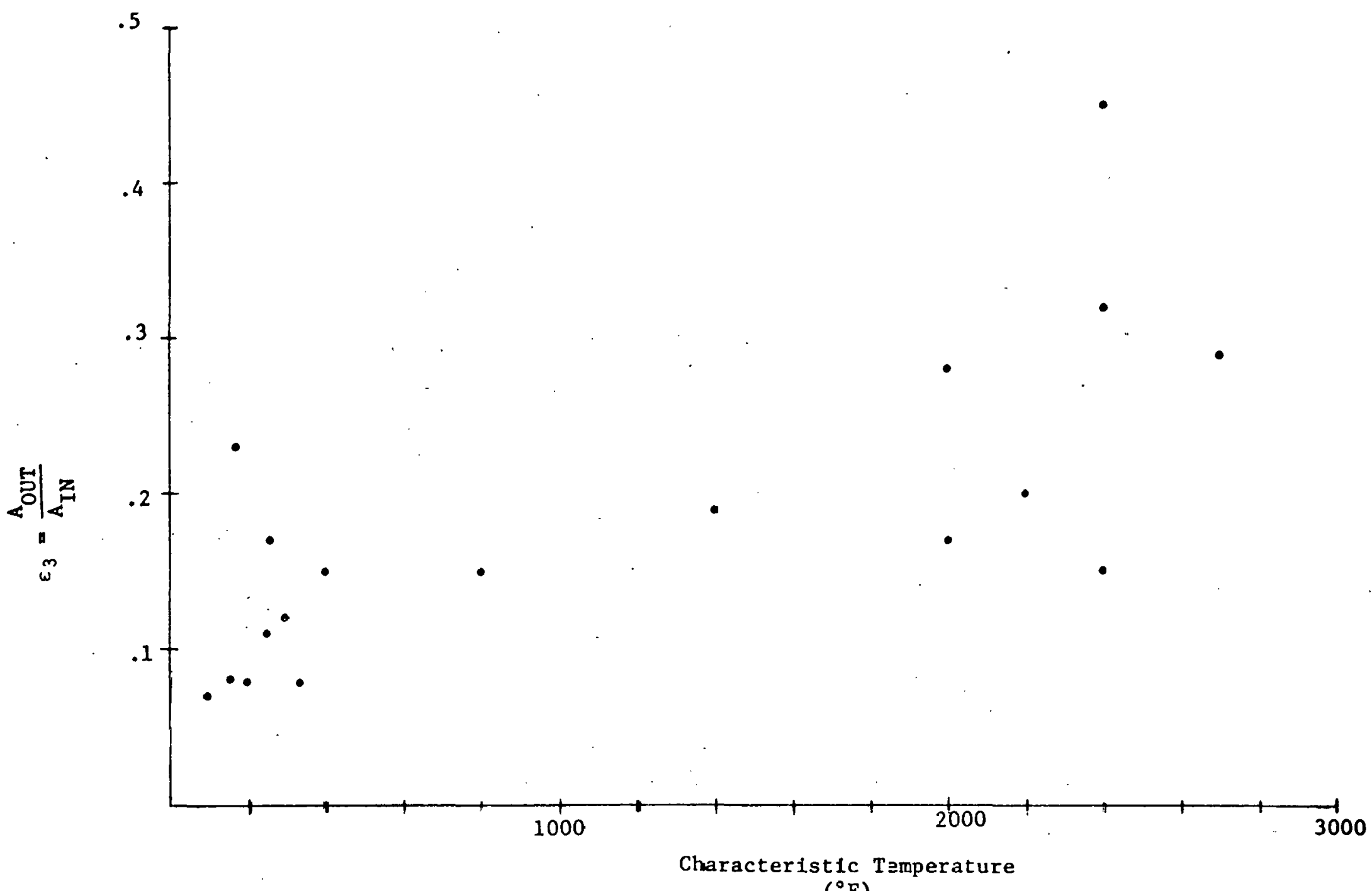

$\left({ }^{\circ} \mathrm{F}\right)$ 
Figure 4.

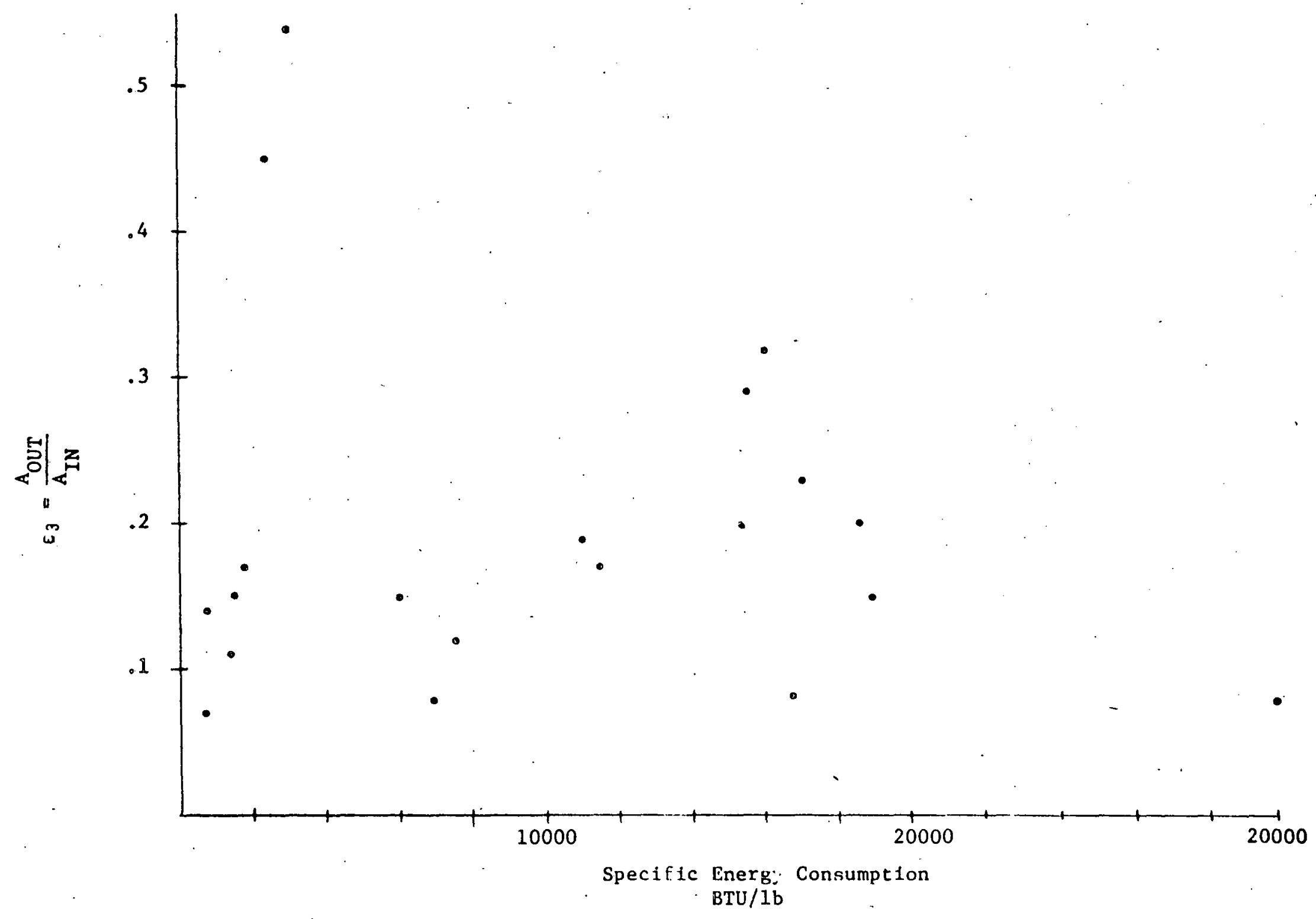


Figure 5.

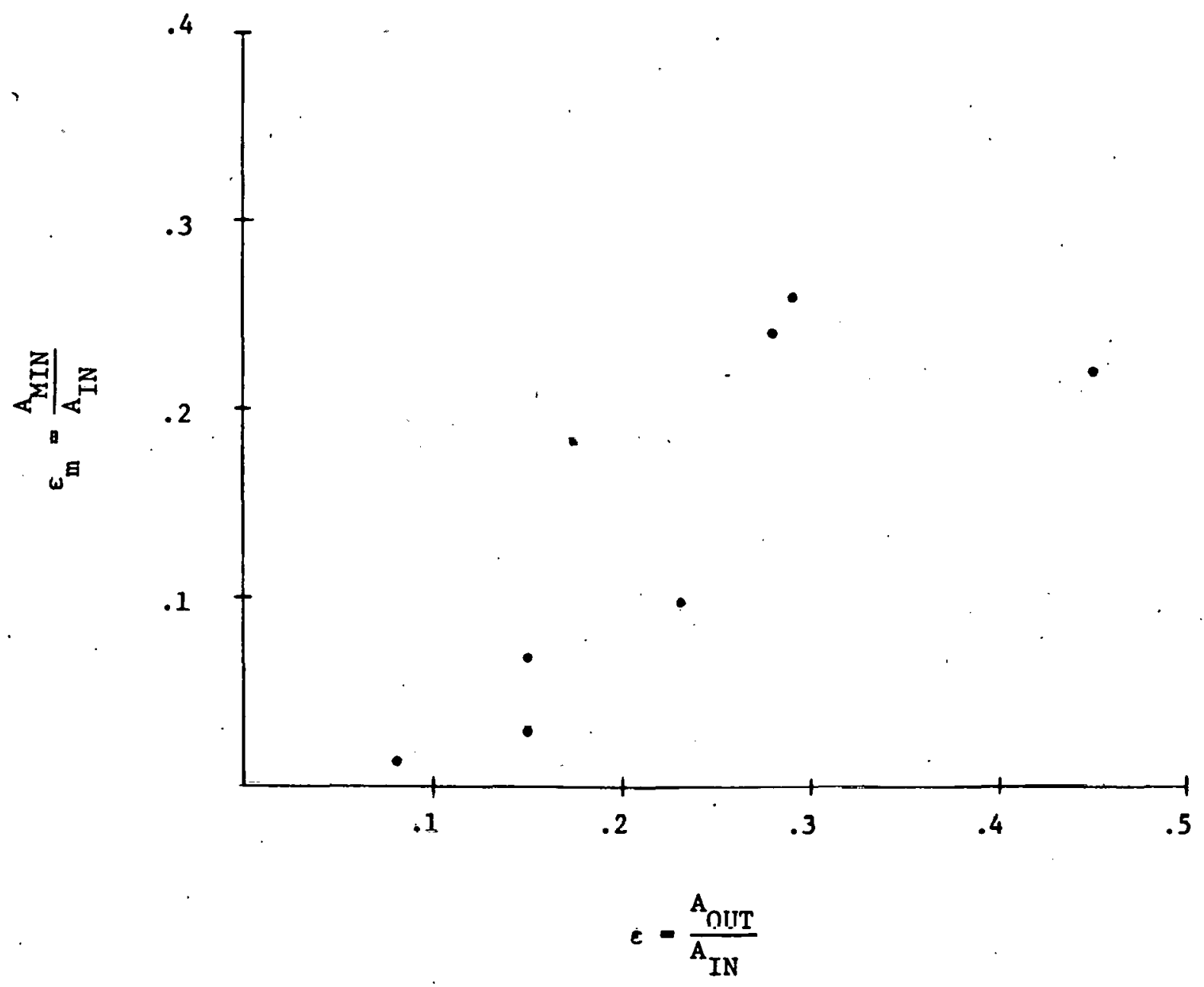


In performing these analysis, each industrial process was analyzed in deta11. In 1976, Drexel University, under contract to the Department of Energy and formerly ERDA, initiated a program to develop a detailed data base of industrial energy utilization. This data base provides a consistant base for the analysis of industrial energy use.

The data base consists of typical process configurations and energy and material balances for 108 industrial processes and represents 60 fourdigit Standard Industrial Classification (SIC) industries. Selected on the basis of energy consumption, these industrfes account for approximately $75 \%$ of the United States industrial energy consumption. Thirteen of the twenty two-digit SIC's in the industrial manufacturing sector are: represented in this data base.

Several of these four-digit industries were further disaggregated to accurately represent the varied product lines and processes.

The approach which was used in calculating the performance factors is shown in the following example. In this example, paper process, each of the unit operations was analyzed to assess its lost work (Table VI). 
Table VI.

SIC 2611 Pulpmills - Kraft Process

Unit Operation String:

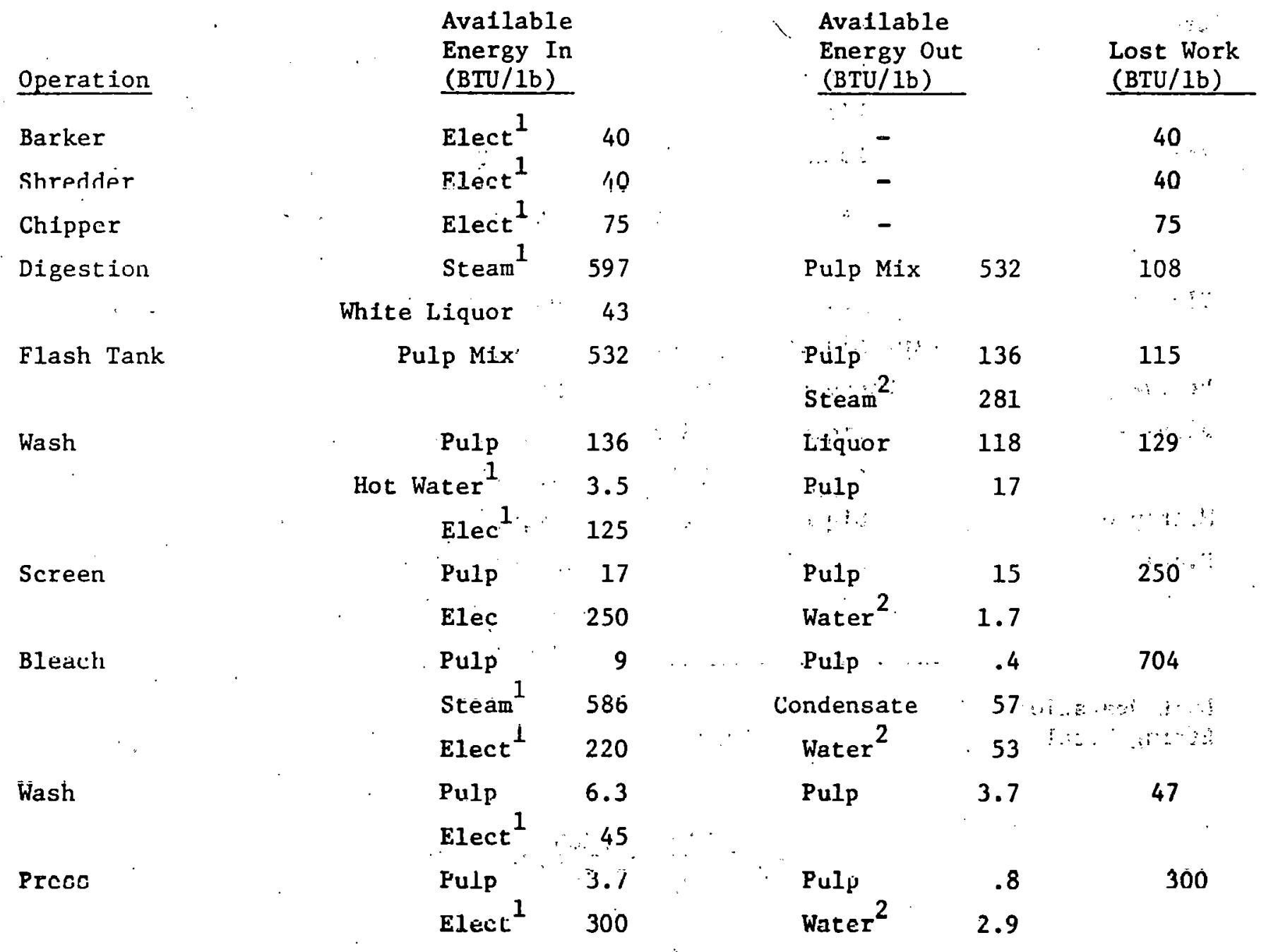




\section{SIC 2611 Pulpmills - Kraft Process'}

Operation

Drying

Riln

Slaker

Recovery

Furnace

Multiple

Evaps

Unit Operation String Total
A IN

$\underline{A_{\text {OUT }}}$

$\underline{\mathrm{LW}}$

755

$\begin{array}{lrlr}\text { Pulp } & .8 & \text { Market Pulp } & .3 \\ \text { Steam }^{1} & 799 & \text { Exhaust }^{2} & 65.3\end{array}$

Elect ${ }^{1}$ ' 100

Condensate ${ }^{2}$

78.3

Fue ${ }^{1}$

475

$A_{\text {ENDO }}{ }^{2}$

250

93

$\mathrm{CaCO}_{3}$

1.5

Stack ${ }^{2}$

44

$\mathrm{CaO}$

89

$\mathrm{CaO}$

89

White Liq.

43

$\cdot 186$

Grn. Liquor

142

Condensate

35.8

$\mathrm{CaCO}_{3}$

1.5

LIquor

8.7

Steam

2235

6543

A exo

9016

Grn. Liquor

142

Stack ${ }^{2}$

140

Liquor

118

Liquor

8.7

615

steam $^{1}$

71.8

3.7

36

Water ${ }^{2} \quad 36$

$$
13289.5
$$

3283.9

10005

$$
\varepsilon_{3}=\frac{A_{\text {IN }}}{A_{\text {OUT }}}=\frac{3283.9}{13289.5}=.25
$$




\section{SIC 2611 Pulpmills - Kraft Process (Cont'd)}

\section{Converters:}

Operation

Botler

Elect Generation

Converter Total

$$
\begin{aligned}
& \text { Available } \\
& \text { Energy In } \\
& \text { (BTU/1b) }
\end{aligned}
$$

$$
\text { Fue1 } 1
$$

3775

Fuel $^{1} \quad 1624.5$

5399.5

$$
\begin{aligned}
& \text { Available } \\
& \text { Energy Out } \\
& \text { (BTU/lb) } \\
& \hline
\end{aligned}
$$

Lost Work

(BTU/1b)

2706

$\begin{array}{lr}\text { Procece Stcam }^{3} & 806 \\ \text { Aux Etcam }^{3} & 93 \\ \text { Stack }^{2} & 170\end{array}$

Electricity ${ }^{3} \quad 570$

931

Prucess Tulal

$$
\begin{aligned}
\varepsilon_{3}=\frac{A_{\text {IN }}}{A_{\text {OUT }}} & =\frac{3283.9-2235+293.5}{13289.5+6399.5-2235-806-570} \\
\varepsilon_{3} & =.09
\end{aligned}
$$

$1_{\text {Process Input Streams ( }}$ IN $)$

${ }^{2}$ Process Output Streams - Waste (A OUT $)$

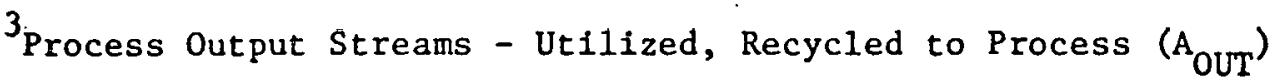

${ }^{4}$ Process Output Streams - Utilized, Product (A $A_{\text {OUT }}$ ) 


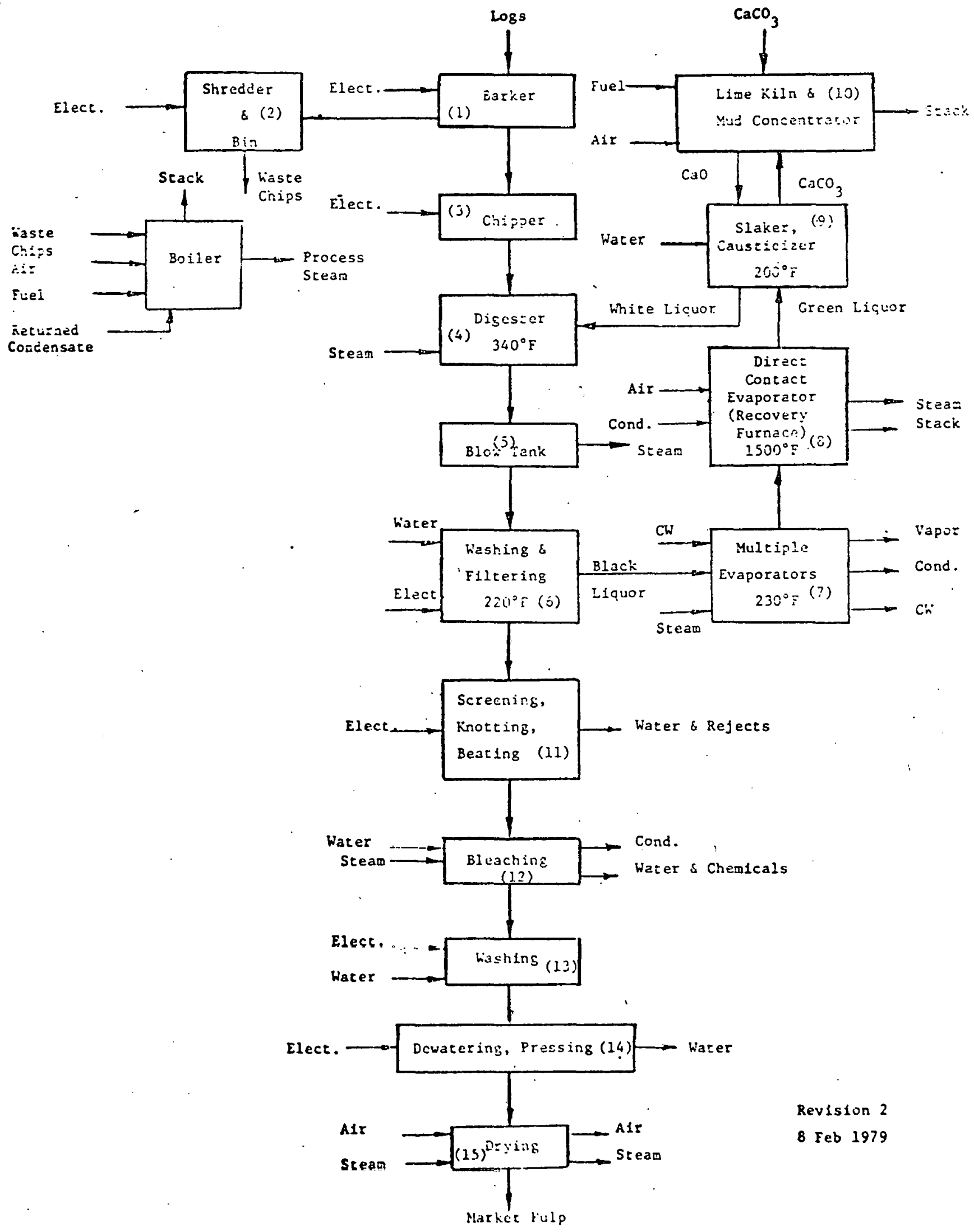




\section{B. Transportation Systems}

The basic conclusions that we draw here are that the transportation system has a larger number of social and political factors that are difficult to quantify in an avallability framework and so the use of avallability measures here is inappropriate. In general, present measures of efficiency seem quite adequate. In this section attempts are made to examine the automobilo and other tranoportation systems within a 2 hld Law fiamewulk, dnd the difficultico in thio approach are nuted.

\section{a) Efficiency and Other Figures of Merit}

It would be very useful if the energy performance of all major categories of energy consumption could be monitored so that technical improvements in performance could be encouraged. The existence of convenient indices would allow easier administration of such areas of public responsibility as the regulation of energy performance. financial subsidies, tax penalties or incentives, and support of research and development related to energy efficiency. Such indices would also assist the consumer. An example of existing systematirally tetermir.d energy performance indices include miles per gallon for different types of automoblles, as measured by the EPA,

Consider, as an example, the measurement of miles per gallon in automobiles. This index of energy performance is obtained by the EPA on the basis of laboratory tests of vehicles under fully standardized conditiuns. Two standard driving regimes are now used: the Federal (urban) driving cycle and constant high speed driving. Standardization in testing is achieved by simulating the driving regimes with stationary equipment. It is likely, as experfence with the standardized tests accumulates, that they will be modifled to reflect certain conditions, like tire resistance and air resistance, more accurately. Nonetheless, these standard tests are

a great improvement over the previous hodgpodge of tests performed by 
manufacturers, magazines and individuals, which produced widely-varying results for a given make and model automobile..

The definition of general energy performance indices for different systems is an important topic for exploration. As useful as such performance indices could be, however, they do not indicate how much technical improvement might eventually be accomplished. Efficiency is a special performance index designed for that purpose. For comparative energy monitoring as defined in the previous section efficiency indices are required. The general energy performance we have been discussing can be thought of as the energy consumption of an appropriately defined ideal system, divided by the efficiency of the system. Thus,

$$
\text { Actual Energy Performance }=\frac{\text { Energy Use by Ideal System }}{\text { Efficiency }}
$$

For example for a car

$$
\text { Actual Energy, Use Per Mile }=\frac{\text { Ideal Energy Use per Mile }}{\text { Efficiency }}
$$

In order to properly define efficiency, however, the definition of task must. he critically studied.

\section{b) Efficiency and Task Definition}

An efficiency should be a number between zero and one which indicates the limits of performance of a-system in carrying out a particular task. We saw above that first-law efficiency may not sätsfy ch1s lilltelivis. The second-law efficiency of a system can be defined as the ratio:

$$
\frac{\text { energy input to an optimal reference system }}{\text { energy input to the actual system }}
$$

where the two systems. perform the same desired task. **

*Some problems remain with this test, however, above and beyond simple questions

of accuracy.: One is the variation of gas mileage from driver to driver. Another

is the varlation in gas mileage as a given automobile gets out of tune or grows

older. While these problems are of interest, they are not so critical as to

render the results of the standardized tests useless.

**This definition can be shown to be the same as that discussed above. 
The value of the efficiency in any particular case may be sensitive to task definition, to the boundary one selects for the system. Consider the following illustration. One way to define the efficlency. of travel is the efficiency of the engine plus drive train of a car with specified weight, air resistance and rolling resistance. The task needs to be further defined in terms of distances and speeds of travel, as in the E.P.A. tests. The efficiency then would be the overall energy delivered to the driving wheels divided by the fuel energy consumed, under the specified conditions.

But this is a very narrow view of the technology of travel. One can attempt to describe the efficiency of a large, more.comprehensive system.." The task would be characterized by many more variables. Let us consider some of them.

The fundamental travel-related service is change of location to endule work, acquisition of products, social interactions and recreation. But how much travel is required to satisfy those needs? It depends upon lifestyle. but it also depends upon technology.

A very important technological variable is geographical distribution. We can call this a technological variable because it is largely a matter of Jeslyn. Tor example, people do much less, roughly $1 / 2$. as much, șhort: distance vehicular travel.in affluent European countries than in the U.S. 1 Urban and regional design can enable people to satisfy demands for funda-. mental travel-related services with much less transportation. Telecommunication might also substitutc for some travel.

Another variable is the transportation process. Here we can consider: modal mix. Some transportation needs can be satisfied effectively by means other than the automobile, depending on the trip and the simultaneous travel 
needs of nearby people. The extent of choice depends on cost and destrability of service. We can well ask whether it is legitimate to simply compare energy use per passenger mile, for example, for different modes of travel.

The next variable is equipment. Automobile weight is, for example, a critical characteristic; and weight may be sharply reduced without reducing interior size. Safety, availability, typical speed of travel, and comfort all depend on equipment design as well as on the other variables.

A final variable is management of the vehicle: the control of speed and of stop and go, and the testing and maintenance of the car, for example.

Whereas the efficiency of the engine and drive train of a given car is about $12 \%$ in typical U.S. driving, ${ }^{2}$ a typical U.S. metropolitan area with its travel equipment has a very low (as yet unanalyzed) efficiency in providing its people with fundamental locational services. As an exercise, an efficiency for the automobile has been defined and evaluated in the next section (as distinguished for the efficiency of the engine and drive. train).

Ayres and Kramer ${ }^{3}$ pointed out the general characteristic: If efficiency 1s defined in terms of a fundamental task of a comprehensive system the values will cend to be very low; concomitantly, the possibilities for technical change are multiple. In the case of travel services the layers of technology which may be altered include: basic geographic design, the modal mix, vehicular equipment, and the broad category of vehicular management. Each'of these layers embodies many options for changc. 
The conclusion we draw from this discussion is simply that care must be taken in comparing the efficiencies of systems which do not have identical tasks, because each of the efficiencies may be sensitive to its task definitions. 


\section{Energy Conversion Systems}

In this section we consider systems that involve conversion from one energy form to another. Our basic conclusion is that with the exception of cogeneration systems the use of availability concepts does not provide any new insights in the reporting process.

As we define energy converters here, the output is an energy stream or form which may then be used to perform some service or function. In general these converters take either fuel, electricity, or mechanical energy and produce either electricity, mechanical energy, heat or a combination of these. This includes: heat engines, heat pumps, fuel cells, cogeneration systems, hot air furnaces and boilers.

In general the usual thermal efficiency or C.O.P. is quite adequate in considering conversion of heat to mechanical energy or vice-versa. Thermal efficiency or C.O.P. is a 2 nd Law derived quantity and has as its upper limit the carnot efficiency: The only difficulty here is if one is to consider conversion as being from chemical energy to mechanical rather than heat to mechanical. The carnot limitation does not apply and the limitation is luw lhe avallable energy in the fuel - this is important in considering fuel cell efficiencies as the carnot limitation does not apply. However, in general the availability differences between the adiabatic flame temperature and the fuel are not major. We conclude here, therefore, that the conventional measures of efficlency for power cycles (fuel to mechanical energy and mechanical to heat) are adequate with the caveats mentioned above. In considering hot air furnaces and boilers, fuel is burned to provide thermal energy at various temperature levels. In order to limit our discussions here of monitoring and ranking we restrict comparison to systems that provide thermal energy at the same temperature - so that the unit functions of the system are the same. 
In general for such systems the lst law efficiencies are unrealistically high when compared to second law effectivenesses:

$\begin{array}{lcc} & \text { 1st Law } & \text { 2nd Law } \\ \text { Hot air furnace }\left(110^{\circ} \mathrm{F} \text { air }\right) & .7 & .08 \\ \left.\text { Boiler (hot water } 120^{\circ} \mathrm{F}\right) & .7 & .09\end{array}$

However, in developing an efficiency measure as a ranking tool for these systems the present first law efficiency is an adequate measure of the performance of the system, provided the system is compared to a like system providing thermal energy at the same temperature. This emphasizes the point made earlier that if one, can adequately quantify the output of a system in like units, then purchased energy per unit output is always an appropriate criteria for ranking purposes.

We conclude therefore that while first law efficiences do not appropriately identify the true inefficiency of a boiler or hot air furnace, they do on the basis of purchased fuel/unit function provide an accurate ranking tool.

In general for two bollers producing steall at two different temperature levels - the higher temperature boller will have a higher effectiveness:

1st Law 2nd Law
Boiler (hot water $120^{\circ} \mathrm{F}$ )
.7
.09
Boiler (steam $320^{\circ} \mathrm{F}$ )
$.7 \quad .22$

This merely indicates the importance of cogeneration in making effective use of high temperature steam - it should not be used as a ranking procedure for the relative efficiency of these boilers. 
For total energy systems, the output of the system is partly thermal, partly mechanical and an appropriate efficiency measure Is difficult.

In this case the second law efficiency is particularly useful in comparing widely differing conversion systems with thermal outputs at differing temperatures.

... Table IX is taken from Reference 1,2 it shows that second law efficiency. for a number of total energy systems in which the outputs are both heat and power, and the appropriate first law efficiency.

In Table $\mathrm{X}$ we summarize the above points.

The advantages of 2 nd law analysis in considering efficiency analysis can be seen in the example taken from Reference 1 . This is the example of an engine driven heat pump, with and without heat recovery. The example clearly shows the advantage of 2 nd law analysis of cogeneration systems. 
Table IX.

Sample Performance of Energy Conversion Devices Supplying Usable Heat and Electricity from "Efficient Use of Energy" A Physics Perspective $7 / 74$.

\begin{tabular}{|c|c|c|c|c|c|}
\hline Device & $\begin{array}{l}\text { Useful Outpu } \\
\text { of Fuel (Ava } \\
\text { Electricity }\end{array}$ & $\begin{array}{l}\text { at per } \\
\text { ilable } \\
\text { He } \\
\text { Usable } \\
\text { heat }\end{array}$ & $\begin{array}{l}\text { ift } \\
\text { Work) Input } \\
\text { at } \\
\text { Temperature } \\
\text { of heat, of } \\
\left({ }^{\circ} \mathrm{C}\right)\end{array}$ & $\begin{array}{l}\text { Second- } \\
\text { law effi- } \\
\text { clensy } \\
\varepsilon^{a}\end{array}$ & $\begin{array}{l}\text { Units of fuel } \\
\text { required to } \\
\text { nrodice the } \\
\text { same electri- } \\
\text { city and heat } \\
\text { separatelyb }\end{array}$ \\
\hline Diesel $^{c}$ & 0.30 & $\begin{array}{l}0.33 \\
0.07\end{array}$ & $\begin{array}{ll}250 & (120) \\
700 & (370)\end{array}$ & 0.44 & 1.70 \\
\hline Gas turbine & 0.20 & 0.70 & $400(200)$ & 0.49 & 1.40 \\
\hline Steam turbine & 0.13 & 0.78 & $400(200)$ & 0.46 & 1.31 \\
\hline Fuel cell ${ }^{e}$ & 0.25 & 0.65 & $300(150)$ & 0.47 & 1.72 \\
\hline
\end{tabular}

a. The second-law efficlency is the sum of the electricity fraction and $(\Delta T / T)$ times each of the usable heat fractions, where $T=$ $\mathrm{T}_{0}+\Delta \mathrm{T}$ is the temperature of the heat and ' $\mathrm{l}_{\mathrm{O}}$, the ambient temperature, is taken to be $40{ }^{\circ} \mathrm{F}$, or $278 \mathrm{~K}$. Background theory appears in Chapier 2.

b. We assume first-law efficiencies of $\mathrm{ne}_{e}=0.33$ for electricity, $n_{t}=0.67$ for small-scale heat-delivery (diesel and fuel cell), and $n_{t}=0.85$ for large-scale heat delivery (gas and steam. turbines).

c. Only a small fraction of the energy ln the 700- $\mathrm{F}$ exhaust stream can be usefully extracted, unless the exhaust is cleaned up.

d. Source: Thermo Electron (1974).

e. Fuel cells can operate at higher electric efficiency than 0.25 but in combined heat and electricity application that may not be optimal. The temperature of fuel cell coolant may be in the range 200 to $400^{\circ} \mathrm{F}$. 
Example of Engine Driven Heat Pump Analysis from "Effictent Use of Energy" A Physics Perspective (Reference 1.).

"The (second-law) efficiency of the engine is $\varepsilon_{1}=\mathrm{W} / \mathrm{B}$ (see the sketch for notation); that of the heat pump is $\varepsilon_{2}=\left(Q_{2} / W\left[1-\left(T_{0} / T_{2}\right)\right]\right.$. It is easy to show that if the-waste heat $Q^{\prime}$ is thrown away, the overall second-law efficiency of the engine-pump combination is

$$
\varepsilon=\varepsilon_{1} \varepsilon_{2}
$$

the same as if the engine were a 'remotely located power plant. The coefficient of performance of the heat pump alone is.

$$
n=\frac{\varepsilon_{2}}{1-\left(T_{0} / T_{2}\right)}
$$

The efficiency may also depend weakly on temperature. The combination (with waste heat discarded) is

$$
n_{t}=\frac{Q_{2}}{|\Lambda H|} \stackrel{\simeq}{=} \frac{Q_{2}}{B}=\frac{\varepsilon_{1} \varepsilon_{2}}{1-\left(T_{0} / T_{2}\right)} \text {, }
$$

where $|\Delta H|$ is the heat of rnmhistion of the fuel cunsunued by the engine.

Suppose now that the waste heat $Q^{\prime}$ is added to $\eta_{2}$ as ueoful hrat

(the exhaust temperature must' satisfy $T^{\prime} \geq T_{2}$ ).

The minimum available work to cupply this heat 13

$$
B_{\text {min }}=\left(Q_{2}+Q^{\prime}\right)\left[1-\left(T_{0} / T_{2}\right)\right]
$$

The second-law efficiency is therefore

$$
\varepsilon=\frac{\mathrm{B}_{\mathrm{min}}}{\mathrm{B}_{\text {actual }}}=\frac{\left(\mathrm{Q}_{2}+\mathrm{Q}^{\prime}\right)\left[1-\left(\mathrm{T}_{\mathrm{O}} / \mathrm{T}_{2}\right)\right]}{\mathrm{B}}
$$




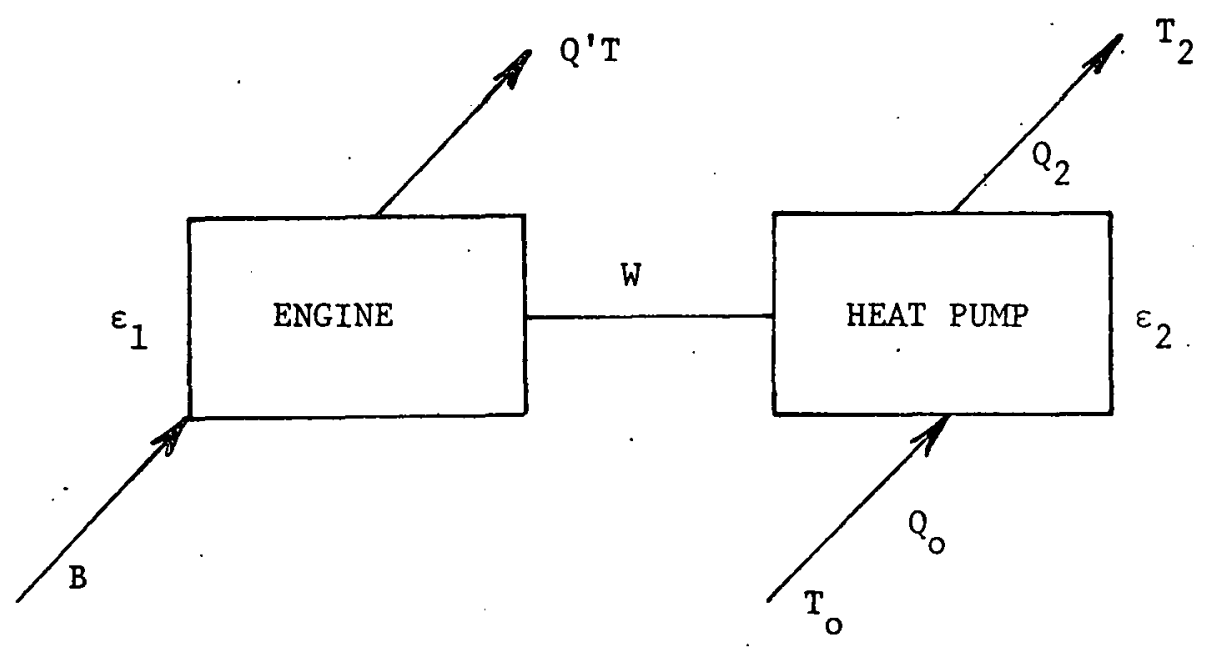

Schematic presentation of an engine-driven heat pump. The engine uses fuel with available work $B$, provides work $W$ to the heat pump, and exhausts waste heat $Q^{\prime}$ at temperature. $T^{\prime}$. Its (second-1aw) efficiency is $\varepsilon_{1}$. The heat pump, with efficiency $\varepsilon_{2}$, takes heat $Q_{0}$ from a reservoir at temperature $T_{0}$ and supplies heat $Q_{2}$ at temperature $T_{2}$. If the engine's exhaust temperature $T^{\prime}$ is adjusted to satisfy $T^{\prime} \geq T_{2}$, the waste heat $Q^{\prime}$ may be added to the useful heat $Q_{2}$. 
To express this in terms of the engine efficiency $\varepsilon_{1}$ and the neat-pump efficiency $\varepsilon_{2}$, we can substitute the following expressions for $Q_{2}, Q^{\prime}$, and $B$ :

$$
Q_{2}=\frac{\varepsilon_{2}{ }^{W}}{I-\left(\mathrm{T}_{0} / \mathrm{T}_{2}\right)} ;
$$

and

$$
B=\varepsilon_{l} / W \text {; and, from energy conservation, }
$$

$Q^{\prime}=|\Delta \mathrm{H}|-\mathrm{W}$. These substitutions provide the following:

$$
\begin{aligned}
& \varepsilon=\varepsilon_{1} \varepsilon_{2}+\left[\frac{|\Delta H|}{B}-\varepsilon_{1}\right]\left[1-\left(T_{0} / T_{2}\right)\right] \tilde{=} \\
& \varepsilon_{1} \varepsilon_{2}+\left(1-\varepsilon_{1}\right)\left[1-\left(\mathrm{T}_{0} / \mathrm{T}_{2}\right)\right] .
\end{aligned}
$$

The new terms are positive, so $\varepsilon_{\text {. }}>\varepsilon_{1} \varepsilon_{2}$, as one would expect.

(The exhaust temperature $T^{\prime}$ does not appear expliçityly. However, it influences the efficiency $\varepsilon_{1}$.)

Numerical results for two models appear in Table XI. Waste-heat recovery nearly doubles the efficiency. in the space-heating model and more than doubles it in the steamproduction model. The substantial gains are not surprising in view of the fact that the engine puts out twice as much heat as work. The greater gain in the higher temperature application is a reflection of the fact that the waste heat is being used for a higher quality application in the steamproduction model. Note also that the heat pump itself is relatively ineffective in the steam-production model because of the large temperature step. W1thout waste-heat recovery, the steam-producing heat pump is inferior to a standard boller. (We must emphasize that these are simplified model calculations. Other factors--such as cost of the local installation and only partial recovery of its waste heat-could erode the apparent advantage of the engine-driven heat pump. )" 
Table xI. Efficiency of an Engine-Drive?n Heat Pump With and Without Waste Heat Recovery

\begin{tabular}{|c|c|c|c|c|}
\hline $\begin{array}{c}\text { Models } \\
\left(\text { For both, } \varepsilon_{1}=\varepsilon_{2}=1 / 3\right)\end{array}$ & $\begin{array}{l}\text { Cop of } \\
\text { heat pump } \\
\text { for the } \\
\text { model } \\
\text { (first-law } \\
\text { efficiency) } \\
\text { (Eq. } 2.7 \text { ) }\end{array}$ & $\begin{array}{l}\text { Se } \\
\text { Waste heat } \\
\text { thrown away } \\
\text { (Eq. 2.6) }\end{array}$ & $\begin{array}{l}\text { Waste heat } \\
\text { used } \\
(\mathrm{Eq} \cdot 2 \cdot 10)\end{array}$ & $\begin{array}{l}\text { iencies } \\
\text { Comparison: } \\
\text { direct com- } \\
\text { bustion, in } \\
\text { engine or } \\
\text { heat pump. }\end{array}$ \\
\hline $\begin{array}{l}\text { Soaze-il zating nodel } \\
\mathrm{T}_{2}= \\
110^{\circ} \mathrm{F}=43^{\circ} \mathrm{C}=316 \mathrm{~K} \\
\mathrm{~T}_{0}= \\
3 \mathrm{C}^{\circ} \mathrm{F}=0^{\circ} \mathrm{C}=273 \mathrm{~K}\end{array}$ & $n_{e}=2.45$ & $\varepsilon=0.111$ & $\varepsilon=0.202$ & $\begin{array}{l}\text { Furnace } \\
n=0.5 \\
\varepsilon=0.082\end{array}$ \\
\hline $\begin{array}{l}\text { Steam-production model } \\
\mathrm{T}_{2}= \\
250^{\circ} \mathrm{F}=121^{\circ} \mathrm{C}=394 \mathrm{~K} \\
\mathrm{~T}_{0}= \\
50^{\circ} \mathrm{F}=10^{\circ} \mathrm{C}=283 \mathrm{~K}\end{array}$ & $n=1.18$ & $\varepsilon=0.111$ & $\varepsilon=0.299$ & $\begin{array}{l}\text { Boiler, } \\
n=0.8 \\
\varepsilon=0.225\end{array}$ \\
\hline
\end{tabular}




\section{HVAC Systems}

In developing a ranking or reporting approach for buildings one must recognize that heating and cooling of buildings can be considered in a simplistic fashion as two somewhat distinct energy systems:

a) The heat gain and loss to the environment and from all internal sources

b) The supply system for keeping the building at some desien condition subject to a).

In general the reporting of the heat gain or loss in terms of Btu/unit function, where the unit functions are: square feet and degree day is probably quite adquate and one can say that second law measures are not relevant to reporting this quantity.

In reporting the supply system performance, again one now uses a measure such as purchased fuel/unit function, where the unit function is the square feet and degree day for the building. The use of the 2nd Law here can be difficult, and its use may actually complicate rather than provide new insights. This is because of several parameters that are difficult to quantify in 2nd Law terms: comfort and aesthetics. One can, of course, calculate 2nd Law efficiencies for supply systems we see this in the following table.

In general, second law efficiencies are considerably. lower than 1st Law etticiencies and appear meaningful only in the design and modification process (see Appendix B for a detailed 2nd Law analysis of a complex HVAC System). However, as long as one compares two supply. systems that provide the same function (within a given building at a . given location) the purchased energy for each is reflective of the relative performance of these systems. 
To summarize:

- The comparison of dissimilar buildings is best done using present criteria.

- The present measures of heat gain or loss from bulldings is quite adequate.

- The measure of asupply system for given buildings at a:given location is purchased energy.

- The use of the 2nd Law is most appropriate in the design and modification process.

\section{Efficiencies of Household Energy Systems}

From "Efficient Use of Energy" Physics Perspective 1974.

\begin{tabular}{|c|c|c|c|c|}
\hline Household Task & $\begin{array}{l}\text { Ambient } \\
\text { Tempera- } \\
\text { ture To } \\
{\left[{ }^{\circ} \mathrm{F}\left({ }^{\circ} \mathrm{C}\right)\right]}\end{array}$ & $\begin{array}{l}\text { Task } \\
\text { Tempera- } \\
\text { ture }{ }^{\mathrm{T}} 2 \\
{\left[{ }^{\circ} \mathrm{F}\left({ }^{\circ} \mathrm{C}\right)\right]}\end{array}$ & $\begin{array}{c}\text { First-law } \\
\text { Efficiency } \\
n .\end{array}$ & $\begin{array}{c}\text { Second-law } \\
\text { Efficiency } \\
\varepsilon\end{array}$ \\
\hline Hot-water heating & & & & \\
\hline Electric & 55 (13) & $120(49)$ & $0.75^{\mathrm{a}}$ & 0.015 \\
\hline Gas & $55(13)$ & $120(49)$ & 0.50 & 0.029 \\
\hline Space heating & & & & \\
\hline at the room & $40(4)$ & $70(21)$ & 0.60 & 0.028 \\
\hline - at the register & $40(4)$ & $110(43)$ & 0.60 & 0.074 \\
\hline $\begin{array}{l}\text { at the furnace } \\
\text { plenum }\end{array}$ & $40(4)$ & $160(71)$ & 0.75 & 0.145 \\
\hline Afr conditioning & $90(32)$ & $55(13)$ & $2.0(\operatorname{COP})^{a}$ & 0.045 \\
\hline
\end{tabular}

The first-law efficiency is smaller if one refers back to the fuel at the electric power plant. (To compute the second-law efficlency, one must refer back to the power-plant fuel.). 
IV. Component Design Application

This section of the study is devoted to the use of thermodynamic, avallability analysis for the identification and specification of energy efficient unit processes.

As noted earlier a significant advantage of examining the availability losses or lost work associated with each component is that in general it is the fuel pcnolty that one pays for the losses in that component. One can therefore optimize the component, independenc of ullies is the syotcm, and then perform a system matching procedure. Gaggioli has made this point very clearly in his analysis of feedwater heater replacement in a plant. To demonstrate the use of lost work in optimizing system components we have here considered four important system components:

- Heat exchangers

- Petroleum Heatess

- Multi-Effect Evaporators

- Distillation processes

The general approach is Lu identify the genmetric parameters for each system that are related to the capllal cost of the unit and then through material, energy, and availability balances show how the lost work of the unit process is set by the geometric parameters. This relationship can be uscd to definc the optimal point where changes in the geometric parameters produce changes in lost work that justify the associated change In capital cost. This justification process should be based on the cost of avallability supplied to the unit process. As changes in the geometric 
parameters are made in the direction of decreasing lost work, the capital cost of the unit process tends to increase. These increases are beneficial until the associated savings due to decreasing lost work no longer justify the added capital. In each example, a simplified model of the system is developed which demonstrates the relationship of geometry, capital cost and lost work. The key to the identification of the optional design point is the point at which incremental capital investment has an after tax return at the minimum low risk cut off rate. This return is determined based on the savings of variable cost which is really the "saving" of lost work. The saving of availability is valued in terms of the supplied availability to the unit process and the future cost projections of availability.

The following examples show the details of applying this concept to some of the most common and widely used unit operations in the processing industry. 


\section{GENERAL CONCLUSIONS}

The object of these component mini-studies was to demonstrate that the selection of certain component geometric parameters during equipment design specification determinations has direct effect on the thermodynamic lost work forever more associated with the operation of that equipment, and that through developing data to provide $\Delta L W / \Delta G P$ (the change in lost work for incremental changes in capital equipment (geometris parameter definition)), the designer can create an intransient interface between capital cost and operating expense. Using various energy cost projection scenarios, the designer can determine where that interface should exist, and using his equipment availability utilization curve, select the appropriate value for his component's geometric parameter.

Each of the four mini studies has also demonstrated that the designer has control of the utilization of supplied availability, and its tradeoff against equipment configuration:

1. Heat. Fxrhanger - Tt was demnngtrated that the total availability of the working (hot) fluid was available to the designer; and the unused portion, discharged by the designer with the working fluid exchanger effluent, determines appropriate surface area of the unit. Therefore, the designer can also evaluate exactly how hot his process fluid can be made (how much theoretical avallability can be taken up), for the specified supplied availability.

2. Petroleum Heaters - As for the exchanger, the supplied availability represents a potential source of work to the designer. Here, this potential represents the release of energy exothermically due to the change in chemical potential of the unit's fuel supply. However, each unit of fuel supplies a 
certain unit of potential availability. It was demonstrated that through specification of the geometric parameter, the designer selects that portion of the supply potential which is to be utilized in performing the component's function. As with the exchanger, the lost work of the component is clearly decided at the descretion of the designer and therefore, if desired, he can view this operating -cost/capital expense interface as a design dimension. 3. Multiple-Effect Evaporators - Again, the designer has the opportunity to utilize the supplied availability to whatever advantage is determined cost justifiable. Here, the designer can determine how concentrated a unit of dilute solute can be made from a unit of supplied availability, and select tradeoffs based on energy/material cost projections.

4. Distillation Column - The backbone of chemical separations has long been examined from the perspective of trading additional stages for enhanced separation (purity, concentration, etc.). However, the mini-study presented has demonstrated the link between the equipment's lost work and this same tradeoff - a unit of supplied availability can provide units of concentration, dependent on the designer's specification of column stages (number of trays) and reflux ratio.

Each of these studies alsoindicates that a maximum lost work exists for each component in a particular service, found by increasing the value of the geometric parameter, and that further increases in this parameter lead to decreases in overall lost work, reflecting that the designer is "stretching" the value of each unit of supplied availability. However, this study can not assert that for all or any cases examined, the geometric parameter should be selected from that portion of the curve where $\Delta L W / \Delta G P$ is negative. This selection is determined strictly from the value placed on each of the two 
terms in the interface - the lost work Btu and the geometric parameter (often heat transfer area).

One final remark should be made concerning the quality of the models used in this study. While simplistic, the mathematical models imbedded in the fortran source listings provided are sufficient to represent the thermo-physical behavior 'of the process fluid undergoing the specified thermodynamic transformation to be accomplished by the equipment. Clearly, refinements of the models are possible and many enhancements could have been provided. 


\section{A. Heat Exchanger}

\section{Introduction}

Heat exchange is one of the most common unit processes in the processing Industry. Typically, the heat exchanger is used to transfer availability from one process fluid to another. The higher temperature stream (the working fluid) transfers heat to the colder stream according. to the performance characteristics of the heat exchange unit. The change in working fluid availability is the "supplied availability" whereas the change in. fluid being heated is the "needed availability." The amount of availability transferred depends on the geometric configuration of the heat exchanger and most strongly on the surface area avallable for heat transfer.

It is the goal of the designer to speci-y heat transfer area so that the maximum heat transfer is obtained consistent with economic guidelines. From an availability point of view, the heat exchange surface ared should be increased until the incremental surface area is no longer justified by a change in lost work.

\section{Process Description}

Referring to Figure 17, a generalized heat exchanger is shown. The hot stream flows through the unit discharging availability through the heat transfer surface to the cold stream which leaves the unit with more availability than it origlnally contalned before it entered the unit. For simplicity, it is assumed that no phase changc occure in either fluid. 
Figure 17.

A General Heat Exchanger

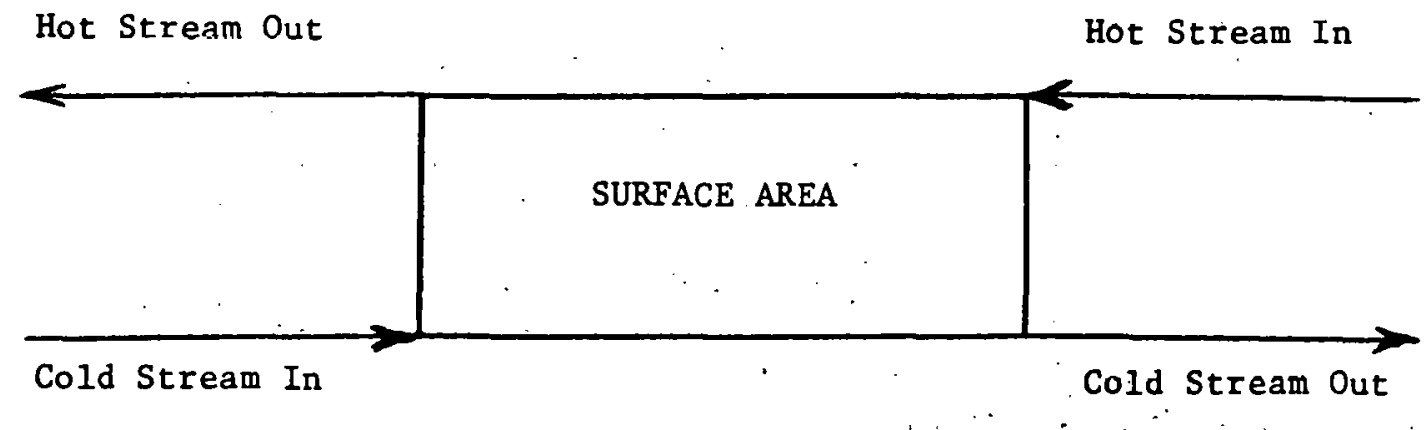




\section{Mathematical Treatment}

The following heat and material balances apply to the system shown In Figure 17.

(a) Working Fluid:

$$
Q_{T}^{\prime}=W_{w} C P_{w}\left(T_{2}-T_{1}\right)
$$

$$
\text { where } \begin{aligned}
\mathrm{Q}_{\mathrm{T}}^{\prime}= & \begin{array}{l}
\text { Total Heat Transferred from } \\
\text { Working Fluid (Btu/hr) }
\end{array} \\
\mathrm{W}_{\mathrm{W}}= & \begin{array}{l}
\text { Mass flow rate of Working } \\
\text { Fluid (1bs/hr) }
\end{array} \\
\mathrm{CP}_{\mathrm{w}}= & \text { Mean Heat Capacity of Working } \\
& \text { Fluid (Btu/1b- } \left.{ }^{\circ} \mathrm{F}\right) \\
\mathrm{T}_{2}= & \begin{array}{l}
\text { Temperature of working fluid } \\
\text { entering the Exchanger }\left({ }^{\circ} \mathrm{F}\right)
\end{array} \\
\mathrm{T}_{1}= & \text { Temperature of the working } \\
& \text { fluid leaving. the Exchanger }\left({ }^{\circ} \mathrm{F}\right)
\end{aligned}
$$

(b) Process Fluid:

$$
Q_{T}=W p C p p\left(t_{3}-t_{4}\right)
$$

where

$$
\begin{aligned}
& \begin{aligned}
& Q_{T}= \text { Total heat transferred to } \\
& \text { Process Fluid (Btu/hr) }
\end{aligned} \\
& \text { Wp }=\text { Mass Flow Rate of Process Fluid } \\
& \text { (1bs/hr) } \\
& C_{p p}=\text { Mean Heat Capacity of Process } \\
& \text { Fluid (Btu/lb } \left.-^{\circ} \mathrm{F}\right) \\
& t_{3}=\text { Temperature of Process Fluid } \\
& \text { Leaving the Exchanger }\left({ }^{\circ} \mathrm{F}\right) \\
& t_{4}=\text { Temperature of Process Fluid } \\
& \text { Entering the Exchanger ( }{ }^{\circ} \mathrm{F} \text { ) }
\end{aligned}
$$


(c) Rate of Heat Transfer:

$$
\begin{aligned}
& Q_{R}=U A \Delta T_{1 m} \\
& \text { where } \quad Q_{R}=\text { Heat Transferred From } \\
& \text { Working Fluid to Process } \\
& \text { Fluid (Btu/hr) } \\
& U=\text { Overall Heat Transfer Coefficient } \\
& \text { (Btu/hr-Ft }{ }^{2}{ }^{\circ} \mathrm{F} \text { ) } \\
& A=\text { Heat Trancfor Surface Area }\left(\mathrm{Fr}^{2}\right) \\
& \Delta \mathrm{T}_{\text {Im }}=\underset{\left({ }^{\circ} \mathrm{F}\right)}{\log } \text { Mean Temperature } \text { Difference } \\
& \Delta T_{1 m}=\frac{\left(T_{2}-t_{3}\right)-\left(T_{1}-t_{4}\right)}{\ln \left[\frac{\left(T_{2}-t_{3}\right)}{\left(T_{1}-t_{4}\right)}\right]}
\end{aligned}
$$

(d) Overall Heat Balance:

$$
Q_{T}^{\prime}-Q_{T}=Q_{R}
$$

(e) Overall Mass Balance:

$$
\left.\begin{array}{l}
w_{w i}=w_{w n} \\
w_{p i}=w_{p o}
\end{array}\right\} \begin{aligned}
& \text { Subscript } \\
& i=\text { in } \\
& 0-\text { out }
\end{aligned}
$$

By specifying stream flows, heat capacities, overall heat transfer coefficient, and inlet temperatures, these equations can be solved simultaneously for a given surface area. The following section shows this procedure.

The thermodynamic availability of both fluids is predicted by the equation:

$$
\text { where } \quad \begin{aligned}
a & =C_{P}(T+460-520(1+\ln ((T+460) / 520))) \\
T & =\text { temperature }\left({ }^{\circ} \mathrm{F}\right) \\
\mathrm{CP}_{\mathrm{p}} & =\text { fluid mean heat capacity }\left(\mathrm{Btu} / 1 \mathrm{~b}-{ }^{\circ} \mathrm{F}\right) \\
\dot{\mathrm{a}} & =\text { fluid intensive availability }(\mathrm{Btu} / 1 \mathrm{~b}) \\
520^{\circ} \mathrm{R} & =\text { dead state } \\
460^{\circ} \mathrm{R} & =\text { conversion to degrees Rankine }
\end{aligned}
$$




\section{Fortran Embodiment}

In order to efficiently demonstrate the concept of trading geometric parameter selection for lost work reductions for a heat exchanger, a computer model was prepared for interactive use. The fortran source listing for this model is presented below. The program is structured to allow definition of the system model by reading certain definitive/ descriptive data into the machine, and subsequently study the effect of the change in a geometric parameter, here the area, against calculated component lost work. Input variables to this program are identified in Table XII, along with output parameters.

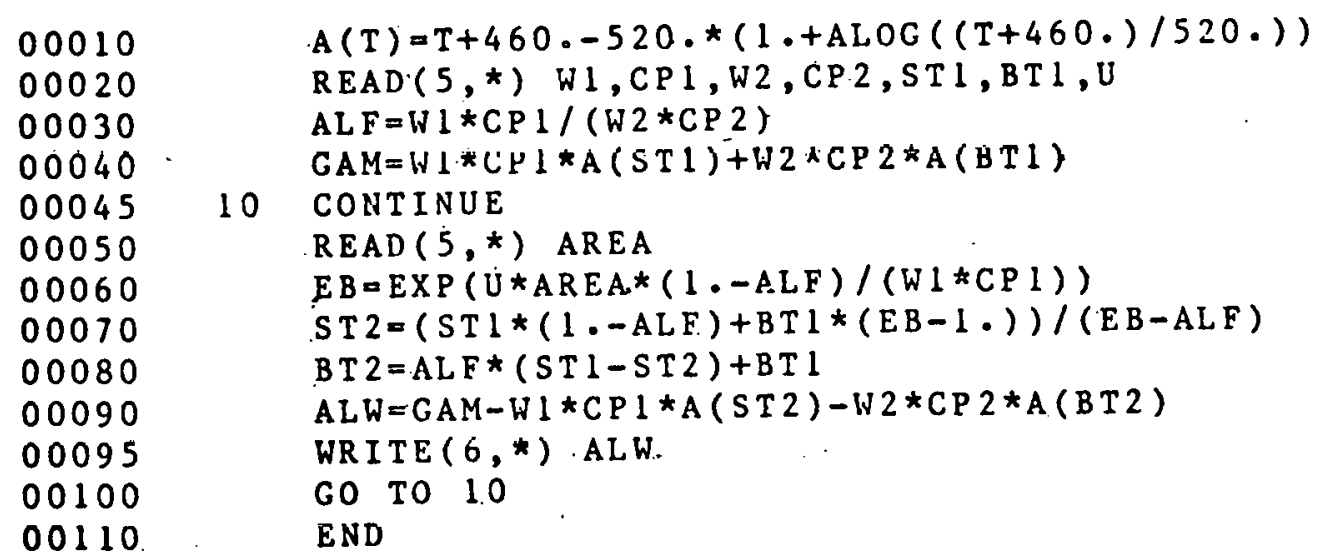




\section{Table XII.}

Fortram Source Listing Input/Output Parameters

INPUT

UNITS

W1

Process Fluid Flow Rate.

lbs/hr

CP1.

Process fluid Heat Capacity

Btu/Ib:F

W2

Working Fluid Flow Rate

lbs/hr

CP2

Working Fluid Heat Capacity

Btu/ $1 b \stackrel{\circ}{F}$

ST1

Process Fluid Inlet Temperature

${ }^{\circ} \mathbf{F}$

Working Fluid Inlet Temperature

Overall Heat Transfer Coefficlent

Surface Area

:F

$\mathrm{Btu} / \mathrm{hr}-\mathrm{Ft} \mathrm{t}^{2}-{ }^{\circ} \mathrm{F}$
$\mathrm{Ft}{ }^{2}$

d

NUTPUT

ALW

Process Lost Work

Btu/hr 
v. Sample Case

Input data to the computer program presented in Figure 3 describing a sample case: whereby a hot stream transfers energy to a cold stream is shown in Table XIII. The input has been structured according to the definitions shown in Table XII. The area parameter was varied to establish the lost work curve for this set of input parameters to demonstrate the shape of the curve and its relattonship to heat exchanger design. As w1ll be shown later this curve allows the determination of the optimal point where incremental surface area is justified by incremental reductions in lost work.

Table XIII.

Sample Case Input Data

Variable

W1

CP1

W2

CP2

ST1

BT1

U

AREA
Value

750000

0.5

1000000

0.85

200

500

300

$1000 \rightarrow 1.7000$ 
vI. Results

The results of the sample case are displayed graphically in Figure 18 . For fixed inlet condition and overall heat transfer coefficient as surface area increases the amount of heat transferred increases. The behavior of lost work however is more striking. As surface area increases, the lost work per unit area decreases uniformly. It is the declining portion of the curve, or where the slope decreases, where the optimal point exists such that the next increment of surface area is exactly justified by the next increment of reduction in lost work. This area is designated in Figure 18 . 


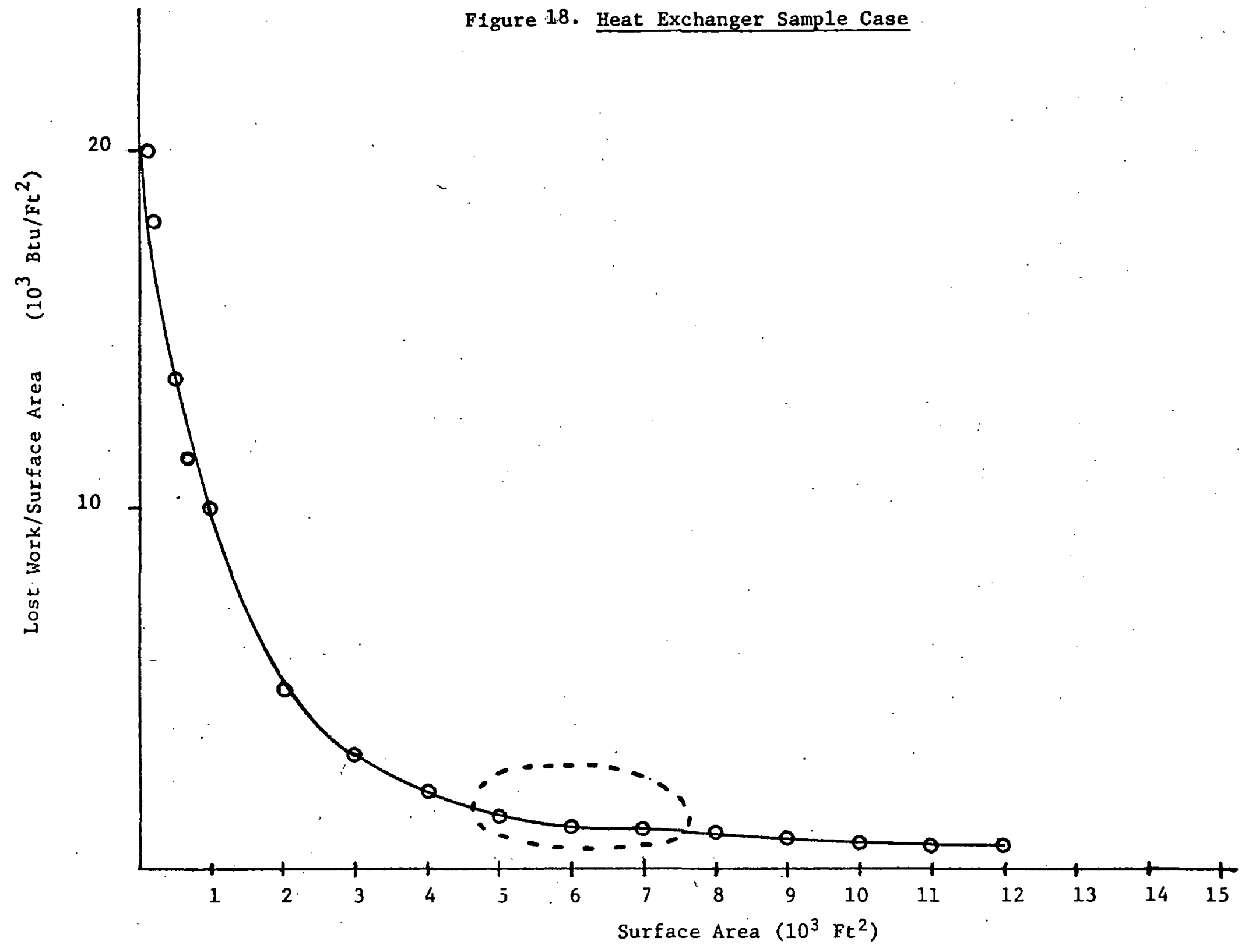




\section{B. Petroleum Heaters}

\section{Introduction}

The general problem of heat transfer in a combustion chamber presents one of the most complex probiems in heat transmission to analyze, as availability exchange is simultaneously accomplished through radiation, convection and conduction mechanisms. Therefore, any theoretical model necessarily includes three components in determining the distribution of heat liberated by combustion. Likewise, the component designer has available certain parameters to help minimize heat loss, usually through convective loss to chamber walls, conduction through the wall and subsequent convective/radiative loss to the environmental sink. However, with the advance of materials science, a wide range of refractories and insulating materials have been developed, including those for high temperature applications $\left(2500-2800^{\circ} \mathrm{F}\right)$, and heat loss to the environmental sink can be minimized in accordance with straight forward energy calculations for Insulation selection determination. More importantly, the designer must establish the optimum component design to effectively utilize the available energy released from fuel combustion, and after component geometric specification, insure that minimum inefficiencies are encountered through the typical lack of adequate combustion controls - the "too much excess air" syndrome. This short study will utilize a simple model to show that the selection of the geometric parameters which spectfy the component configuration - for the petroleum heater, the heat sink surface area - can be based on maximizing the utility of available energy or conversely minimizing the lost work in proportion to the accepted dollar value of lost work, and Incremental costs for Increases in purchased sink surface areas. 


\section{Process Description}

Referring to Figure 19, fuel and sufficient combustion air are supplied to a combustion chamber where, upon ignition, the chemical avallability supplied with the fuel is released from the reaction exotherm. Through a combination of convection and radiation, this exothermic heat is transferred to process fluids pumped through the combustion chamber in a variety of piping networks and associated fire box - burner - stack configurations, some of which are shown in Figure 20. Each configuration allows the designer certain options in specifying process piping (sink surface area) in relation to the heat transmission mechanism to be utilized.

Returning to Figure 19, the sink surface area has been schematically shown as a simple thru pass piping arrangement, however, the intent is to demonstrate that the process piping is exposed to the flame temperature through radiative coupling, and to the combustion gas flow, allowing for additional heat transfer through convection and conduction, much the same as a gas/liquid heat exchanger. Cooled combustion gases are usually discharged to the environmental sink through a process stack.

The lost work balance considers the thermal availability change of the process fluid, the needed availability, and the chemical availability of the fuel input less the thermal availability of the combustion gases as the supplied availahility. The component'c lost work is equal to the portion of the supplied availability not transmitted to the process fluid along with the irreversibility of transfer. 
Figure 19.

General Combustion/Heating Component

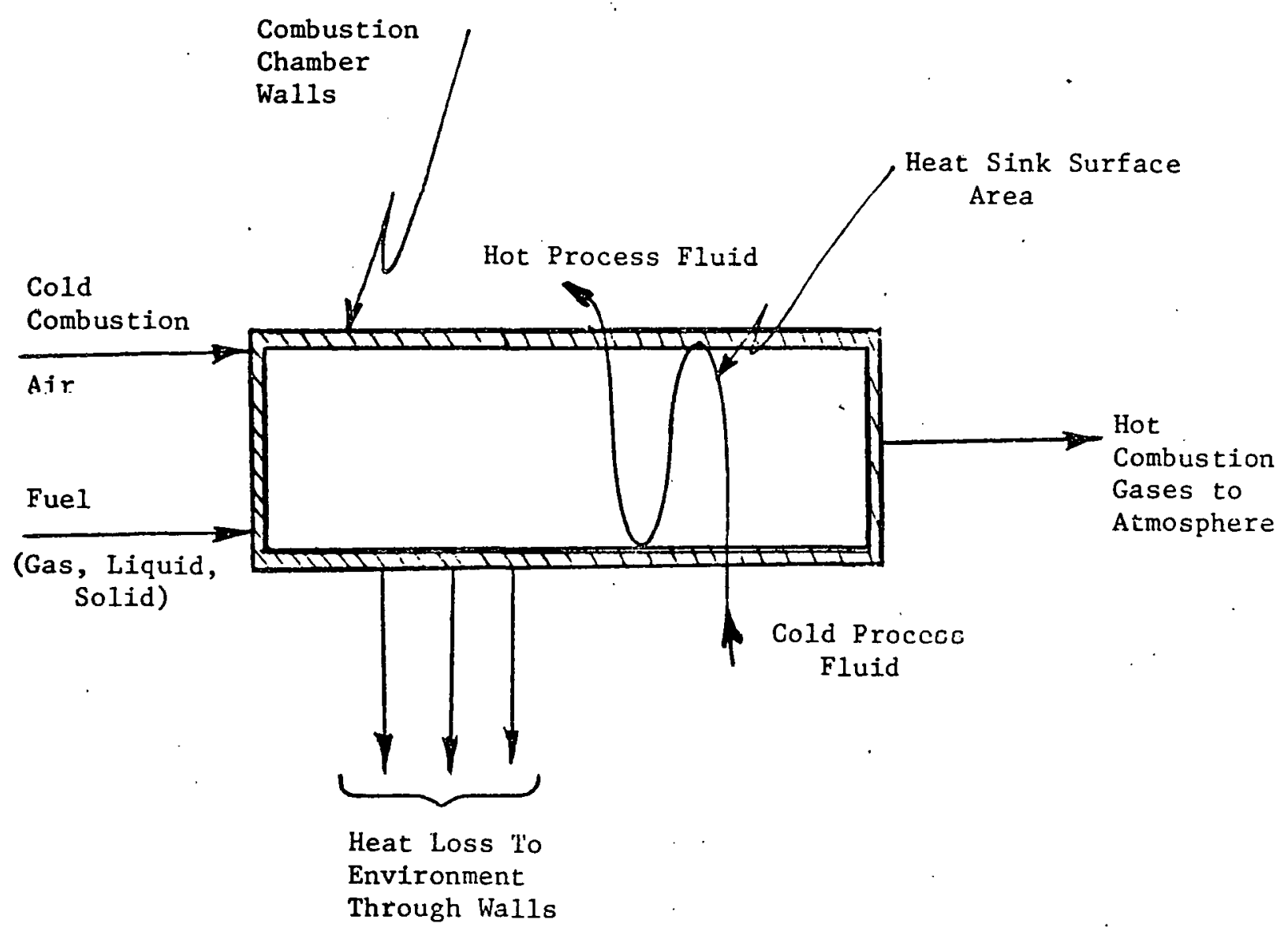


F1gure 20.

- TIRED PROCESS EQUIPMENT
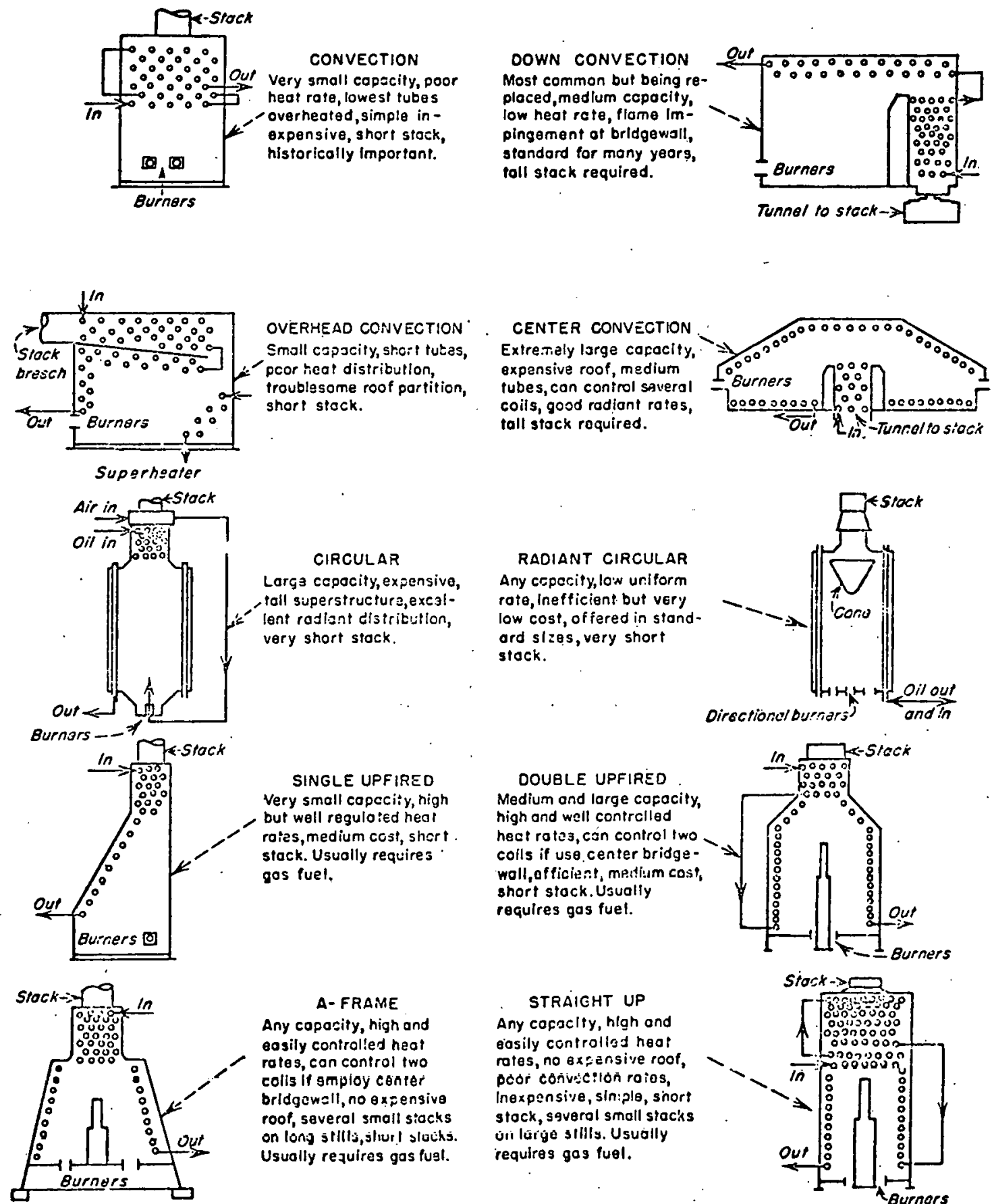

A- FRAME

Any capasify, high and eosily conirolted haat rates, con control two colis if smploy center brldgewall, no $\theta x \bar{x}$ ensive roof, several small stacks on lonj s $\mathrm{Pllis}$, jlivil slocks. Usually re zuires gas fual.

DOUBLE UPFIRED Medium and large capacity, high and well contralled hect rotes, cón control two colls if use center bridge woll, of ficient, mettium cost, short stack. Usually roquires gas fuel.

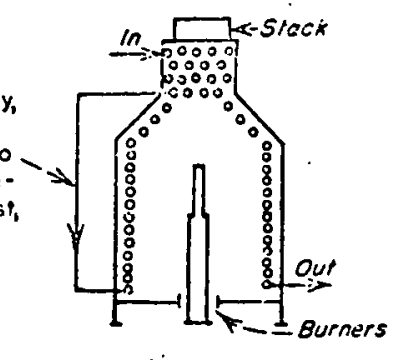

STRAICHT UP Any cofacliy, hloh and cosily controlls hoo: rates, no expensive roof, pedr coñive:lón roies, Inexpensive, sin:ple, short stock, sgveral small stacks üi lúige sillily. Usually requires gas fuel.

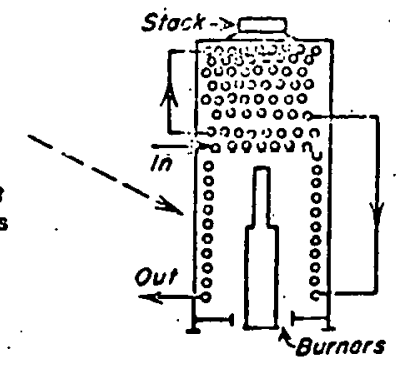

Reference: This figure appears in the $4 \mathrm{th}$ edition, Chemical Engineer's Handbook, by J. H. Perry, Page 9-37. 


\section{Mathemat1cal Treatment}

The following heat and mass balances can be written for the system component presented in Figure 13.

(a) Process Fluid: Heat Balance: $Q_{T}^{\prime}=W_{i} C_{P}\left(T_{2}-T_{1}\right)$

where

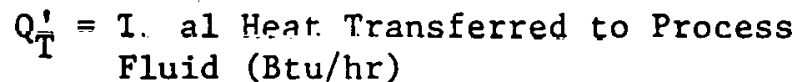

$$
\begin{aligned}
& W p_{i}=\text { Mass flow rate of process fluid (lb/hr) } \\
& { }_{\mathrm{P}_{\mathrm{p}}}=\underset{\text { Mean heat capacity of process fluid }}{\left(\mathrm{Btu} / 1 \mathrm{~b}-{ }^{\circ} \mathrm{F}\right)} \\
& \mathbf{T}_{2}=\text { Temperature of hot process fluid } \\
& \text { leaving heater }\left({ }^{\circ} \mathrm{F}\right) \\
& \mathrm{T}_{1}=\text { Temperature of cold process fluid } \\
& \text { entering heater }\left({ }^{\circ} \mathrm{F}\right) \\
& \text { Mass Balance: } \mathrm{Wp}_{\mathrm{i}}=\mathrm{Wp}_{1}=\mathrm{Wp}_{2} \\
& W p_{1}=\text { mass flow of process fluid to heater } \\
& \mathrm{Wp}_{2} \text { - Masa flow of process fluid from heater }
\end{aligned}
$$

(b) Fuel Supply/Combustion Air/Combustion Gases:

$$
\text { Heat Balance: (1) } Q_{T}=w_{F} H_{F}
$$

where

$$
\begin{gathered}
Q_{T}=\begin{array}{l}
\text { Total Heat Released from fuel } \\
\text { supplied (Btil/hr) }
\end{array} \\
\begin{array}{c}
W_{F} \equiv \text { Mass flow rate of fuel supplied } \\
\text { (Lb/hr) ; }
\end{array} \\
\begin{array}{c}
H_{F}= \\
\text { Hcoting value of fuel supplied } \\
(B t u / 1 b) .
\end{array}
\end{gathered}
$$

$$
\text { (2) } Q_{T}=Q_{T}^{\prime}+Q_{L}+Q_{S}
$$

where

$$
\begin{aligned}
Q_{L}= & \text { Hcat loss through the rhamber wall } \\
& \text { refractory to the environmental } \\
& \text { sink (Btu/hr) } \\
Q_{S}= & \text { Sensible heat gain between combustion } \\
& \text { products and reactants }(B t u / h r) .
\end{aligned}
$$




$$
\begin{aligned}
\text { Mass Balance: } & \mathrm{W}_{\mathrm{F}}+\mathrm{W}_{\mathrm{A}}=\mathrm{W}_{\mathrm{CP}} \\
\text { where } \quad \mathrm{W}_{\mathrm{A}}= & \begin{array}{l}
\text { Mass flow rate of combustion } \\
\text { air }(\mathrm{lb} / \mathrm{hr}) \cdot .
\end{array} \\
\mathrm{W}_{\mathrm{CP}}= & \begin{array}{l}
\text { Mass flow rate of combustion } \\
\text { products }(1 \mathrm{~b} / \mathrm{hr}) .
\end{array}
\end{aligned}
$$

The terms $Q_{S}$ and $Q_{T}^{\prime}$ need to be further defined as follows:

$$
\begin{aligned}
& Q_{S}=\left\{\left[\left(W_{C P}\right)\left(C_{P_{c}}\right)^{\prime}\left(T_{4}-T_{\operatorname{Ref}}\right)\right]-\left[\left(W_{F}\right)\left(C_{P_{F}}\right)\left(T_{3}-T_{R e f}\right)\right]\right. \\
& \left.-\left[\left(\mathrm{W}_{\mathrm{A}}\right)\left(\mathrm{CP}_{\mathrm{A}}\right)\left(\mathrm{T}_{3_{A}}-\mathrm{T}_{\mathrm{Ref}}\right)\right]\right\}
\end{aligned}
$$

$Q_{T}^{\prime}=\overbrace{\sigma\left(T_{F}^{4}-T_{C}^{4}\right) A_{C} F_{C F}}^{\text {Radiation }}+\overbrace{h_{C} A_{C}^{\prime}\left(T_{F}-T_{C}\right)}^{\text {Convection }}$

where $\sigma=$ Stefan-Boltzman Constant

$$
\begin{aligned}
T_{F} & =\text { Flame Temperature }\left({ }^{\circ} \mathrm{F}\right) \\
T_{C} & =\text { Uniform Sink Temperature }\left(\left(\mathrm{T}_{1}+\mathrm{T}_{-2}\right) / 2\right)\left({ }^{\circ} \mathrm{F}\right) \\
A_{C} & =\text { Sink area exposed to radiative flux }\left(\mathrm{Ft}^{2}\right) \\
A_{C}{ }^{\prime} & =\text { Sink area exposed to convective flux }\left(\mathrm{Ft}^{2}\right) \\
{ }_{\mathrm{C}} & =\text { Convective heat transfer coefficient. }
\end{aligned}
$$

For petroleum heaters, the term $h_{c} A_{c}$ ' has been assigned an average value of $7 \dot{A}_{c} F_{C_{F}}$, as the term is relatively unimportant when compared to the radiative 
term. The relation then reduces to

$$
Q_{T}^{\prime}=\left[\sigma\left(T_{F}^{4}-T_{C}^{4}\right)+7\left(T_{F}-T_{C}\right)\right] A_{C}{ }^{F} C_{F}
$$

${ }^{F_{F}}$ can be determined as specified in Perry's Chemical Engineers' Handbook ( 4 th edition, pages 10-40 through 10-45). This interchange factor is a function of gas emissivity and tubing configuration. While the impact of tubing configuration on $\mathrm{F}_{\mathrm{C}_{\mathrm{F}}}$ could have. $\mathrm{b}_{-2 n}$ used in this survey of petroleum heaters as a geometric parametér tradeoff against lost work, it was decided to use the parameter more readily associated with thermal transfer - sink surface area.

IV. Fortran Embodiment

In order to efficiently demonstrate the cuncept of trading geometric parameter selection for lost work reductions for a petroleum heater, a computer model employing the mathematical descriptions of Section III was prepared for interactive use. The fortran source listing for this model is proscnted in Figure 21. The program is structured to allow definition of the system model (refer to lines 20 and 30 of Figure 3) by reading certain definitive/descriptive data into the machine, and subsequently study the effect of the change in $a$ geometric parameter, here the area (refer to line 130); against calculated component lost work (refer to line 320). Input variables to this piughall are Identitied In Table XIV, along with output parameters.

The thermodynamic availability of the process fluid and stack gascs 13 . determined in identical manner to the streams in the heat exchanger examplc (refer to equation [7] of A.III).. The chemical availability of the fuel stream. supplied to the heater was considered totally available. The lost work computation is performed on line 310 of the source listing. 
P1gure 21.

FORTRAN SOURCE LISTING FOR PETROLEUM HEAT AVAILABILITY MODEL

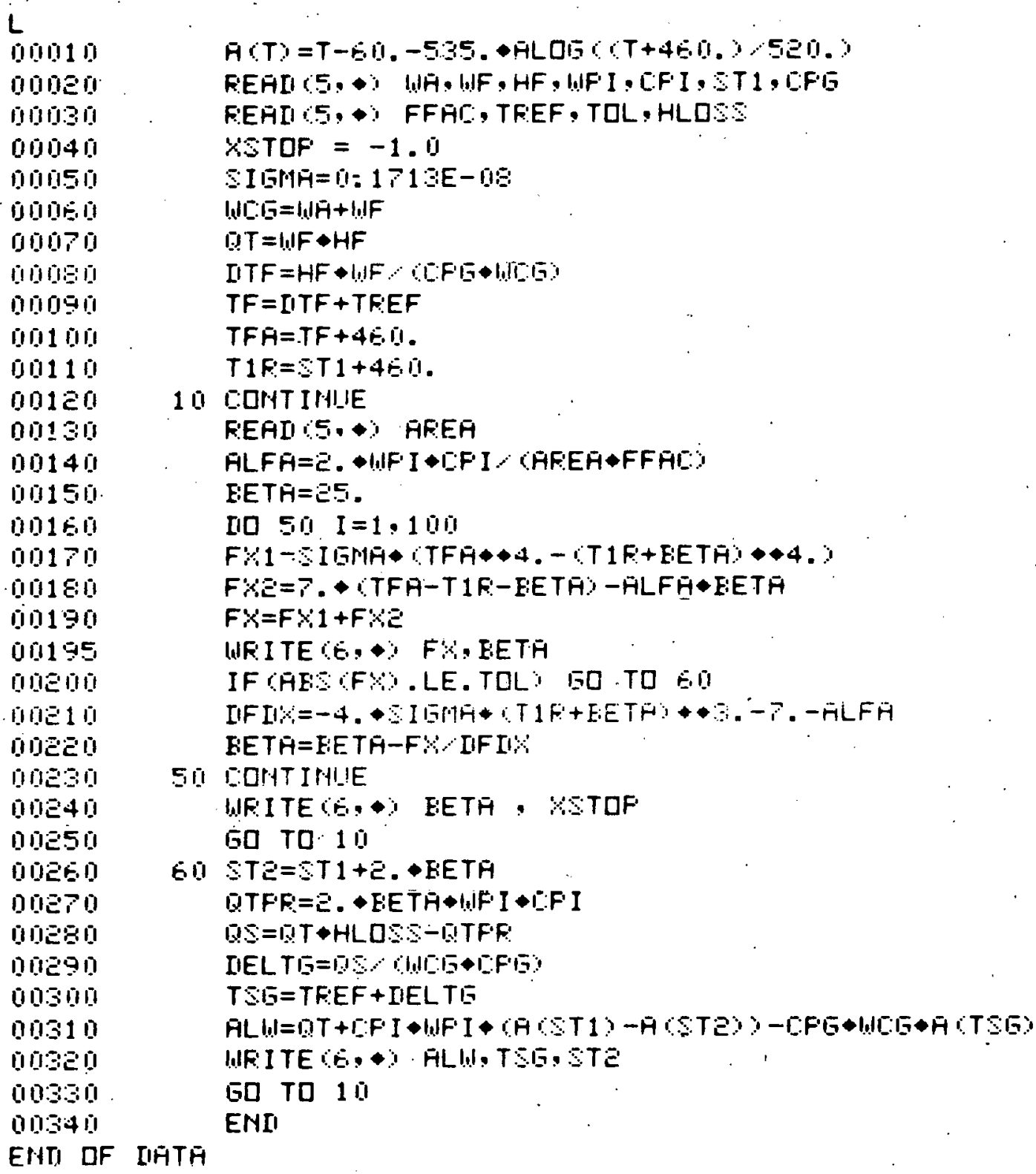


Table XIV.

\section{Definition of Fortran Model Parameters}

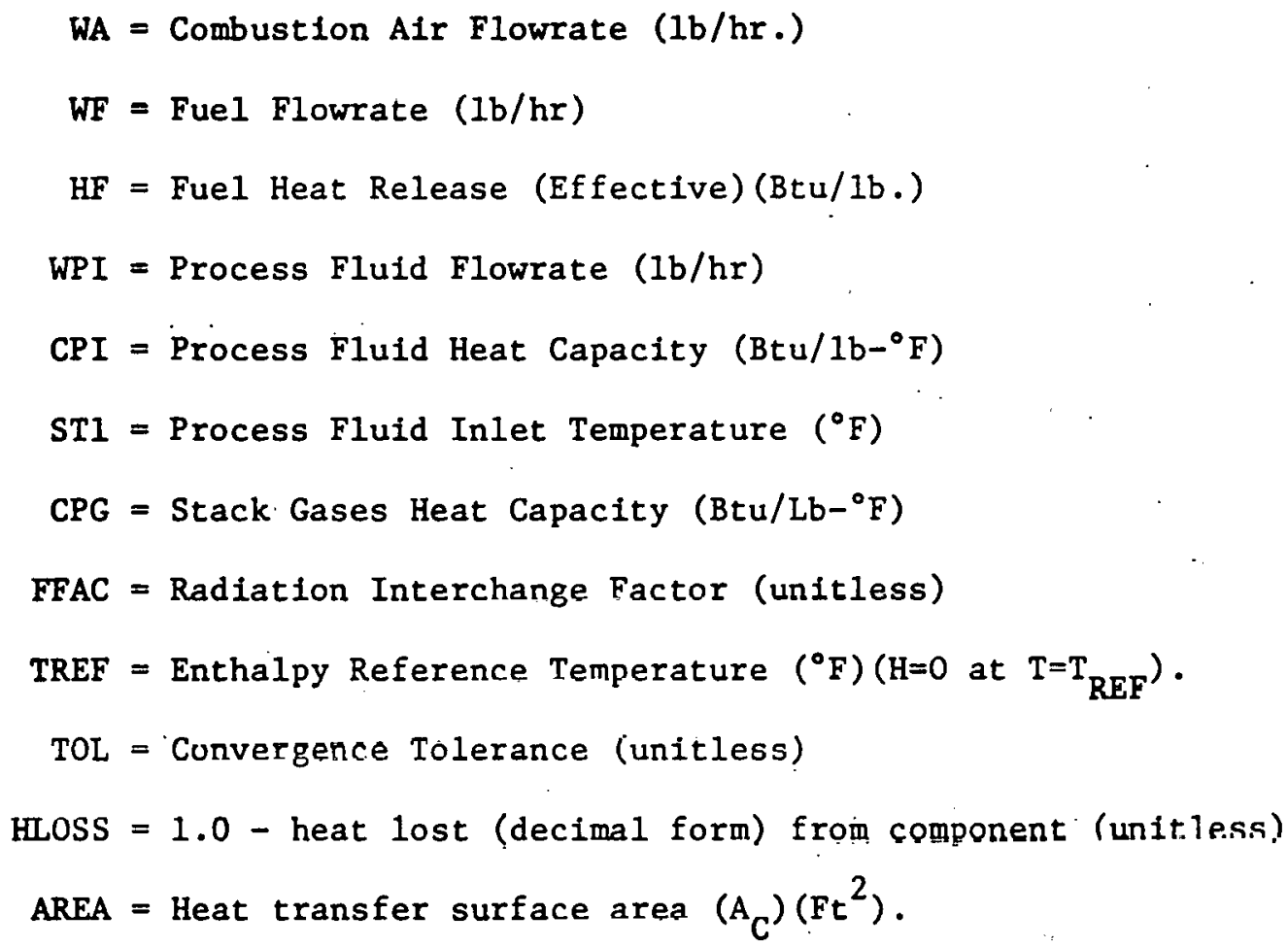


The program incorporates the theory presented in equations [1] through [8] above, however, in order to solve equation [8] to determine the uniform sink temperature $T_{c}$, certain assumptions are made:

\begin{tabular}{|c|c|}
\hline & $T_{c}=\left(T_{1}+T_{2}\right) / 2.0$ \\
\hline Define & $\beta=\left(T_{2}-T_{1}\right) / 2.0$ \\
\hline & $T_{c}=T_{I}+B$ \\
\hline
\end{tabular}

Rewriting [1],

$$
Q_{T}^{\prime}=W_{P_{1}} C_{P_{P}}\left(T_{2}-T_{1}\right)=W_{P_{i}} C_{P_{P}}(2 B)
$$

Equating [12] with [8],

$$
\begin{aligned}
& 2 W_{P_{1}} C_{P_{P}} B=A_{C} F_{C_{F}}\left[\sigma\left(T_{F}^{4}-\left(T_{1}+\beta\right)^{4}\right)+7\left(T_{F}-\left(T_{1}+\beta\right)\right)\right] \\
& \text { Define } \\
& \alpha=2 W_{P_{i}} c_{P_{P}} / A_{C} F_{c_{F}}
\end{aligned}
$$

Then, rearranging [13], we get:

$$
\left[\sigma\left(T_{F}^{4}-\left(T_{1}+\beta\right)^{4}\right)+7\left(T_{F}-\left(T_{1}+\beta\right)\right)\right]-\dot{\alpha} \hat{s}=0
$$

The program is supplied $A_{c}$ (Area) to allow determination of $\alpha$, providing delniliun for all. Lerms in [15] except $\beta$, which is calculated by a Newton-Raphson technique in the model (1ines 160 to 230), where equation [15] represents $F(X),(X=B)$, and $F^{\prime}(X)$ is defined as:

$$
\text { then } \quad \begin{aligned}
& F^{\prime}(\beta)=-4 \sigma\left(T_{1}+\beta\right)^{3}-7-\alpha \\
& \beta_{1+1}=\beta_{1}-F\left(\beta_{1}\right) / F^{\prime}\left(\beta_{1}\right)
\end{aligned}
$$

Convergence is evaluated by determining $F\left(\beta_{1+1}\right)$ and comparing the result to $O$ (equation [1.5]), allowing some insignificant error to exist for efficiency (convergence tolerance). 


\section{Sample Case}

- Input data to the computer program presented in Figure 3, describing a sample case whereby a cold petroleum fraction is heated by natural gas, are presented in Table XV. Note that the input has been structured in accordance with the variable definitions (descriptions and corresponding units) provided in Table XIV. The area parameter was examined sufficiently to define, in graphiral format, the ehapo of ito rclationship witl cumpultul lost work. From that curve, $\Delta$ lost work/ $\Delta$ area can be estimated, and the specific point identified where the associated incremental costs determine optimality. 
Table XV. Sample Case

Input Data

Input Element *

WA

WF

HF

WPI

CPI

ST1

CPG

FFAC

TREF

$\mathrm{T} \emptyset \mathrm{L}$

HLOSS

AREA

${ }^{*}$ Refer to Table XIV.
Value

$100,000.0 \mathrm{lbs} / \mathrm{hr}$.

$5,000.01 \mathrm{bs} / \mathrm{hr}$.

$20,000.0 \mathrm{Btu} / \mathrm{Ib}$.

$200,000.01 \mathrm{~b} / \mathrm{hr}$.

$0.85 \mathrm{Btu} / 1 \mathrm{~b}-{ }^{\circ} \mathrm{F}$

$150.0 \quad{ }^{\circ} \mathrm{F}$

0.32 Btu/1b $-{ }^{\circ} \mathrm{F}$

$0.7-$

$60.0{ }^{\circ} \mathrm{F}$

0.1 -

$0.98-(2 \%$ Heat Loss)

$100,200,300,400,500 \mathrm{Ft}^{2}$ 
VI. Results

The attached graph (Figure 22) presents the results of executing the fortran program presented in Figure 21 using the sample data provided under Table XV. As expected, with additional heat exchange surface area, more process irreversibility is produced, generating more process lost work. It 1s clear. from this study chere is a continuing decrease in lost work/unit area with the continuing increases in surface area. From this, tradeoffs may be made.

Knowing the capital tradeoffs associated with his particular. component system, the designer could utilize the attached curve to exactly define the sensitivity of component thermodynamic efficiency to incremental changes in the selected geometric parameter. Thereby, he defines the static constituent of the equipment's operating expense while simultaneously speclfying its capital cost. Having related present vaiue to availability Btu's, he can then better consider what impact future energy pricing may have on initial equipment design specification. 
F1gure 22. Total Lost Work/Heat Transfer Area Vs. Heat Transfer Area

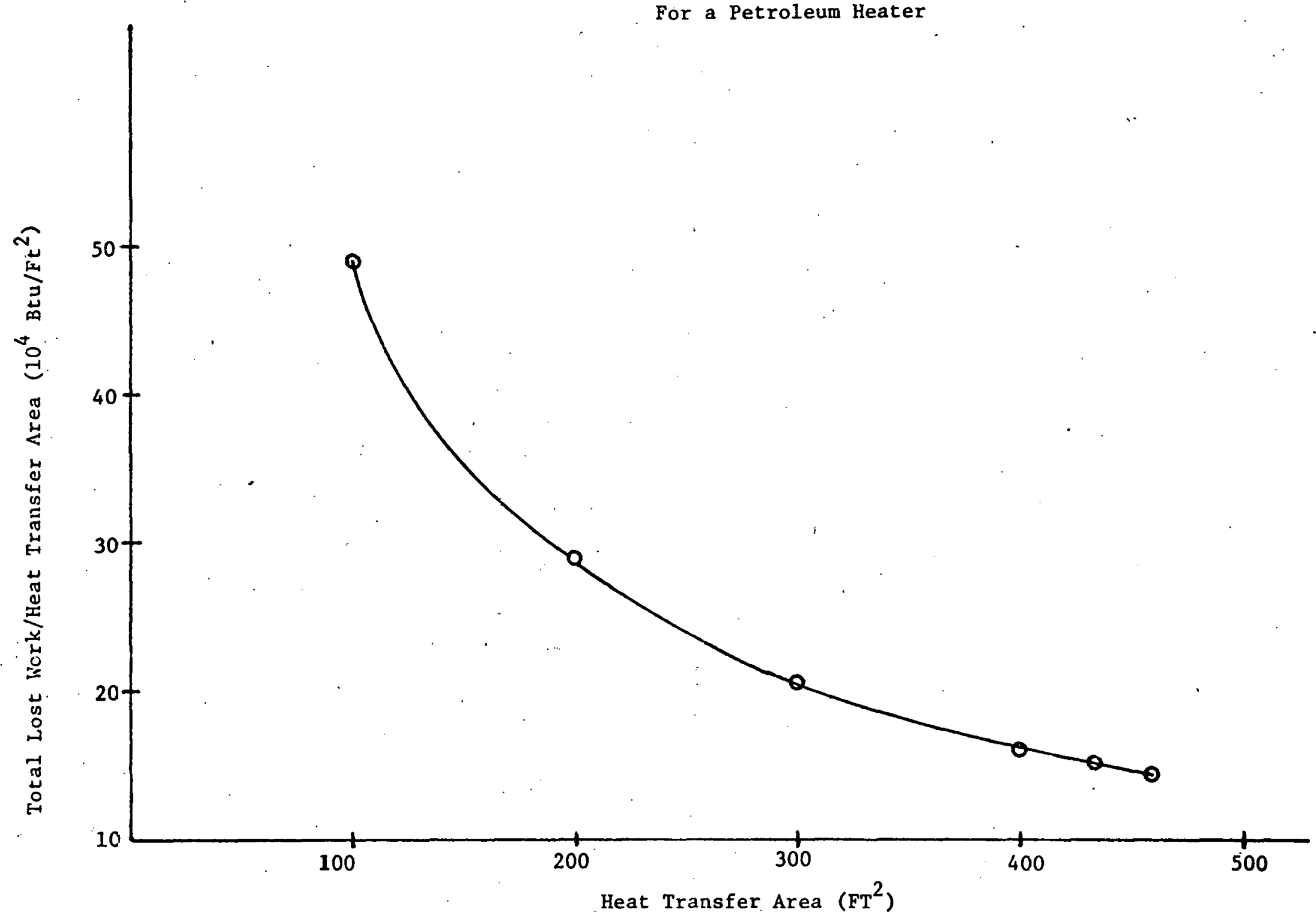




\section{Multiple-Effect Evaporators}

I. Introduction

For years, chemical engineers have examined the heat; mass and momentum transport phenomena associated with the removal of solvent as vapor from a solution or a slurry through the physical process known as evaporation. The cvaluation of that examination has resulled in tuday's basic design approach which considers three separate elements: heat transfer, vapor-liquid equilibria and subsequent physical separation, and energy utilization. Selection of these three elements does not . ignore the importance of materials of construction, mechanical configuration and its effect on pressure profiles, etc. However, these elements truly classify and characterize the appropriateness of evaporation for the purposes of concentration, and/or separation, and/or vaporization.

Heat transfer has been considered the ..."most important single factor in evaporator design since the heating surface area represents the largest part of evaporator costs."(1) However, as is obvious from the recent. plethora of research into stage cascaded evaporation, wiped film evaporators, etc., energy utilization must now be considered the single most important design consideration. Both engineers and scientists remain perplexed at the substantial difference which exists between typical efficiencies for conventional evaporation systems, and the thermodynamically predicted minimum energy requirement. Van Ness and others have long studied that minimum, which is determined as the ideal isothermal work of separation, or simply visualized as the amount of heat liberated if the feed were reconstituted by mixing the concentrated liquor and the condensed vapors. 
This heat of mixing does not include any thermodynamic dependencies resulting from the piase change associated with evaporation. It is this phase change energy which can never be eliminated from the evaporation process. Others have attempted to minimize the phase change energy by using freezing rather than vaporization to accomplish separation and/or concentration. However, much additional development effort needs to be accomplished before the attendant benefits can be derived from proven technology.

Meanwhile, our attention has been focused on means of evaluating the thermodynamic effectiveness of evaporation systems, and more importantly, providing the designer a tool to specify geometric parameters in relation to their effect on the component's lost work, and, as dictated by incremental capital cost and availability (energy) costs, select parameters which will provide optimality.

This short study will utilize a simple model to show that the selection of the geometric parameters which specify component configuration for multiple effect evaporators, the total heat transfer area - can be based on maxlmlzlus the ut1lity of available energy or conversely minimizing total lost work in proportion to the accepted dollar value of lost work.

\section{Process Description}

Referring to Figure 1, a dilute feed solution is fed to the "body" of the evaporator stage, where a minimum reservoir of liquid at its bubble point is maintained. The energy to vaporize this liquid is likewise supplied to the body, and heat transfer is accomplished either indirectly, across a metal interface, or through direct contact with the boiling reservoir. The evaporated solvent leaves the body of the evaporator as vapor, and the 
resldual liquid from the reservoir, containing presumably all the originall, fed solute (per unit of solvent), is discharged from the body as strong solution.

Figure 23 is a schematic of a single "effect" evaporator, where an "effect" is defined as one body or stage where sufficient energy is supplied to vaporize a specified amount of solvent at the desired thermodynamic state. Various physical configurations have been developed, as shown in Figure 24, to ensure circulation past heating surface areas, minimize pressure drop, enhance vapor-1iquid separation, minimize fouling, allow for washing of salt depositions on exposed metal surfaces, etc. It should be noted that each embodiment presented in Figure 24 represents a single effect, and each evaporator type can be characterized by certain physical or geometric parameters. Each configuration, therefore, affords the designer certain options in specifying process heat duty, however, single effect cvaporatul systems are usually reserved for unique services, such as where exotic materials of construrtion are required, cuntaminated vapors can not be reused to supply heat to subsequent effects, or the required heat load san nnt justify incremental costs of added effects. Typically, hnwever, in ordcr to economize energy ronsumption, the desiguer w1ll utilize several similar type effects in series, (eg. Figure 2.5) such that the vapor from the preceding effect can be used as the heating medium for another effect, in which boiling occurs at a reduced temperature and pressure. The decreasing temperature and pressure profiles through a multiple-effect evaporation train allows the designer the opportunity to cascade availability, such that a unit of work can be reused over and over, according to the number of effects in the train. Naturally, inherent irreversibility eventually 


\section{F1gure 23.}

Schemat1c Representation of a Single Effect Evaporator

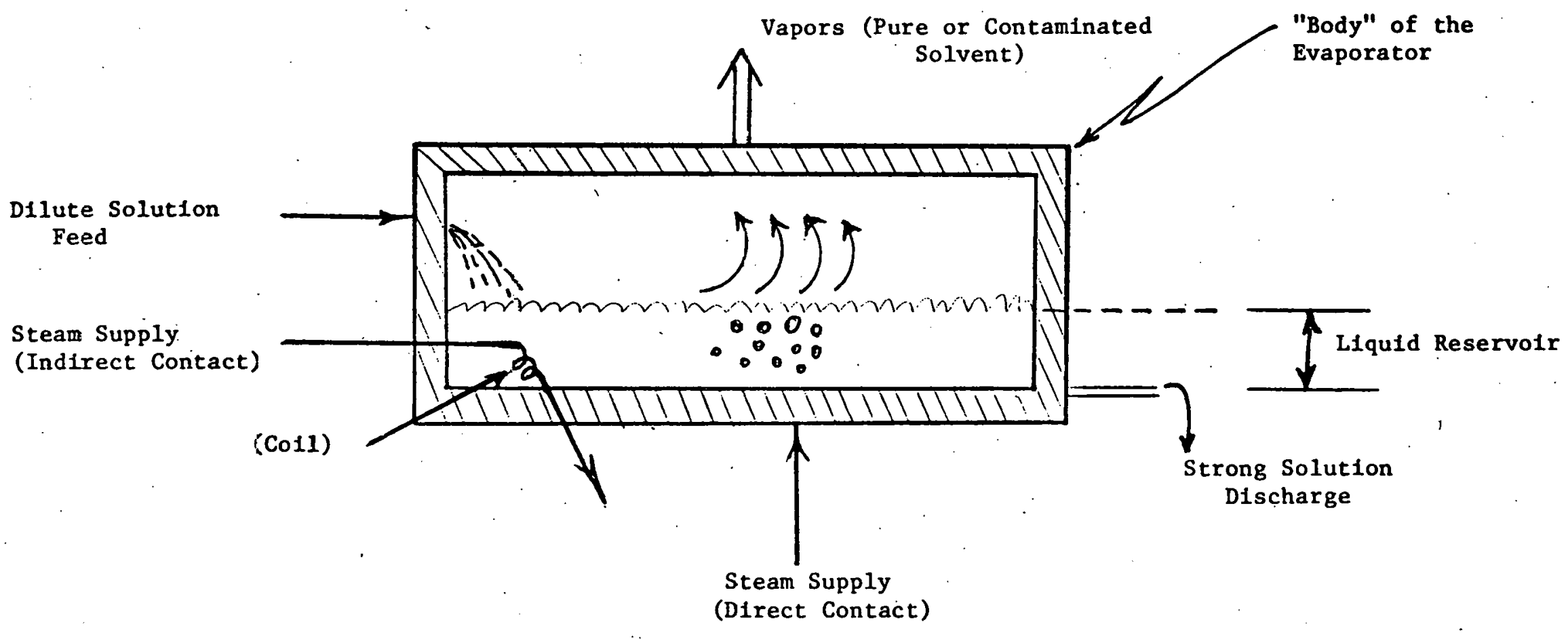


Figure 24.

Evaporator types. (a) Forced circulation, (b) submerged-tube forced circulation, (c) Oslo-type crystallizer, (d) short-tube vertical, (e) propeller calandria, (f) long-tube vertical (ENT'T-separated entrainment outlet), (g) recirculating long-tube vertical, (h) falling film, (i) horizontal-tube evaporator. C, condencatc; F, feed, G, vent; P, product; S, steam; V, vapor.

NOTE: This is figure 11-17 from Reference (1).

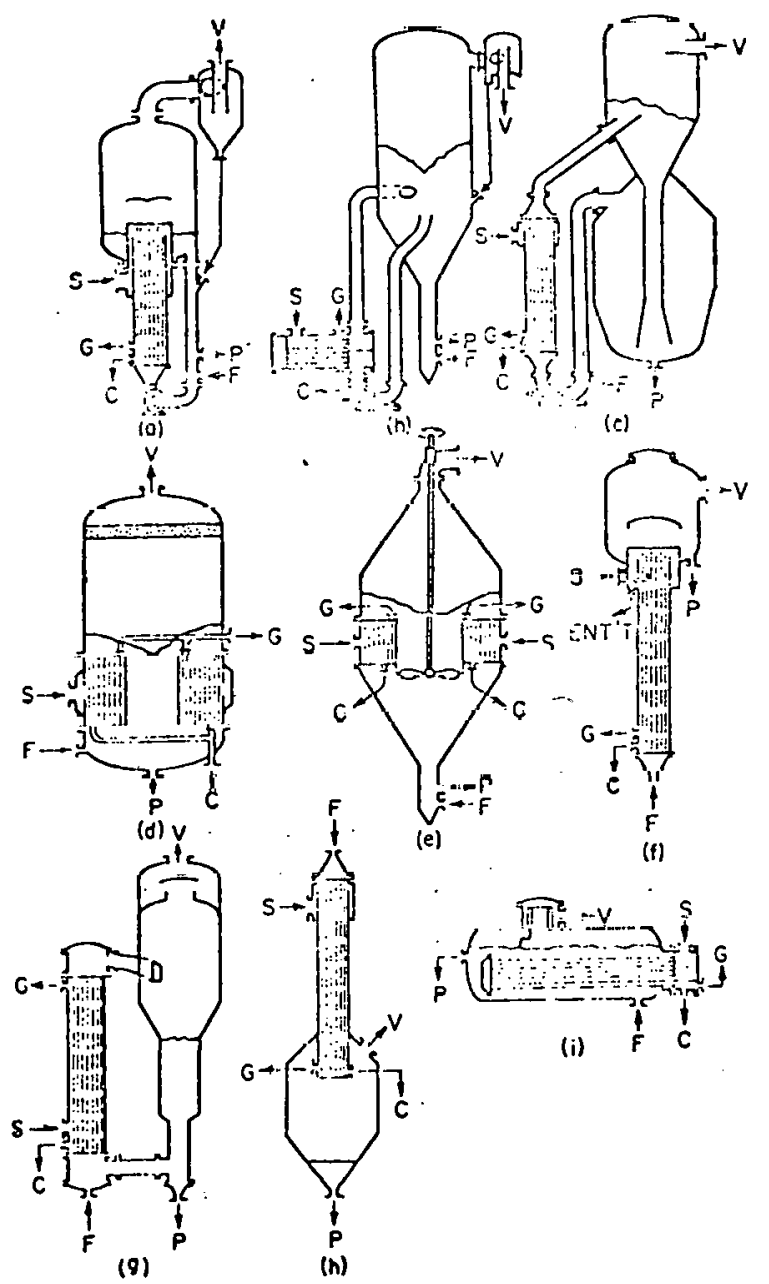

Reference (1): Chemfcal Englneers' Handbook, J. H. Perry, 4th edition, McGraw Hill, Inc. 
F1gure 25.

Typical Multiple Effect Systems

(Figure 16-11 of REference (2))
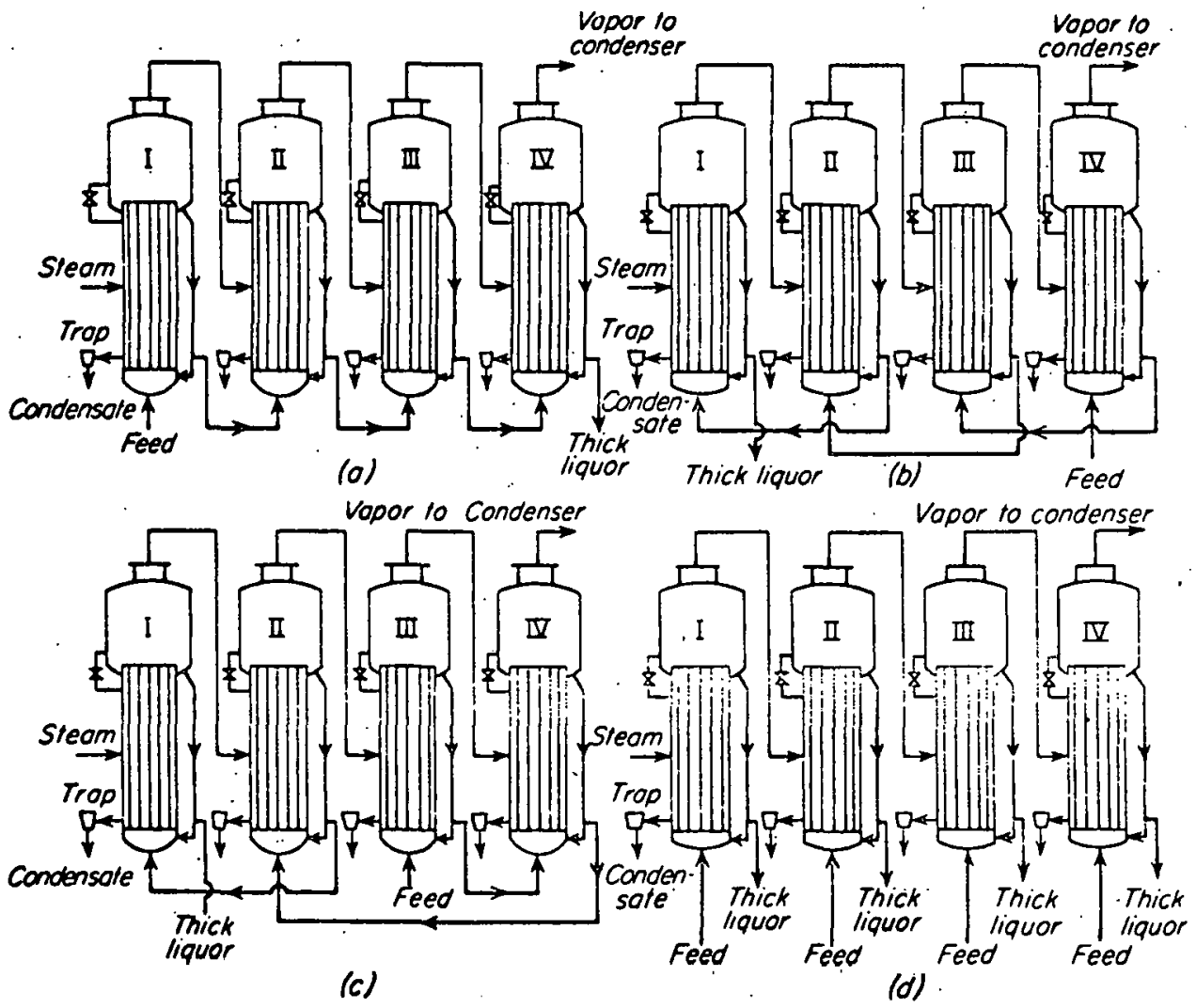

Pallerns of liquor flon: in mulliple-rffecl cuaporalors: (a) Forward seed.

(b) Backiuard feed. (c) Mixed fecd. (d) Parallel fecd. 
consumes the dwindling cascaded availability. To generalize, the energy effectiveness of a multiple-effect evaporator will increase in proportion to the number of effects in the train, and the effectiveness for a train of $\mathrm{N}$ effects will be always less than the linear combination of $\mathrm{N}$ single effect efficiencies. As the train adds effects; then, the law of diminishing "availability", returns suggests that eventually; little additional benefit is derived frnm adding an extra stage when compared to incremental cost. At that point, the vapor effluent may be condensed and/ or subsequently discharged to the environmental sink.

Referring to Figure 26, the lost work balance for a multiple effect evaporator considers only inputs to the first stage and effluents from the last stage, or in other terms, assumes that the train represents the control volume, and considers only associated inputs and outputs. The supplied availability to the evaporator train is the difference in availabilities of the inlet energy stream (usually steam) and the discharged condensate, while the needed availability is detcrmined by the change in thermodynamic state (temperature, pressure, and composition) of the dilute solute feed stream. The objective of this study will be satisfied by determining how the total lost work of a multiple effect * evaporator changes, as additional effects (heat transfer area) are added Un Llie Lfalin.

\section{Mathematical Treatment}

Heat transfer is the most important single factor in evaporator design since heating surface represents the largest part of evaporator cost. Equipment costs are usually correlated against surface area, type and materials of construction. The type of evaporator selected will directly 
F1gure 26. Mult1ple Effect Evaporator

(Lost, Work Balance)

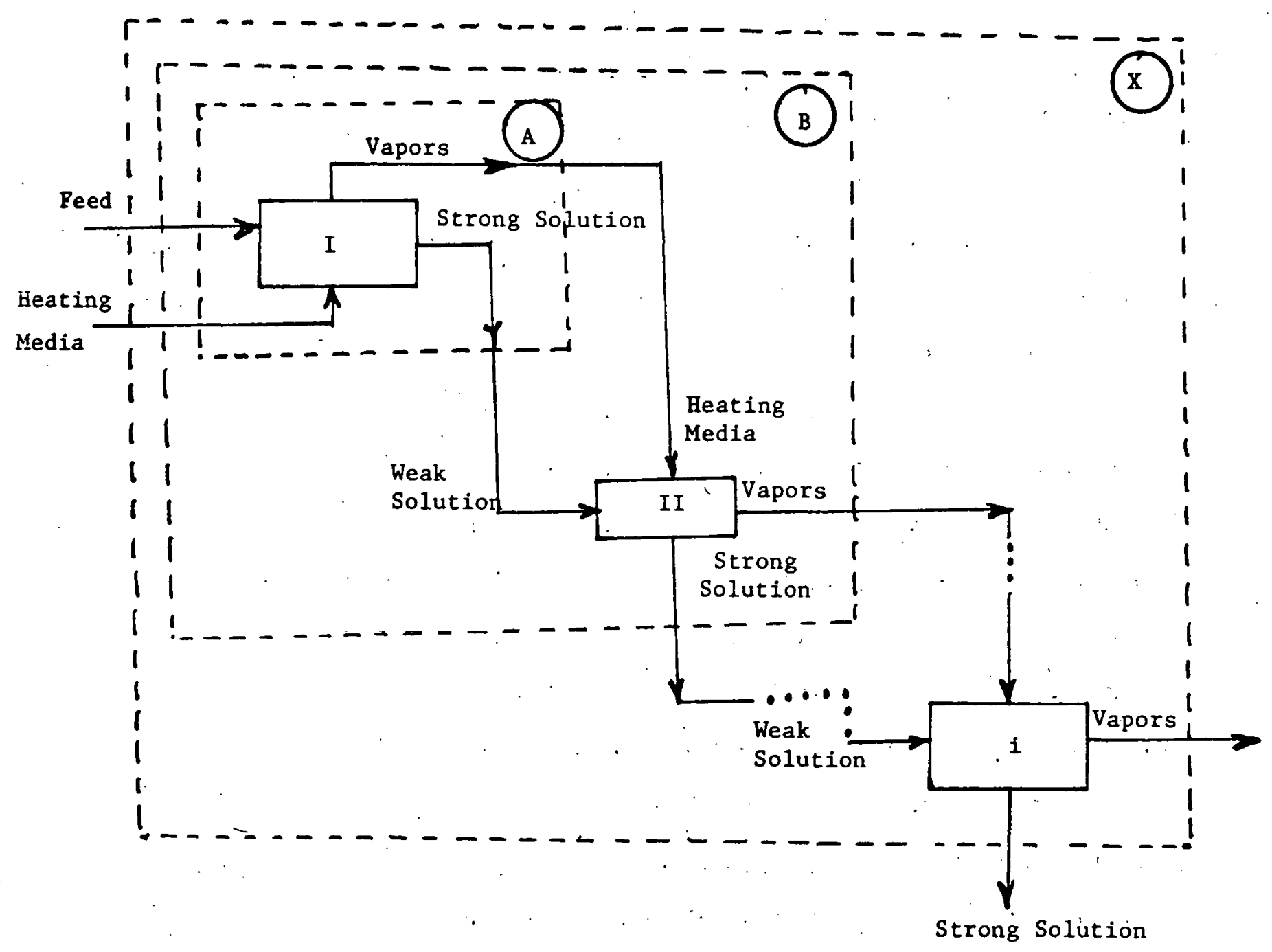

Legend

$\prod_{i=-\infty}^{i}$ Control Volume for Lost Work for $i$ stages

I

Effect I (I, II, $\cdots, i)$

Loot Work Balance

L. W. $=A_{\text {Feed }}+A_{\text {Heating Media }}-A_{\text {Vapor }}-A_{\text {Strong Solution }}(A=$ Avallability $)$

(Avallabilities for each stream determined in accordance with equation [7], A. III (heat exchanger)). 
Impact the overall heat transfer coefficient for each individual effect, and therefore, our study of lost work versus geometric parameter selection could be based on evaluating geometric types for equivalent multiple effect services, where each train type would have a specific lost work assoclated with it, and naturally, price tag as well. To avoid restricting ourselves to certain hardware characteristics, this study will consider heat transfer surface area as the most representative geometric parameter, common to all evaporation systems.

Wê stârt by considering an overall heat balance for a single effect evaporator, as shown in Figure 23.

$$
\begin{aligned}
& \text { Heat Duty }=Q=\dot{M}_{S} \lambda_{S}=\dot{M}_{D F} C_{P}\left(T_{E}-T_{D F}\right)+\left(\dot{M}_{D F}-\dot{M}_{S S}\right) \lambda_{T E} \\
& \text { where } Q=\text { Heat Duty of Effect }(B t u / h r) \\
& \dot{\mathrm{M}}_{\mathrm{S}}=\text { Steam Supply Flowrate }(1 \mathrm{~b} / \mathrm{hr}) \\
& \begin{aligned}
\lambda_{S}= & \text { Heat of Vaporization of Steam at Steam } \\
& \text { Temperature and Pressure (Btu/lb) }
\end{aligned} \\
& \dot{M}_{\mathrm{DF}}=\text { Dilute Fead Solute Flowratc }(1 \mathrm{~b} / \mathrm{hr}) \\
& \mathrm{CP}_{\mathrm{DF}}=\text { Heat Capacity of Dilute Feed Solute (Btu/lb - }{ }^{\circ} \mathrm{F} \text { ) } \\
& T_{E}=\text { Effect Temperature }\left({ }^{\circ} \mathrm{F}\right) \\
& \mathrm{T}_{\mathrm{DH}}=\text { Dilute Eeed Temperature }\left({ }^{\circ} \mathrm{F}\right) \\
& \dot{\mathbf{H}}_{\mathrm{SS}}=\text { Utruing Jululiun Dlsclialge Fluwrace (1b/hr) } \\
& \begin{array}{l}
\lambda_{T_{E}}=\text { Heat of Vaporization of Solution al Lite } \\
\text { Temperature of the Effect }(B t u / L b) .
\end{array}
\end{aligned}
$$

Llkewise, the mass balance for the effect can be written:

$$
\dot{\mathrm{M}}_{S}+\dot{\mathrm{M}}_{\mathrm{DF}}=\dot{\mathrm{M}}_{\mathrm{SS}}+\dot{\mathrm{M}}_{\mathrm{V}}
$$

where

$$
\dot{\mathrm{M}}_{\mathrm{v}}=\text { Vapor Flowrate from the Effect }
$$

However, the heat load must also be defined according to our geometric parameter as follows: 


$$
Q=U_{E} A_{E} \Delta T_{E}
$$

where

$$
\begin{aligned}
U_{B}= & \text { Overall heat transfer coefficient for } \\
& \text { the type effect (Btu/hr } \left.-\mathrm{ft}^{2}-{ }^{\circ} \mathrm{F}\right) \\
\mathbf{A}_{\mathrm{E}}= & \text { Effect heat transfer surface }\left(\mathrm{ft}^{2}\right) \\
\Delta \mathrm{T}_{E}= & \text { Effect Temperature Driving Force }\left({ }^{\circ} \mathrm{F}\right)
\end{aligned}
$$

It has been shown ${ }^{(2)}$ that the overall heat transfer coefficient $\left(U_{E}\right)$ for an effect can be approximately modeled using the following equation:

$$
\left.U_{E}=U_{0} e^{b\left(T_{E}\right.}-T_{0}\right)
$$

where

$$
\begin{aligned}
U_{0}= & U_{E} \text { at a known temperature, } T_{0} \\
b= & \text { constant determined for each liquid } \\
& \text { and the kind and condition of the } \\
& \text { heating surface. }
\end{aligned}
$$

The temperature driving force for the effect is the difference between

the temperature of the supplied availability stream (e 8 . our steam supply) minus the temperature of the liquid reservoir, $T_{E}$, the effect temperature, or:

$$
\Delta T_{E}=T_{S}-T_{E}
$$

where

$$
\mathrm{T}_{\mathrm{S}}=\text { Steam Temperature }\left({ }^{\circ} \mathrm{F}\right) \text {. }
$$

The above equations can be readily solved to determine effect temperature, final solute concentration, etc. for given sample case information. Likewise, the avallability balance is readily determined, and can be related to the specific $A_{E}$ (surface area) selected for the sample case.

\footnotetext{
(2) Unit Operations of Chemical Engineering, McCabe and Smith, McGraw Hill, Inc.
} 
We would like to expand this model to include multiple effects and thereby allow determination of a train's lost work as a function of number of effects (total heat transfer surface area).

The multiple-effect evaporation system in Figure 26 is a linear combination of single effects. Connections between effects are made so that the vapor from effect $i$ serves as the heating media for effect $1+1$. The first effect can be fed steam or other suitable fluid, and 1 is in this effect that the vapor space pressure (and corresponding boiling temperature) is highest. Likewise; the pressure of the vapor space in the last effect is at a minimum, usually determined by the vacuum established by ejertnr or vacuum pump. The pressure in each successive effect is lower than that from which it receives a heating media, and higher than that to which it discharges a strong solute solution. The temperature profile along the train and the drop through each eftect corresponds with the pressure profile and stage-wise drop.

To model the multiple effect evaporation system; we need to generalize the expressions presented in equations [1], [2], and [3], ac follows, Lu allow their application to the $i-t h$ effect where $i=1$, $N(N=$ total etfects in tho train):

[1]

$$
\begin{aligned}
& \left.\eta_{1} \equiv \dot{\mathrm{M}}_{3} \lambda_{3}=\dot{\mathrm{M}}_{\mathrm{DF}} r_{1} \mathrm{P}_{\mathrm{DF}_{1}}\left(\mathrm{~T}_{\mathrm{E}_{1}}-\mathrm{T}_{\mathrm{DF}_{1}}\right)+\dot{\mathrm{M}}_{\mathrm{DF}}-\dot{\mathrm{M}}_{\mathrm{SS}_{1}}\right) \lambda \mathrm{T}_{\mathrm{E}_{1}} \\
& \mathrm{Q}_{2}=\left(\dot{\mathrm{M}}_{\mathrm{DF}}-\dot{\mathrm{M}}_{\mathrm{SB}_{1}}\right) \lambda \mathrm{T}_{\mathrm{E}_{1}}=\dot{\mathrm{M}}_{\mathrm{DF}_{2}} \mathrm{C}_{\mathrm{P}_{\mathrm{DF}}}\left(\mathrm{T}_{2} \dot{\mathrm{E}}_{2}-\mathrm{T}_{\mathrm{DF}}\right)+ \\
& \left(\dot{\mathrm{M}}_{\mathrm{DF}}-\dot{\mathrm{M}}_{\mathrm{SS}_{2}}\right) \lambda \mathrm{T}_{\mathrm{E}_{2}} \\
& \text { : } \quad \vdots \quad \text { : } \\
& Q_{1}=\left(\dot{M}_{D F}(i-1)-\dot{M}_{S S_{(1-1)}}\right) \lambda T_{E_{(i-1)}}=\dot{M}_{D_{F}} C_{P_{D F}}\left(T_{E_{1}}-T_{D F_{1}}\right) \\
& +\left(\dot{\mathrm{M}}_{\mathrm{DF}}-\dot{\mathrm{M}}_{\mathrm{SS}_{1}}\right) \lambda \mathrm{T}_{\mathrm{E}_{1}}
\end{aligned}
$$


[2]

$$
\dot{M}_{S_{1}}+\dot{M}_{D_{1}}=\dot{M}_{S_{S}}+\dot{M}_{v_{1}}
$$

But, for [7] we also now know

$$
\begin{aligned}
& \ddot{M}_{v_{1}}=\dot{M}_{S_{1+1}} \\
& \text { and } \quad \dot{M}_{D F_{1+1}}=\dot{M}_{S S_{1}}
\end{aligned}
$$

[8] Indicates that the vapors from the 1-th stage are the heating media for the $(1-t h+1)$ stage, and likewlse the dilute feed to the $(1-t h+1)$ stage is the strong solution from the ith stage.

$$
\begin{aligned}
& \text { Finally, [3] } \rightarrow Q_{1}=\mathrm{U}_{E_{1}} \mathrm{~A}_{1} \Delta \mathrm{T}_{1} \\
& \text { where } \\
& U_{E_{i}}=U_{0} e^{b\left(T_{E_{i}}-T_{0}\right)} \\
& \text { and } \\
& \Delta T_{1}=T_{S_{1}}-T_{E_{1}}
\end{aligned}
$$


IV. Fortran Embodiment

In order to effectively demonstrate the concept of trading geometric parameter selection for ultimate lost work reductions for a multiple effect evaporator, a computer model employing the mathematical descriptions of Section III was prepared for interactive use. The ofortran source listing for this model is presented in Figure 27 . The program is strurtured to allow definition of the system mode1 (refer. to line 50 of Figure 27) hy reading certain descriptive/definitive data into the machine, and subsequently study the effect of the change in the number of effects, or geometric parameter; assuming constant heat transfer area for each effect. Note that the number of effects (NSTGS) and Effect Area (AREA) are input on line 180. The program determines the total lost work for separate affect systems of $1,2,3, \cdots N$ stages (where $N=N S T G S$ ), so that the overall system's lost work can be compared against increasing number of effects (heat transfer area) (refer to output line 420).

Input variables to this program, nutput parameters and key intcrnal arrays are identified and specified on Table XVI.

The program incorporates the theory presented in Section TTT ahnve, however, to solve equations [6] and [10] to determine the stage temperature, $\mathrm{T}_{\mathrm{E}_{1}}$, or the temperature drop between the temperature of the energy stream supplied, $T_{S_{1}}$, and $T_{E_{i}},\left(\Delta T_{1}=T_{B_{i}}-T_{L_{i}}\right)$, sertain numerical procedurce nre. followed :

(1) Define $\beta=\Delta T_{1}$

(2) Rewrite [6] as $F(\beta)=Q_{1}-\dot{M}_{D_{1}} C_{P_{D F}}\left(T_{E_{i}}-T_{D F}\right)$

$$
+\left(\dot{M}_{D F_{1}}-\dot{M}_{S_{S}}\right) \lambda T_{E_{1}}=0
$$


(3) Substitute $U_{E_{1}} A_{1}{ }^{B}$ for $Q_{1}$ in (2) to get (2)*

(4) Substitute $\left.U_{0} e^{b\left(T_{s}\right.}-\beta_{i}-T_{0}\right)$ in $(2)^{*}$

(5) Determine $F^{\prime}(8)$

(6) Determine $\beta_{i+1}=\beta_{i}-F\left(\beta_{i}\right) / F^{\prime}\left(\beta_{i}\right)$

(7) Evaluate $F\left(\beta_{i+1}\right)$ to see if $\beta_{i}$; the temperature drop has been correctly estimated within some specified tolerance.

Note that a number of refinements to the fortran model are possible, such as allowing for boiling point elevation as a function of solute concentration which reduces the total available temperature drop, and allowing for the influence of reservoir liquid head, which also serves to reduce available temperature drop. However, it was felt that the above model, perhaps simplistically, provides a resonable and sufficient description of the behavior of a multiple effect evaporator to demonstrate the basic hypothesis of this study, that lost work can be directly related to surface area, and that such relation.serves as an intransient interface, between operating expense and capital equipment costs.

Finally, in order to reasonably predict availability, the following equation was used to predict changes in the heat capacity of the strong solution as a function of Inctusing solute concentration:

$$
c_{P_{2}}-1.0-\left(1.0-c_{p_{1}}\right) * x_{2} / \dot{x}_{1}
$$

'where

$$
\begin{aligned}
& X_{1}=\text { solute weight fraction } \\
& C_{P_{1}}=\text { heat capacity } \\
& \left(C_{P}=C_{P_{1}} \text { at } X=X_{1}\right)
\end{aligned}
$$


Pigure 27. FORTRAN SOURCE LISTING FOR MULTIPLE EFFECT EVAPORATOR AVAILABILITY MODEL.

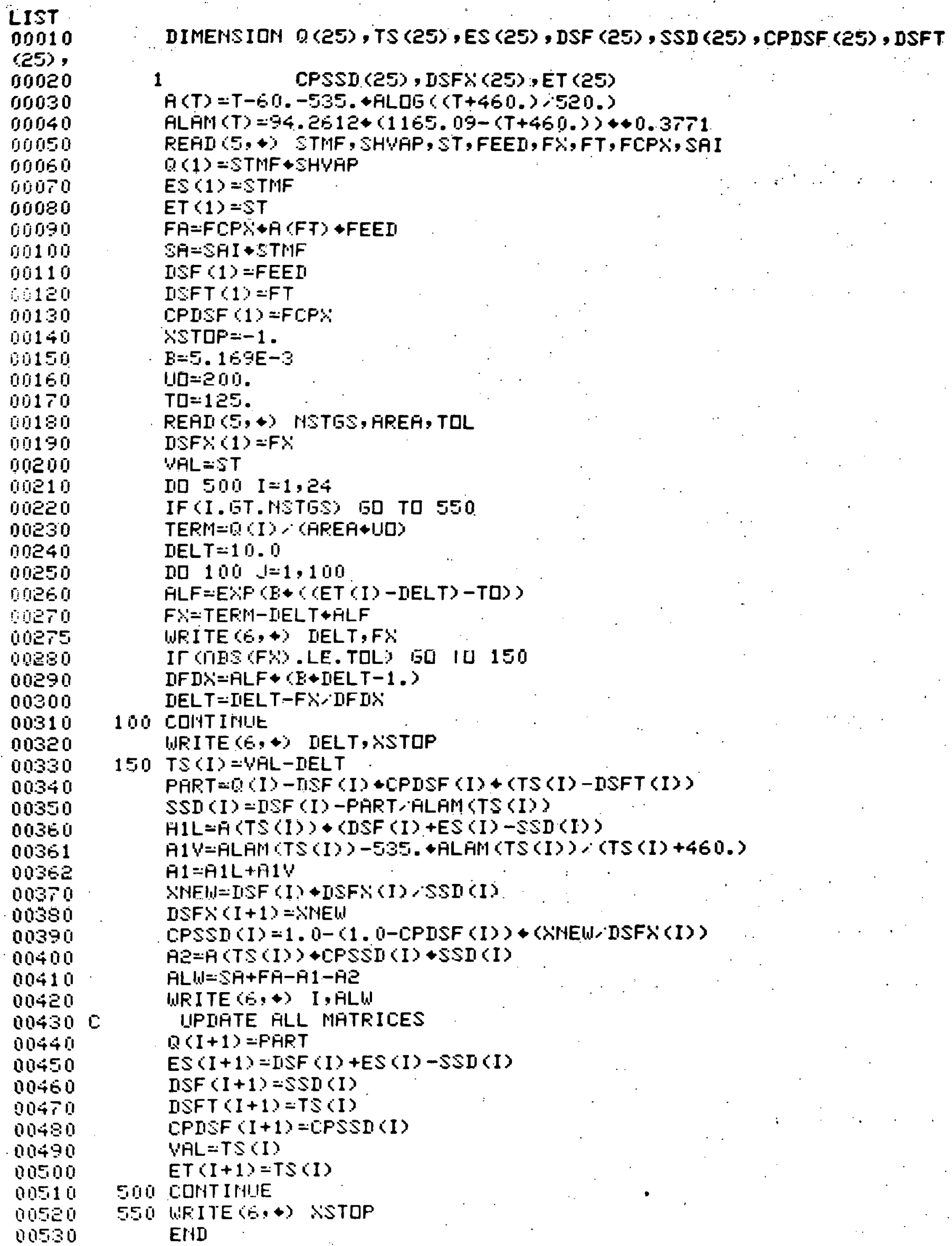


Table XVI.

Definition of Fortian Model Parameters

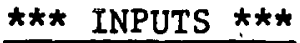

$\begin{array}{lll}\text { STMF } & =\text { Steam Flow Rate to Stage } 1 \text { (lbs/hr.) } \\ \text { SHVAP } & =\text { Supplied Steam's Heat of Vaporization (Btu/lb) at ST } \\ \text { ST } & =\text { Supplled Steam Temperature }\left({ }^{\circ} \mathrm{F}\right) \\ \text { FEED } & =\text { Dilute Solution Flow Rate to Stage } 1(1 \mathrm{bs} / \mathrm{hr} .) \\ \text { FX } & =\text { Dilute Solution Solute Weight Fraction (Lbs/1b Sol.) } \\ \text { FT } & =\text { Dilute Solution Feed Stream Temperature }\left({ }^{\circ} \mathrm{F}\right) \\ \text { FCPX } & =\text { Dilute Solution Feed Stream Heat Capacity }\left(\mathrm{Btu} / \mathrm{Lb}-{ }^{\circ} \mathrm{F}\right) \\ \text { SAI } & =\text { Supplied Steam Implicit Availability }(\mathrm{Btu} / 1 \mathrm{~b}) \\ \text { NSTGS } & =\text { Number of Evaporator Effects (Stages) } \\ \text { AREA } & =\text { Area for Heat Transfer in each effect }\left(\mathrm{Ft}^{2} / \mathrm{stage}\right) \\ \text { TOL } & =\text { Convergence Tolerance (unitless) }\end{array}$

\section{$\star \star \star$ OUTPUTS $\star * \star$}

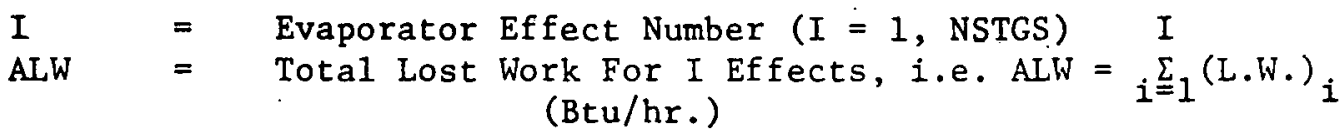

FEK INTERNAL ARRAYS $* * *$ ("I" refers to Stage $i, i=1$, NSTGS)

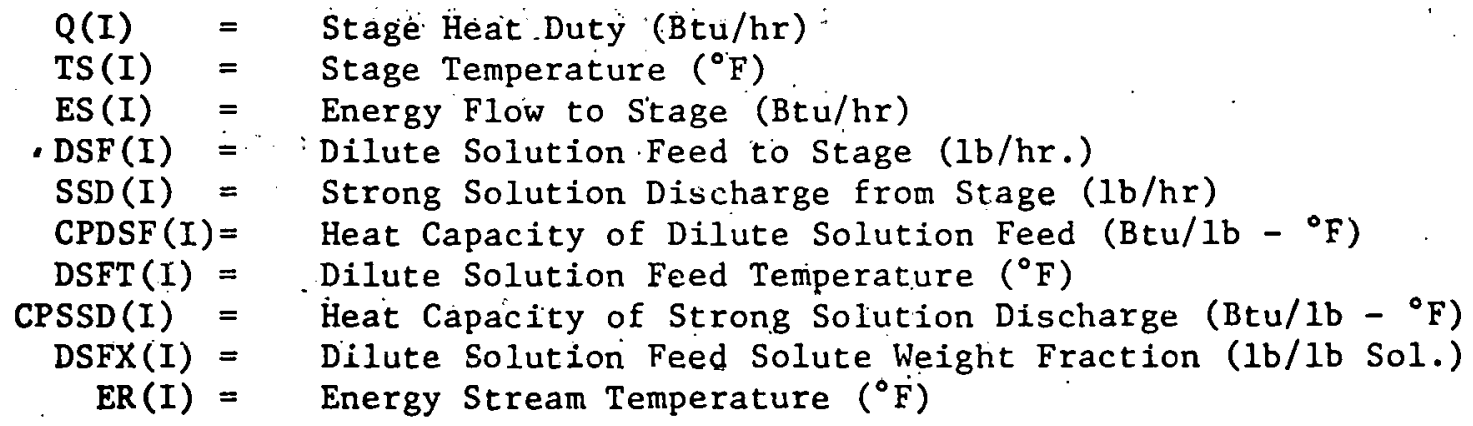




\section{Sample Case}

Input data to the computer program presented in Figure 27, describing a sample case whereby a dilute salt stream is to be concentrated by $15 \mathrm{psig}$ steam in single and multiple effect evaporators, are presented in Table XVII. Note that the input has been structured in accordance with the variable definitions (descriptions and corresponding units) provided in Tablc XVI. The number of effects was allnwed tn raigu to 20 , such that the heat transfer area's effect on lost work could be determined, and the shape of the relationship adequately evaluated for graphical presentation. From that curve, $\Delta$ lost work/ $\Delta$ area can be estimated, and the specific pnint ideullfled where the associated incremental costs determine optimality.

Table XVII.

\section{Sample Case Input Data}

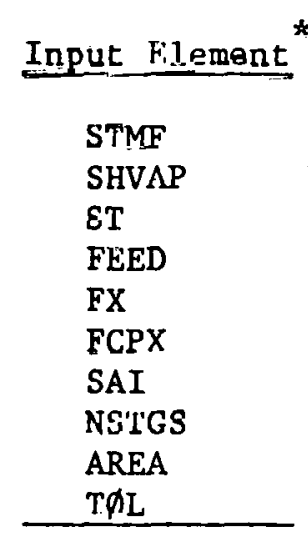

$$
\begin{aligned}
& \text { Valuc } \\
& 6000.0 \mathrm{lbs} / \mathrm{hr} \\
& 948.6 \mathrm{Btu} / \mathrm{lb} \\
& 249.0^{\circ} \mathrm{F} \text { (15 psig.) } \\
& 55000.01 \mathrm{bs} / \mathrm{hr} \\
& 0.03 \text { 1bs/1bs sol. } \\
& 0.98 \mathrm{Btu} / 1 \mathrm{~b}-{ }^{\circ} \mathrm{F} \\
& 253.0 \mathrm{Btu} / 1 \mathrm{~b} \\
& 20 \text { Total Stages } \\
& 1000.0 \quad \mathrm{Ft}^{2} / \mathrm{Stage} \\
& 0.1 \text { - }
\end{aligned}
$$

${ }^{*}$ Refer to TableXVI. 


\section{Results}

The attached graph (Figure 28) presents the results of executing the fortran program presented in Figure 27 using the sample data provided under Table XVII. As expected, with additional heat transfer surface area, more ' process irreversibility is encountered, generating more process lost work. As shown, the lost work per unit area again decreases with increasing area; from such curves the optimum design point may be found.

Knowing the capital tradeoffs associated with his particular component system, the designer could utilize the attached curve to exactly define the sensitivity of component thermodynamic efficiency to incremental changes In the selected geometric parameter: Thereby, he defines the static constituent of the equipment's operating exrense while simultaneously specifying its capital cost. Having related present value to availability Btus, he can then better consider what impact future energy pricing may have on initial equipment design specification. 


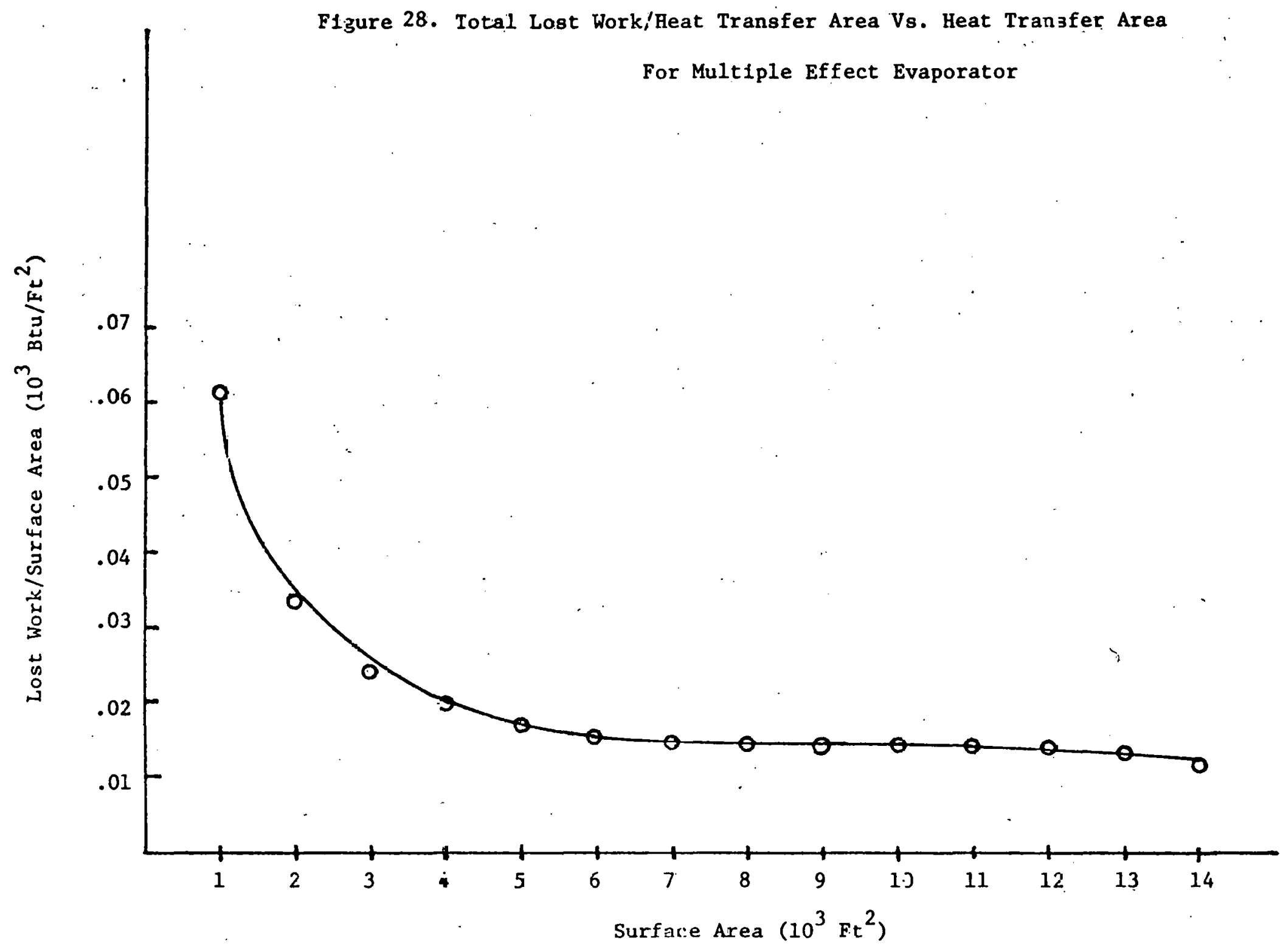




\section{DISTILLLATION}

\section{Introduction}

Distillation is the most common separation process in the processing industry. The analysis of distillation from an availability point of view is a challenging problem which can be undertaken on a number of levels. This treatment of Distillation will address thermal effects only since they contribute the most to the overall process lost work. Distillation des1gn procedes by specifying the desired split between key components. This together with a specified reflux ratio sets the column material and heat balance. It is the objective of the designer to set the reflux ratio so that reflux is minimized consistent with optimization of capital costs. It is the objective of this analysis to show that the optimum distillation design point for a given split is the point where incremental reductions in lost work are balanced exactly by the cost of incremental capital.

\section{Process Description}

A saturated liquid feed of two components is fed to a distillation tower containing trays. Vapor load for the column is provided by a sceam heated-reboiler. Overhead vapors are condensed by cooling water and are split into a distillate stream. and a reflux returned to the column. The significant geometric parameters are distillation colum height and diameter and the surface area required for reboiling and condensing. In general as reflux increases the stage requirements decrease, decreasing column height. However, column diameter increases together with surface area requirements for rebolling and condensing. It is the objective of this design technique to identify the point where reflux can be reduced 
such that the 1ncreasing capital cost is exactly justified by the Incremental reduction in lost work. Figure 29. shows a schematic description of the process system.

\section{Figure 29.}

\section{Distillation Syatem}

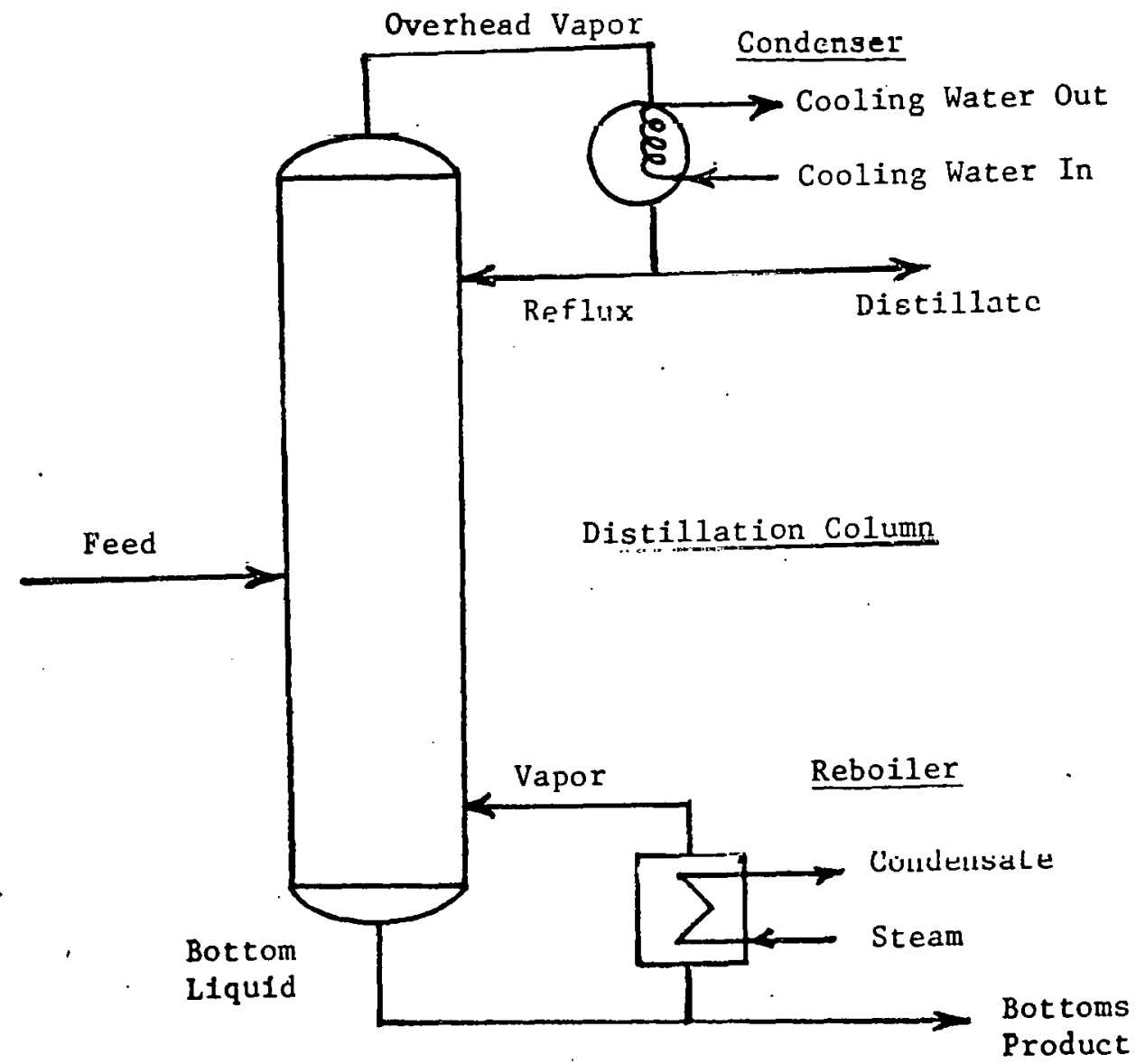




\section{Mathematical Treatment}

The mathematical treatment for distillation is drawn in majority from Perry's Chemical Engineers Handbook, 4th Edition, Section 13. The equilibrium stage requirements are calculated according to the method of Underwood for partial reflux. The relevant relationships are as follows:

$$
y=\left(\frac{L}{V}\right) x+b
$$

The equilibrium line:

$$
\left[\frac{L}{V}(\alpha-1)\right] k^{2}+\left[\frac{L}{V}+b(\alpha-1)-\alpha\right] k+b=0
$$

where:

$$
\begin{aligned}
& y \text { - vapor mole fraction of component } \\
& x \text { - liquid mole fraction of component } \\
& \alpha-\text { relative volatility } \\
& \frac{L}{V}-\begin{array}{l}
\text { liquid vapor ratio in appropriate } \\
\text { section of column. }
\end{array}
\end{aligned}
$$

The roots of equation. [2] are determined as follows:

For the rectifying section:

$$
\begin{gathered}
0<\mathrm{k}_{1}<1 \\
\mathrm{k}_{2}>1
\end{gathered}
$$

For the stripping section:

$$
\begin{gathered}
k_{1}<1 \\
0<k_{2}<1
\end{gathered}
$$

The number of ideal equilibrium stages is the computed for each section by the following expression:

$$
n \log \frac{\alpha /(L / V)}{\left[1+(\alpha-1) k_{1}\right]^{2}}=\log \frac{\left(x_{p}-k_{1}\right)\left(k_{2}-x_{o}\right)}{\left(k_{0}-k_{1}\right)\left(k_{2}-x_{p}\right)}
$$


For the rectifying section:

$$
\begin{aligned}
& x_{0}=\text { composition on feed tray } \\
& x_{p}=\text { distillate composition }
\end{aligned}
$$

For the stripping section:

$$
\begin{aligned}
& x_{0}=\text { bottoms composition } \\
& x_{p}=\text { con. isition on the feed tray }
\end{aligned}
$$

Adding the stripping and rectifying stages gives the total stage requirements. The column height is determined by assuming that the tray spacing is 12 " and that the stage efficiency is $66 \%$. Hence,

$$
\mathrm{H}=1.5 \text { (ideal stages) }
$$

The distillation colum diameter is set by the vapor load imposed by the reboller based on the selected reflux ratio. The overall material balance is as follows:

$$
F=D+B
$$

The componential balance is:

$$
X_{F} F=X_{D} D+x_{\dot{B}} B
$$

$$
\text { where } \quad \begin{aligned}
F & =\text { Feed rate, moles } / \mathrm{hr} \\
\mathrm{D} & =\text { distillate rate, moles/hr } \\
\mathrm{B} & =\text { bottoms rate, moles } / \mathrm{hr} \\
\mathrm{X}_{\mathrm{F}} & =\text { mole fraction of component in feed } \\
\mathrm{X}_{\mathrm{D}} & =\text { mole fraclion of component in distillate } \\
\mathrm{X}_{\mathrm{B}} & =\text { mole fraction of component in bottoms }
\end{aligned}
$$


Solving 5 and 6 for $D$ and $B$,

$$
\begin{aligned}
& D=F \frac{\left(X_{F}-X_{B}\right)}{\left(X_{D}-X_{B}\right)} \\
& B=F \frac{\left(X_{B}-X_{F}\right)}{\left(X_{D}-X_{B}\right)}
\end{aligned}
$$

The overhead vapor rate is computed by.

$$
\mathrm{v}_{\mathrm{o \mu}}=(\mathrm{R}+1) \mathrm{D}
$$

where

$$
\begin{aligned}
\mathrm{V}_{\mathrm{O \mu}} & =\text { overhead vapor } \\
\mathrm{R} & =\text { reflux ratio }
\end{aligned}
$$

The reflux liquid is

$$
\mathrm{L}_{\mathrm{REF}}=\mathrm{RD}
$$

The bottom liquid is:

$$
\mathrm{L}_{\mathrm{BOT}}=\mathrm{F}+\mathrm{L}_{\mathrm{REF}}
$$

This assumes a saturated liquid feed. The reboiler vapor is

$$
V_{\text {REB }}=L_{B O T}-B
$$

The distillation column diameter can now be set by the following equation:

$$
D_{1 A}=0.592 \cdot \sqrt{(R+1) F \frac{\left(X_{F}-X_{B}\right)}{\left(X_{D}-X_{B}\right.}}
$$

where; $D_{1 A}=$ diameter in feet.

The area of condenser and reboiler are determined as follows:

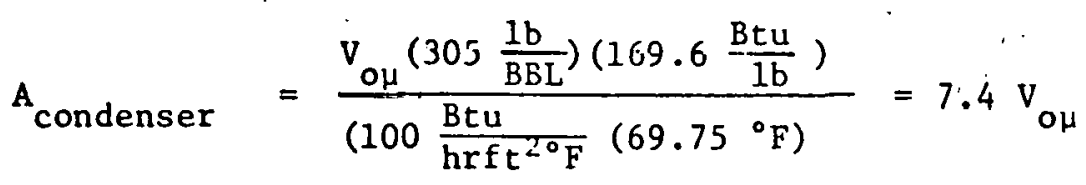


The reboller area can be determined by the following equation:

$$
A_{\text {rebolier }}=\frac{v_{\text {reb }}\left(305 \frac{1 b}{B B L}\right)\left(156.24 \frac{B t u}{1 b}\right)}{100 \frac{B t u}{\mathrm{hrft}^{20} \mathrm{~F}}(350-228.2)}=3.9 v_{\text {reb }}
$$

The cost of the distillation system is then determined from the following cost equations :

(a) Distillation column

$$
\text { Cost } \$=1008 \cdot\left(D_{1 A}\right)^{0.88} \cdot(\mathrm{H})^{0.94}
$$

(b) Reboiler and Condenser

$$
\text { Cost } \$=1000 .(\mathrm{A})^{0.65}
$$

The total cost of the system is calculated by adding the results of equations [15] and [16].

Finally, the lost work is determined from the availability balance around each component and then the lost work of each componcnt is formed to get the system total.

The thermodynamic availability is predicted by

$$
a=\Delta h-T_{0} \Delta s
$$

where:

$$
\begin{aligned}
a & =\text { thermodynamic availability, Btu/lb } \\
\Delta h & =\text { change in enthalpy, Btu/lb } \\
T_{0} & =\text { dead state temperature, }{ }^{\circ} \mathrm{R} \\
\Delta s & =\text { change in entrapy, Btu/1b } \circ^{\circ} \mathrm{R}
\end{aligned}
$$


The enthalpy is defined as zero at $32^{\circ} \mathrm{F}$ and is given by the following expression

$$
h=C_{P_{\ell}}\left(T_{B}-32\right)+\lambda+C_{P_{v}}\left(T-T_{B}\right)
$$

where $\mathrm{h}=$ enthalpy, Btu/1b

$$
\begin{aligned}
\mathrm{C}_{\mathrm{P}_{\ell}} & =\text { liquid heat capacity, Btu/Lb }{ }^{\circ} \mathrm{R} \\
\mathrm{C}_{\mathrm{P}_{\mathrm{V}}} & =\text { vapor heat capacity, Btu/Lb }{ }^{\circ} \mathrm{R} \\
\mathrm{T}_{\mathrm{B}} & =\text { normal boiling point, }{ }^{\circ} \mathrm{F} \\
\mathrm{T} & =\text { material temperature, }{ }^{\circ} \mathrm{F} \\
\lambda & =\text { latent heat of vaporization, Btu/1b }
\end{aligned}
$$

If no phase change occurs, (i.e. liquid state) the two right hand terms in equation [18] are zero and $T_{B}$ becomes the temperature of interest, $T$. The entropy is defined by the following

$$
\mathrm{S}=\mathrm{CP}_{\ell^{\ln }}\left(\frac{\mathrm{T}_{\mathrm{B}}+460}{492}\right)+\frac{\lambda}{\mathrm{T}_{\mathrm{B}}+460}+\mathrm{CP}_{\mathrm{v}} \ln \left(\frac{\mathrm{T}+460}{\mathrm{~T}_{\mathrm{B}}+460}\right)
$$

where $\quad S=$ entropy, $B t u / 1 b{ }^{\circ} \mathrm{K}$ other terms as in equation [18]

If no phase change has occurred, the two right hand terms are zero and equation [19] is used to evaluate the liquid $S$ with $T_{B}$ equal to $T$.

\section{Fortran Embodiment}

The mathematical model previously described has been coded into an Interactive Fortran computer program for the purpose of demonstrating the analysis technique. The code is shown in Figure 30 with relevant input and output variables defined in Table XVII. 
F1gure 30.

Fortran Source Program for Distillation

00010

00020

00030

00040

00050

00060

00070

00000

00090

00100

00110

00120

00130

00140

00150

00150

00170

00180

00190

00200

002 10

00250

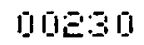

00240

obesio

00260

00270

0 0

0 onego

00300

00310

00520

vilso

00340

00050

00350

00370

00300

00390

00400

00410

$004=0$

00430

00440

00450

00460

00470

00480

00490

00500
FEAII $(5, \leftrightarrow)$ FLF, $\because I I, \therefore E, Y Y F, F$

$\mathrm{I}=\mathrm{F}+(\mathrm{SF}-\mathrm{S} \mathrm{E}) \cdot \mathrm{NI}-\mathrm{SE}$

$\mathrm{E}=\mathrm{F}+\mathrm{NI}-\mathrm{S}) \cdot \mathrm{SI}-\mathrm{SE})$

10 PEFI $(5,+)$ F:

$V \mathrm{DH}=(\mathrm{E}+1 . \mathrm{Y}+\mathrm{I}$

FLLF:EF $=\mathrm{F}+\mathrm{II}$

ALE:DT $=F+F$ FLFEF

YFEE $=$-FLE:DT-E:

$A P=F+(H L F-1).(E R+1$.

$E F=(F)(F+1.5)+C F+C F L F-1.)(R F+1)-.F L F$

$C F=P I \cdot C F+1$.

CALL RODTS (AF, EF, CF, R1, FE)

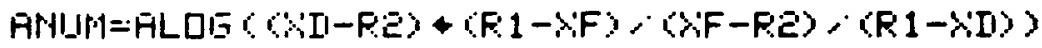

HIIEH $=(1 .+(\mathrm{ALF}-1.9+\mathrm{R} \mathrm{C})++\mathrm{C}$

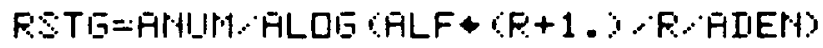

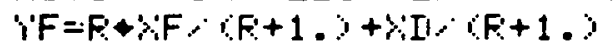

$\mathrm{IIEL}=\mathrm{YF}-\mathrm{SE} \cdot \mathrm{SF}-\mathrm{SB}$

$A F=I E L+C H L F-1.2$

$\mathrm{EF}=\mathrm{IIEL}+1 .-\mathrm{IIEL})+\mathrm{XE}+(\mathrm{F} L F-1)-.\mathrm{FLF}$

$C F=(1 .-I I E L)+C E$

CALL FOOTS (AF, EF, IF, R1, RE)

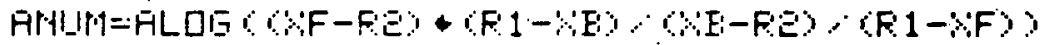

AIIEY $=(1 .+$ HLF -1.$)+F E O++E$

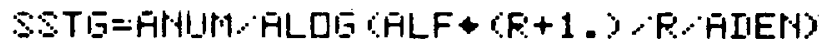

TSTG=KSTG+STTE

$H=1: 5+7 \leq I B$

II $=10.5=+30 R T(C F+1)+I$.

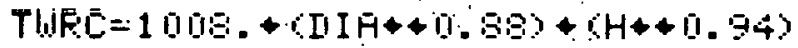

$\mathrm{FCOH}+\mathrm{I}=\overrightarrow{\mathrm{r}} .4+(\mathrm{F}+1)+.\mathrm{I}$

AREE $=3.9+(\mathrm{F}+1.9+\mathrm{II}$

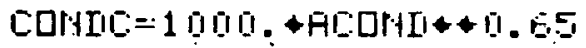

REEC=1000. +AREE + + 0.65

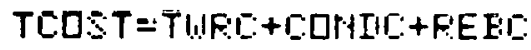

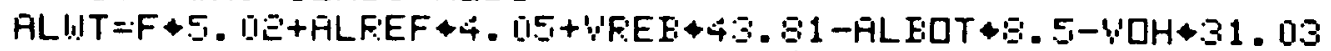

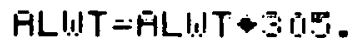

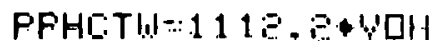

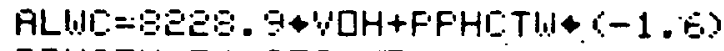

PPHSTM=:54. $9 \mathrm{~S} 3+\mathrm{WFEE}$

PLUR=VFEE + $(-10769.6)+F F H S T H+209.98$

$T L W=\bar{H} L W T T+F L W I C+F L W E:$

WIRITE (E, \$) TSTE, IIIA, H: FICDHI, AREE

WRITE SE, $\rightarrow$ FI, TLOST: TLU

GD TO 10

ENII

SUEROITIHE FEOTS (F, E, C, R.1, RE)

$S=E D R T(E+E-4 .+F+C)$

$R^{\prime} 1=(S-E) \cdot E \cdot A$

$R E=((-S)-E), E . A A$

RETUIFN

ENI 
Table XVIII

Computer Program Input and Output Variables

Variable

INPUT

ALF

$\mathrm{XD}$

$\mathrm{XB}$

$\mathbf{X} F$

F

$\mathbf{R}$

OUTPUT

TSTG

DIA

H

ACOND

AREB

$\mathbf{R}$

$\mathrm{T} \cos \mathrm{T}$

TLW
Relative Volatility

Distillate Mole Fraction

Bottoms Mole Fraction

Feed Mole Fraction

Feed Rate

Reflux Ratio

Number of Ideal Stages

Tower Diameter

Tower Height

Condenser Heat Transfer Area

Reboiler Heat'Transfer Area

Reflux Ratio

Total Cost of System

Total Lost Work
$\$ 1979$

Units

Barrels/hr.

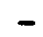

FT

FT

$\mathrm{FT}^{2}$

$\mathrm{FT}^{2}$

$\mathrm{BTU} / \mathrm{Hr}$ 
V. Sample Case

The input values for a sample case are shown in Figure 31 . The variables are defined in order as shown in Figure 30 . The sample problem assumes a binary split of high purity where reflux ratio will be decreased from a large value until the curve of lost work versus capital cost is generated so that the point where decreases in lost work exactly justify the increased capital for more ideal stages.

\section{Figure 31.}

Sample Case Input Values

Variable

Relative Volatility, ALF

Disțillate. XD

Bottoms, $\mathrm{XB}$

Feed, XF

Feed Rate, F

Reflux Ratio
Value

2.4

0.99

0.01

0.642

$100 \mathrm{BBLS} / \mathrm{Hr}$

$1.056 \rightarrow 4$ 
F1gure 32.

DISTILLATION SYSTEM

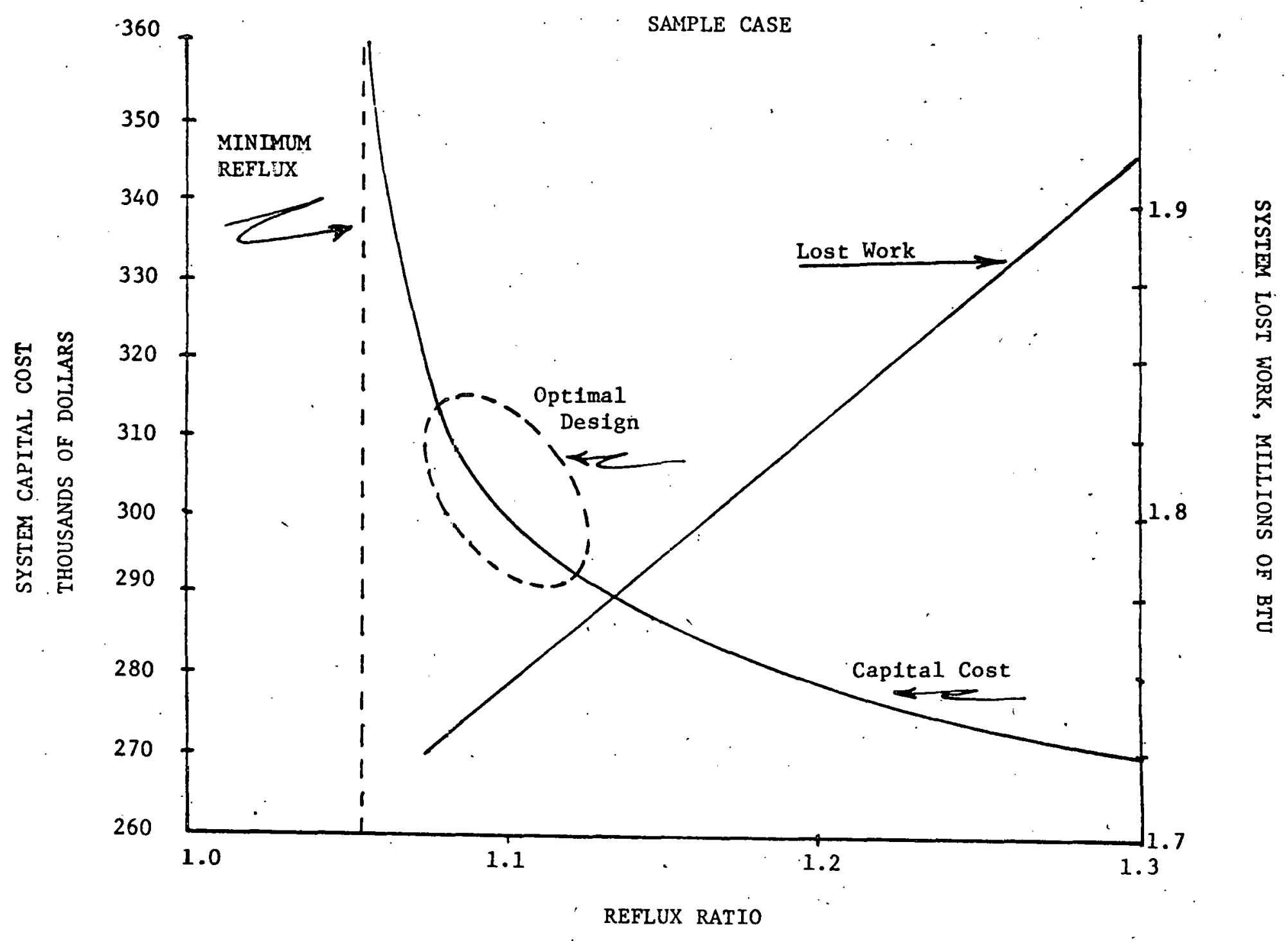




\section{Results}

The results of the sample case are shown in Figure 32. As the reflux ratio is decreased, the system capital cost increases due to increasing distillation tower stages (height). This has the beneficlal effect of reducing lost work in the system and reducing capital cost for heat exchange in condensing and reboiling. The dcsign point where incremental capital investment is exactly offset by reductions in lost work is shown schematically on the up slope of the capital cost curve as the "area of optimal Design." Depending on the exact economic criteria selected, this area of the curve can be used to select the nptimal dcoign point. It should be noted that this study varied reflux ratio only. The program can be used to generate parametrics for changes in relative volatility, split and feed rate, thus examining the potential response of tesigu parameters and optimal design to the particular range of design parameters present in a specific case. 
v. Process Design and Modification Applications .

\section{Summary}

Perhaps the best application of avallability and second law considerations 18. In the design and modification of components and systems.

The great advantage of a lost work approach is that the lost work at a glven point in the system is the fuel penalty that system incurs for this loss. Let us consider a simple, system in Figure 33 with components $R_{1}, R_{2}, H H_{1}, H X_{2}$ and fuel and feedstock inputs. Using present design and optimization methodology, for each change in system configuration, a new system energy and mass balance would be required (especially if the changes in the system were remote from the point of direct fuel use). This heat and mass balance would define the new energy/capital tradeoff for the system. Given the number of geometric parameters in the system - an imnense number of calculations can result.

Using an availability approach one can first consider each component in Isolation - using techniques similar to that shown in Section IV on component optimization. Each component would therefore have an optimal point; however; a matching of components would then be necessary. In this system matching step the temperatures, pressures and mass flows would be matched subject to system constraints. In this step one would have to move away from the optimal point to match the components. During this step the energy/capital tradeoff would be examined and the decision made to keep certain components closer to their optimal point than others. Within the scope of this study we have not performed such a total design optimization, but have, rather, examined six processes in detail using a computerized avallability evaluation procedure. This examination, is of course, preliminary to any optimization procedure, and does reveal in detall the losses at each step in the process. 
Figure 33.

Optimization of Design

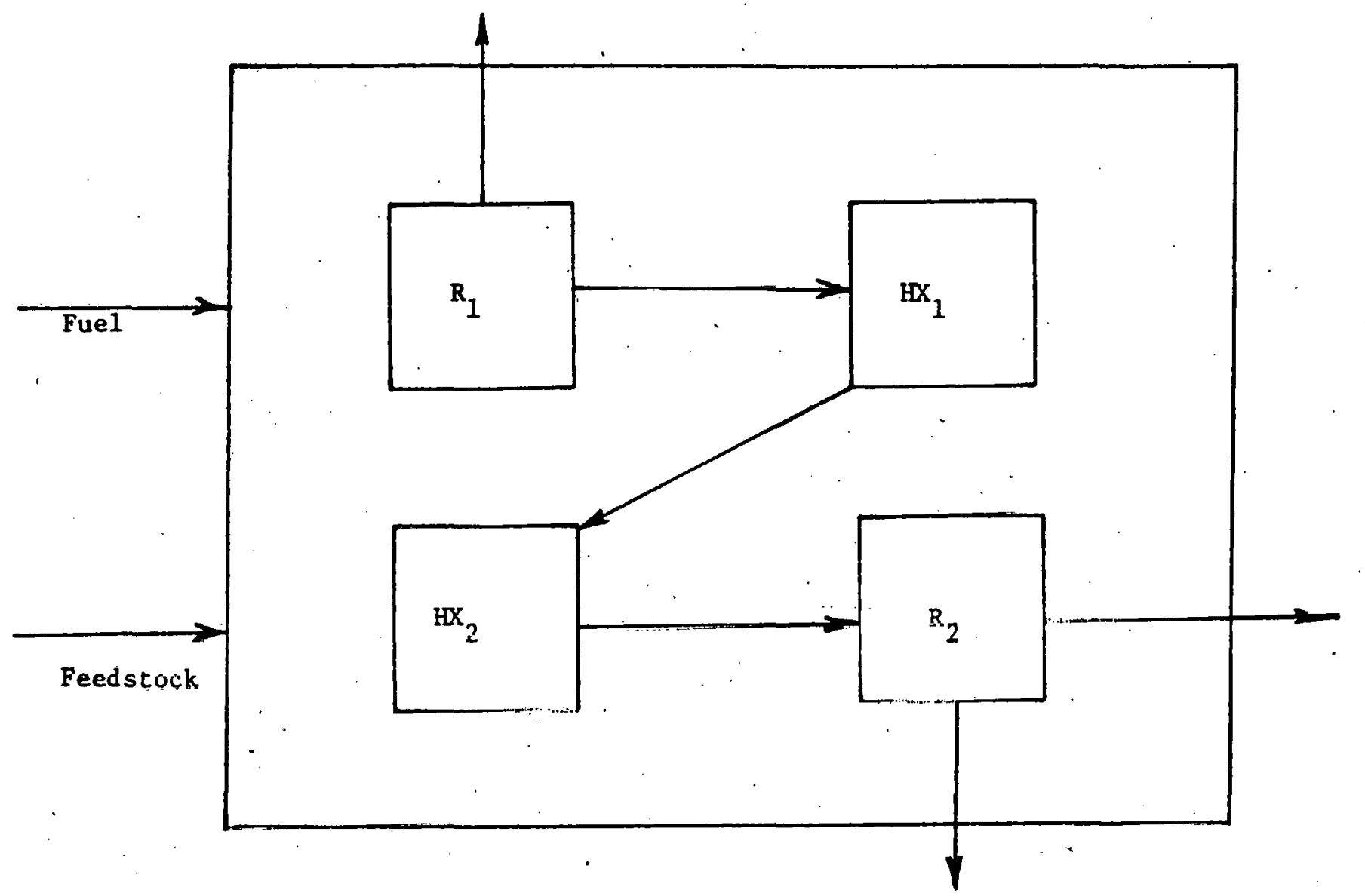

.. 1. Optimire Rimgnusule Individually. . • ,

2. Match Components through selectively sacrificing component nptimality. 


\section{Pulp M111s (Kraft Process)}

\section{Process Description}

The manufacture of paper and paper products is made possible from the conversion of wood stocks into market pulp, and subsequently processing pulp into paper goods. As indicated in previous studies, $(5)$ the most significant consumption of. availability occurs in the pulping process, and therefore, our attention is directed at a- typlcal pulp mill.

Cellulose, the chief ingredient in market pulp, is extracted from wood feed stocks through a series of mechanical, thermal and chemical unit operations. Feed logs are stripped of their bark and chipped prior to chemical treatment. Wood chips are solubilized in a digestor, where they are "cooked" in a white liquor solution of sodium hydroxide (sodium carbonatel sodium sulfide) to facilitate the subsequent decomposition of liquid bound fibers. The "black 1iquor" most associated with pulping process waste streams results from this chemically induced decomposition, and is regenerated via a slaking/causticization cycle involving the hydration of calcium oxide, contact with sodium carbonate to create calcium carbonate and subsequent direct contact thermal regeneration through incineration. The chemically freed cellulose is washed, filtered, bleached, and dried to market pulp consistency.

In order to orlent the reader to availability flows for a typical field Installation, the detailed flowsheet analysis was conducted on a facility whose dally pulp production was 1000 tons/day. $(83,500 \mathrm{lb} / \mathrm{hr}$.$) .$ 


\section{Process Ideal Work Basis}

The process 1deal isothermal work computation is based on the minimum Gibbs energy to accomplish the translation of wood into usable market pulp. This translation involves both chemical reaction and chemi-separation (chemically induced disintegration of the fiber matrix). As discussed in detail elsewhere, (5) the chemical equilibrium model necessary to describe these interacting processes in detail has never been exactly defined, and to do so is beyond the scope of this study. Rather, it is recognized and agreed with other reporters $^{(5)}$ that the major reactions involved, the separation energies, and their thermodynamic descriptions are complex, and present definition is seriously hampered because of the quality and availability of existing thermodynamic data. Therefore, the simpliștic. reaction model presented elsewhere ${ }^{(5)}$ was ut1lized, and the associated upper limit of 220 Btu of availability per pound of product was assumed for our calculation of process efficiency: The ideal actual work of production was determined by selecting that proress efficiency assumed achipvable by a carnot engine aud dlviding the minimum availability requirement by that efficiency.

\section{Process Efficiency:}

The lost work efficienry based on the jient ischllutulul vorle value is $2.4 \%$. The same efficiency based on the ideal actual work is $3.3 \%$. It can be accn that Llis efflclency would be expected because unlike reaction systems, the principal purpose of the chemical agents utilized is to affect separation. Therefore, any determination of thermodynamic process efficiency should result In values similar to those long developed and accepted for separation systems. $(2-5 \%)$.

The total lost work for the process is $735.5 \mathrm{Million} \mathrm{Btu/hr}$. or about 8810 Btu lost work per pound of product. 
IV. Major Lost Work Unit Operations

This type of, analysis permits focusing on major process steps responsible for significant components of the process energy use inefficiencies. For the process examined, the following 1tems were major contributions to lost work:

\section{Unit}

.. Direct Contact Recovery Furnace (GDCRF)

Dryer (GDRYR)

Bleaching (GBLCH)
$\%$ of Total Lost Work

74.3

7.7

6.3

Process design efforts should obviously be concentrated at improvements to the thermal regeneration segment of the white liquor/black liquor process: cycle. Significant overall process improvements could be attained, therefore, as this unit controls the availability effectiveness of the process. Likewise, it suggests that in addition to the environmental impact related reasons to explore alternate chemical cycles, energy costs/pound product present real. opportunities for supporting cycle replacement.

\section{Process Efficiency Parameters}

The parameters generated by the nodal utilization accounting system characterize how effective the process utilizes (cascades, recycles, etc.) supplied avallability. The overall process Gaggioli efficiency of $33.9 \%$ shows a moderate level of process integration with substantial potential available for Improvcment. However, the degree of internal cascade (28\%) suggests limits to further integration, due to the necessary linear sequencing of process operations following chemical treatment. 


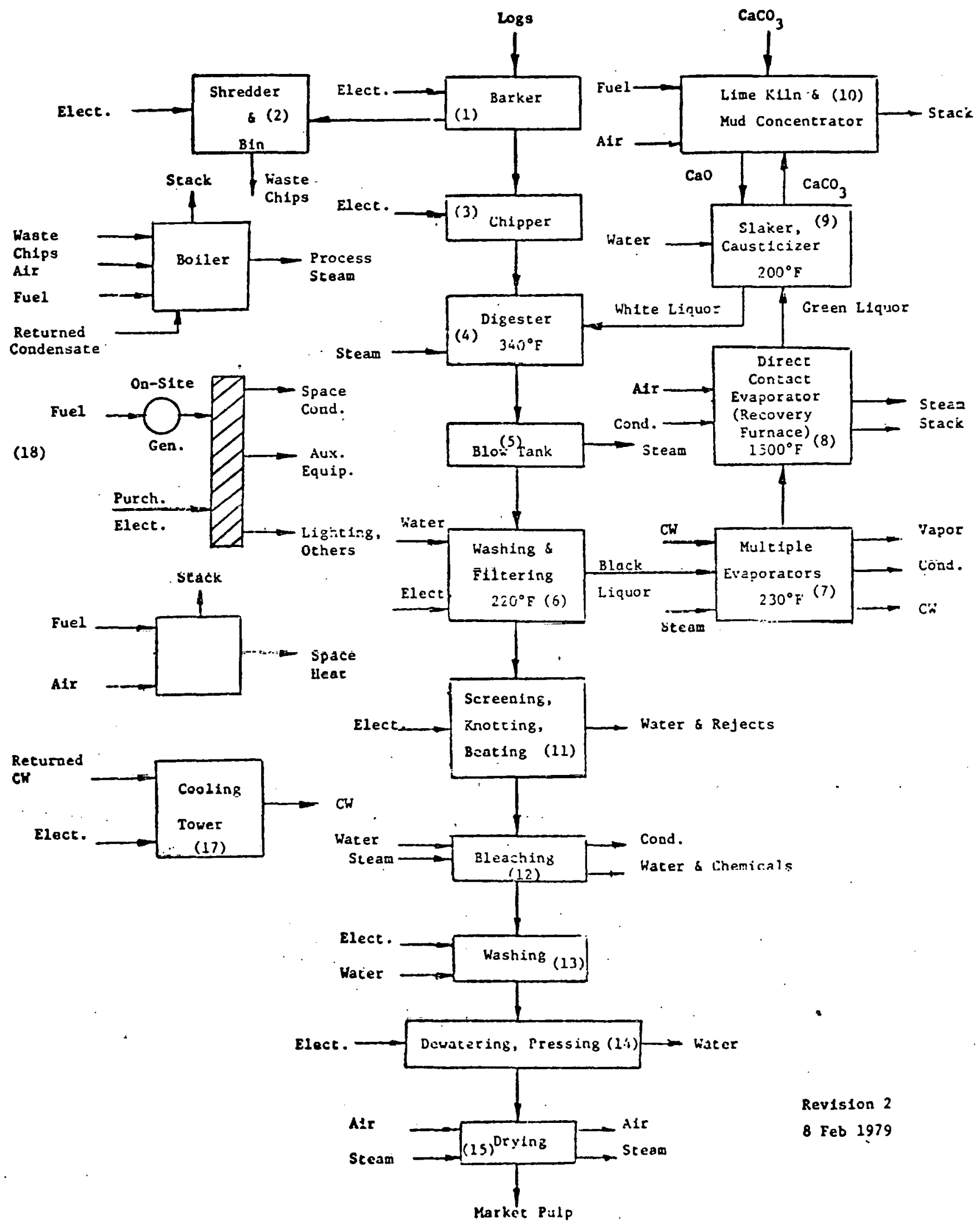




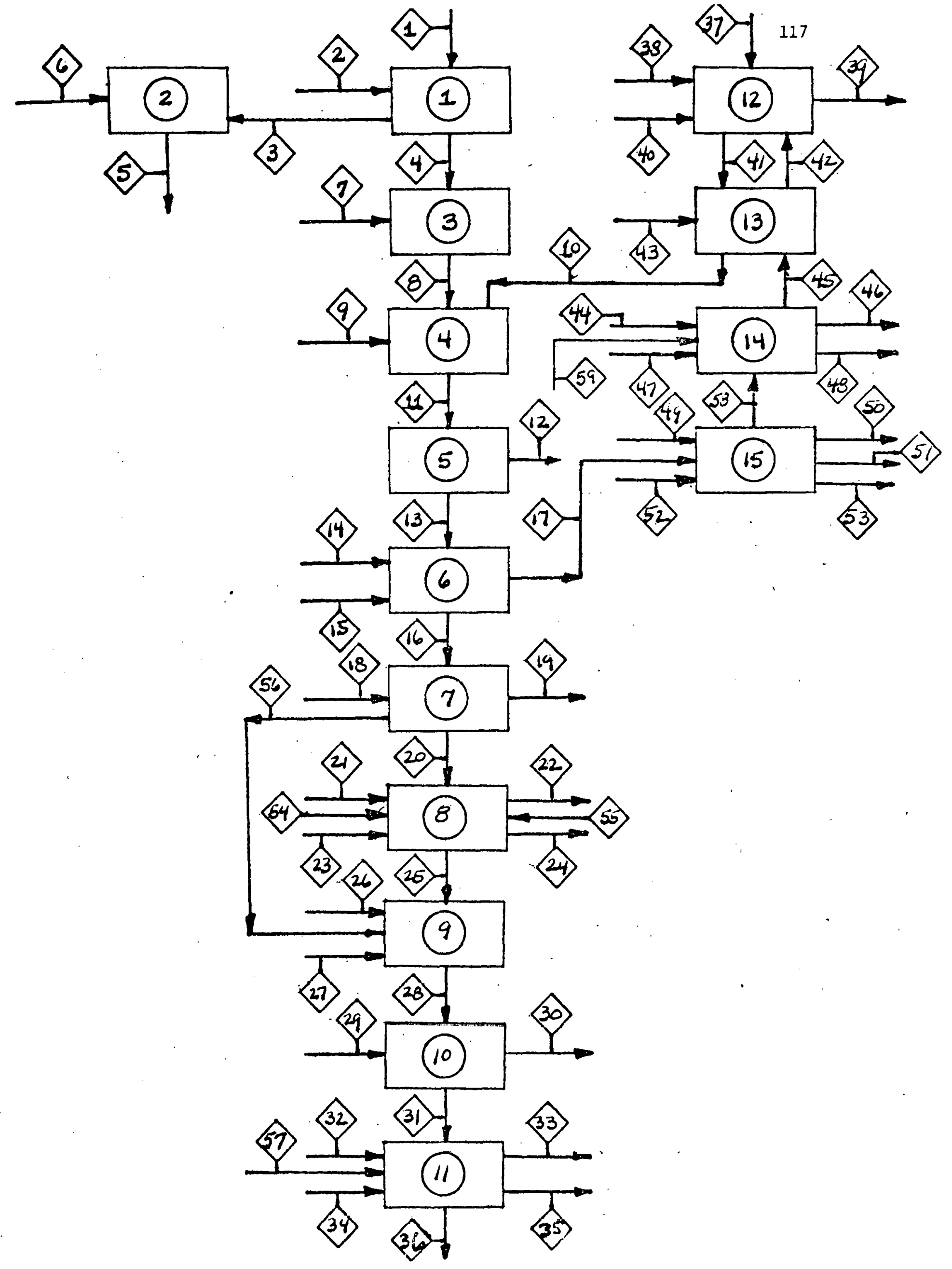




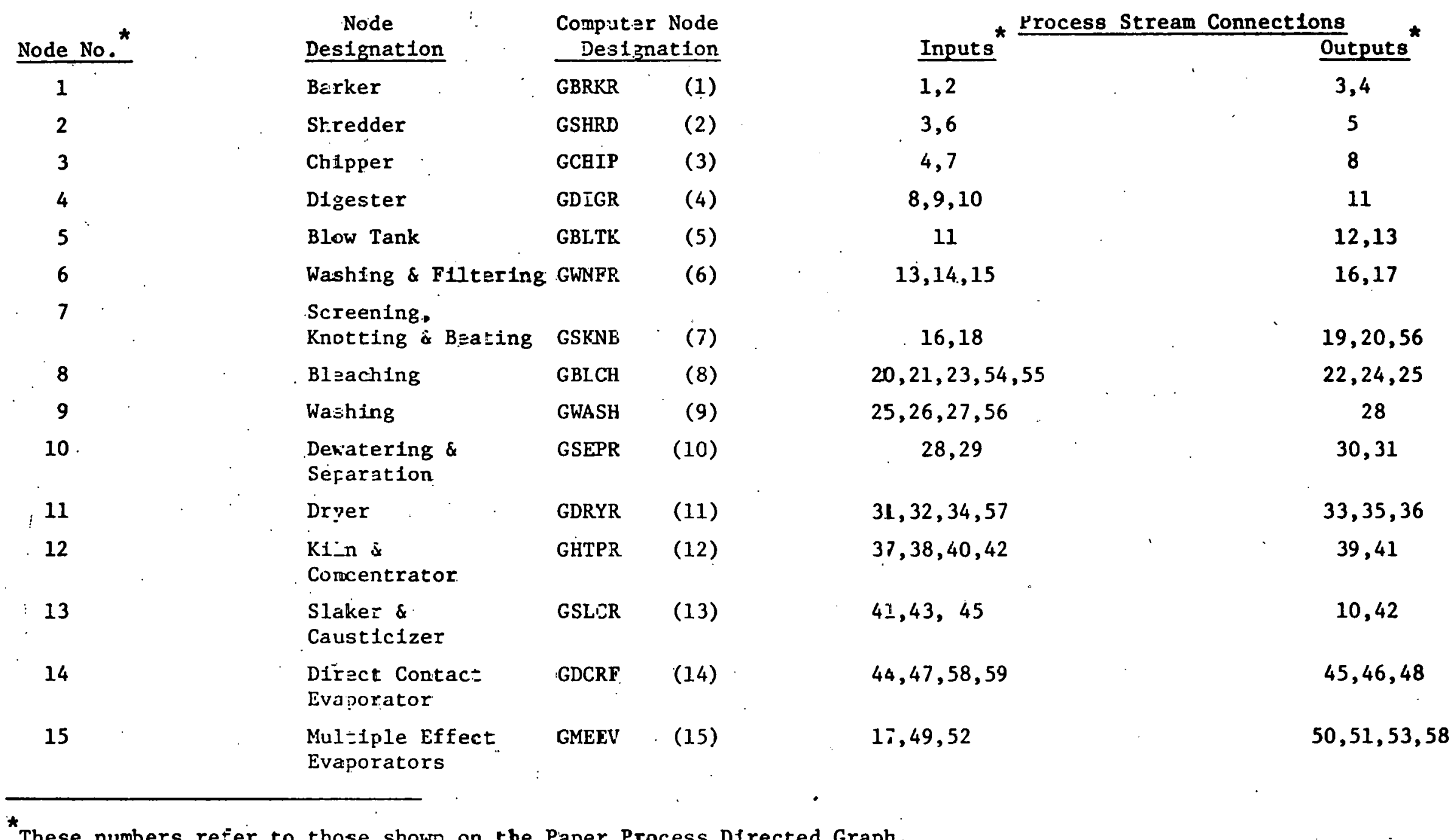




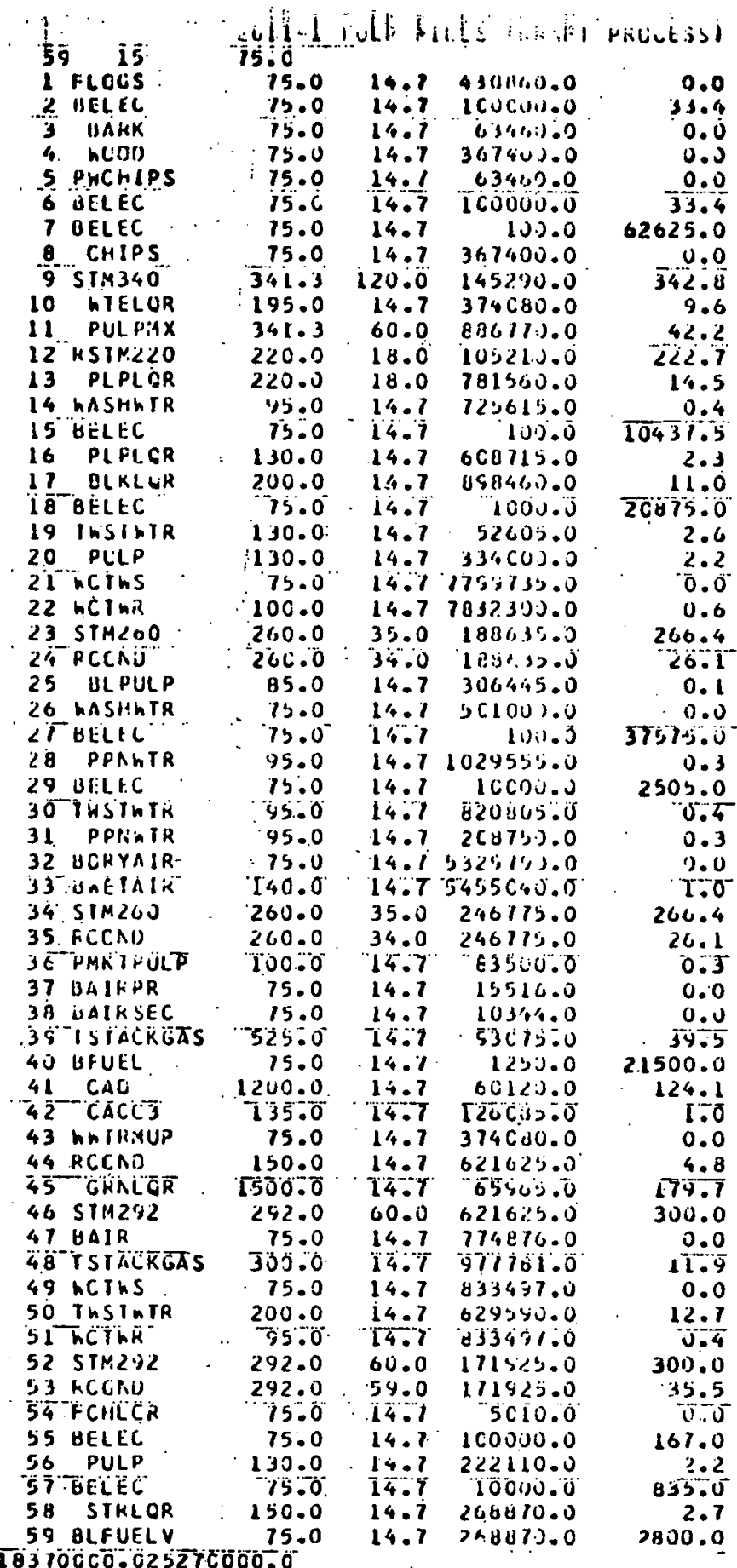




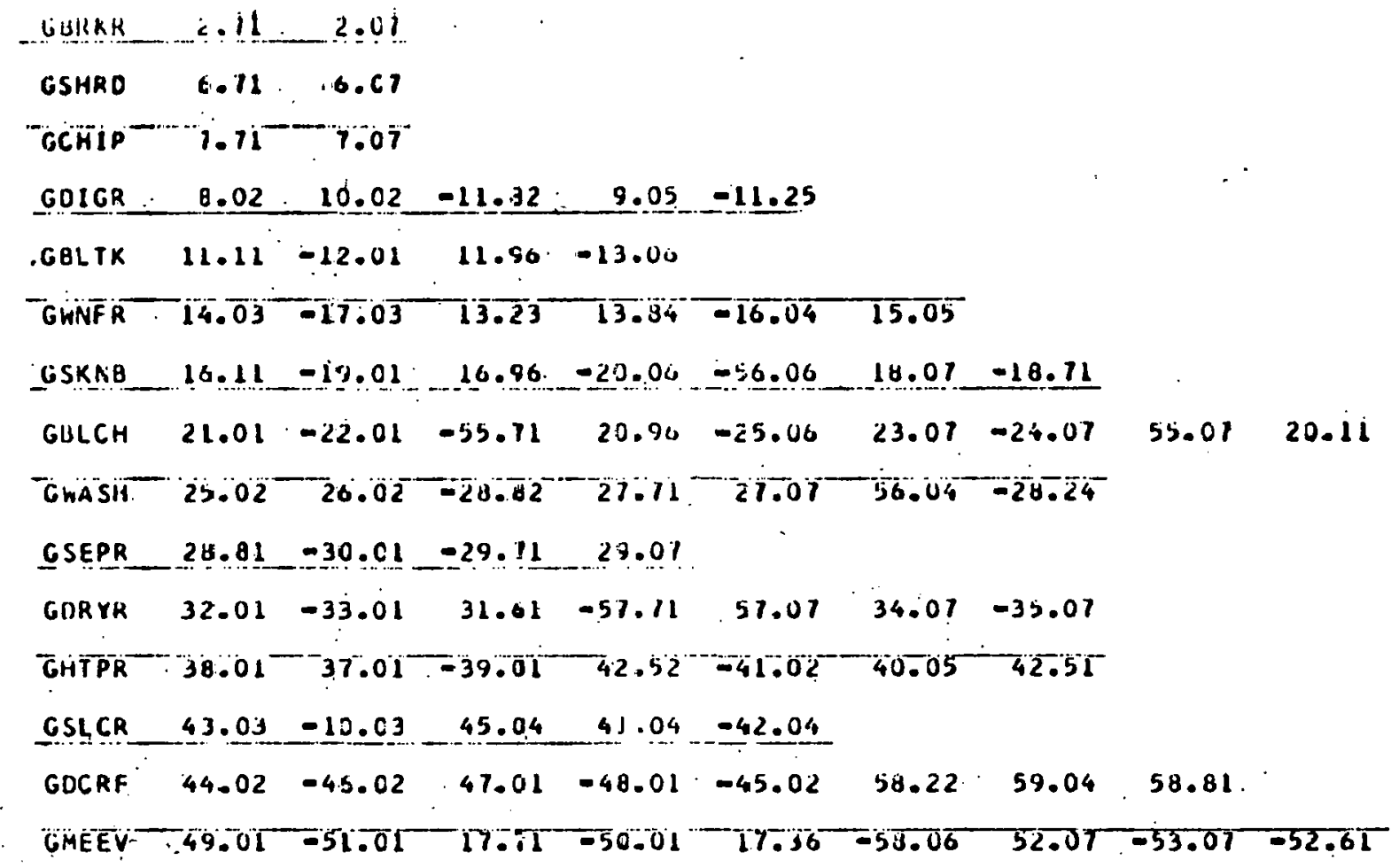




\section{$2611=1$ PULP MILLS (KRAFT PROCESS)}

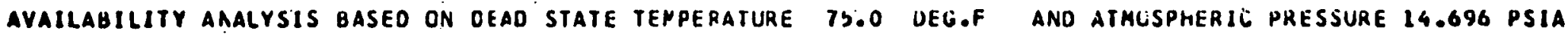

* * stancaro ngual analysis

ILOST hGRK analysis ano gaggicli befFicienciesi

PROCESS PARAMETERS:

Ti) IDEAL ISCTHERAG HCRK OF SEPATATIICN

12) IOEAL_ACTUAL WCHK CF PFOUUCTICA

(3) TOTAL PRLCESS LUSI nCRK

PROCESS EFFFICIENCYY:-

- '11 bASEO CA PROCESS PAHAMETERS (11) ARU (3)

(2) BASEO (A PROCESS PAFAMETERS (2) ANU (3) ICODGE ANO VAR AESSI

\section{$0.1837 \overline{C O O O O}$ CB BITSThR \\ 0.2527 ccocoo ou BTUS/hR \\ 0.735523562009 BIUS/HR}

$0.2436063490 \quad 01 \quad(21$

$0.3321531790 \mathrm{Cl} \quad(x)$

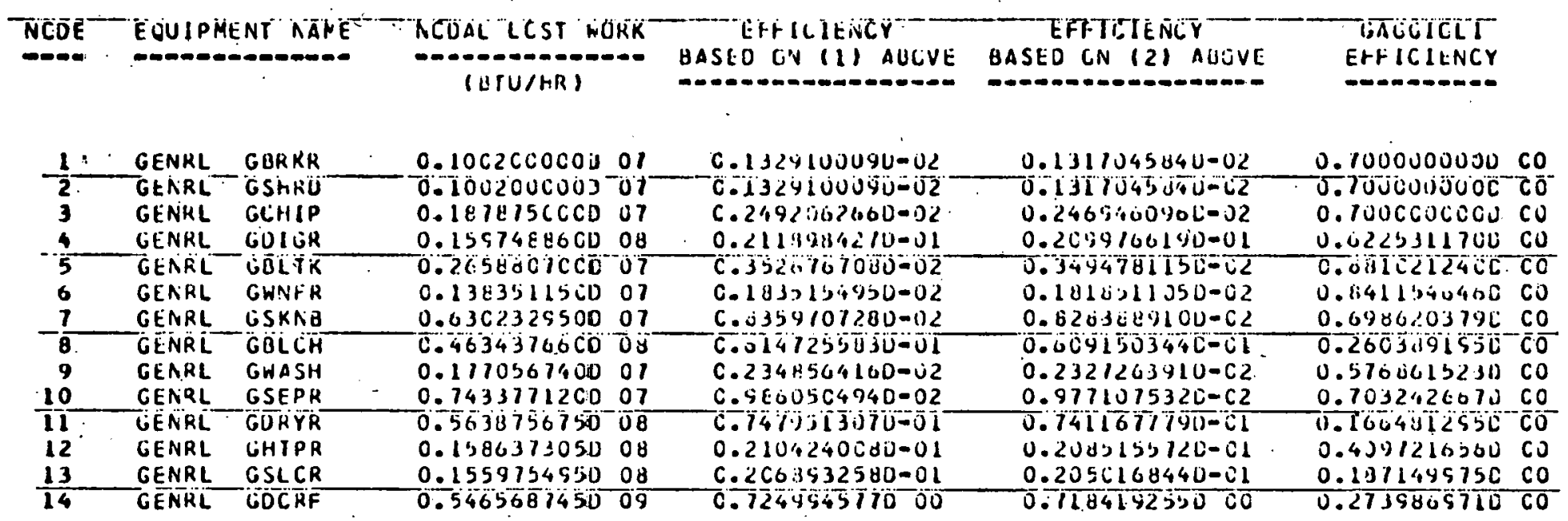


2EL1-1 PULP MILLS (KRAFT PROCESS)

AVAILABILITY ANALYSIS BASED EN CEAD STATE IEMFERATURE 75.0 DEG.F. ANU ATMLSPHERIC PRESSURE I4.GSG PSIA

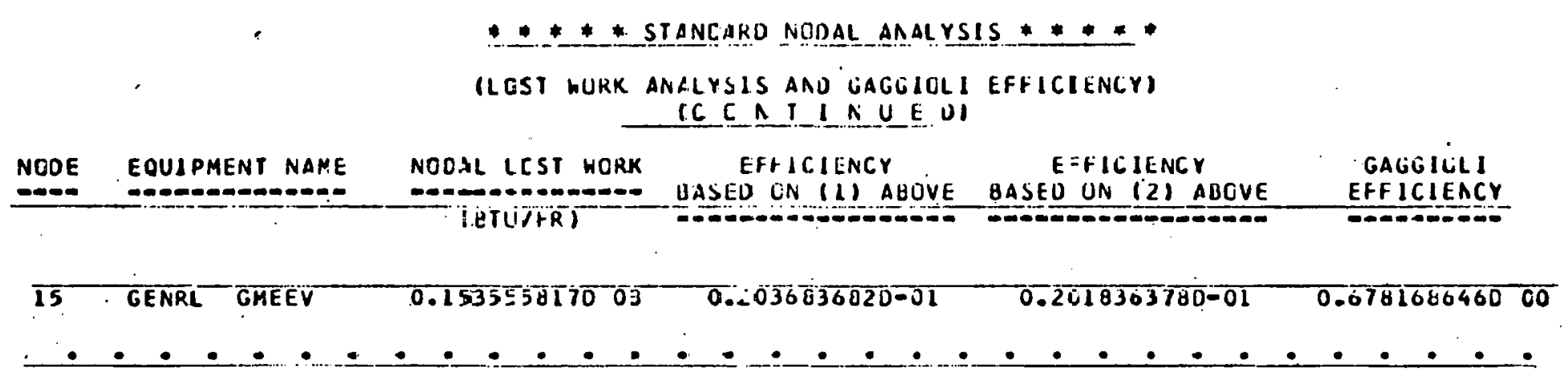




\section{* * * nOOAL UILlLILATICN ACCUUNTINo SYSTEM * * * * *}

IIHE - COMP $(1, \mathrm{~J})$ A ARRAY, WHERE 1 INUEXES COUIPMENI NUMBLR, PROVIDES A OLSLKIPIIUN.

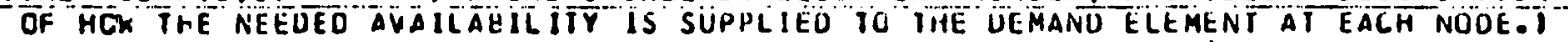

IAN EXPLANATICN CF JHE ACCUUNIJNG SYSIEM IS GIVEN BELUW THROULH IHE OEFINIJILN LF EACH CLLUMN.11).I

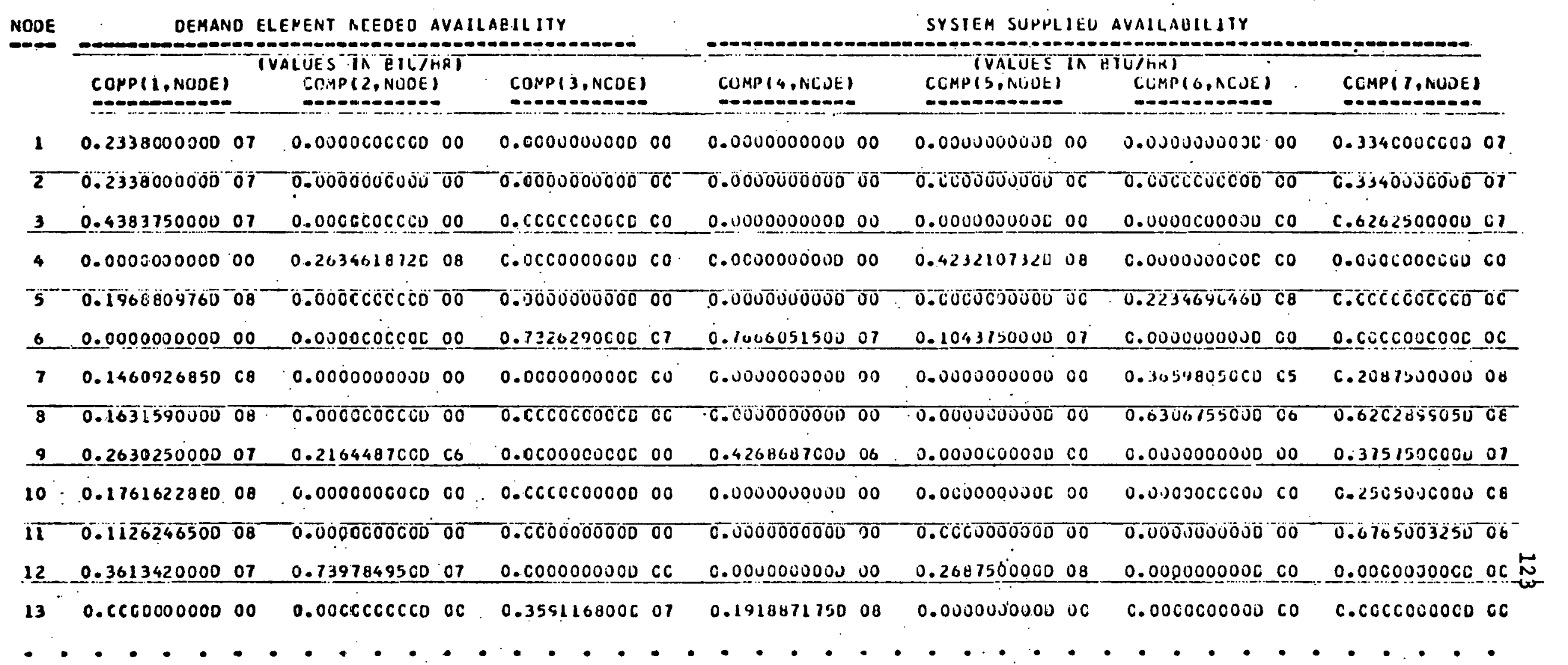




\section{6:1-1 PULP MILLS IKHAFT PROCESS}

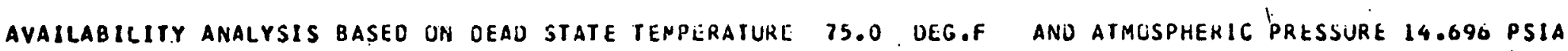

* * * ngoal uillizatron acicunting system ***** *

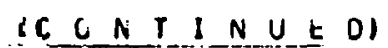

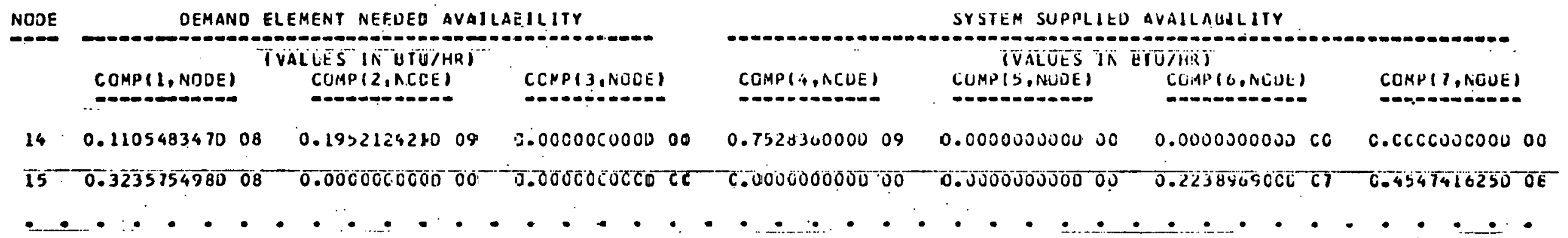


2611-1 PULP MILLS (KKAFI PKOCESS)

AVALLABILITY ANALYSIS BASED ON CEAD STATE TEMPERATURE 75.0 DEG.F AND ATMLSPHEKIC PRESSURE I4.6SG PSIA

* * nudal ujilization accculiting syjieig * * * *

D E FIA I T L C N O F C O L U M N H E A U I N G S

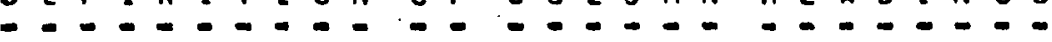

IN THE PROCESS. IT IS ESSENIIAL TO KEEP TRACK UF THE AVAILABILITY WHICH IS exchangeo at each node, accgrcing to the pafticular nude operiatilun. the tikainsfer

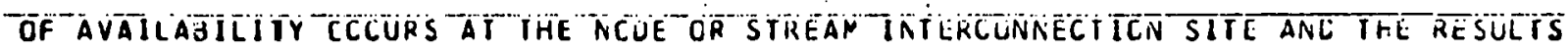

of this transfer ake apparent in the state changes which cccur in the aVallauiliti TRANSPGRT MEUIA,ICIL;AIR, ANI hATERI, REAUILY OISTINGUISHAULE THRUUGH COMPARISONS OF

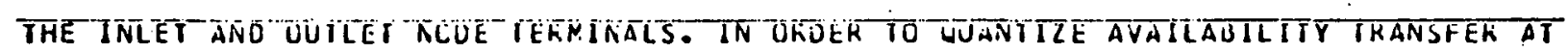
EACH NCDE, IHE RAJCR CLASSIFICATICAS OF ACTIVIIY WERE ESTABLISHEU GY GAGGLLLIi

11 AVAILAGILITY NEECED EY NCCE TC PERFCAM ITS SPECIFIC SYSTEM FUNCJION

(2) AVAILABILITY SLPPLIEO TC NGUE TC PKCVIDE CAPACITY IC ACCCMPLISH ITS. SPECIFIC GPERATICN

IN CROER TO FURTHEY CHARACTERIZE AVAILABILIIY INTERCHANGES AT THE NUOE, THE

PROGRAM SEPARATES nEECEO aVAILABILITY INTO 3 MURE SPECIFIC CATALORIES AND SUPPLIEC AVAILABIIITY INT̄O 4 SUBOIVISICAS. IAFERMAIICN UN THE TOTAL NCOE PERFGRPANLE IS

CONTAINEO IN. THE ARRAY CEMPII,J) WHERE J IS THE NUDE NUMGER; $1=1,7$ WITH POSITICNS

$1.2,3$ BEING NEEOEO AVAILAUILITY CLASSES ANO 4 THRUUGH 7 SUPPLY GROUPS.

AORE SPECIFICALLY, EXACT CCLUNN DEFINITIUNS FOLLUW UN THE NEXT PAGE. 
201L-L PULP MILLS IKRAFI PROCESS!

AVAILABILITY ANALYSIS BASED ON DEAD SIATE TEMPERAFUHE 75.0 DEG.F ANO ATMOSPHERIC PHESSURE I4.690 PSIA

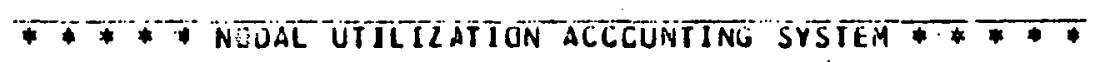

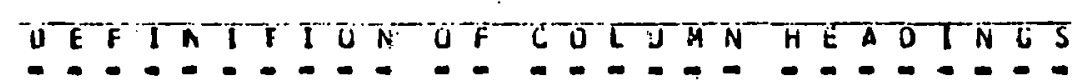

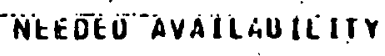

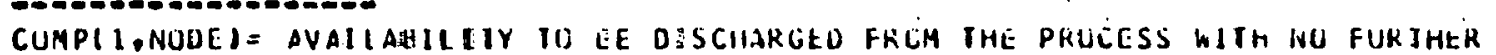

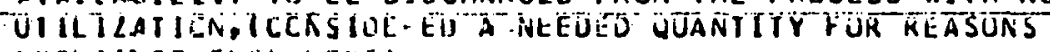
EXPLAINEC ELSTAREHEI.

COUAP CUE IC UCLNUAFY SUPPIY OF AVAILAJILITY

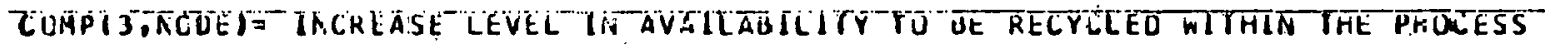
UUE TL RECYCLE SUPPLY CF AVAILAUILITY.

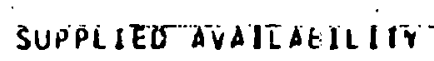

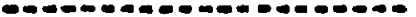

CUMP $14, N C O E)=$ RECYCLED AVAILABILIIY SUPPLIEC IO THE NUDE TO BE CASCAUEU WITHIN THE PRLLESS.

COMPIS.NGOEI= BCUNCAZY LIMIIS AVAILABILITY SIJPPLIEO TO THE NOOE TO BE CASCAOEO WTHEIT YAE PHECESS.

COMP $(G, N C U E)=$ RECYLLED. ANAILABILITY SUPPL IED TO THE NOUE TU HE DISCHARGEIS FRLIA THE PK.CESS WITH INC FURTTER UTLILATTLN.

CUMP(T,NCOE) E BCUNOAZY LIMITS AVAILAUILITY SUPPLIEO TU THE NLDE TO BE OISCIHARGEO

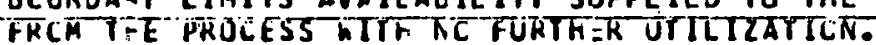


2611-1 PULP. MILLS (KFAFI PKUCESSI.

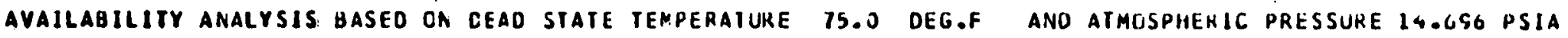

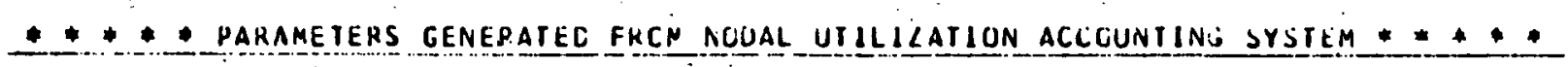

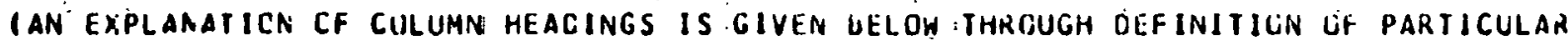

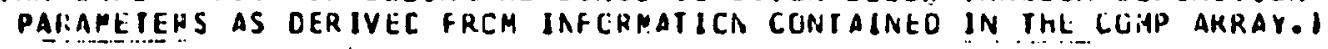

\begin{tabular}{|c|c|c|c|c|c|c|c|c|}
\hline & $\begin{array}{c}\text { NEEDEO } \\
\text { AVALEABILITY } \\
\text { IDIUUHR! } \\
\end{array}$ & $\begin{array}{c}\text { SUFPLIED } \\
\text { AVAILAUILITY } \\
\text { IBIU/HRI }\end{array}$ & $\begin{array}{l}\text { RELATIVE NGDE } \\
\text { EFFICIEACY }\end{array}$ & $\begin{array}{c}\text { AOUMP } \\
\text { EFFICIENCY }\end{array}$ & $\begin{array}{l}\text { KECYCLE } \\
\text { CASCAUÉ } \\
\text { EFFICIEINCY } \\
\end{array}$ & $\begin{array}{l}\text { BCUND.LIM. } \\
\text { CASTAUE } \\
\text { EFFICIENCY } \\
\end{array}$ & $\begin{array}{r}\text { ILTAL } \\
\text { LASCAUE } \\
\text { EFFILIENCY } \\
-0.0 .0 .0\end{array}$ & 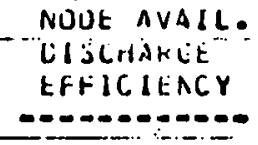 \\
\hline 1 & $0.23380000 \mathrm{CD} 07$ & $0.334<00000007$ & 1.063 & 0.100 & 0.000 & $0.000^{\circ}$ & 0.000 & c. $7 \mathrm{CC}$ \\
\hline$i$ & $\overline{0.233800000007}$ & 0.334600000007 & 1.063 & 0.700 & $0 . \overline{000}$ & 0.000 & $0.6000^{\circ}$ & $0.760^{\circ}$ \\
\hline 3 & 0.438375000007 & 0.626350000007 & $1 . \operatorname{ct} 3$ & $0.70 \mathrm{~s}$. & 0.000 & 0.000 & 0.000 & c.1co \\
\hline 4 & 0.263461872008 & 0.423310732008 . & 0.834 & 0.000 & 0.000 & C.000 & 0.623 & 0.000 \\
\hline 5 & 0.196880976000 & $0.2230 .090460 \mathrm{Cb}$ & 1.596 & 0.881 & 0.000 & 6.000 & 0.000 & $0.0 \mathrm{ei}$ \\
\hline 6 & 0.732629000007 & $0.87058015000 ?$ & 1.478 & 0.000 & 0.000 & 7.019 & 0.041 & c. Ecc \\
\hline 7 & 0.146092685008 & $0.2051 .159810 \mathrm{CB}$ & 1.059 & 0.699 & 0.000 & $c .000$ & 0.000 & c.65s \\
\hline-8 & 0.163159000000 & 0.626556060008 & $=0.233$ & $0.26 \overline{5}$ & 0.030 & 0.000 & 0.000 & $0.20 \bar{c}^{-}$ \\
\hline-9 & $0.2413001300 \mathrm{Cr}$ & 0.418436470007 & $0.70 \mathrm{C}$ & 0.629 & 0.507 & 0.000 & $0.5 \mathrm{Cl} 7$ & C. $.7 \mathrm{CC}$ \\
\hline 10 & 0.176162280008 & 0.250500000008. & 1.072 & .0 .703 & 0.000 & $c .000$ & 0.000 & c. $7 \mathrm{cs}$ \\
\hline$\pi$ & $0.1 \overline{12624650008}$ & 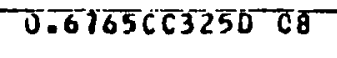 & $=0.5 c 9$ & 0.166 & 0.000 & 0.000 & 0.000 & $0.160^{\circ}$ \\
\hline 12 & 0.110112695008 & 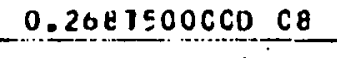 & 0.207 & 0.114 & 0.000 & 0.000 & $0.27 \mathrm{~s}$ & $c .0=0$ \\
\hline 13 & 0.359116800001 & $0.1918871750 \mathrm{CB}$ & -0.449 & 0.000 & 0.000 & 0.000 & 0.187 & 0.000 \\
\hline 16 & $0 . \overline{206} 267255009$ & 0.752336006009 & -0.193 & 0.015 & $0.25 y$ & 0.000 & 4ونة & $\operatorname{cocco}$ \\
\hline
\end{tabular}


2611-1 PLLP MILLS (KAAFT PROCESS)

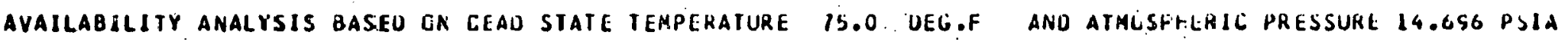

* * * PARA EETERS GENERATEC FRCH NOJAL UTILILATION ACCCUNTING SYSIEM *****

\begin{tabular}{|c|c|c|c|c|c|c|c|c|}
\hline NOOE & $\begin{array}{l}\text { NEEUEO } \\
\text { AVALLAGTLITY }\end{array}$ & $\begin{array}{l}\text { SUPPLIEJ } \\
\text { AVAILAOILEIV }\end{array}$ & $\begin{array}{l}\text { RELATIVE NCOE } \\
\text { EFFICIEACY } \\
\text { EDA }\end{array}$ & $\begin{array}{l}\text { AOUMP } \\
\text { EFFICIENCY }\end{array}$ & $\begin{array}{l}\text { RECYCLE } \\
\text { CASCADE } \\
\text { EFFICIENCY }\end{array}$ & $\begin{array}{l}\text { WUIVOLIM. } \\
\text { CASLAUE } \\
\text { EEFICIENCY }\end{array}$ & $\begin{array}{l}\text { ICIAL } \\
\text { CASCAUE } \\
\text { EFFICITINGY }\end{array}$ & $\begin{array}{l}\text { TiUTR AVAll. } \\
\text { GISCHAKCE } \\
\text { EFILIEACY }\end{array}$ \\
\hline & 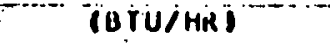 & IBTUKHRI & & & $-0-0-0-0-0-00$ & $-0-0-0-0=-0-\infty$ & 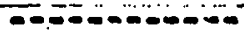 & $=-\infty-\infty-\infty-\infty-\infty-\infty-0$ \\
\hline
\end{tabular}


2611-1 PULP MILLS: (KRAFT PKOCESSI.

AVALLABILITY ANALYSIS BASED OA CEAD STATE TEMPERATURE 75.0 DEG.F aNO ATMLSPHERIC PKESSURE IG.

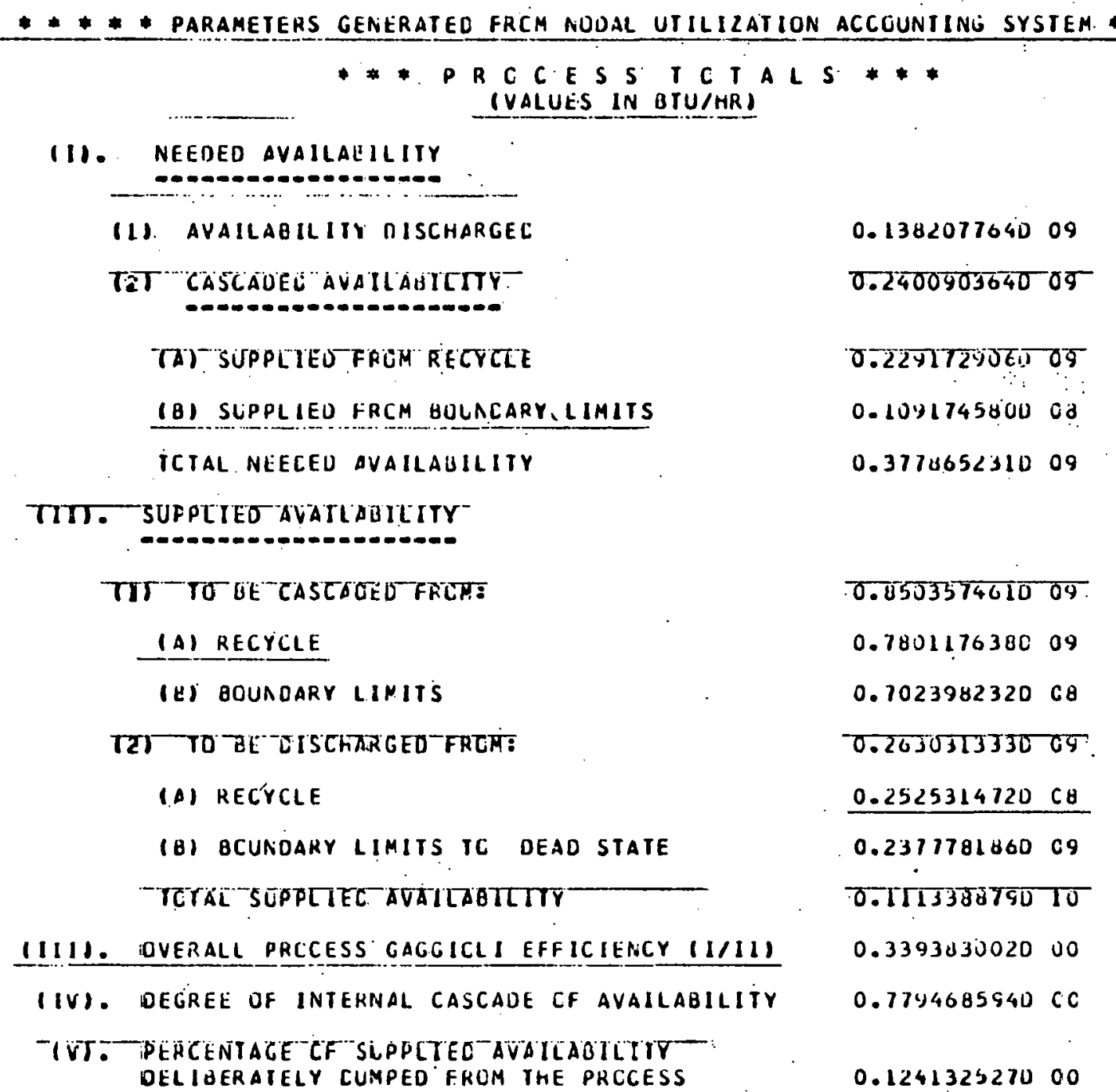


COLUMN HEADING DEFINIIICNS:

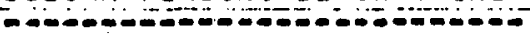

(1) NEEDED AVAILCEILITY - THE AVAILABILIIY REUUIRED TU PRUUUCE THE DESIREU SIAIE

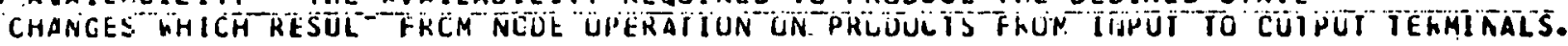

- cualifications *

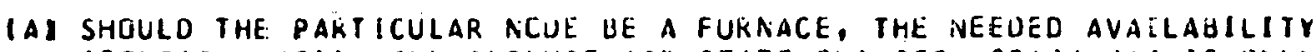
ICCMP(8, NUUE)l aILL IACLUDE aIR STATE ChANUES. STACK LAS IS CNLY

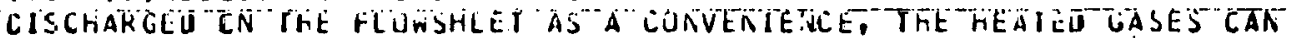
QE UTILILED TO IACKEASE PKLICESS GACCLULI EFFICIENCY AIVI) VECREASE LOST mCRK.

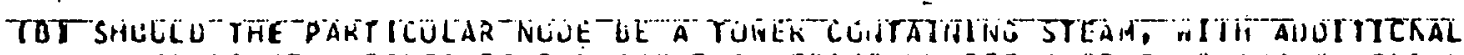

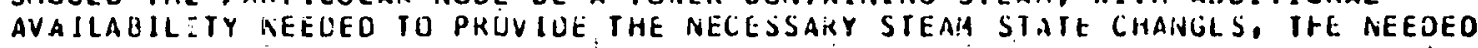

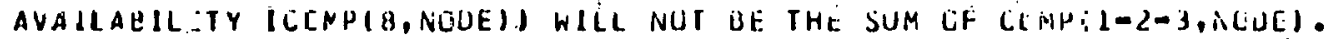

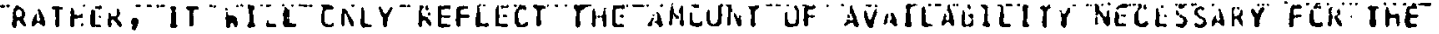
NEEDED CIE STATE CFAINGES, FROM CULUMN FEEDISS IC PACUULIS.

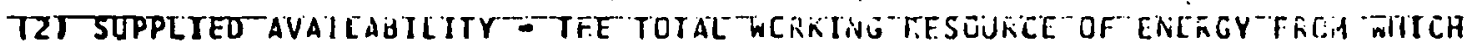

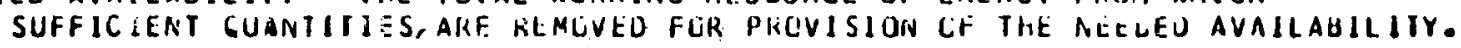

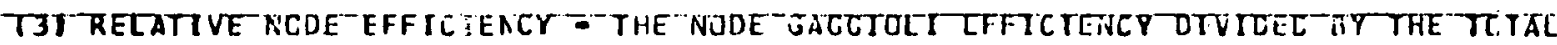
PRECESS CACOIELI EFFICIEACY.

Tद ACOMP EFFICTEKCY - THE DMCUNT CF AVATLAGILITY DISCHAKGEO FRGM THE PRJCESS AT EACH NGGE CiVIDED OY THE TOTAL SUPPLY GF AVAILAUILITY TO IHAT NOUE.

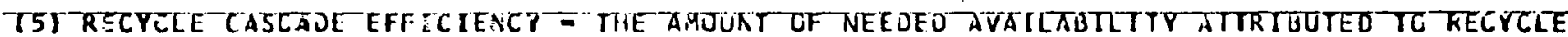
CASCACEC THRCUCh ThE PHCLESS FRCN EACH NCLE CIVIDEO UY THE AMUUNI CF SUFPLIEC AVAILAdLIIY FRUM KECYCLE TU THAT NLUE.

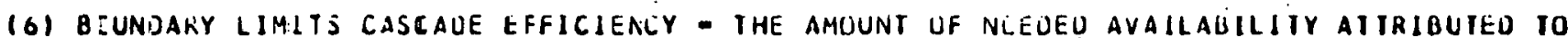
GOLINDAEY LIMIOS CASEADEU THRUUGH THE PKLCESS FRUM EALH NLUE UIVIUED OY TrE

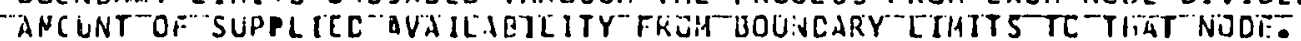

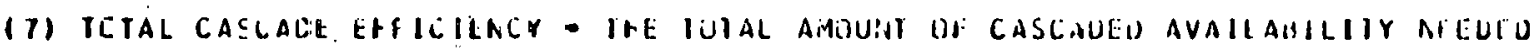

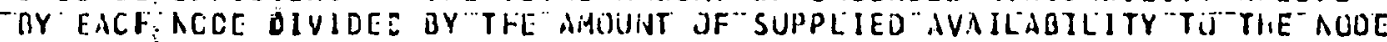
EATMARREC FCR PRUVIZING CASCAUE PUIENTIAL.

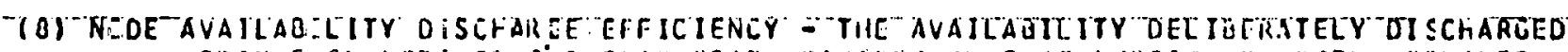
FRCM EACF NCDE TO RIE CLAU SIATE UIVIUED BY THAT PLHIIUN GO WUTH MECYCLED ANC HCURDARY LIRIBS SUPPLIED AVAILABILIIY. 


$$
\begin{aligned}
& \text { 2812-1 Alkalies and Chlorine } \\
& \left(\mathrm{NaOH}, \mathrm{Cl}_{2}-\text { Diaphragm } \mathrm{Cell}\right)
\end{aligned}
$$

\section{Process Description}

Numerous types of processes produces chlorine and/or sodium hydroxide in solution, however the most prevalent process technology involves the production of both, using a diaphragm cell, driven by an electr1c power supply, and supplied with a. specified brine solution (NaCl in water). At the cell, under current and at a specified temperature, the cathode/anode decomposition produces chlorine, hydrogen and sodium hydroxide at the expense of approximately $50 \%$ of the inlet sodium chloride. The process under review includes the separate drying, compression, refrigeration and subsequent liquifaction of chlorine; the drying and release of hydrogen gas; and the concentration of sodium hydroxide with simultaneous recycle of crystallized sodium chloride.

For establishing realistic availability flows for a fleld installation of interest in today's economic environment, the process under review was selected to produce 300 tons $(25000 \mathrm{lbs} / \mathrm{hr})$ of chlorine per day.

\section{Process Idea1 Work Basis}

The process ideal isothermal work is based on the REDOX reaction EMF, for the following reactions at the cathode and anode:

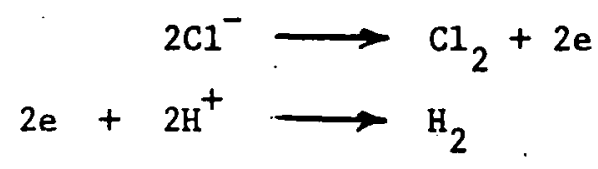

The EMF for the overall reaction

$$
(2 \mathrm{e}+) 2 \mathrm{Cl}^{-}+2 \mathrm{H}^{+} \longrightarrow \mathrm{Cl}_{2}+\mathrm{H}_{2}(+2 \mathrm{e})
$$


can be converted to the change in the Gibbs function assuming isothermal conditions using the well known Nernst equation. To expect that the reaction does not take place at the dead state, but that the endothermic (electrical) requirements must be met at a design temperature of roughly $200^{\circ} \mathrm{F}$, the ideal isothermal work of $1600 \mathrm{Btu}$ of availability/pound of chlorine is less than the ideal actual work value. These quantities reflect the endothermic influence on ideal process requirements, and to process efficiently, it is apparent that supplied availability brought to the process must be totally available, i.e. electrical in nature.

\section{Process Efficiency}

The lost work efficiency of the overall process based on the mimimum, Ideal isothermal work is $29.1 \%$, while the same efficiency based on the ideal actual work of production is $31.7 \%$. As staced earlier, these values could be anticipated as the process efficiency is controlled by electrical supply cell induced current efficiencies. The total lost work of the process is 97.5 million Btu/hr or about 3900 Btu of lost availability/pound of chlorine.

\section{Major Lost Work Unit Operations}

This type of analysis allows for the rapld 1dentification of major process components (equipment) which are "worst offenders" in ranking process equipment according to an overall acceptable process energy efficlency. Fur. the process reviewed, the diaphragm cell represents $76.5 \%$ of the total process lost work, clearly sufficient explanation to understand why many major chemical industry members have developed proprietary cell configurations, ever attempting to improve performance. However, because any solution cell process necessitates the transformation of power line current to. current in solution, the configuration is necessarily limited to those inherent efficiencies 
necessitated by the associated laws of physics and its practical limitations. Cell power consumption (voltage necessary to induce solution current) is therefore key to process efficiencies.

\section{Process Efficiency Parameters}

The parameters generated by the nodal utilization accounting system characterize the effectiveness with which availability is interchanged within and utilized by the process. The overall process Gaggioli Efficiency of $45 \%$ demonstrates a moderate level of effectiveness considering supplied availabllity is primarily totally available (i.e. electricity). The relatively low degree of cascade $(30 \%)$ demonstrates that opportunity for better integration exists, however, due to the limits of cell efficiency, the Implementation of additional integration opportunities may not return sufficient improvements in overall process effectiveness to make them worthwhile capital ventures. 
2812-1 -ALKALIES AND CHLORINE

(NaOH, Clz-Dlaphragm Cell

Process Elow

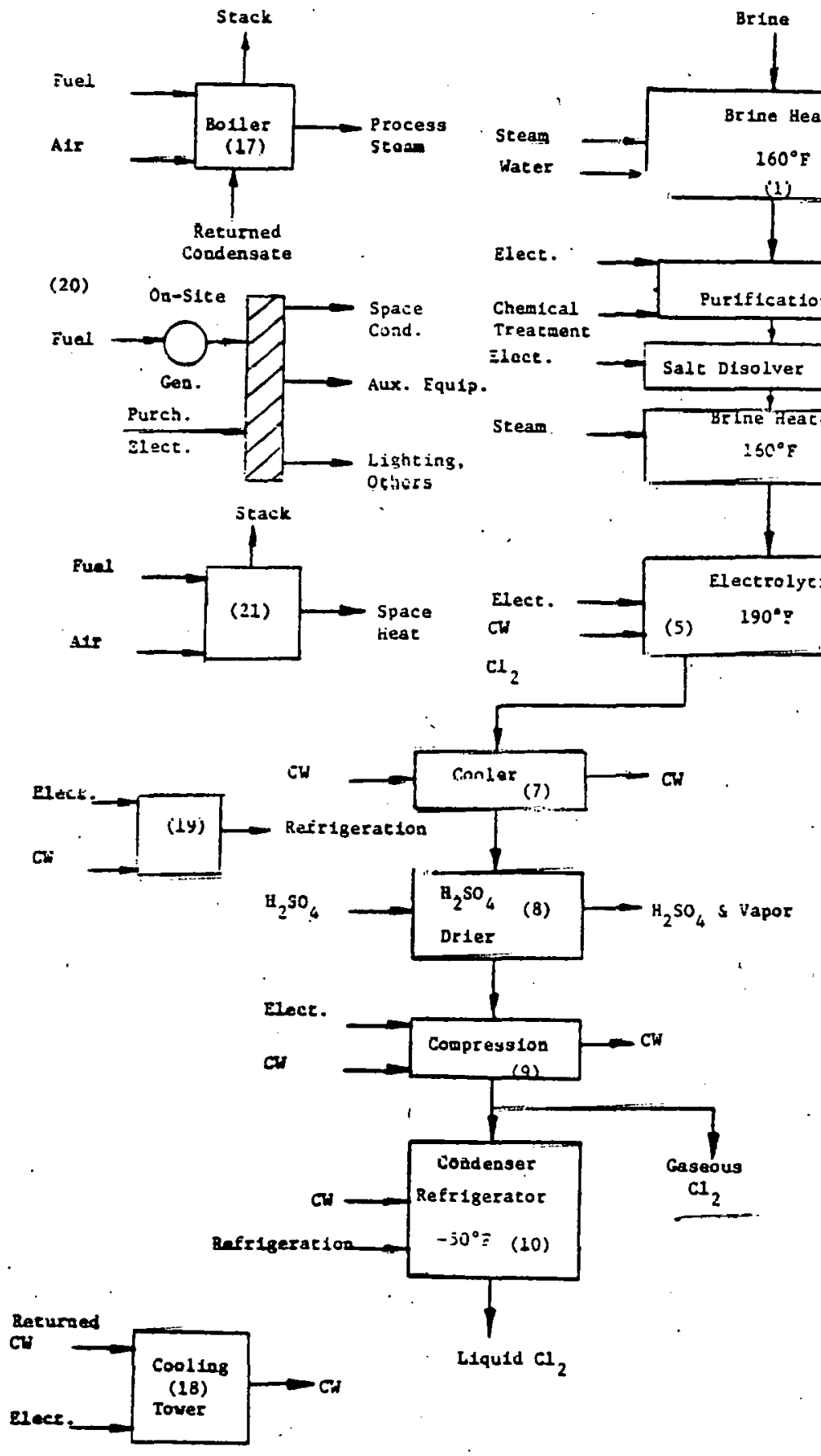

(3) jal= 


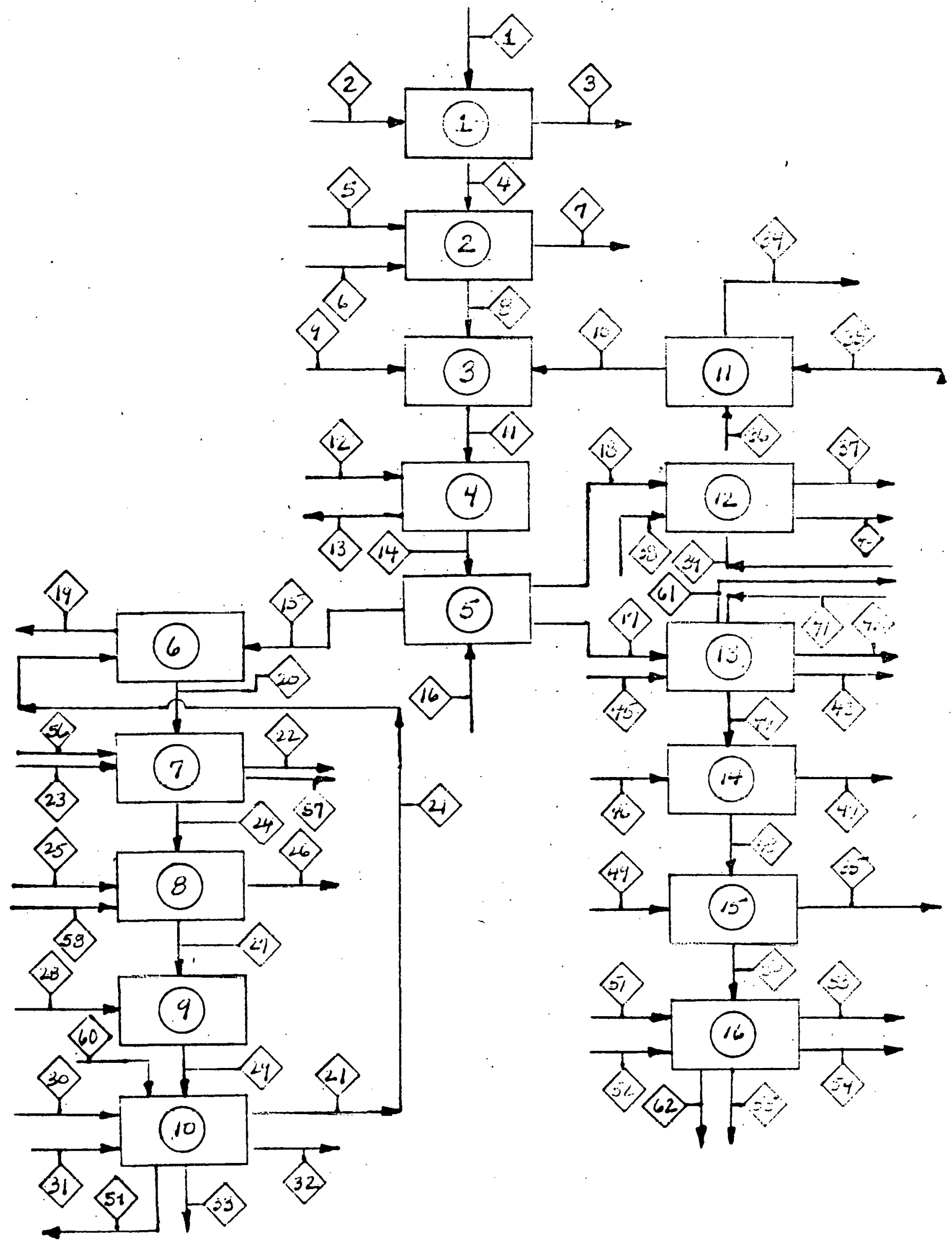




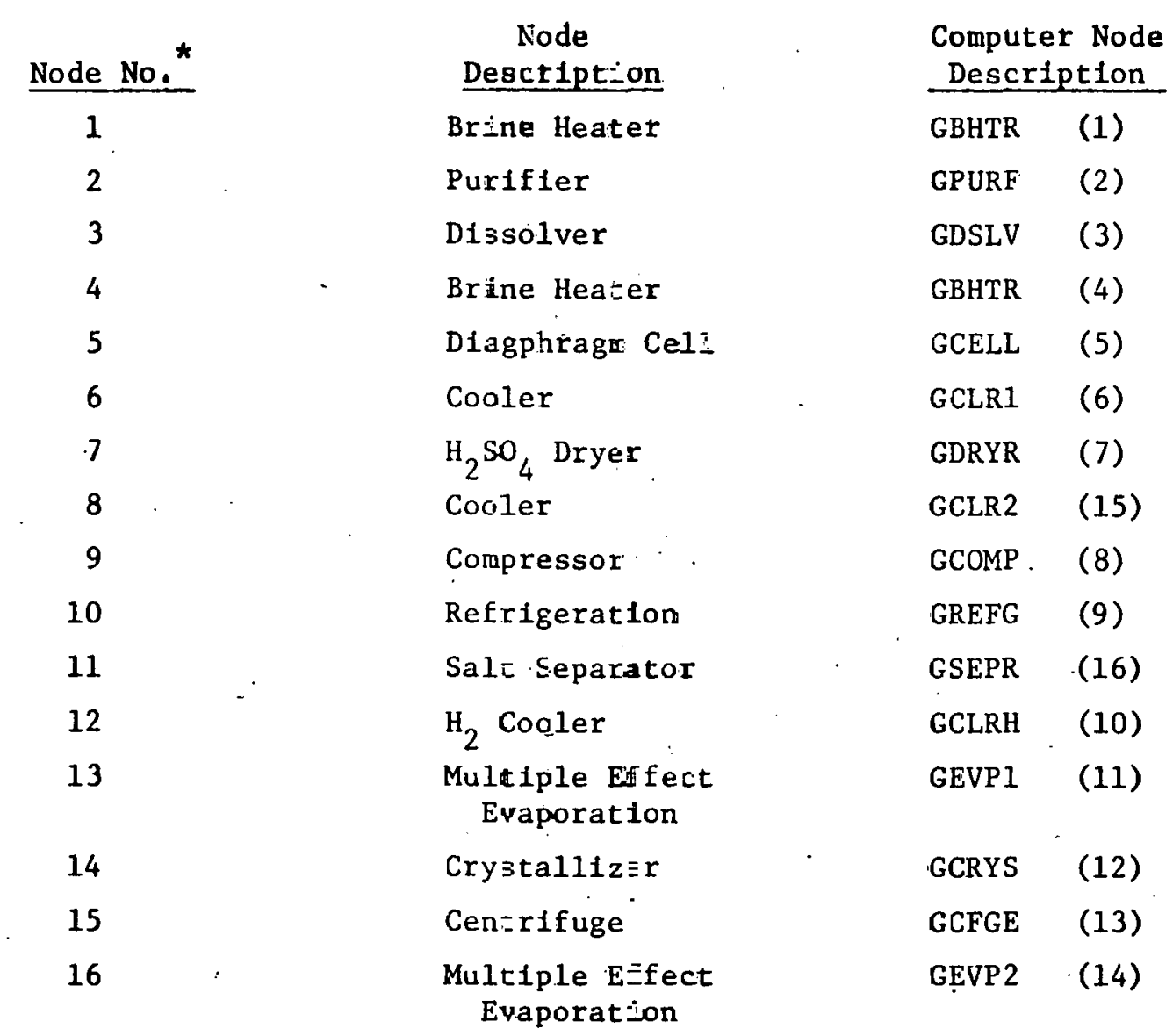

\begin{tabular}{cc}
\multicolumn{2}{c}{ Process Stream Connections } \\
Inputs $^{*}$ & $\frac{\text { Outputs }}{3,4}$ \\
1,2 & 7,8 \\
$4,5,6$ & 11 \\
$8,9,10$ & 13,14 \\
11,12 & $15,17,18$ \\
14,16 & 19,20 \\
15,21 & $22,24,57$ \\
$20,23,55$ & 26,27 \\
$24,25,53$ & 29 \\
27,28 & $21,32,33,59$ \\
$29,30,31,60$ & 10,34 \\
35,36 & 37,40 \\
$18,38,30$ & $42,43,44,61$ \\
$17,41,45$ & 47,48 \\
44,46 & 35,50 \\
48,49 & $53,54,55,62$ \\
$50,51,52$ &
\end{tabular}

* These numbers refer to those shown on the Chlorine Process Directec Graph. 
2612-1 ALKALIES ANC CHLURINE IOLAPHRAOM CELLLI

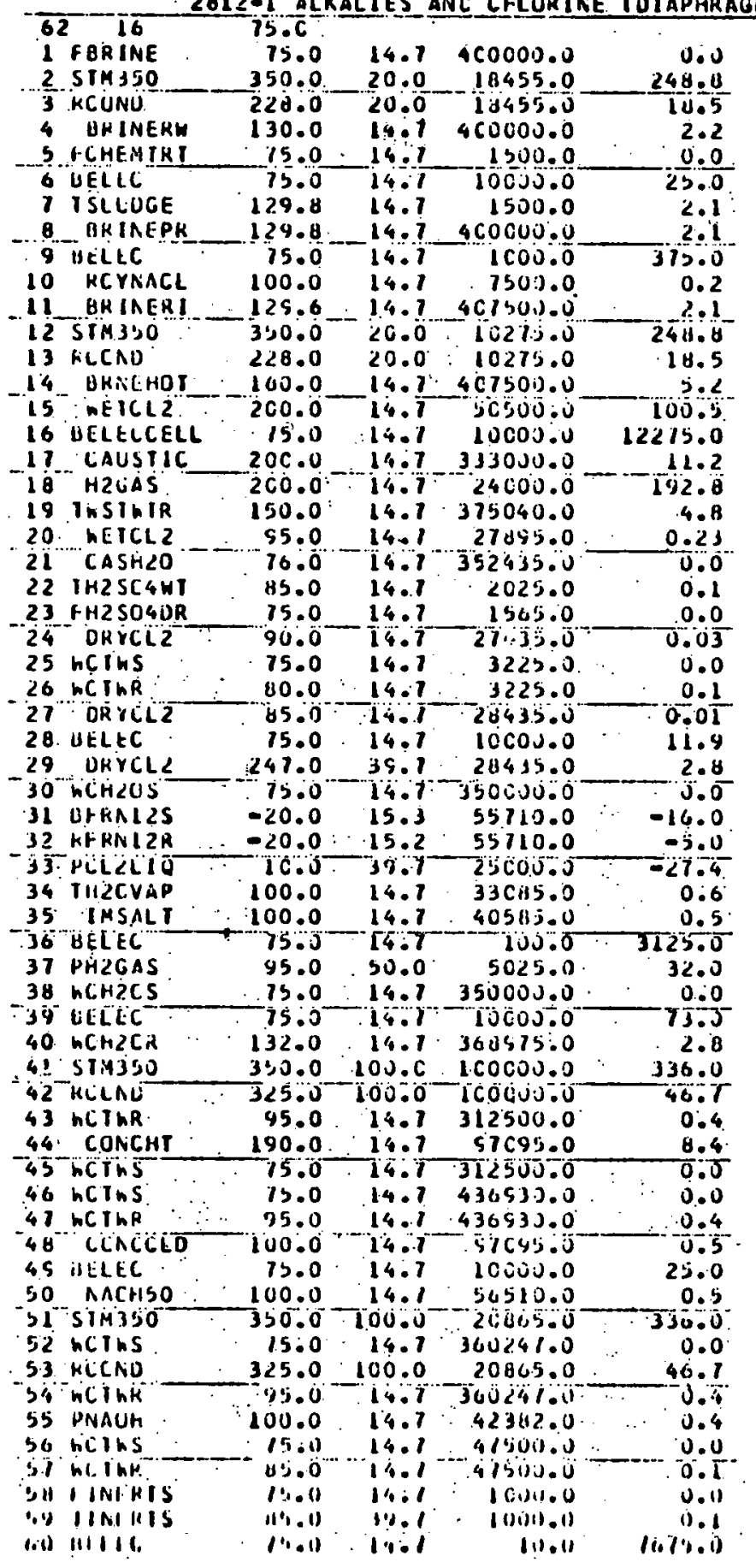




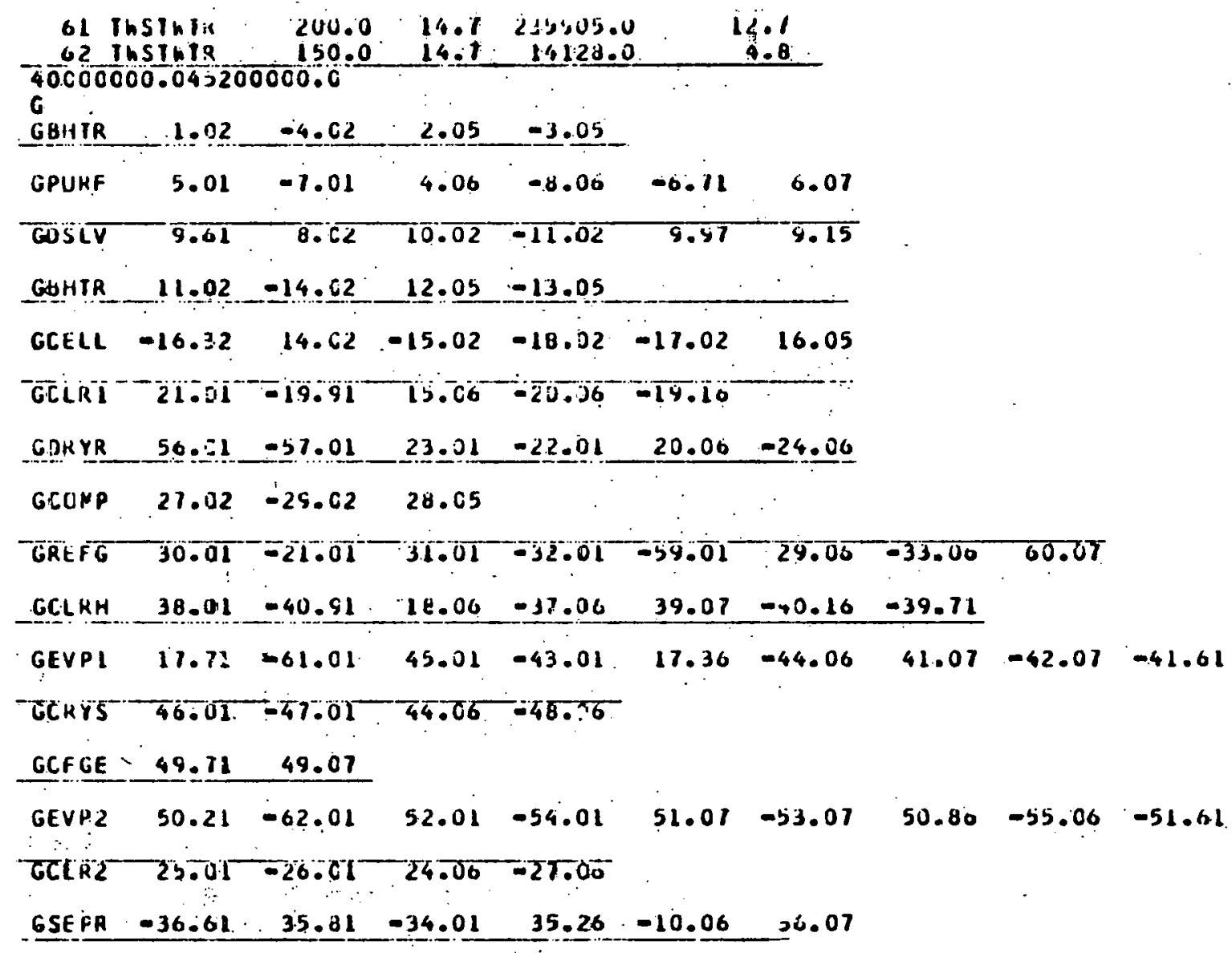


2812-1. alkalies ano CHLChINE IOIAPhraGM CELL!.

AVAILABILITY ANALYSIS BASEO ON.DEAD STATE TEMPERATURE 15.0 OEG.F. ANU ATMUSPHEKIC PRESSURE 14.6 GG PSIA

* * * standard nugal analysis. **** * *

(LOST hCRK ANALYSIS ANO GAUGIOLI EFFICIENCIESI

\section{PROCESS PARAMETERS:}

\section{(I) TUEAL TSCTHERNAL WCKK CF SEPAKATICN}

(2) IDEAL ACTUAL HCRK CF PRCDUETICA

(3) TUTAL PRCCESS LCST hCRK

PROCESS EFFTCIENCY:-

(1) GASED Ca pRocess parameters (1) año (3)

(2) BASED GN PRECESS PARAMETERS (2) AND (3) I DUCLCE ANU VAN NESSI.

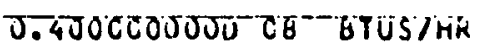

0.4520000000 or Hrisilin

$0.9753409000 \mathrm{CB}$ BILS/HR
\end{abstract}

$0.290835716002 \quad(*)$

0.310671441002 (7)

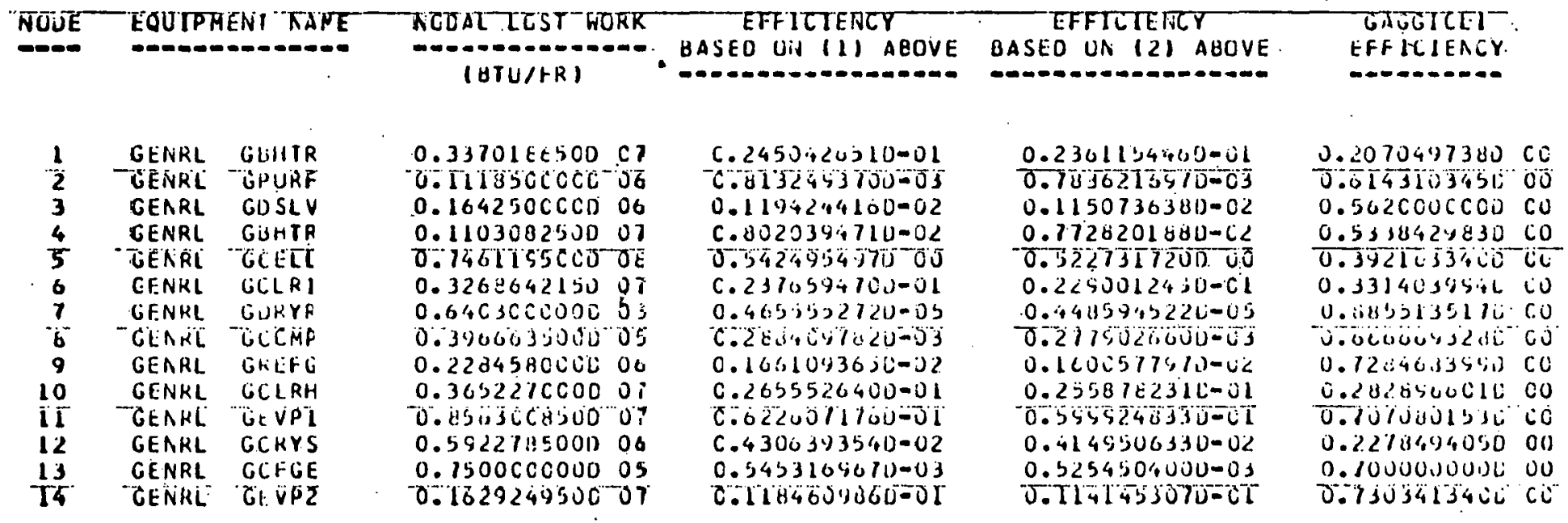


2AL2-1 CLKALIES ANO CHLCRINE IOIAPHRAGM CELLI

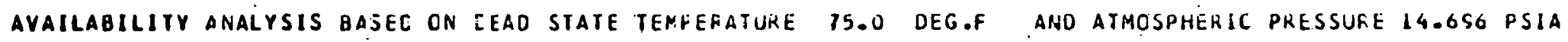

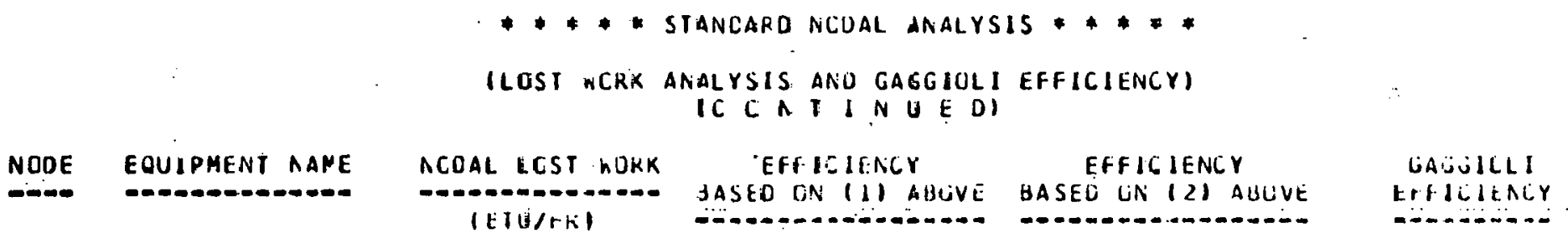


2812-1 ALKALIES ANU CHLGRINE CDIAPHRAGM CELLI

AVAILABILITY ANALYSIS GASEO ON CEAD STATE TERPERATURE 75.0 DEG F ANU AIMOSPHERIC PRESSUKE I4.6S6 PSIA

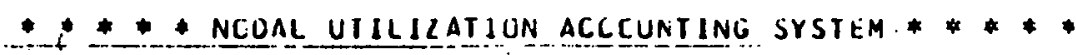

ITISE -CCMPII,JI: ARREY, HFEFE I INUEXES EqUIPMENT NUMUER, PRLVIUES A ULSCRIPIICN

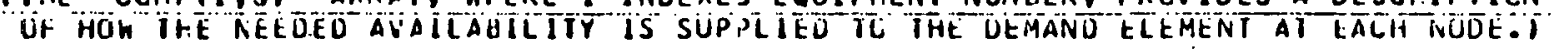

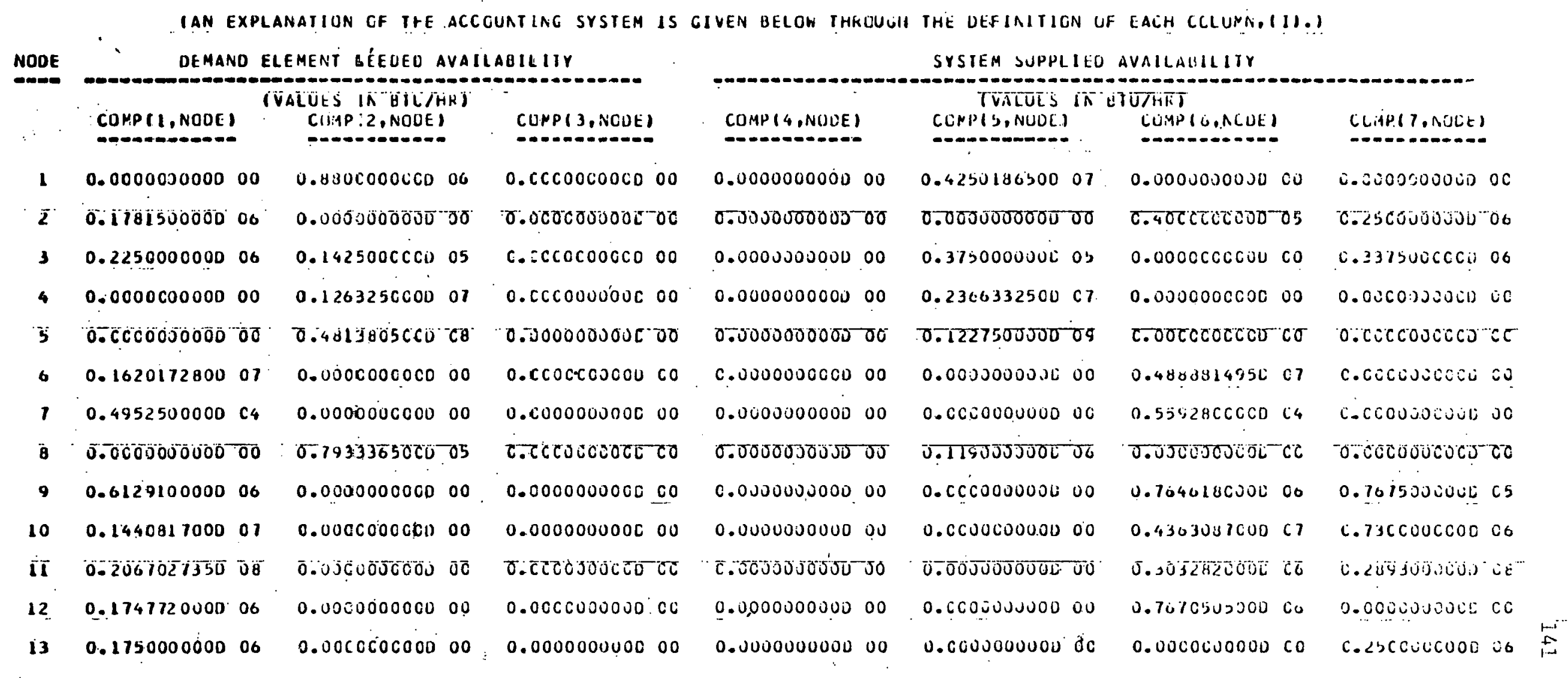




\section{I 2-1 ALRALILS_AND_CHLCKINE IOIAPHKAGIA CELLI}

AVALLABLITY ANALYSIS GASEC ON GEAO STATE TEMPERATLRE 75.0 DEG.F ANO ATMUSPLLRIC PKLSSUKE I4.6GG PSIA

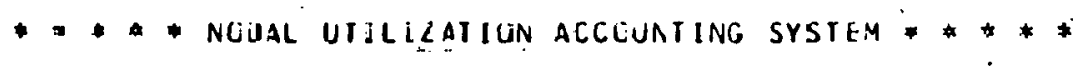

$$
\text { (C. C } A \text { I I } N \cup \text { U D) }
$$

\section{NOUE}

$=-\infty$

DEMANO ELEMENT NEEDED AVALLABILITY

SYSTEM SUPPLIEU AVAILABILITY

COMP(L, NOUE)

IVALLUES IA OETIIHRI

CQTP $(2, H O C E)$

CORP(3, NCOE)

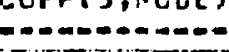

(VALUES Ih UTUThIJ

(UIAP $(6$, N T UE)

CLMP(7. ALUE)

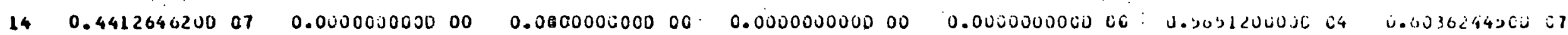

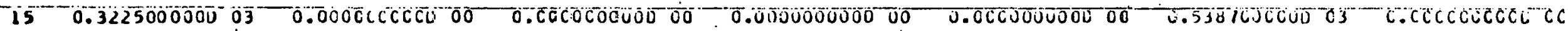

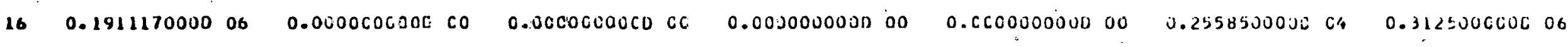




\section{2-1 ALKALIES AND CHLCKINE IOLAPhRAÖH CELLI}

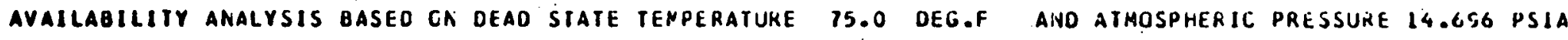

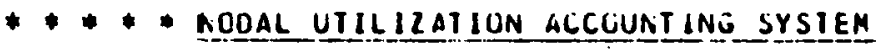

DEFINIIIUN D I I C OLU H N HEAOINGS

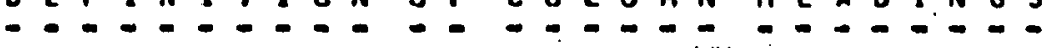

IN THE PROCFSS. IT IS ESSENTIAL T.U KEEP IRALK UF THE AVALLASTILITY hHILH IS

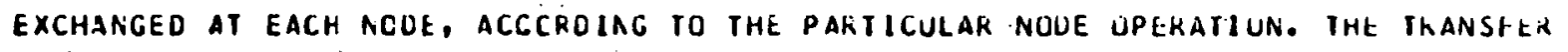

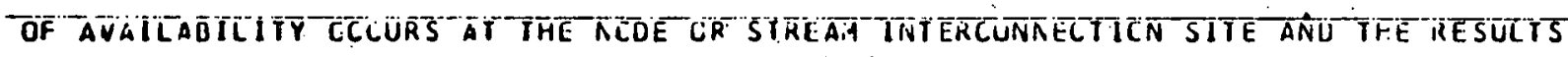
OF THIS IRANSFER ARE APPARENT IN THE.STATE CHANGES NHICH CCCUR IN THE AVAILAUILITY TRANSPORT MEUIA,ILIL, AIR, AND MATERI,READILY OISTINUUISHABLE IHROUGH CUMPAKISUNS LF

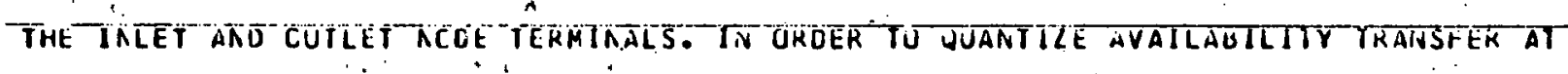
EACH NUDE. IHO MAJLR CLASSIFICAIICAS UF ACTIVITV WERE ESTABLISHEO BY GAGIIULI:

(1) aVAILABILITY nEEDE bY NCCE TC PERFCRH ITS SPECIFIC SYSTEM FUNCTIUN 12) AVAILAQILIIY SISPPLIEL TO ACOE TC PROVIDE CAPACITY TO ACCCMPLISH ITS

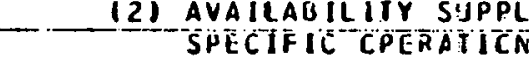

IN CKUER TO FURTHER CHAKACTERILE AVAILAOILITY INIERCHANGES AT THE NUUE, IHE

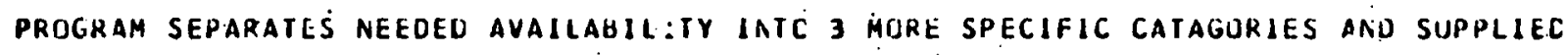
AVAILAGILITY INTO \& SUEDIVISTCNS. INFGRMATION.ON THE TUTAL NLUE PERFCRNANCE IS CUNTAINED IN JHE ARRAY CCMPII,JI hHERE J IS THE NUUE NUMUER; I=1, 7 hITH PUSIIICNS

- 1.2,3 being needed ayatlagility classes añ 4 thruUgir 7 supply grlups. 
2812-1 ALKALIES ANO ChLGRINE IUIAPHRAGM CELLI

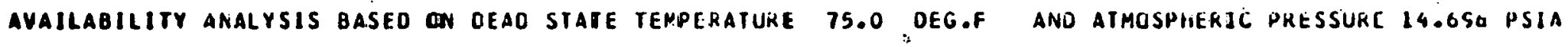

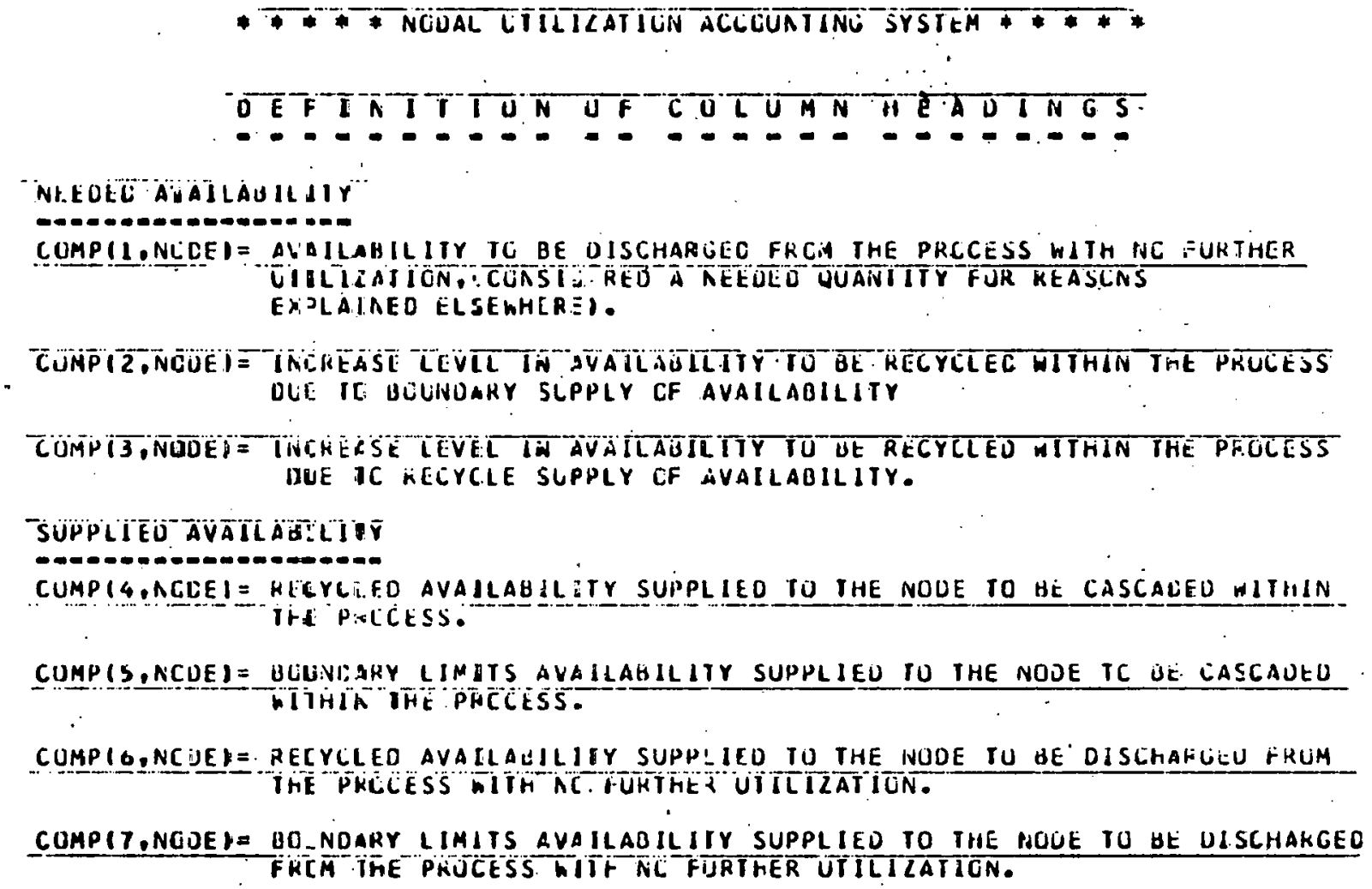




\section{2-1 ALKALIES ANU CHLOKINE (DIAPHRAGM CELL)}

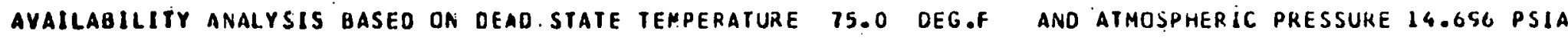

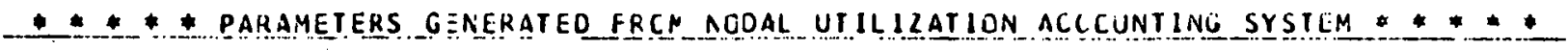

IAN EXPLARATICN CF COLIJMA HEADINGS IS GIVEN BELUiN THKUUGH DEFINITILN OF PAKTICULAH PARAMEIERS AS QERIVEC FRLM INFCRMATICN CONIAINEU IN IHE COMP ARRAY.I

\begin{tabular}{|c|c|c|c|c|c|c|c|c|c|}
\hline NOQDE & $\begin{array}{c}\text { MEEDEO } \\
\text { AVAILAHILIIY } \\
\text { (BTU/HR) }\end{array}$ & $\begin{array}{c}\text { SUEPLIEO } \\
\text { AVAILABILITY } \\
\text { IUIUIHRI }\end{array}$ & $\begin{array}{l}\text { RELATIVE NCDE } \\
\text { EFFICIENCY }\end{array}$ & $\begin{array}{c}\text { AUUMP } \\
\text { EFFICIENEY }\end{array}$ & $\begin{array}{l}\text { RECYCLE } \\
\text { CASCAUE } \\
\text { EFFICIENCY } \\
\end{array}$ & $\begin{array}{l}\text { BLUNO.LIM. } \\
\text { CASLALE } \\
\text { EFHICIENCY } \\
\end{array}$ & $\begin{array}{l}\text { TUIAL } \\
\text { CASCIUE } \\
\text { EFFICIIACY }\end{array}$ & $\begin{array}{l}\text { ACUL AVALL } \\
\text { OLSCHINEE } \\
\text { LHFICILACY } \\
\end{array}$ & \\
\hline 1 & 0.880000000006 & 0.425018650007 & -0.541 & 0.000 & 0.000 & 0.000 & 0.207 & c.coe & \\
\hline 2 & 0.178150000006 & $0.28 \bar{C} C \overline{C O} 000006$ & 0.363 & 0.614 & 0.000 & $0: 000$ & $3.0 \% \bar{J}$ & $\because .61 \overline{4}$ & \\
\hline 3 & 0.210750000006 & $0.375 \mathrm{cccoc0u} c 6$ & $0.247^{\circ}$ & 0.000 & 0.000 & 0.000 & 0.380 & C.teo! & \\
\hline 4 & $0.1263250000 \quad 07$ & $0.2366332500 \mathrm{C7}$ & 0.184 & 0.000 & 0.000 & $0.000^{\circ}$ & 0.334 & 0.000 & \\
\hline 5 & $0 . 4 8 \longdiv { 3 8 0 5 0 \mathrm { CD } 0 8 }$ & $0.1227500 \mathrm{CCDC}$ & -0.130 & 0.000 & 0.000 & 0.000 & 0.392 & $\mathrm{c.00 \textrm {C }}$ & \\
\hline 6 & 0.162017280007 & $0.0888814950 \mathrm{Cl}$ & -0.265 & 0.331 & 0.000 & 0.000 & 0.000 & C.331 & \\
\hline 7 & 0.495250000004 & $0.5592800000 \cdot 04$ & 0.964 & 0.836 & 0.000 & 0.000 & $0 . c 00$ & $C . \dot{a} \Delta t$ & \\
\hline$\cdot 8$ & 0.793336500005 & 0.119000000006 & 0.479 & 0.000 & 0.000 & 0.000 & 0.667 & 0.000 & \\
\hline 9 & $0.6129100000 \mathrm{C6}$ & 0.841360000006 & 0.616 & 0.728 & 0.001 & 0.000 & i.cog & $0.72 \varepsilon$ & \\
\hline 10 & 0.144081700007 & 0.509300100007 & -0.372 & 0.283 & 0.000 & 0.000 & $0 . c .00$ & 0.281 & \\
\hline II & 0.206702735008 & 0.242332820008 & $0.50 y$ & 0.107 & 0.000 & 0.000 & $\overline{c . C} \overline{\mathrm{VO}}$ & 0.107 & \\
\hline 12 & 0.174712000006 & 0.767050500006 & -0.455 & 0.220 & 0.030 & 0.000 & $0 . \mathrm{COO}$ & $C .228$ & \\
\hline i3 & 0.115000000006 & 0.250000000006 & 0.553 & 0.700 & 0.000 & 0.000 & 0.000 & 0.700 & u \\
\hline 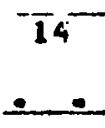 & $\begin{array}{l}0.441 \overline{264020007} \\
0.0 .\end{array}$ & $\begin{array}{l}0.604109570007 \\
.\end{array}$ & 0.620 & 0.710 & 0.000 & $0 . \overline{000}$ & $\begin{array}{r}0.000 \\
. \\
\end{array}$ & $\begin{array}{r}c .13 i \\
.\end{array}$ & \\
\hline
\end{tabular}


2812-1 ALKALIES ANJ E-LCRINE COIAPHRAGM CELL)

AYAILABILITY aMALYIS GASED DN DEAU SIATE IEHPERATURE 15.0 DEG of ANO ATMOSPHEZIC PKESSURE I4.696 PSIA

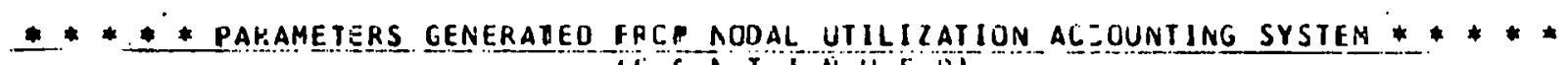

IC CA T NUE UT

\begin{tabular}{|c|c|c|c|c|c|c|c|c|}
\hline NODE & $\begin{array}{c}\text { NIFUED } \\
\text { AVAILABILITY }\end{array}$ & $\begin{array}{c}\text { SUFPLIED } \\
\text { AVAILAUILIIY } \\
\end{array}$ & $\begin{array}{l}\text { RELATIVE NCGE } \\
\text { EFFICIEACY }\end{array}$ & $\begin{array}{c}\text { TOUMP } \\
\text { EF }=\text { ICIENCY }\end{array}$ & $\begin{array}{l}\text { KEOYCLE } \\
\text { CASLAUE } \\
\text { EFFDIENCY }\end{array}$ & $\begin{array}{l}\text { BGUNJOLIIT. } \\
\text { CAS ACE } \\
\text { EFFLIEIVCY }\end{array}$ & $\begin{array}{l}\text { TUIOAL } \\
\text { CASCAUE } \\
\text { EFFICIENLY }\end{array}$ & $\begin{array}{l}\text { NUUE TAVAIL. } \\
\text { LISCHARCE } \\
\text { EFFICIEACY }\end{array}$ \\
\hline & IBTU/HRI & (BTUARR) & & & $0-0-0-0-0-0$ & $-\infty-=-\infty=-\infty$ & 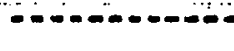 & $\because-\infty+\infty-\infty$ \\
\hline 15 & $0,32250000010.03$ & $0.5307 c 0000003$ & 0.328 & 0.599 & 0.000 & 0.000 & 0.000 & 0.359 \\
\hline 16 & 0.191117000006 & 0.315058500006 & 0.346 & 0.607 & c.000 & 0.000 & 0.000 & 0.601 \\
\hline
\end{tabular}




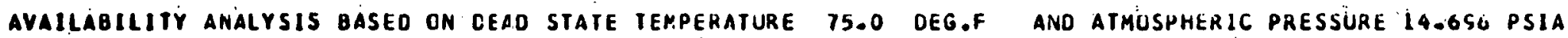

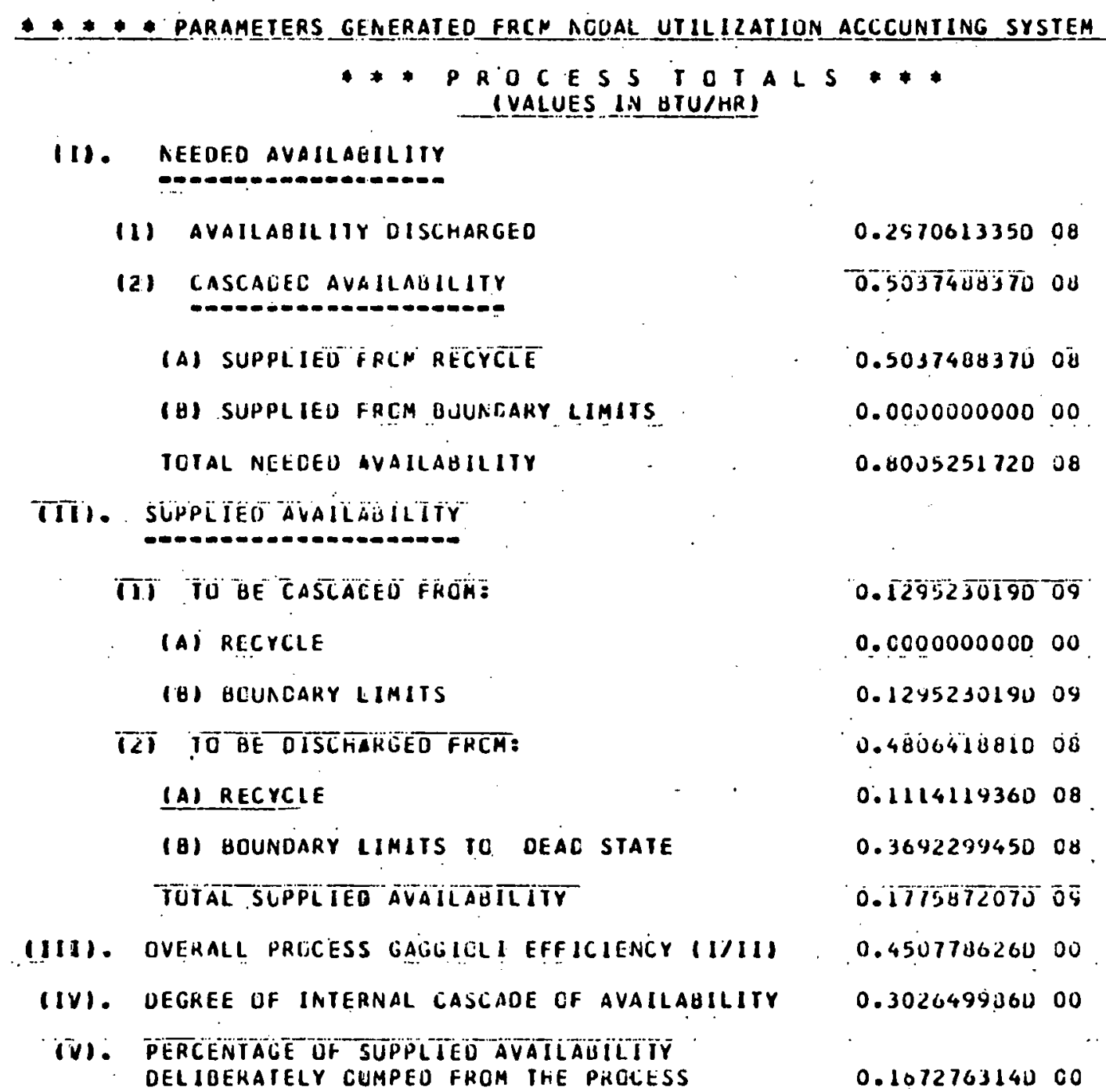




\section{COLUMN FEADING DEFIMIIICNS:}

(1) NEEDEO AVAILA3ILITY - THE AVAILAUILIIY REQUIRED TQ PRODUZE THE UESIREO STATE

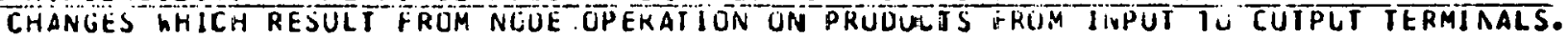

\section{* qlalificaigens.* *}

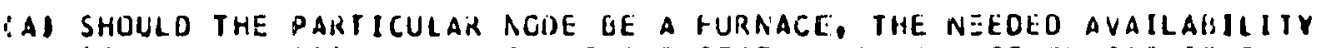
(COLFI8,NJJE)I WILL IACLUDE AIR STATE LAANGES. STACK GAS IS ONLY

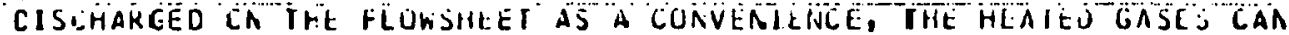

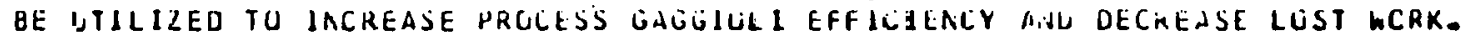

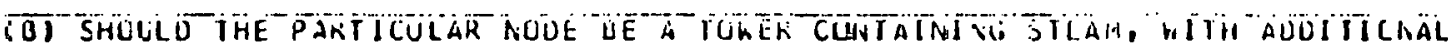
AVAILAUILITY AEECEO TO PKUVIDE THE NLCESSAKY STEAM SIATE ChANCES, THE NEEOEO

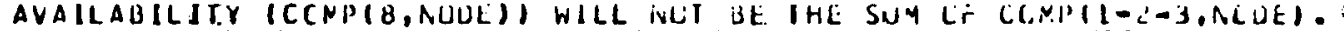
RAIHER, II WILL CALY NEFLELT THE AMUUNT LF AVALLAIILIIY NELESSASY TCK IHE AEECFD JIL STAIE CHANGES, FRLM CULUMN FEEUISI IL PFLUULTS.

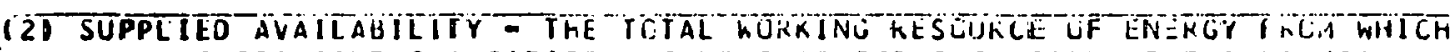
SUFFICIEAT GUANIITIES ARE KEMGVEO FLR PHCVISICN UF THE NEELFO AVAILAUILIIY.

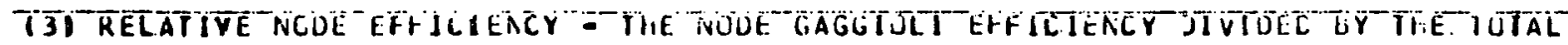
PRCCESS CAGCIELI EFFICIEACY.

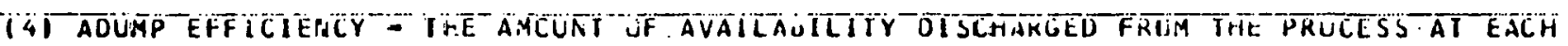
PCCE. DIYIOEJ HY THE ICTAL SUPPLY UF AVALLABLLIIY TJ ItAT NOUE.

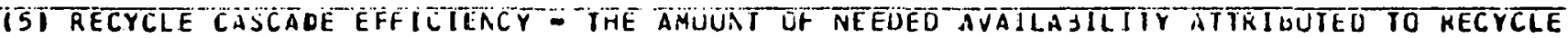
CASCACEC THRCJGh THE PRCLESS FPCM EACH NCCE DIVIUË BO ThL AAOUNT OF SUPPLIEO AVAILAEJLIIY FROM RECYCLE TO IHAT NCUE.

(6) BCUADAHY LIIA-S CASCALE EFFICIENCY - THE AMOUNT GF NEEOE.J AYAILAUILIIY AIIRLBUIED TO HOUNCAR LIMIIS CASLACLD IITKOULH THE PKLCESS FKGM SACH NCDE DIVIOLO BY IRE

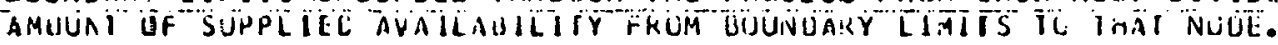

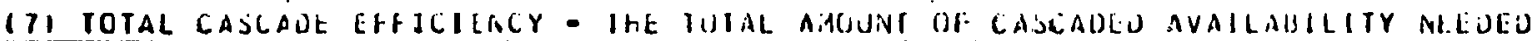

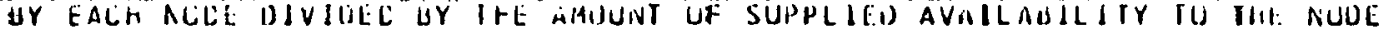
EARMAKKEL FEK PRLVILING LASLAUL PLIENIIAL.

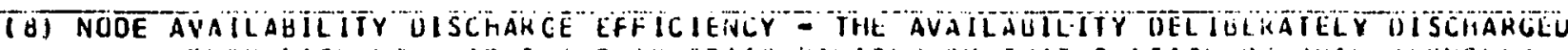
IIILH EAER NUUE IO ITE CLAU SIAIE UIVIDEJ BY IHAT PSKIICN UH BUIH KECYCLEU ANU LCUMOAKY LIMIIS SUPPLIEO AVAILABILITY. 
2869-1 Industrial Organic Chemicals

(Ethylene)

\section{Process Description}

Ethylene, a major commodity chemical is produced by the thermal cracking of ethane. Ethane enters the cracking furnaces and is heated to $1600^{\circ} \mathrm{F}$ where thermal decomposition to ethylene and by products occurs. The hot gases are sent to a quench tower to cool the products of decomposition. After cooling and washing the products are compressed and fed to acetylene removal. Compression with cooling precedes the final fractionation and recycle of by products. Utilities included are the boiler house, space heating, and cooling tower service. The base ethylene production rate is one billion pounds per year.

\section{Process Ideal Work Basis}

The process ideal isothermal work is based on the Gibbs Free Energy change of the ethane feed versus the final products. This was calculated. on a componential basis by assuming pseudo component properties for the : heavier fractions. The ideal actual work of production was calculated by including the change in thermal availability between reactants and products.

\section{Process Efficiency}

The lost work efficiency of the overall process based on ideal isothermal work is $31.0 \%$. The lust work efficiency of the overall process based on ideal actual work is $35.7 \%$. It can be seen that this efficiency would be expected for technology of this type because endothermic reaction is occuring together with combustion and fractionaction.

The total lost work of the process 1 s 384.7 million Btu/hr or about 3370 Btu lost work per pound of product. 
IV. Major Lost Work Unit Operations

This type of analysis allows one to focus on the major lost work unit processes. For the process in question the following items were major lost work areas:

Unit

Acetylene Removal

Boiler House

Space Heating

Furnace
$\%$ of Total Lost Work

34.6

21.1

14.2

13.3

Process design adjustments in each of these areas should be investigated to reduce lost work and Improvie process efficiency.

\section{Process Efficiency Parameters}

The parameters generated by the nodal utilization accounting system characterize the effectiveness with which availability is interchanged and utilized in the process. The overall process Gaggioli efficiency of $34.4 \%$ shows a moderate level of process interconnected exchange of availability and unit processes with a potential for significant improvement in availab1lity effeotiveness. The degree of internal cascade of availability of $17.1 \%$ confirms this observation. 
2869-1 Induerial Organle Cb

(Echylene)

Frocese Fou
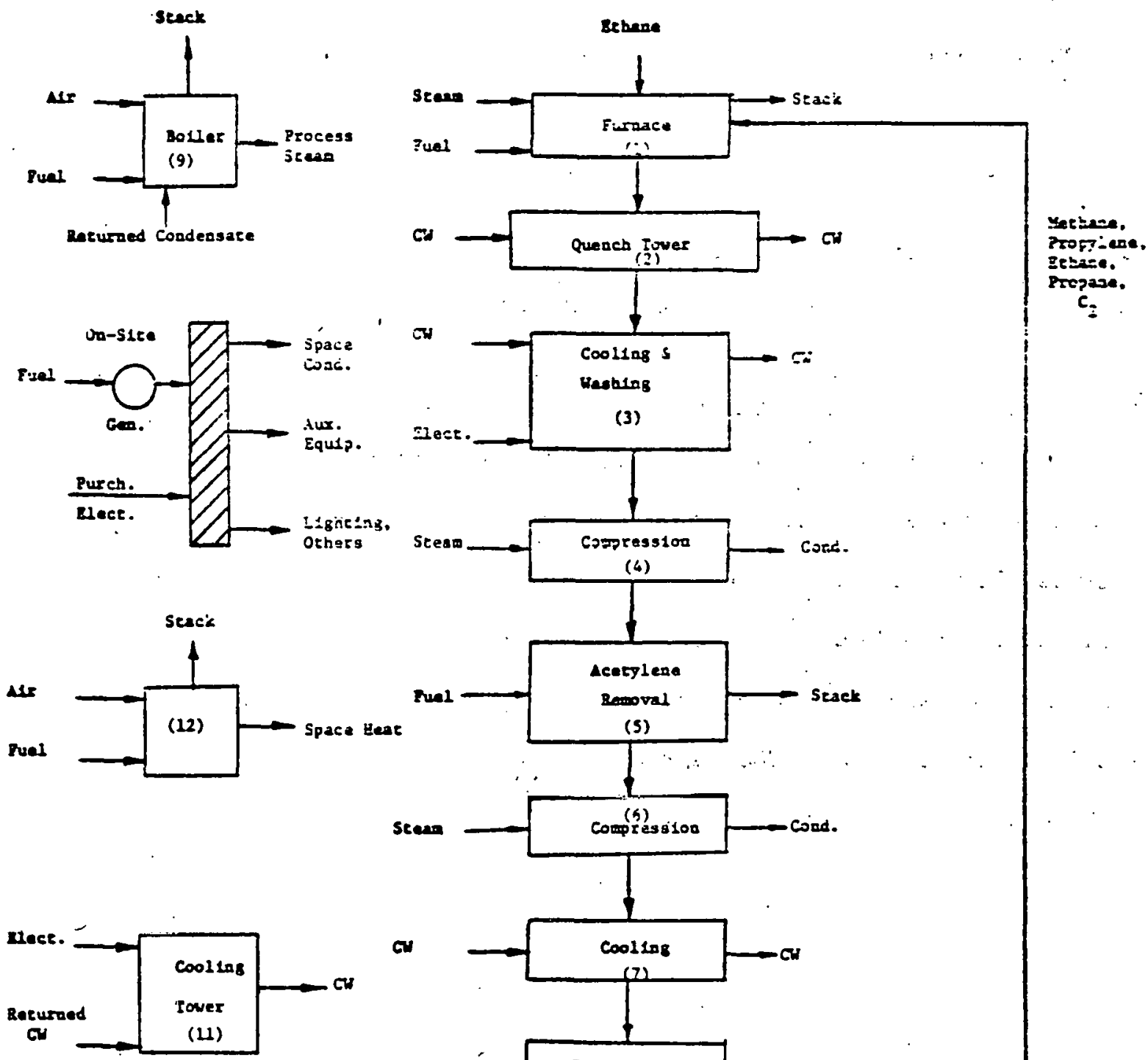

a)

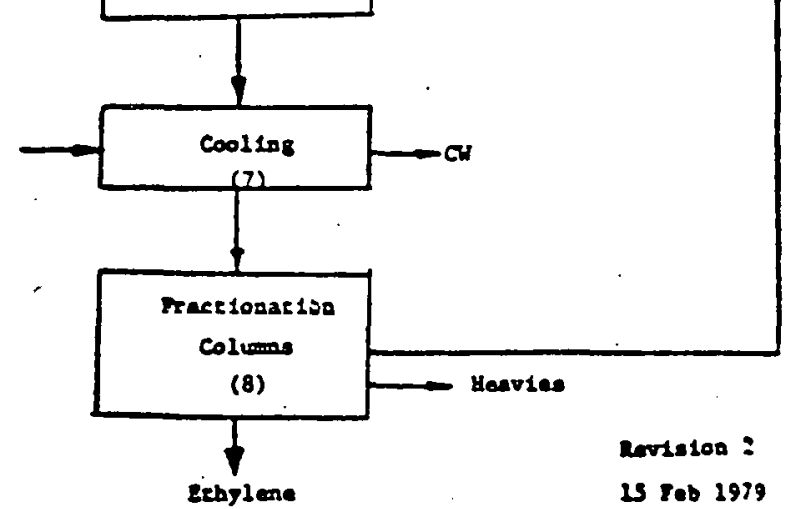


15
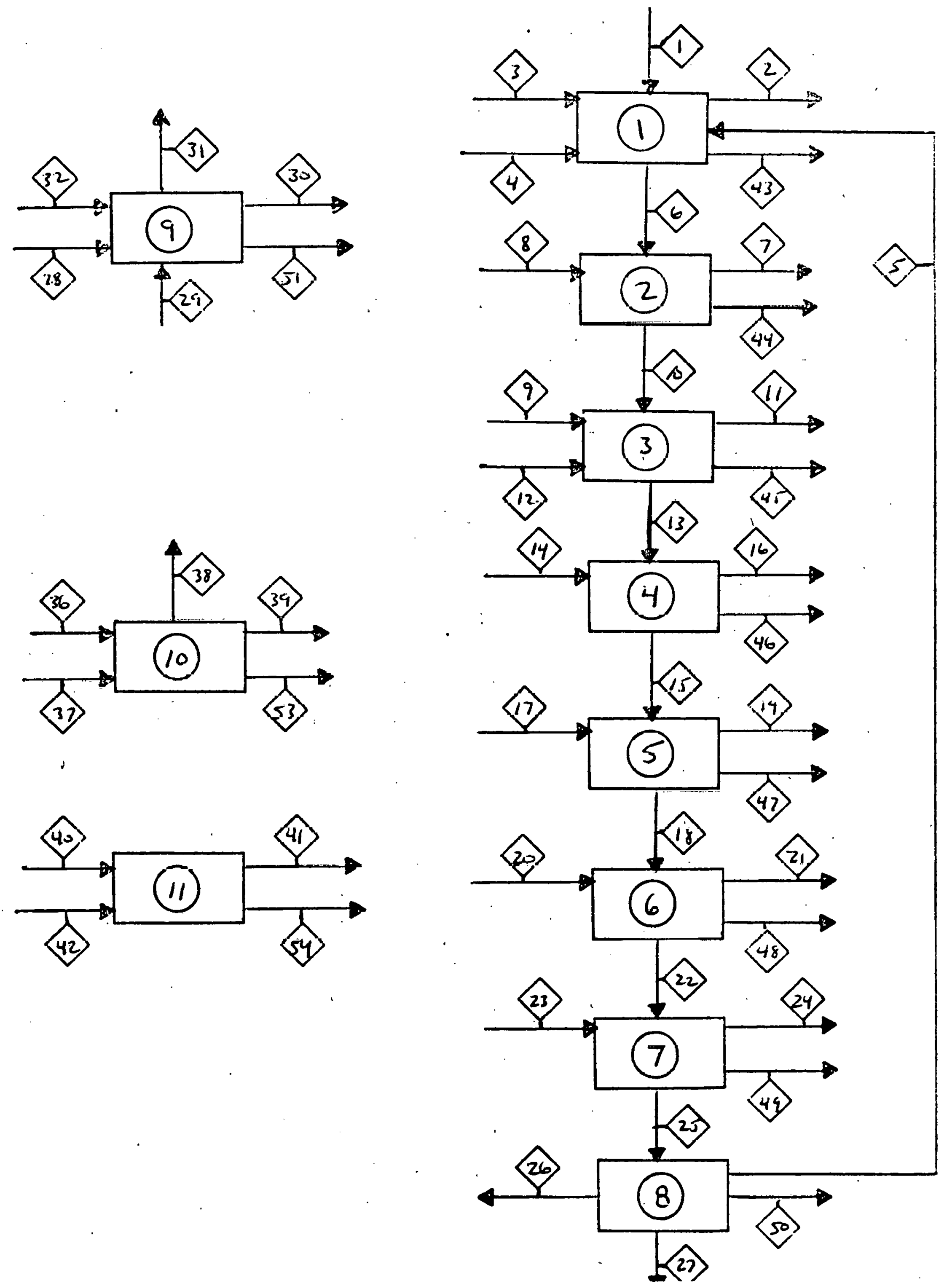


\section{9-1 Industrial Organtc Chemicals (Ethylene)}

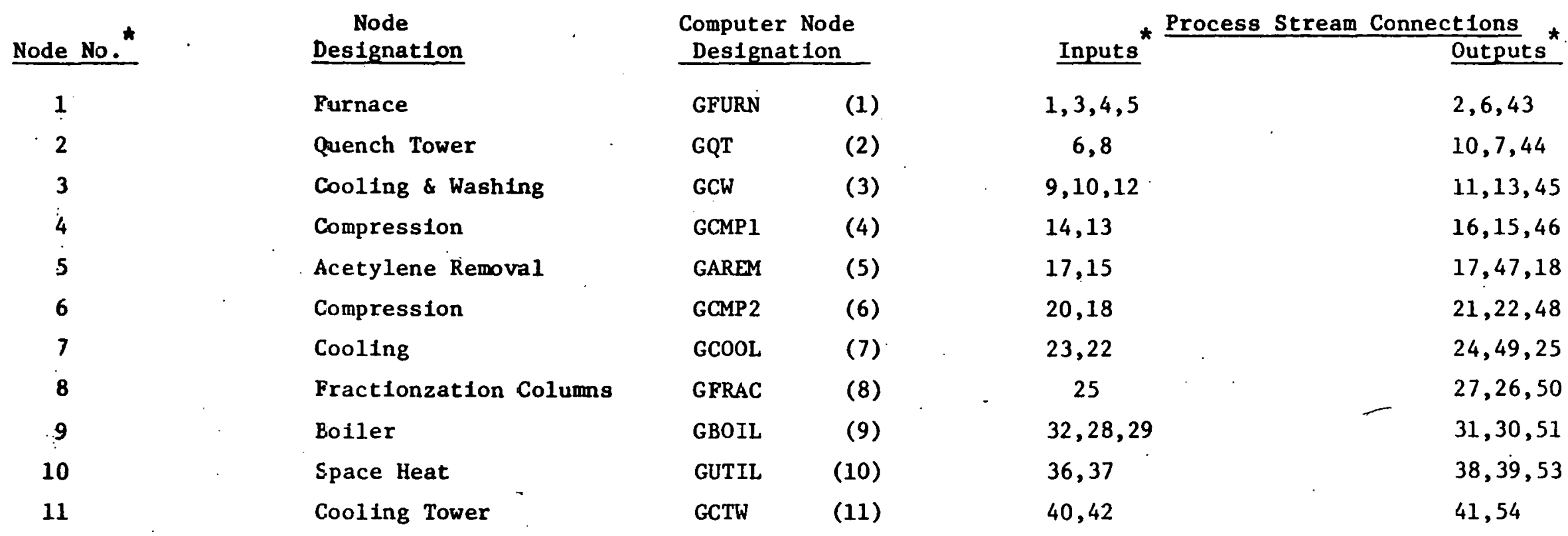

* These numbers refer to those shown on the Ethylene Process D1rected Graph. 


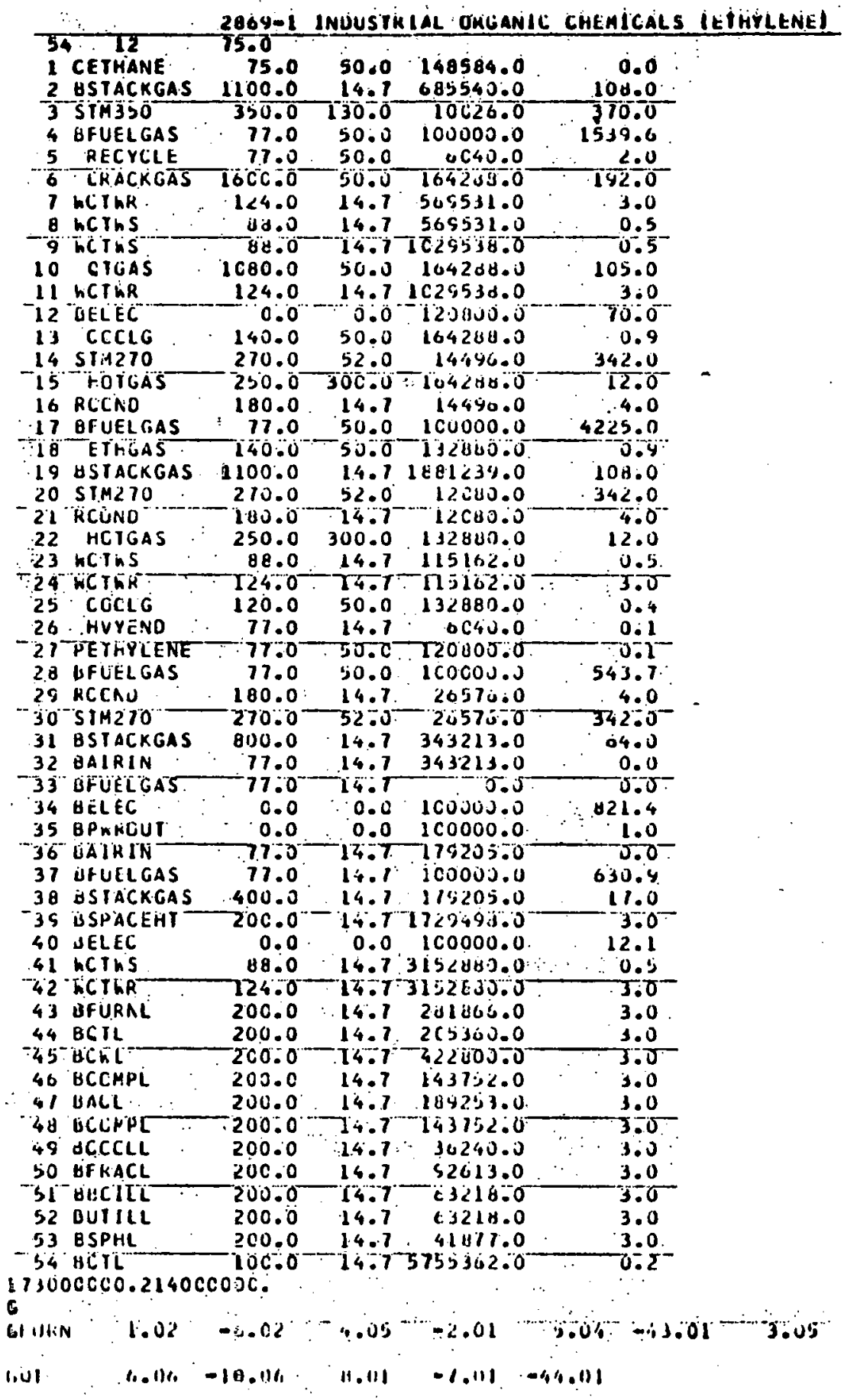




$\begin{array}{lllllll}\text { GCH } & 10.06 & -13.06 & 9.01 & -11.01 & -45.01 \\ \text { GCHPI } & 13.02 & -15.02 & 14.05 & -16.05 & -46.01 \\ \text { GAKEM } & 15.02 & -18.02 & 17.95 & -19.05 & -47.01 & 17.12 \\ \text { GCMPL } & 18.02 & -22.02 & 20.05 & -21.05 & -48.01 \\ \text { GCOCL } & 22.06 & -25.06 & 23.01 & -24.01 & -49.01 \\ \text { GFHAC } & 25.02 & -27.02 & -5.02 & -20.02 & -50.01 & 30.15 \\ \text { GBOIL } & 29.02 & -30.02 & 32.01 & -31.01 & 28.05 & -51.01 \\ \text { CUTIL } & -35.05 & 33.05 & 34.05 & -52.01 & \\ \text { CSPHT } & -39.02 & 36.01 & -38.01 & 37.05 & -53.01\end{array}$


28E9-1 INCUSTRIAL CR GANIIC CHEMICALS IETHYLENEI

AVAILABILITY ANALYSIS BASEO CN DEAD STATE TEMPERATUKE 75.0 DEG F AND ATMCSPHERIC PRESSURE I4.69G PSIA

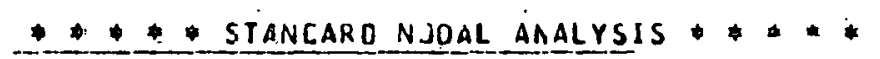

(LOST HUKK ANALYSIS AVO GAGGIGLI EFFICIENCIESI

FROCESS PARAMETERS:

TIT IOEAL ISG THEATAL GCRK Ó SEPÁRATICN

121 IOEAL ACTUAL WCAK CF PRODUCTICA

(3) TUTAL PRCCESJ LEST nORK

PAOCESS EFFICIENCY:-

111 BASEO ON PROCESS PARAMEIERS 11 . AND 131

(2) 3ASED CA PROC.ESS PABANETERS 121 AND (3) (CCCEE ANC WAN HESS)

\subsection{BTUS\% \\ 0.214000000009 BIUS/RR \\ 0.3646585850 C9 EIUS/HR}

$0.310208537062 \quad(\%)$

$0.3574919370 .02 \cdot(4)$

\begin{tabular}{|c|c|c|c|c|c|c|c|c|}
\hline NQOODE & Eculp & II $A \overline{A N E}$ & $\begin{array}{c}\text { KC JAL LCST hO } \\
\text { (ETUItRI }\end{array}$ & $1 R \overline{1}$ & $\begin{array}{l}\text { EFFTCTERICY } \\
\text { BASED (IV I I) ABCVE }\end{array}$ & $\begin{array}{l}\text { EFFICIEINCY } \\
\text { BASEO CA } 121 \text { ABOVE }\end{array}$ & $\begin{array}{l}\text { GACEICLT } \\
\text { EFFICIENCY }\end{array}$ & \\
\hline 1 & $\begin{array}{c}: \\
\text { GENRL }\end{array}$ & LFURN & 0.5125445000 & $O H$ & C. $9.190526900-01$ & $0.856112031 L-01$ & 0.074 .740 .61370 & co \\
\hline $\begin{array}{l}2 \\
3 \\
4\end{array}$ & $\begin{array}{l}\text { GEARL } \\
\text { GENRL } \\
\text { GENRL }\end{array}$ & $\begin{array}{l}\text { GGF } \\
\text { GCW } \\
\text { GCMPL }\end{array}$ & $\begin{array}{l}0.1225314850 \\
0.3320013580 \\
0.2644755200\end{array}$ & $\begin{array}{l}06 \\
04 \\
07\end{array}$ & $\begin{array}{l}C .2157130350-01 \\
C .2377695391)-01 \\
0.4742423030-02\end{array}$ & $\begin{array}{l}0.2036064760=01 \\
0.2214863640=01 \\
0.4411941010-02\end{array}$ & $\begin{array}{l}0.1427201700 \\
0.2246614110 \\
0.4002011010\end{array}$ & $\begin{array}{l}\text { Cu } \\
C U \\
C U\end{array}$ \\
\hline $\begin{array}{l}5 \\
6 \\
7\end{array}$ & $\begin{array}{l}\text { GERKL } \\
\text { GENRL } \\
\text { GEARL }\end{array}$ & $\begin{array}{l}\text { GAREA } \\
\text { GCMPZ }\end{array}$ & $\begin{array}{l}0.13354 \angle C E 30 \\
0.21764160 C 0 \\
0.11441 E 3 C C D\end{array}$ & $\begin{array}{l}09 \\
07 \\
07\end{array}$ & $\begin{array}{l}C .234356306000 \\
C .3903282330-02 \\
0.00521)\end{array}$ & $\begin{array}{l}0.223057074000 \\
0.3635913784-02 \\
0.1412131040-02\end{array}$ & $\begin{array}{l}0.2458453920 \\
0.4668035090 \\
0.2613430\end{array}$ & $\begin{array}{l}c 5 \\
c c \\
c 0\end{array}$ \\
\hline $\begin{array}{r}0 \\
9 \\
10\end{array}$ & $\begin{array}{l}\text { GEARL } \\
\text { GENRL } \\
\text { GENRL }\end{array}$ & $\begin{array}{l}\text { GIVAOC } \\
\text { GWOIL } \\
\text { GUIIL }\end{array}$ & $\begin{array}{l}0.6354482000 \\
0.23232 C 26 C L \\
0.0185034600\end{array}$ & $\begin{array}{l}06 \\
08 \\
08\end{array}$ & $\begin{array}{l}0.1110201,0730=02 \\
0.41657701040=01 \\
0.116167117000\end{array}$ & 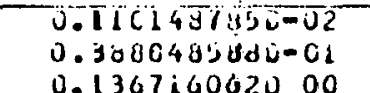 & 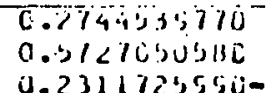 & $\begin{array}{l}\mathrm{Ci} \\
\mathrm{cu} \\
\mathrm{Cu}\end{array}$ \\
\hline 11 & $\begin{array}{l}\text { GEAKE } \\
\text { GENKL }\end{array}$ & $\begin{array}{l}\text { GSTH I } \\
\text { GCTW }\end{array}$ & $\begin{array}{l}0.3412935000 \\
0.15411276 \mathrm{CD}\end{array}$ & $\begin{array}{l}08 \\
01\end{array}$ & $\begin{array}{l}C .813 i 1300=01 \\
C .14239+5830-c 1\end{array}$ & $\begin{array}{l}0.4141363060=01 \\
0.132642041 U=01\end{array}$ & 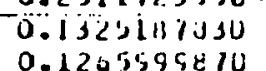 & cu \\
\hline
\end{tabular}




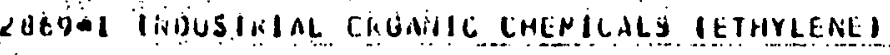

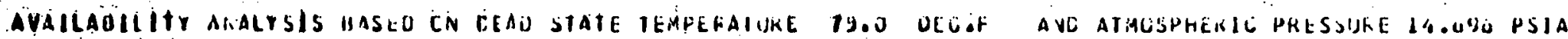

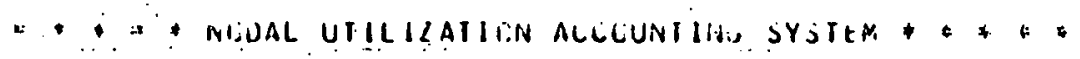

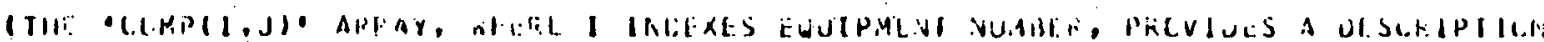

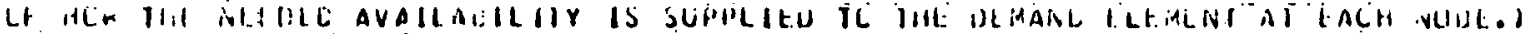

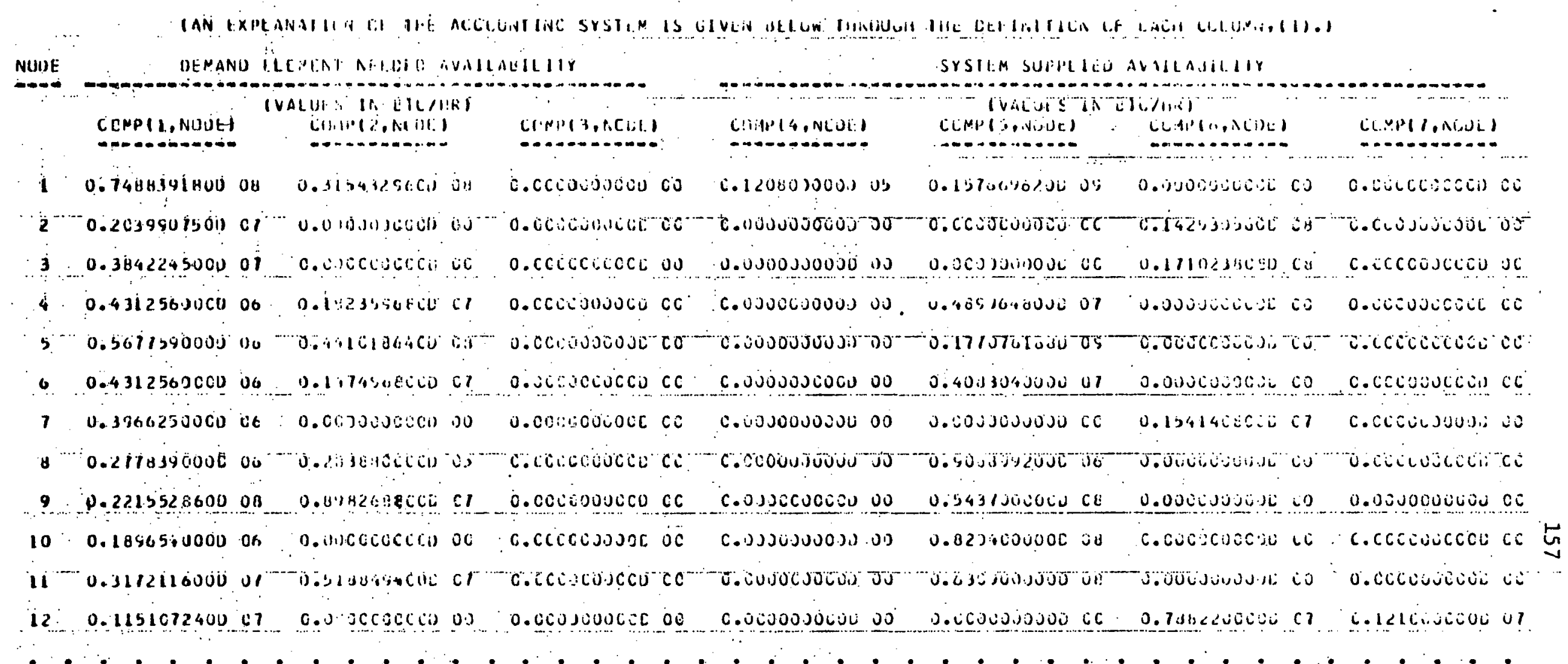


28E9-1 INQUSTH:IAL CRGANIC CHEMICALS IEIHYLENEI

AVAILABILITY ANALYSIS gASED CA CEAD STATE TEMPERATURE 75.0 DEG.F ANU ATMCSPHERIG PAESSURE IG.696 PSIA

* ** nGOAL UIILILATION AECCUNTING SYSTEM *****

C E F I D I I I N OF C ULU HN HEA UINGS

a. - .

IN THE PRUCESS, II IS ESSENTIAL IC KEEP TKACK OF THE AVAILAUILITY WHHILH IS exchanged at each noce, accorcing tu the pakticular noue uperaticn. ihe tKansfer OF AVATLABIL TYY CCCURS TT TFE ICOE OR STREAH INTERCINNECTICN STTE ANE ThE RESULTS OF IIIIS TRANSFER ARE AFPAKENT IN THE STATE CHANGES hHICH LCCUR IA IHE AVAILAGILITY TRANSPGRT MESIA.ICIL,AER, ARI WATERI, REACILY OISTINGUISHABLE THRUUGH LCMPAKISUNSS CF

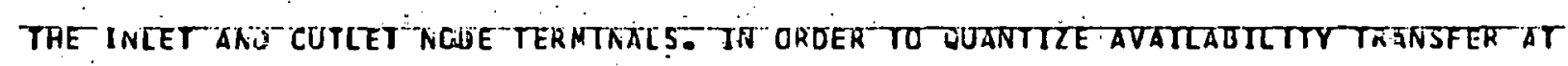
EACH NCDE, IWO MAJCF CLASSIFICAIICNS OF ACIIVIIY HERE ESTALLISIEED UY LIAGCICLI;

I1) AVALLABILITY NEECEU. HY ACJE TC PERFCRM HS SPECIFIC SYSJEM FUNCTION I2) AVALLABILITY SUPPLIEC IG ACDE IO PRCVIUE CAPACIIY IC ACCCMPLISH.IIS SPECIFIC CPERATICA

IN CRUER IO FURTHE. CHARACIERIZE AVAILABILIIY INTEKCHA.VGES AT THE NGGF, THE

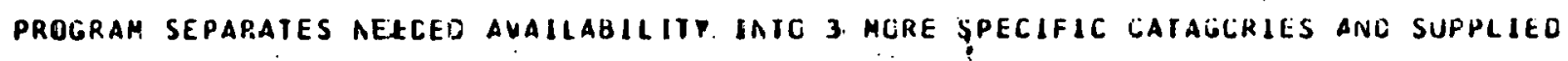

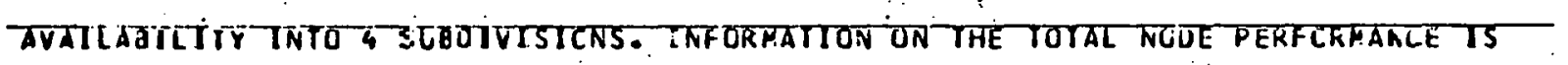
COHTAINEU IN THE AFRAY CCMPII,J) WHEFE J IS THE NOUE WUIAEKI I=1,7 WITH FGSIIICNS

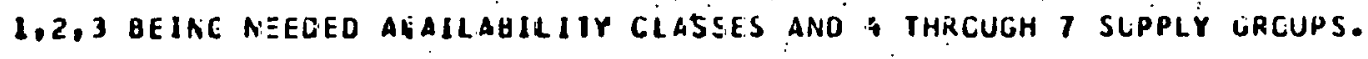


2869-1 INOUSIRIAL ORLANIC CHEMICALS (ETHYLENE)

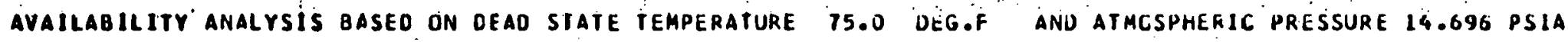

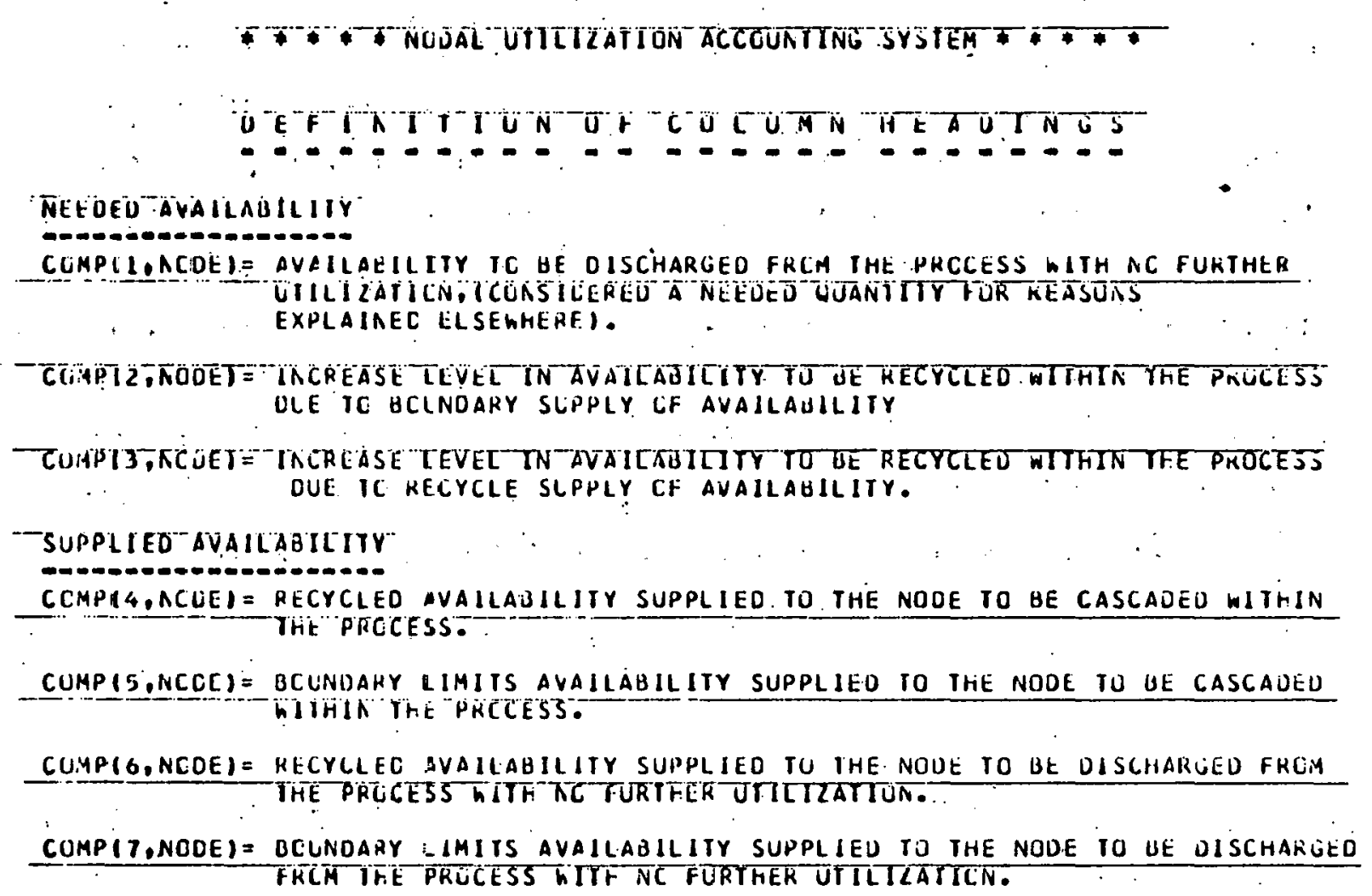

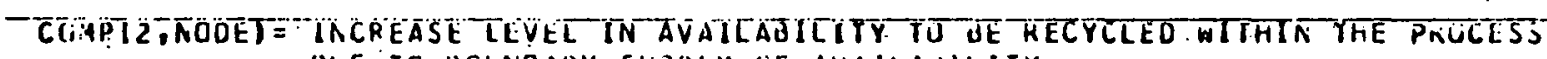
DLE IC BCLNOARY SLPPLY LF AVALLAULIITY

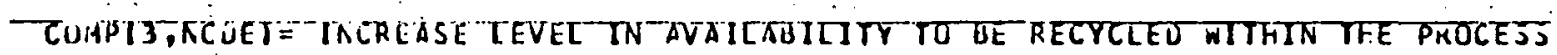
DUE IC RECYCLE SLPPLY CF AVAILAGILITY.

-SUPPLIED AVALLABILITY"

CCMPI4,ACUEI = RECYCLED AVALLABILIIY SUPPLIED. TO THE NOOE TO GE CASCADEU WITHIN THit PRECESS.

CUMPISINCCEI= BCLNDAHY LIMITS AVAILABILITY SUPPLIEO TO THE NODE TO UE CASCAUEU WITHIN THE PRECESS.

CU.YP $(6, N C D E)=$ KECYLLEC SVAILABILITY SUPPLIED TU THE NOUE TO BE UISCHARLEO FRGM THE PRGGGESS hITH TC FURTFER UTILTLATIUN.

COMPIT,NODE) = OCLNOARY -IMITS AVAILABILITY SUPPLIEU TO THE NODE TO UE DISCHARGED FRCA ITEE PRÚCESS WITH NC FURTHER UTILTLATICN. 
Z869-1 INDUSIRIAL CRGANIC CHEMICALS (ETHYLENE)

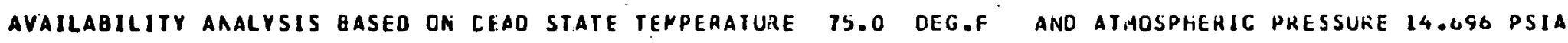

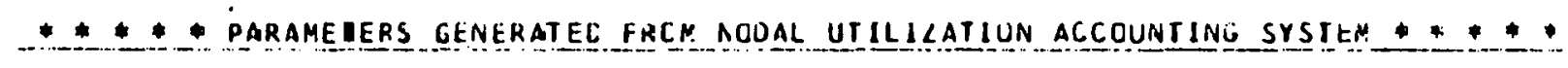

IAN EXPLAAATICA EF CCLUMA HEACINGS IS GIVEN bLLOW IHRUUGH DEFINITIUN GF PARTICULAR PARAHEIEHS AS DER IVEC FRCNI IAFCHMATICN CONIAINEU IN ITE COMP ARRAY.I

\begin{tabular}{|c|c|c|c|c|c|c|c|c|}
\hline NODE & $\begin{array}{c}\text { NEEDED } \\
\text { AVAIIAUIL ITY } \\
\text { (BIU/HR) }\end{array}$ & $\begin{array}{c}\text { SUPPLIED } \\
\text { AVAILAUILITY } \\
\text { (UTL/HK) }\end{array}$ & $\begin{array}{l}\text { RELAUIVE NCDE } \\
\text { EFFICIEACY } \\
-\end{array}$ & $\begin{array}{c}\text { ADUMP } \\
\text { EFFILIENEY } \\
-0-0-0-0-0-\infty\end{array}$ & $\begin{array}{l}\text { RECYCLE } \\
\text { CASCAUE } \\
\text { EFFICIENCY } \\
\end{array}$ & 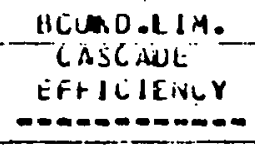 & $\begin{array}{l}\text { TLIAL } \\
\text { EASCAUL } \\
\text { EFEILIEACY }\end{array}$ & $\begin{array}{l}\text { NUUE AVAIL. } \\
\text { OISCMAICE } \\
\text { EFFICIEACY } \\
\end{array}$ \\
\hline 2 & $0.2639907500 \mathrm{C7}$ & 0.1425305600000 & -0.585 & 0.143 & 0.050 & $=.0 .50$ & $\bar{c} \cdot \bar{c} \bar{c}$ & $c: 1+3$ \\
\hline 3. & $0.3842245000 \quad 07$ & $0.171: 2311080 \mathrm{c8}$ & -0.346 & 0.225 & 0.000 & 3.020 & 0.000 & $C .223$ \\
\hline 4 & $0.2254852800 \quad 07$ & 0.489564100027 & 0.319 & 0.086 & 0.000 & $=.000$ & 0.372 & $6 . \operatorname{ccc}$ \\
\hline 5 & 0.435341050009 & $0.1+1676186 \overline{3} 5$ & -0.235 & 0.005 & 0.000 & 3.000 & 0.249 & c. $c c^{\circ}$ \\
\hline 6 & 0.190622400007 & 0.4083040000 .27 & 0.358 & 0.106 & 0.000 & $\therefore 000$ & 0.301 & $c \cdot c c c$ \\
\hline 7 & $0.396 .6250000 \quad 06$ & $0.15414\left(B 0 C_{1}\right) 07$ & -0.231 & 0.257 & 0.000 & 0.000 & 0.000 & C. 257 \\
\hline 8 & $0.249 \overline{4} 1000006$ & $\overline{0} . \overline{0} \overline{8} \overline{\bar{S}} \overline{2} \overline{0} \overline{0} \overline{0} 0 \overline{6}$ & -0.202 & 0.306 & 0.000 & $c .000$ & 0.031 & $C .500$ \\
\hline 10 & 0.189654000006 & 0.820400000008 & -0.543 & 0.002 & 0.000 & 0.000 & 0.500 & C.cic \\
\hline$\overline{1} \pi$ & $0 . \overline{836061000007}$ & $0.63 \bar{c} \bar{c} \overline{0000} 0 \overline{08}$ & -0.614 & 0.050 & 0.000 & 6.000 & 0.032 & $\pi . \overline{c o s}$ \\
\hline 12 & 0.1151072400 .07 & $0.909 \div 200000<7$ & $=0.632$ & 0.121 & 0.000 & 0.000 & 0.000 & 0.1218 \\
\hline
\end{tabular}




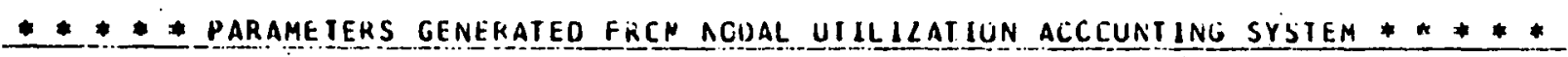

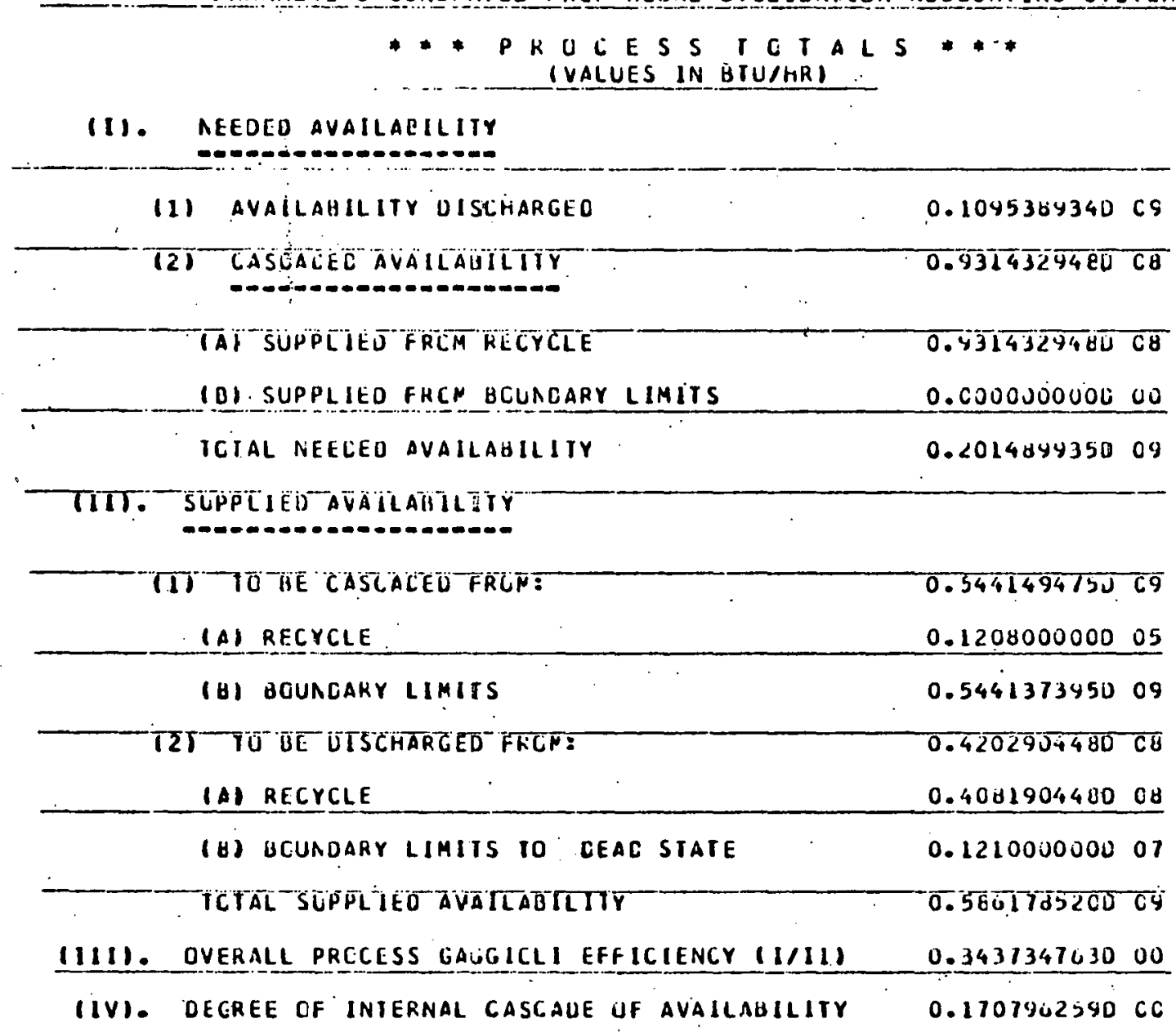




\section{CQLUMN HEAOING DEFINITIONS:}

(1) NEEDEO AVALLAEILITY - THE AVAILABILIIY KEUUIRED IO PRUDUCE THE DESIRED SIATE CHANEES WR ICH RESULT FRCM NOUE UPERATION UN PKOUUCTS FRLM SNPUT TO CUTPLT TERMINALS.

\section{* * Cualificai!luns * *}

(A) Sacllo the particular ngue ge a furfeace. The neEdeg aVallabillity ICCYF(A.NOUE) WILE INCLUUE AIR STAIE ChANGES. STACK LAS IS OALY

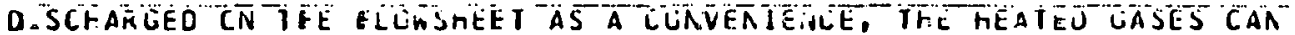

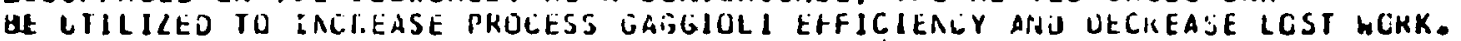

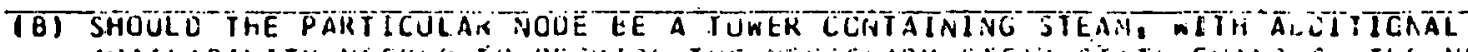

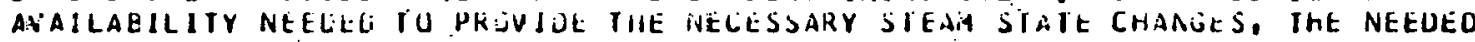
AYAILAUILITY ICCNPIS,NOUED hILL NOT BE THE SUM LF CLNF(L-2-3, ACUE).

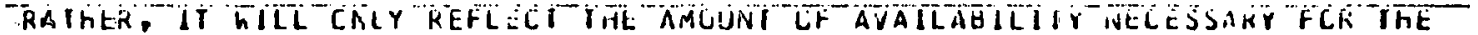

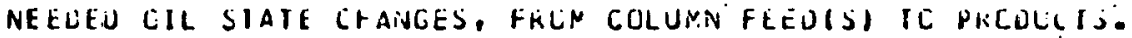

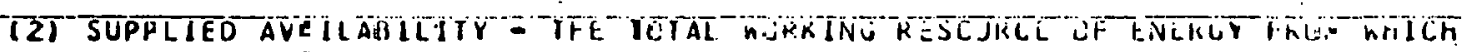
SUFFIZIEIVI GUANTIIILS LKL KEMGVED FLK PRUVISICN UP THE REELED AVAILAUILITY.

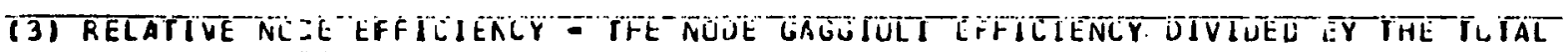
PRCCESS GAGGICLI EFFICBENCY.

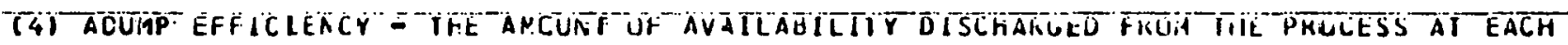
NUCE IVIDEC BY THE TCTAL SUPPLY CF AVAILABILITY TO IHAI NïUE.

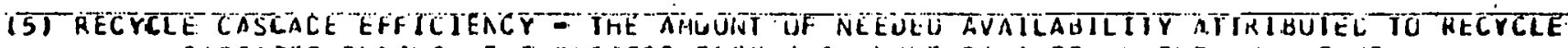
CASCADEC THKLUGh THE PRCLESS FRLM EACH NUUE DIVIUED UY THE -AMUNA LF SUPPLIEC AVAILAEILIIY FRCM RECYCLE IC IHAI NCDE.

(6) GCUNOAKY LIAIIS CASCACE EFFICIENCY. - IHE AMUUAT OF NEEUED AVAILAGILITY AITKIBUTED TU UCUNCARYY LIMIIS CASCAQEQ THKLUCh THE PRCCESS FWIM EACh NLLE DIVIUEC UY IHE

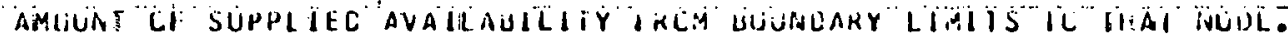

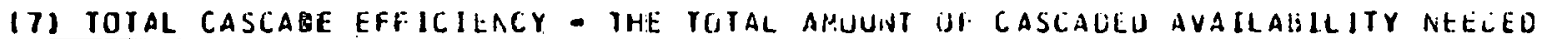

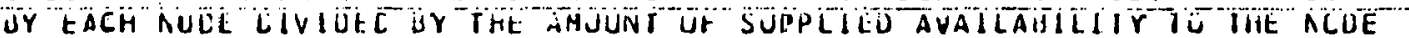
EAKMAFKE FCR PHCVICING CASCAGE PUTENIIAL.

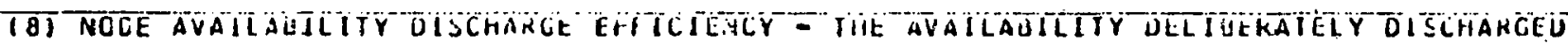
FRCM ENCr NICUE TO THE LEAU STATE DIVIDED OY THAT PGETILN LF BUTH RECYCLED ANC BG UNCARY LIMIIS SUPPLILO EVAILAUILIIYY. 


\title{
2911 - Petroleum Refining
}

\section{Process Description}

This process consists of the unit operations found in a typical Petroleum Refining process:

\author{
Crude Oil. Distillation \\ Vacuum Distillation \\ Catalytic Cracking \\ Catalytic Reforming \\ Hydro Treating \\ Isomerization \\ Alkylation \\ Dist1llate Hydroforming \\ Lube 0 il Processing \\ Asphalt Processing \\ Vis-Breaking
}

The crude oil feed rate was assumed to be 100,000 barrels per day.

\section{Process Ideal Work Basis}

The ideal isothermal work for this process was calculated on a pseudo component basis for the crude ofl feed and the Individual products although selected reaction endo-therms and exo-therms were accounted for, the majority of ideal work is accounted for by fractionation/composition change and hence overall process efficiency will tend to be low. The ideal actual work is calculated by adding the change in thermal availability to the 1deal isothermal work. 


\section{Process Efficiency}

The lost work efficiency of the overall process, based on ideal isothermal work is $3.4 \%$. The lost work efficiency of the overall process based on ideal actual work is $3.6 \%$.

It can be seen that this efficiency would be expected for technology of this type because the majority of work is required for separations/ fractionation processes which have a low thermal availabilily efflclency. Total process lost work is 1151 million Btu/hr or abuut 270,240 . BTU lost work per barrel of crude feed.

IV. Major Lost Work Unit Operations

This type of analysis allows a focus on the major consumers of availability in the process system. For the process under study, the following unit operations were major lost work areas:

$\underline{\text { Unit }}$

Catalyc1c Reforming

Crude Distillation

Catalytic Cracking

Alkyjation

Varuum Dietillation
$\%$ of Total Lost Work

20.6

19.9

10.9

18.2

$\mathbf{6 . 6}$

These process unit operations are the first areas to screen for process improvements.

\section{Process Efficiency Parameters}

The parameters generated by the nodal utilization accounting system characterize the effectiveness with which availability is interchanged and utilized in the process. The overall process Gaggioli efficiency of $16.0 \%$ shows a low level of process interconnection and exchange of availability. 
The process structure should be reviewed for improvements in heat integration between units. The degree of internal cascade of avaijability of $11.4 \%$ confirms this observation. 
2911 - Petroleum REfining

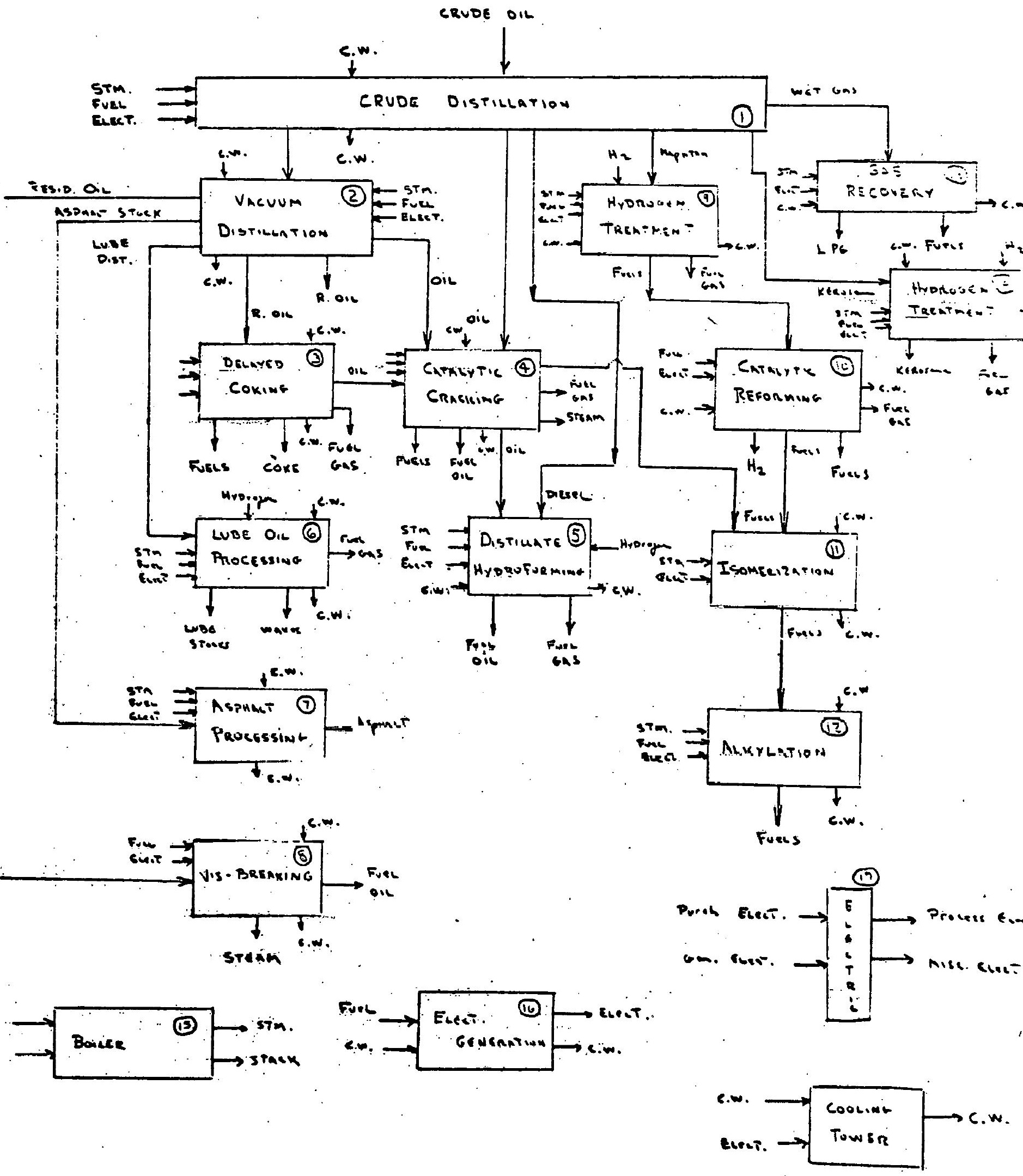




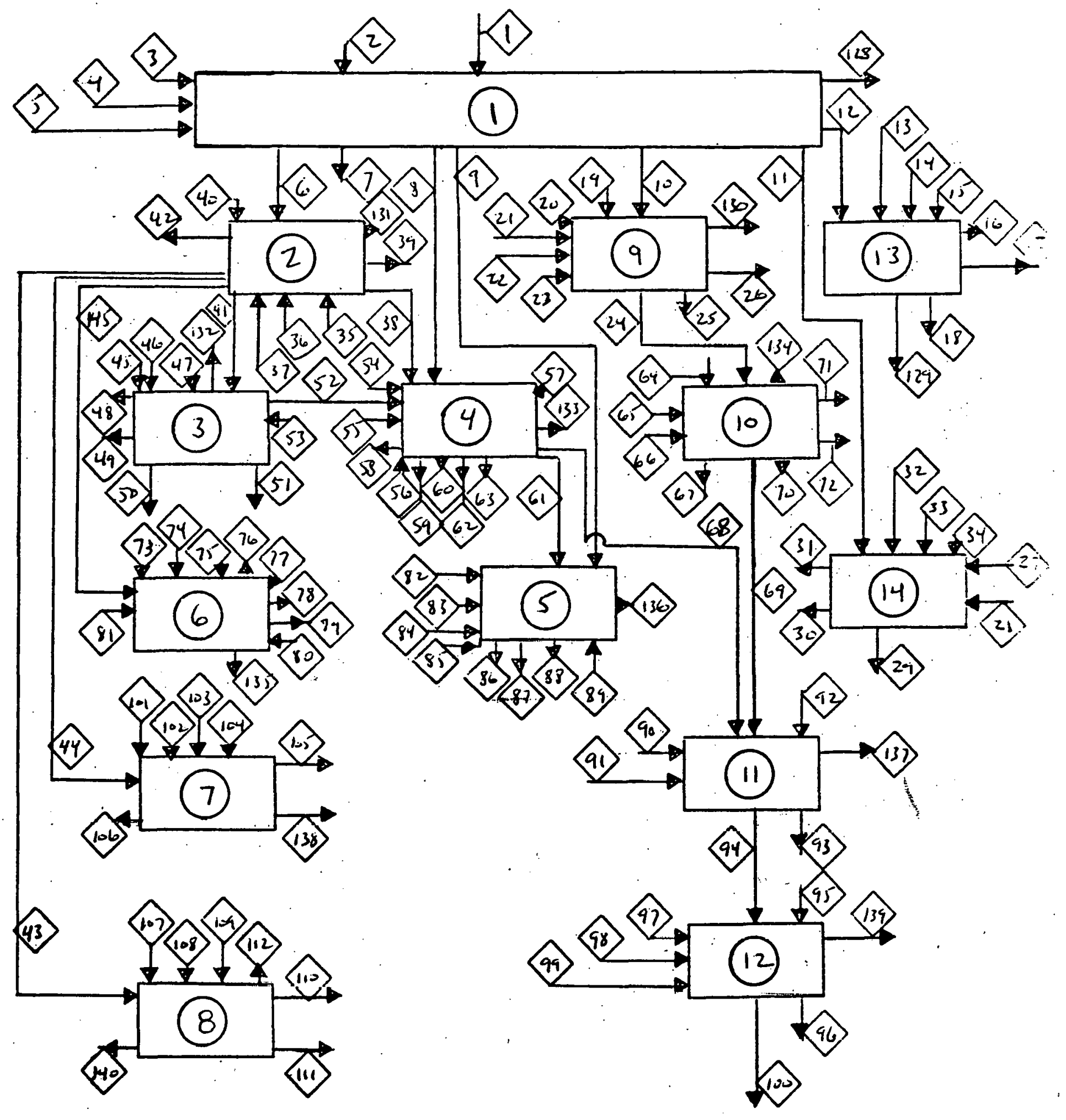


2911 - Petroleum Refin1ing

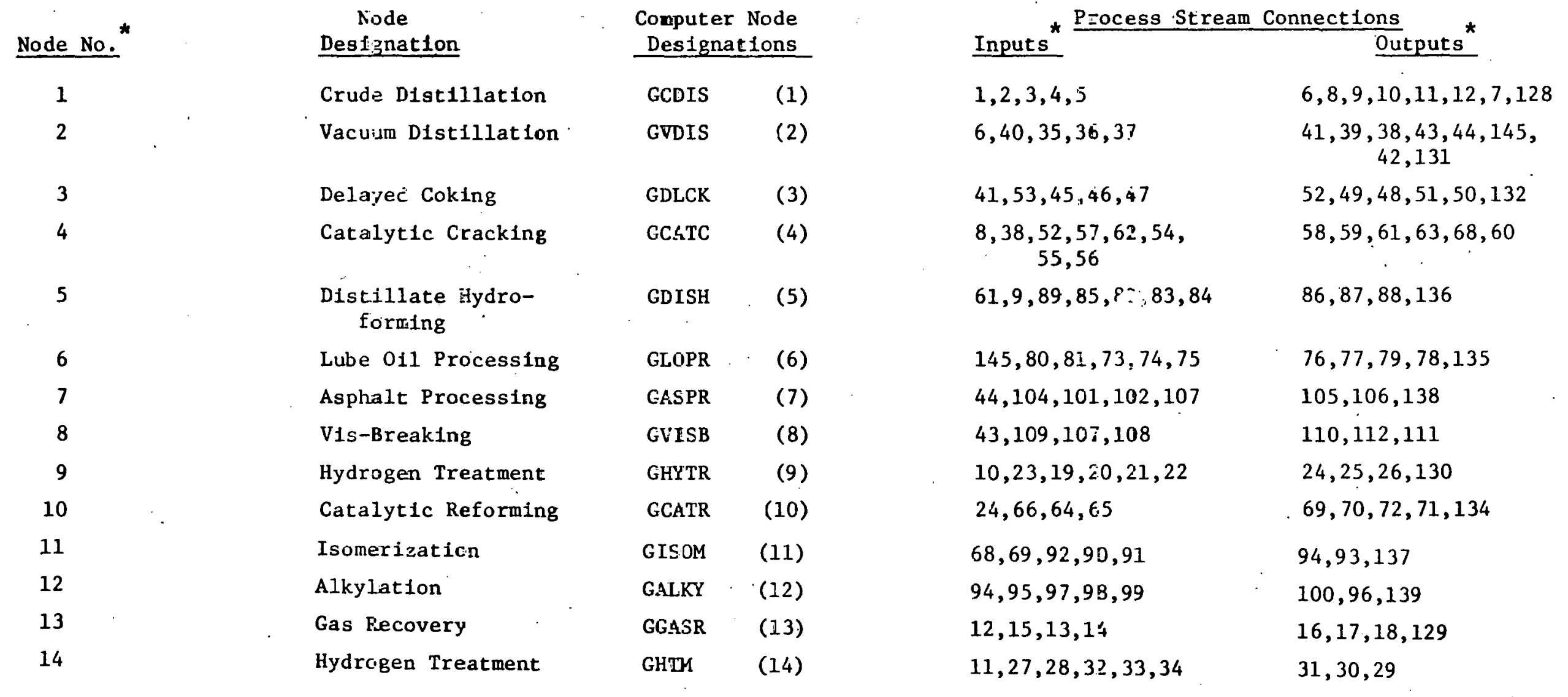

*These numbers refer to those shown on the Refinery Process Directed Grafh. 
291L - PETHCLEUM REFINING

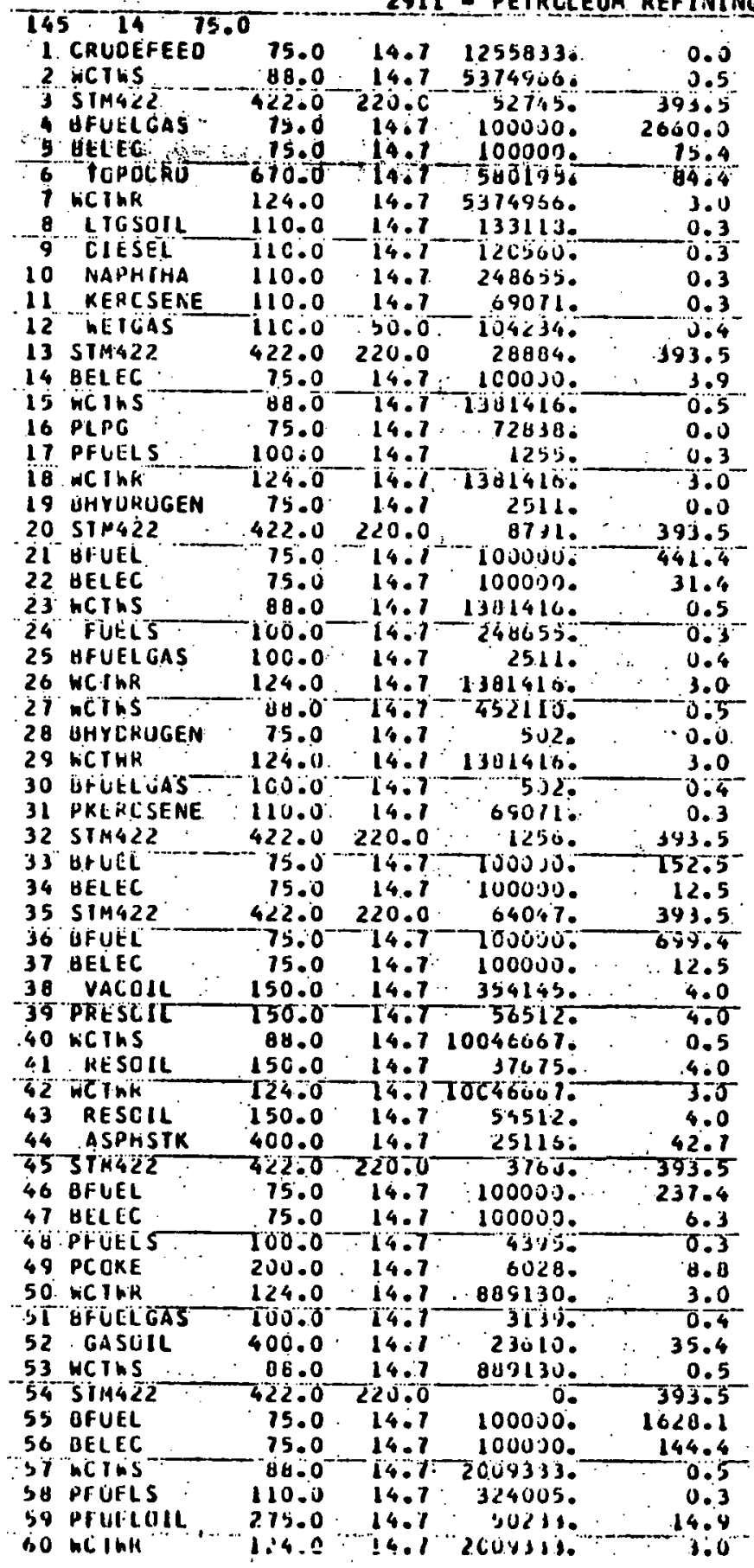




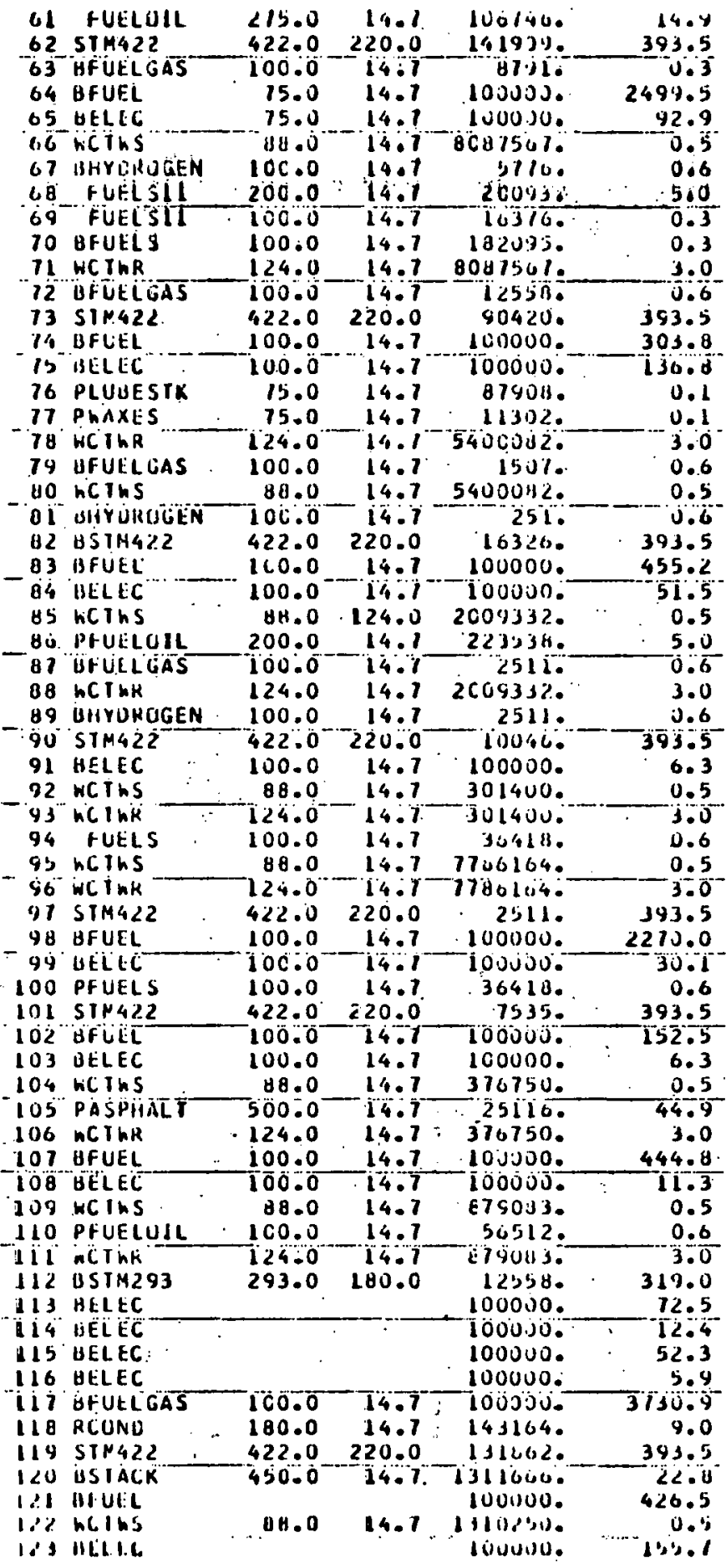




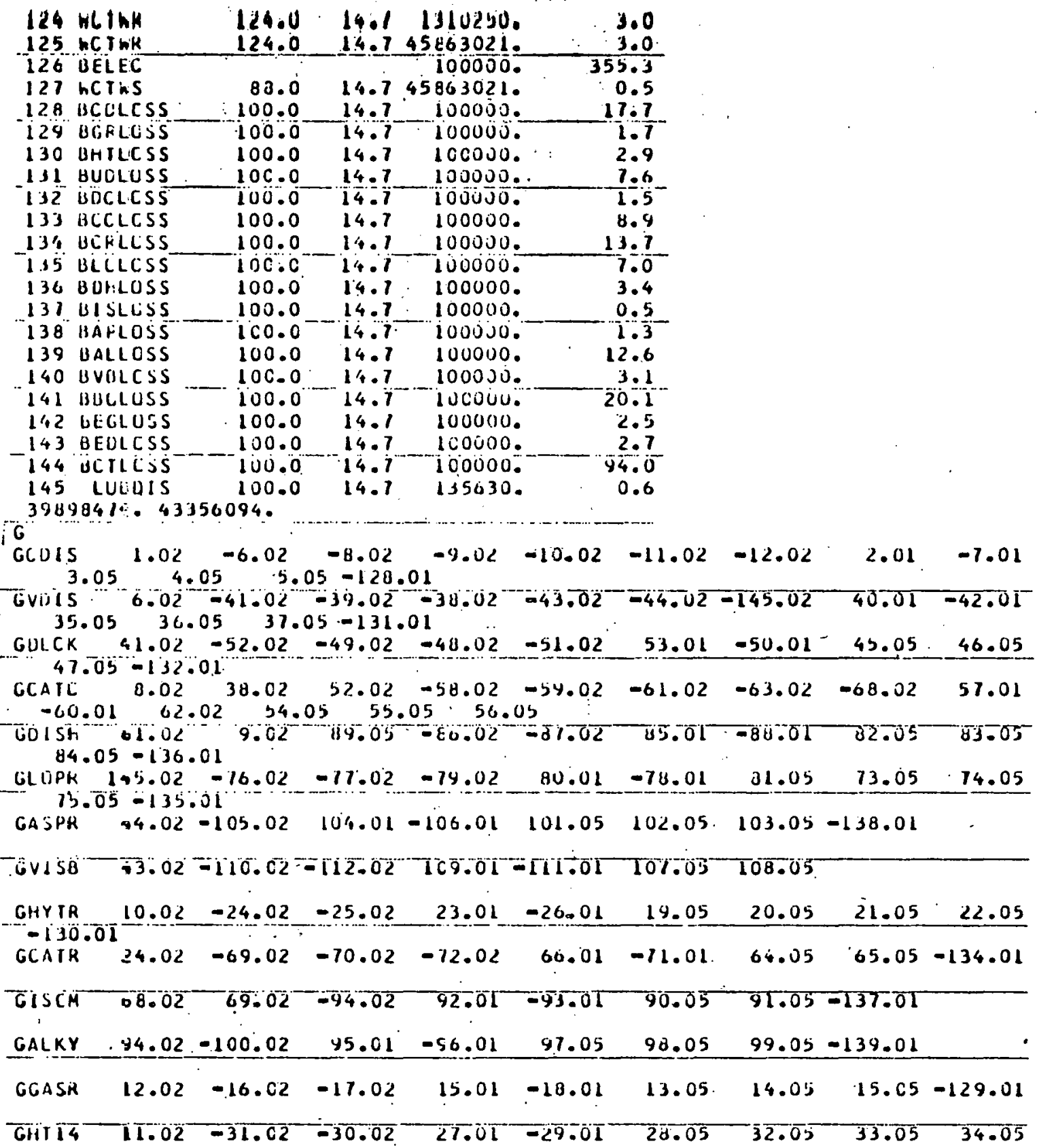


2911 - PEIRLLEUM REFINING

AVAILABILITY ANALYSIS GASED ON OEAD STATE IENPERATURE 75.0 DEG .F AND ATMCSPHEHIC PRESSURE L'. G96 PSIA

* * * stangard ngual analysis ******

(LOST hORK ANALYSIS AND GAGGIOLI EFFICIEIVIES)

\section{PROCESS PARAMEIERS:}

TIT IDEAL ISOTHERMAL WCHK CF SEPARATICA

$0.398984740008-8 T U S \% h R^{-}$

(2) IDEAL ACIUAL hCRR. CF PRODULTICH

0.433560440000 EIUSTRK

131. TOTAL FRECESS LOST WCRK

$0.113 L 394 / 0010$ UIUS/HR

FACCESS EFFICIENCY:

111 BASEU CN PROCESS PARAMEIERS (1) AAC (3)

(2) BASEO CN PRUCESS PAKANETERS (2) ANC (3)

I GCOCE GND VAN MESSI

$0.334861120001 \quad(21)$

$0.3628274+1001 \cdot(\%)$

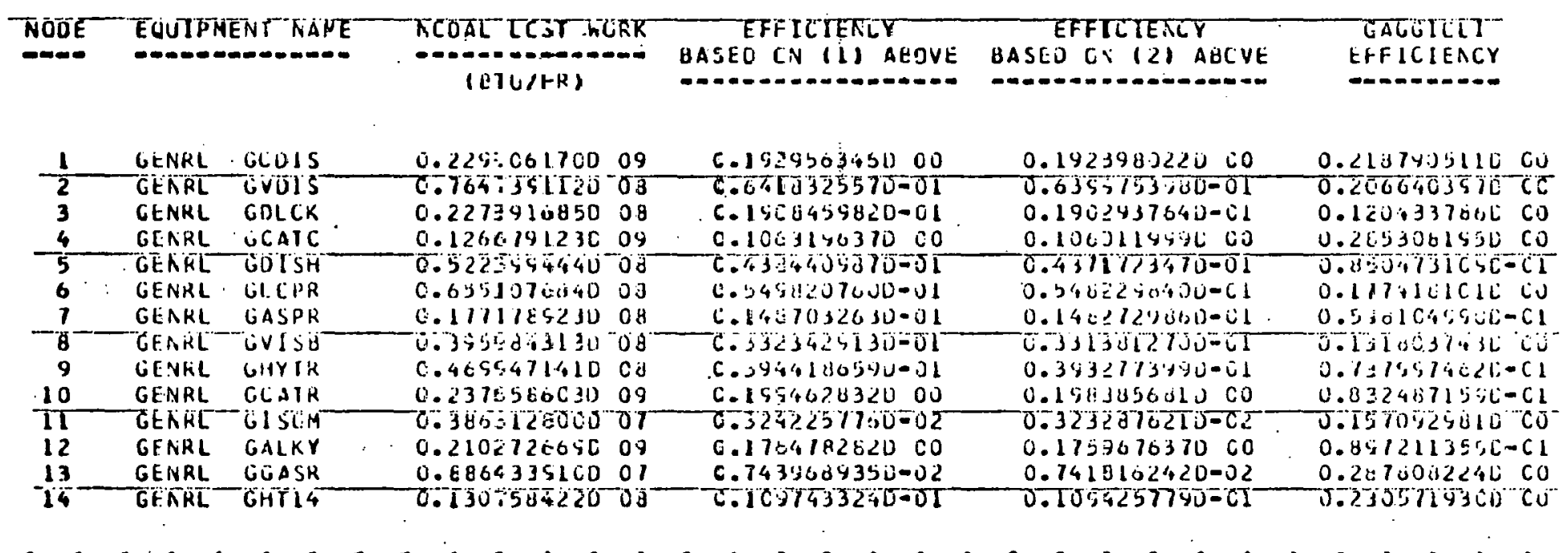


2911 - PETHOLEUM REFININL

AVALLAGILITY ANALYSIS BASED ON DEAO STAIE IEMPERATURE 15.0 DEG .F ANO ATMOSPHERIC PRESSURE I4.G9G PSIA

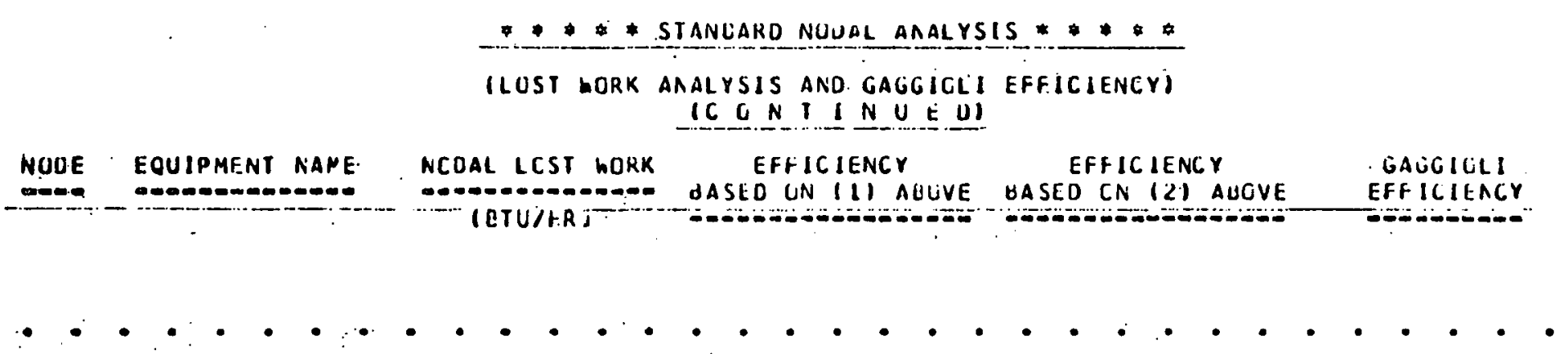




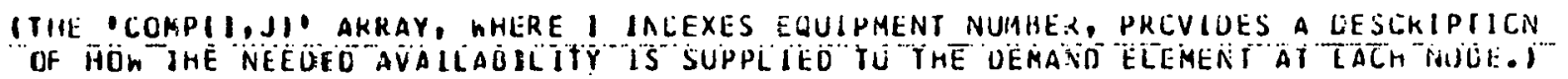

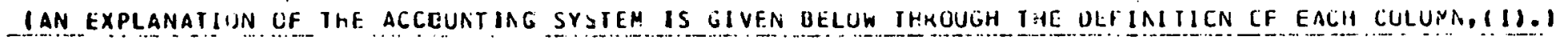

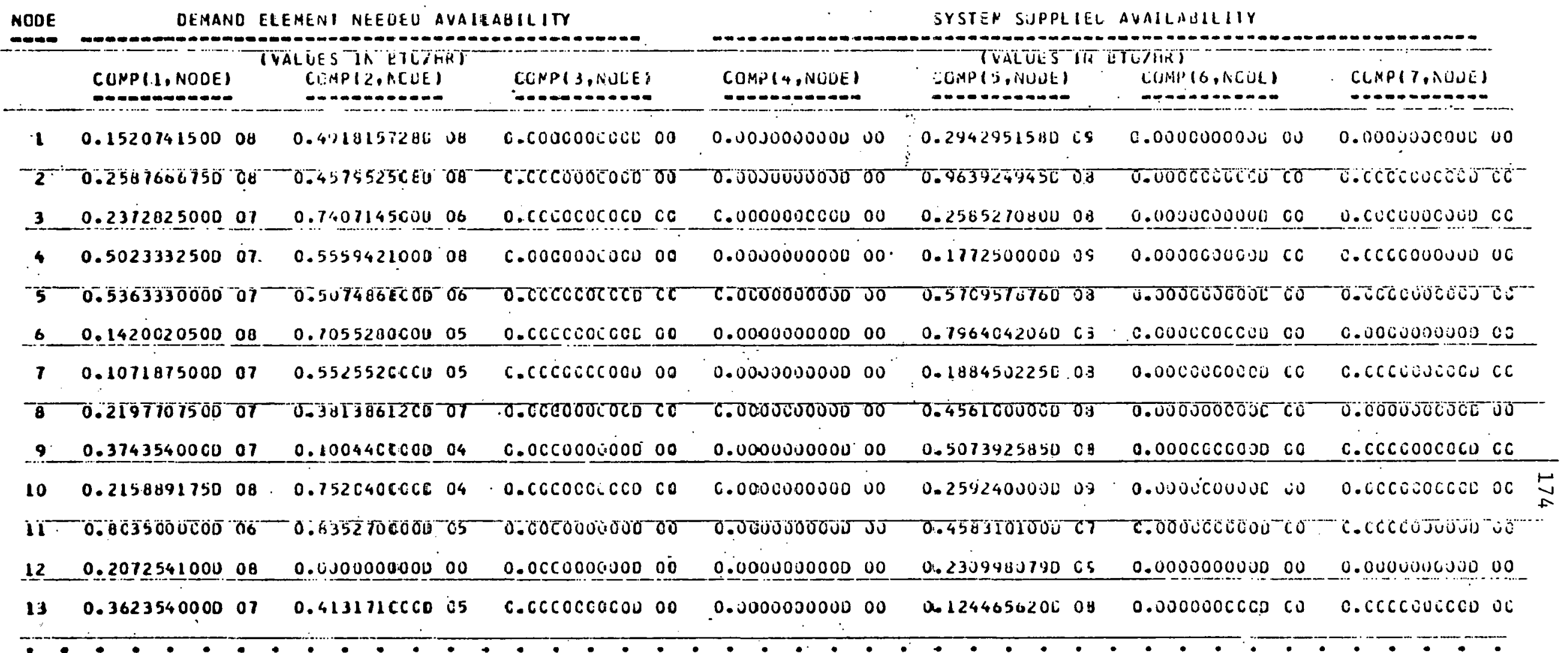




\section{1 - PEIROLEUA REFINING}

AVAILABILITY ANALYSIS BASEO ON DEAL STATE IEMPERATURE 15.0 UEG.F ANU ATMOSPHEKIC PRESSURE 14.G9U PSIA

* * * NCOAL UIILILATION ACCOUNTINL SYSTEM * * * * *

ICCAIINUE UII

NODE

SYSIEM SUPPLIEU AVAILAISILITY

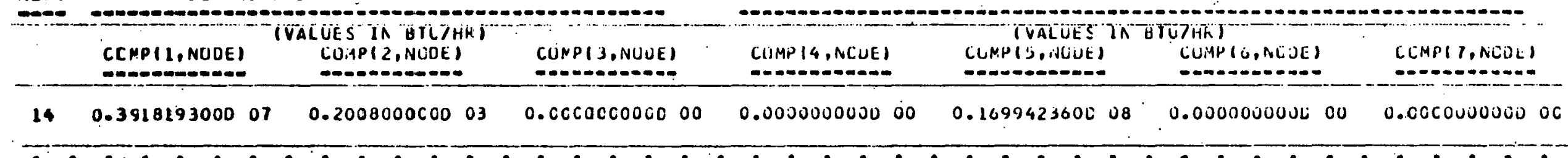




\section{$2711-$ PEIROLEUN REFINING}

AVAILABILITY ANALYSIS BASEO OA JEAD STATE TEMPERATURE 75.0 DEG F. AHD ATMCSPHERIC PRESSURE I4.6S6 PSIA

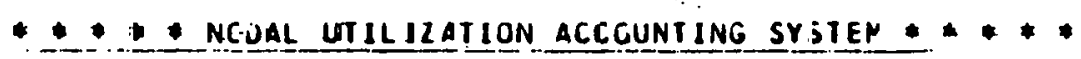

OEFINIII ON OFCOLUMN HEADINGS

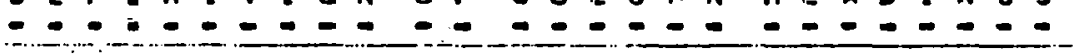

IN THE PROCESS. II ISESSENTIAL TO KEEP TRACK OF THE AVAILAUILIIY HHICH IS

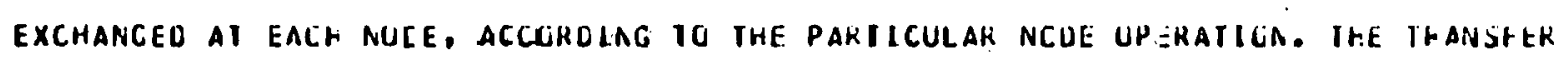

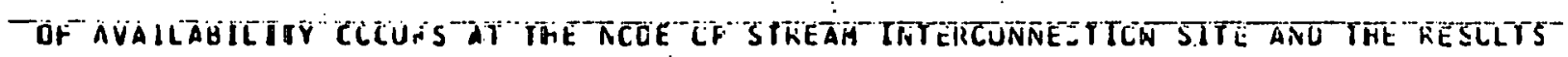
OF IHIS IKANSFER AKE APPAEENI IN THE STATE C.TARGES WHICH CCCUR IN THE AVAILAGILITY

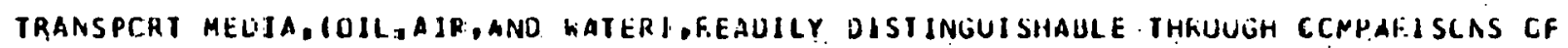

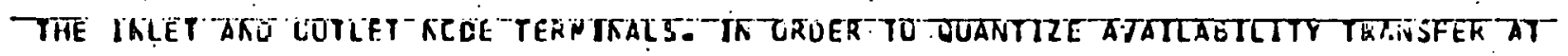
_EACH NCDE. IWJ MAJOK CLISSIFICAIILES OF ACTIVIIY WEKE ESTAU-1SHEU UY GAGGICLL:

IL AVAILABILITY REECEL OY RCCE IL PERF UHA IIS SPECITIZ SYSIEM FUNCTIUIN 121 AVAILABILITY SUPPLIEO TO RCUE TO PHEVIOE CAPACITY IO AECLMPLISH IIS SHECSFTC CPBRTITEC

IN CRDER TO FLRTHER CHAKALTERIZE AVAILABILITY INTGKLHAVGES AT THE MULE, THE

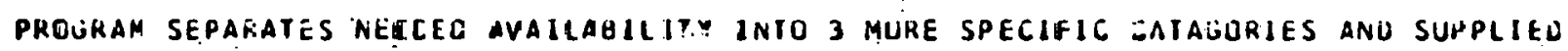

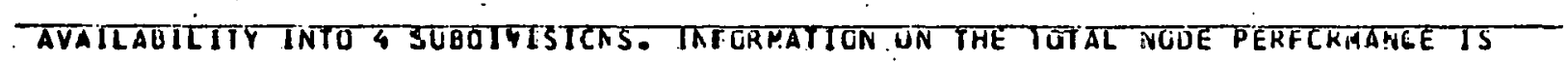
COMIAINEO IN THE ARR AY CCMPI1, I WHERE'J IS THE NCOE HUMUER: $1=1,1$ WIIT PCDIIICAS

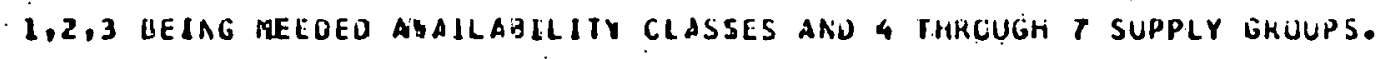

MOHE SPECTETCALCY, EXACT CCLUHN OEFINITTCNS FULLON UN THE NEXT PACE. 


\section{1 - PEIHCLEUM REFINING}

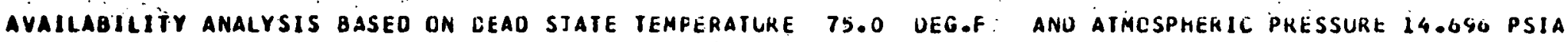

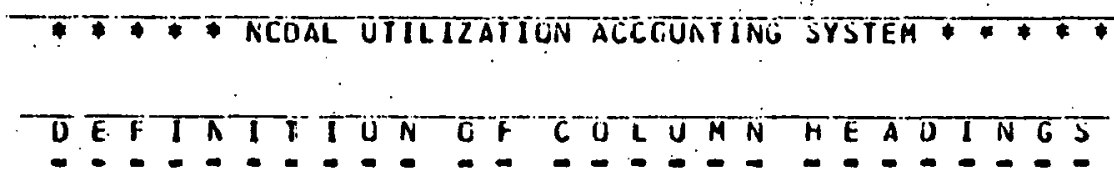

NEECEO ATEATLÄB̈LLITY

COMP(I,NODE) = AVAILABILITY. IC BE DISCHARLEC FRUM IHE PHUCESS WITH NC FURTHEK

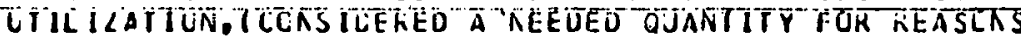

EXPLAINEC ELSERTERE).

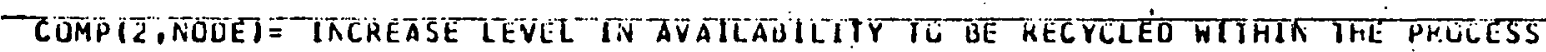
CUE TC BOUNDAKY SLPPLY CF AVAILABILITY

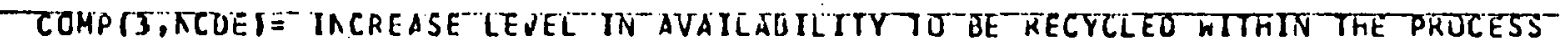
LUE IC RECICLE SLPPLY UF AVAILABILITY.

SUPPLIERTAUATLARILITY

CUMPIG ONCUE)

CUMP(4.NCUE) = RECYCLEU AVAILABILITY JUPPLIEU TO THE NUDE TO BE CASCADEU WITHIA THE PKCCESS.

COMP(5.NUDE) = GLUNUARY LIMITS AVAILAUILITY SUPPLIED TO THE NUUE TO bE CASCAUED TITHIA IFE PRCCESS.

COMP(G,NUOE) = RECYCLEU AVAILABILITY SUPPLIED TU THE NUUE TO UE DISCHARGED FKUM THE PROCESS hITH NC FURTHER UTILTLATION.

COMP(T, NCUE) = BGUNUARY LIMITS AVAILATILITY SUPPLIEO TO THE NOUE TO GE DISCHARGEO FRCA THE PRCCESS WITH NC FURTFER UTICILATICK. 


\section{1 - PEIROLEUM REFINING}

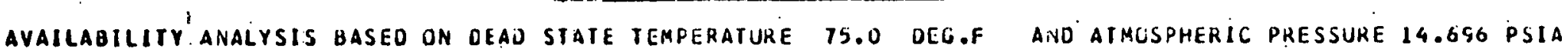

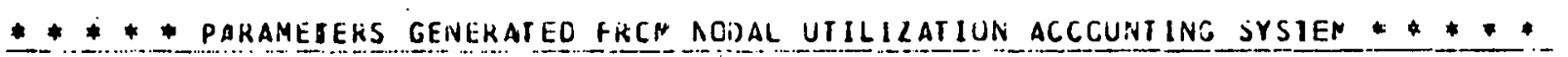

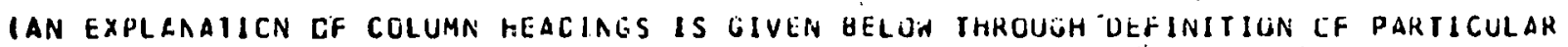
PARAMETERS AS DERIVEC FRCM INFCFMATICN COIITAINED IN THE CCMP AKRAY.H

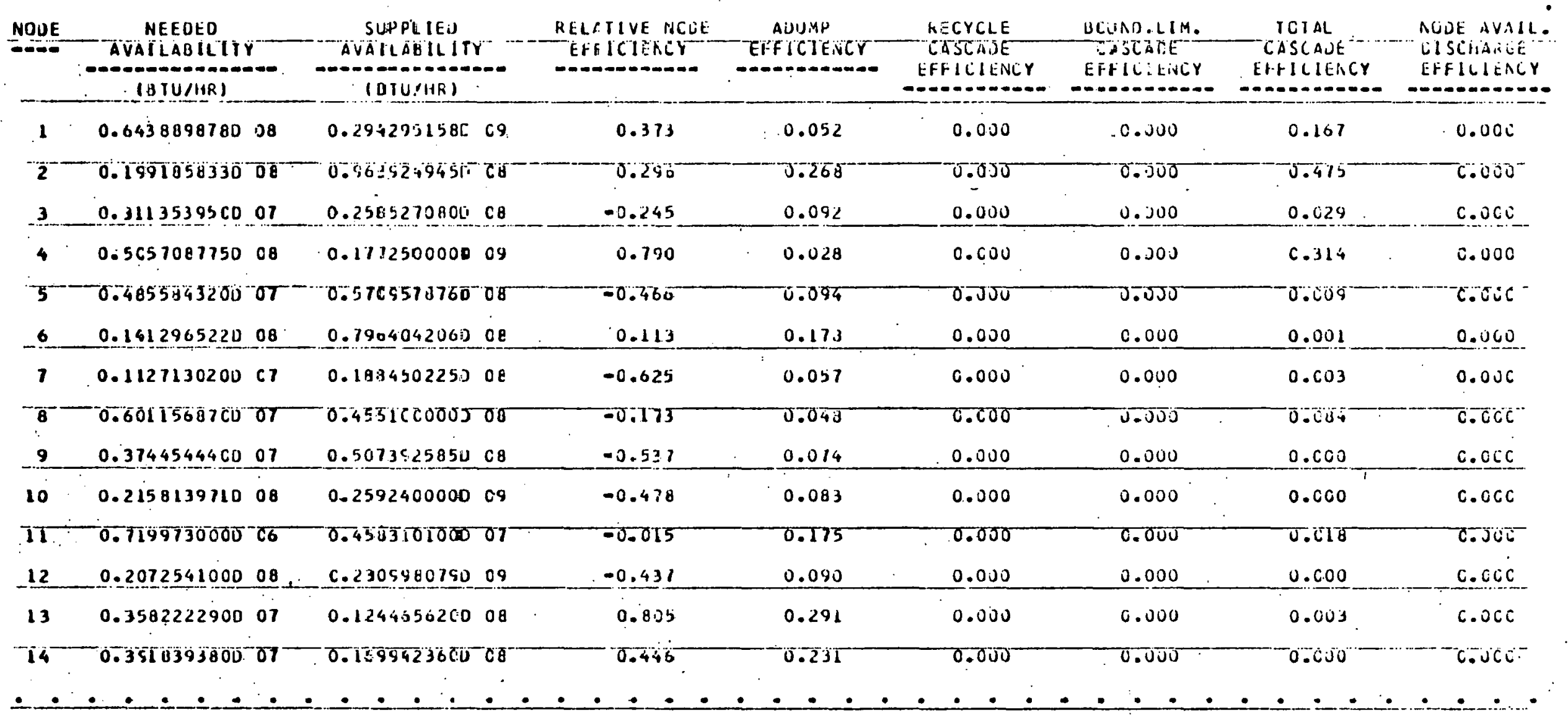


2911 - PEIROLEUM REFINING

AVAILABILITY. ANALYSIS GASED ON CEAD. STATE TEMPERATURE 75.0 DË̈.F ANO ATMUSPRERIC PRESSURE I4.G9U PSIA

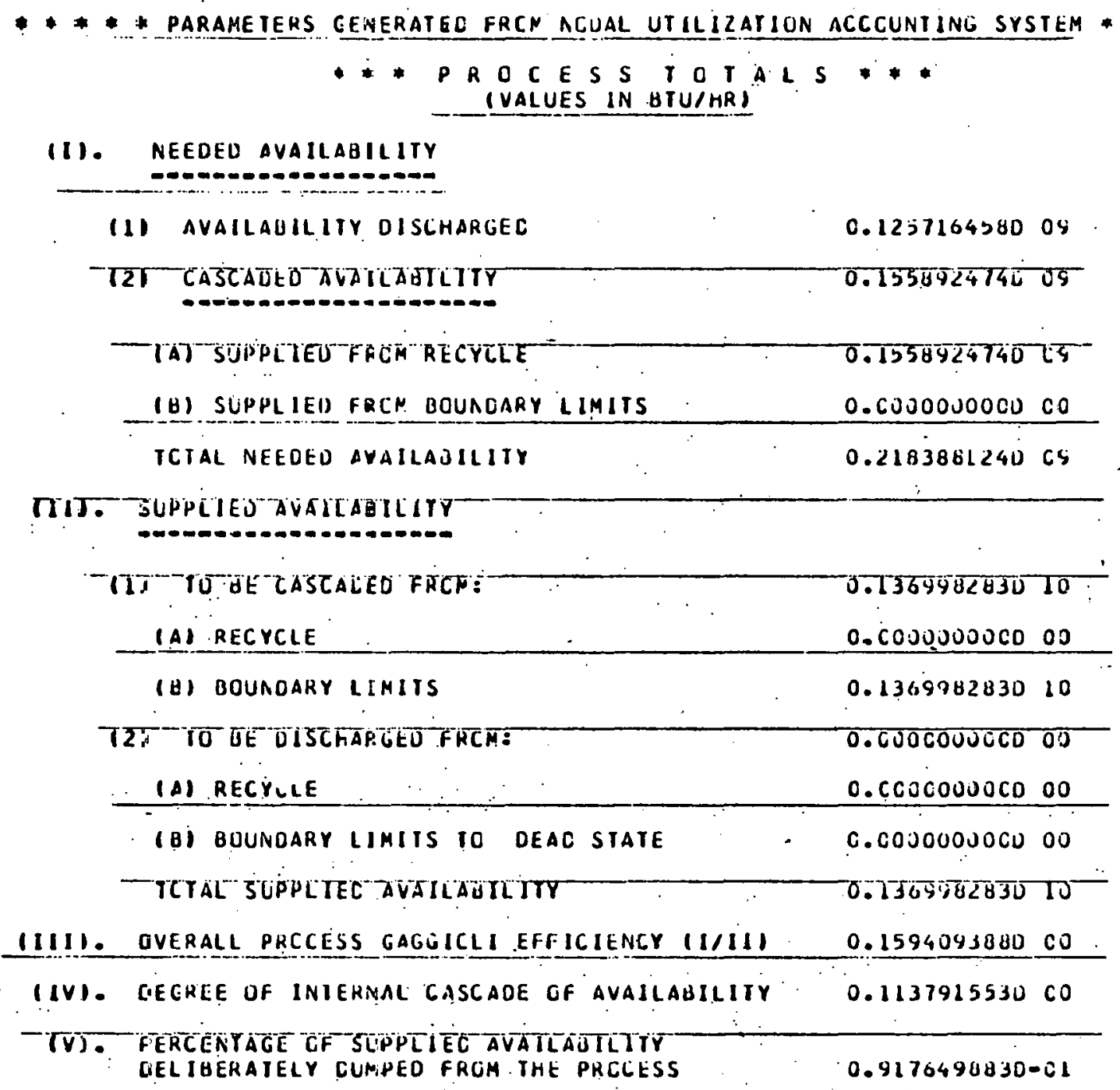


II NEEÓED AVILABILITY - THE AVALLABILITY heUUIKED JO PRUUUCE THE DESIRED STATE

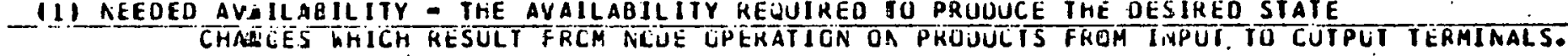

\section{* cualifications * *}

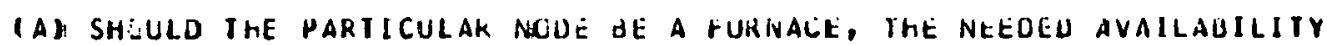
ICCNPI8,NOUEII hILL INCLUDE AIR STATE CHANCES. STACK GAS IS GNLY

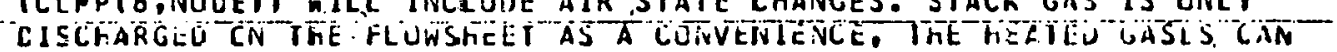
EE UTILIZEO TO IACREASE PRCCESS GAÜLOLI EFFiCIEACY AIN UECREASE LUST WCRK.

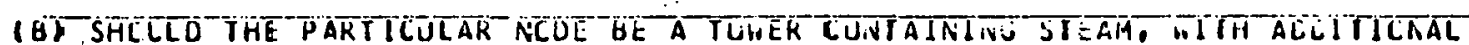

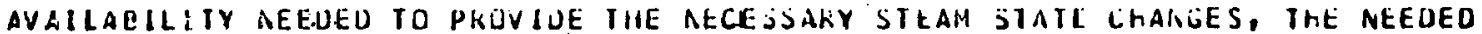
AVAILAUIL:TY (CCNP(B,NLDE)) WILL INCI DLC TIAE SUA CF S.LMPIL-L-J,ACOEI.

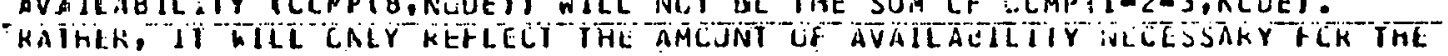

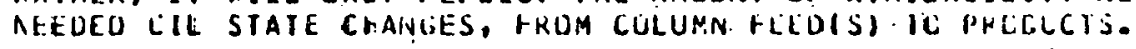

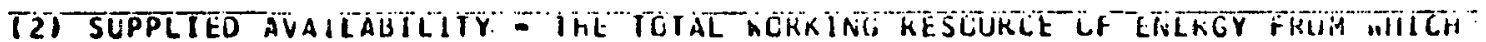
SUFFICIEAT UUANTITIES ARE KEMUVED FCK PHUVISILN UF. IHE NEELLU AVAILABILIIY.

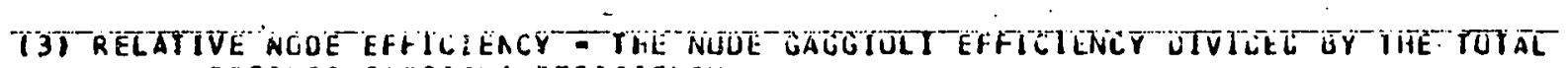
PRCCESS GAGGIBLI EFFICIENCY.

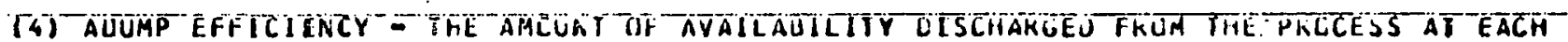
NOEE DIVIUED SY THE IOTAL SUPPLY UF AVAILABILITY TU TH:AT NCUE.

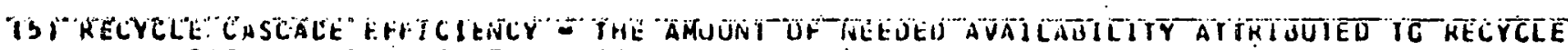

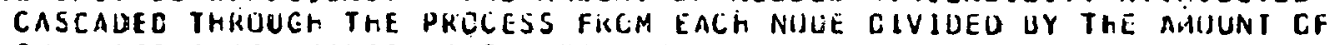
SUL_LIEC AVAILAdLIIY FKCM RECYCLE TU IHAT NOUL.

(6) BEUNDARY - IMITS LASLALE EFFICIENCY - IHE AMUUNT OF NEEDEU AVAILAUILITY ATTRIBLIED IJ HOUNDARY LIMITS CASCAOEU IHRLUGh THE PRUCESS FhGM EALh NILE CIVIUKC UY IHE

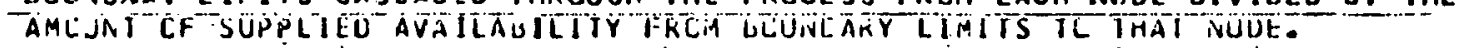

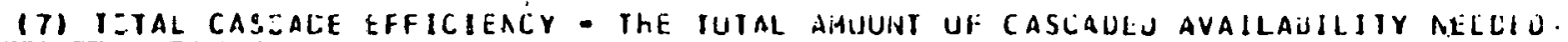

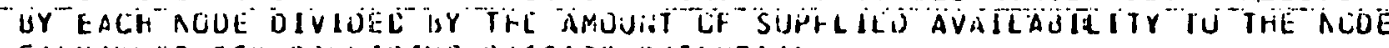
EAT:MAKLEC FCK PALVILENG CASCADE PLILNTIAL.

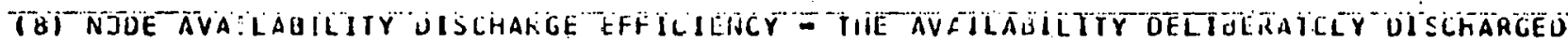
FRLM EACH NCOE 10 ITE CEAO SIAIE UIVIJEU EY IHAT PCKIILA CF UGIH KECYGLEO ANC BULNLARY LIMITS SUPPLIEU AVAELABILITY. 
3241 - Cement, Hydraulic

(Portland Cement)

\section{Process Description}

The manufacture of cement requires extensive use of electro-mechanical unit operations in the handling and processing of solids and slurrys. In the Portland Cement process selected, limestone, sand and clay are crushed, ground, kiln heated to create clinker material which is subsequently cooled and mixed with gypsum to produce Portland Cement. To orient the reader to the availability flows associated with a field facility of interest in today's economy, stream data were created for a plant sized to manufacture 750,000 tons of cement per year.

As can be noted from inspection of the process flow diagram, each unit has an electricity input, and the processing sequence is nearly linear, Indicating that anticipated overall process Gagiolli efficiency should be quite high.

\section{Process Ideal Work Basis}

As with paper processing, in order to determine the minimum ideal isothermal work necessary to produce a unit of product from proportionate raw materials, a detailed chemical/physical equilibrium model is required of the system, parcliculasly llab eleüent in both the wet and dry train Identfled as the kiln. (A guvd description of the actual opcration of the kiln in achieving its function along the process path is provided

elsewhere. (5)) To provide such a model (which would necessarily be limited by the scope of this study) requires better definition of the phenomenological behavior of the system than can be presently achieved with the quality and 
avallability of system thermodynamic data. Again, therefore, the simplistic modeís already presented for a specific Portland cement formulation (5) were used. The associated minimum isothermal work is approximately 400.0 Btu of availability/pound of product. Again, to respect that availability transfer Is limited from non-dead state to dead state sink conditions or other sink conditiuns, the process efficlency can never reach such value, however, it . may approach some other value, namely that for a carnot engine, the ideal actual work of production was based on a ćarnot efficiency engine, performIng to provide the ideal work required.

\section{Process Efficiency}

The lost work efficiency of the overall process based on the ideal 1sothermal work is $28.2 \%$ The same efficlency based on the actual work is 32.8\%. It would seem that these efficiencies are substantially below expectation, however, as w1ll be described, because the majority of the process lost work is assoctated with the kiln operations, the process efficlency is more nearly that expected of thermal separation processes. than, say, that of exo/ endothermic systems, and electrical processing, such as the Primary Aluminum and Chlorine Cell Systems.

The total lost work of the Cement Process considered is 193.2 million Btu/hr or approximately 1020 Btu of lost work/pound of throughput.

IV. Major Lost Work Unit Operations

This type of analysis allows focusing of attention in auditing of extsting facilities or designing new facilities on system "bad actors." For the process system reviewed, the following unit operations were major lost work offenders: 
Unit

Wet Side Kiln

Wet Side Kiln Waste Heat Boiler

Dry Side Kiln

Dry Side Kiln Waste Heat Boiler
$\%$ of Process Lost Work

30.7

24.7

11.2

11.2

Uniquely, these units are associated with the only process energy loads provided by the conversion of fossil fuels to avallability supply. These direct contact units, again similar to the direct contact recovery furnace In the paper process, offer the greatest opportunity for process energy utilization improvement. Consideration to better integration of the heat load between each kiln, the clinker cooler for each process. product output, and the waste heat boilers is suggested. Likewise, plasma arc imaging or other high temperature electrical processing may provide attractive alternatives, supported by opportunities for substantive improvements to process energy efficiencies.

\section{Process Efficiency Parameters}

The parameters generated by the nodal utilization accounting system characterize the effectiveness with which supplied availability is utilized (cascader, recycled, etc.) within the process. The overall process Gaggioll efficlency of $68.5 \%$ shows a substantial use of electrictty, while the .. Internal degree of cascade of 1.03 identifles very effective use of supplied avallability (predominantly electricity) within the linear process structure. 


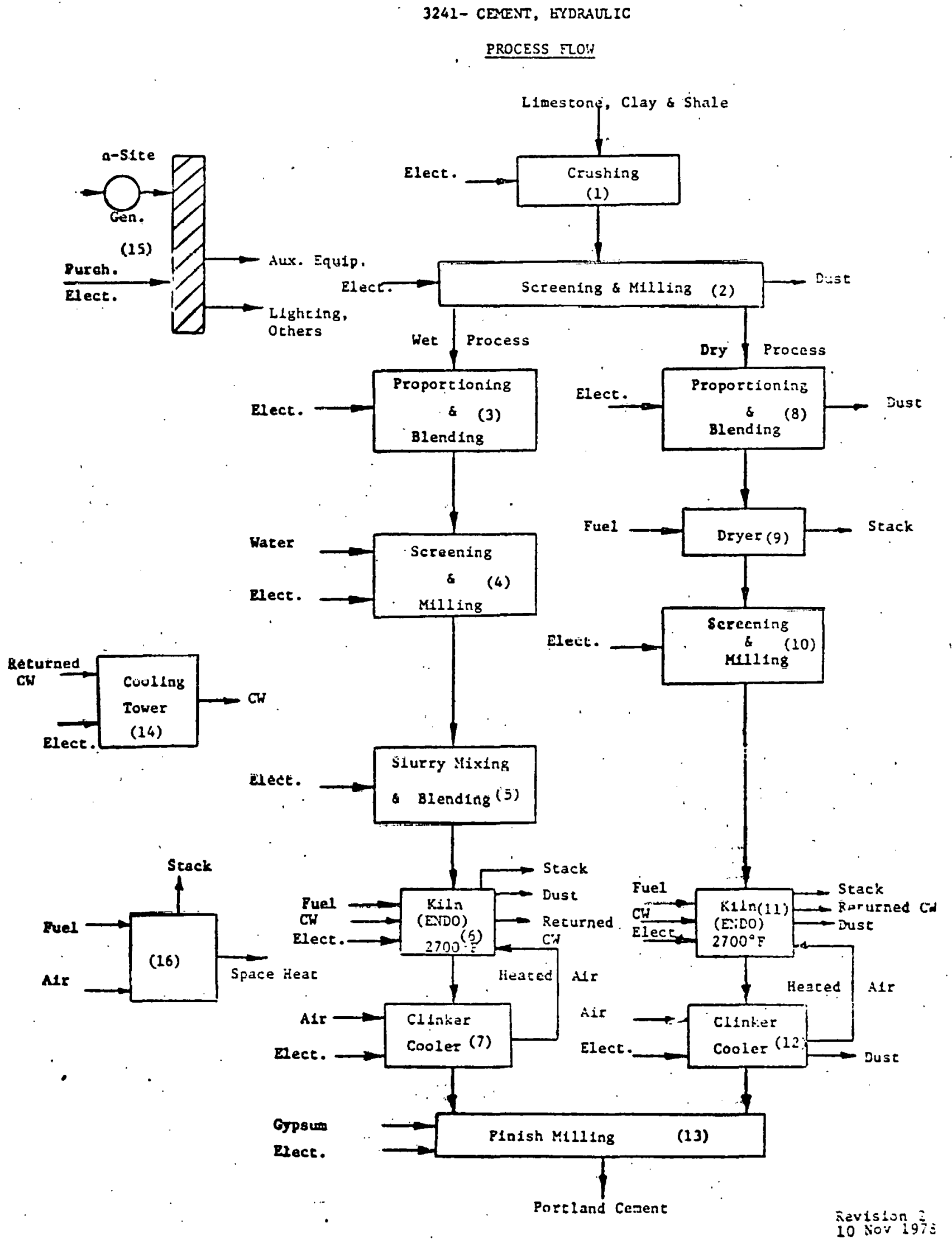




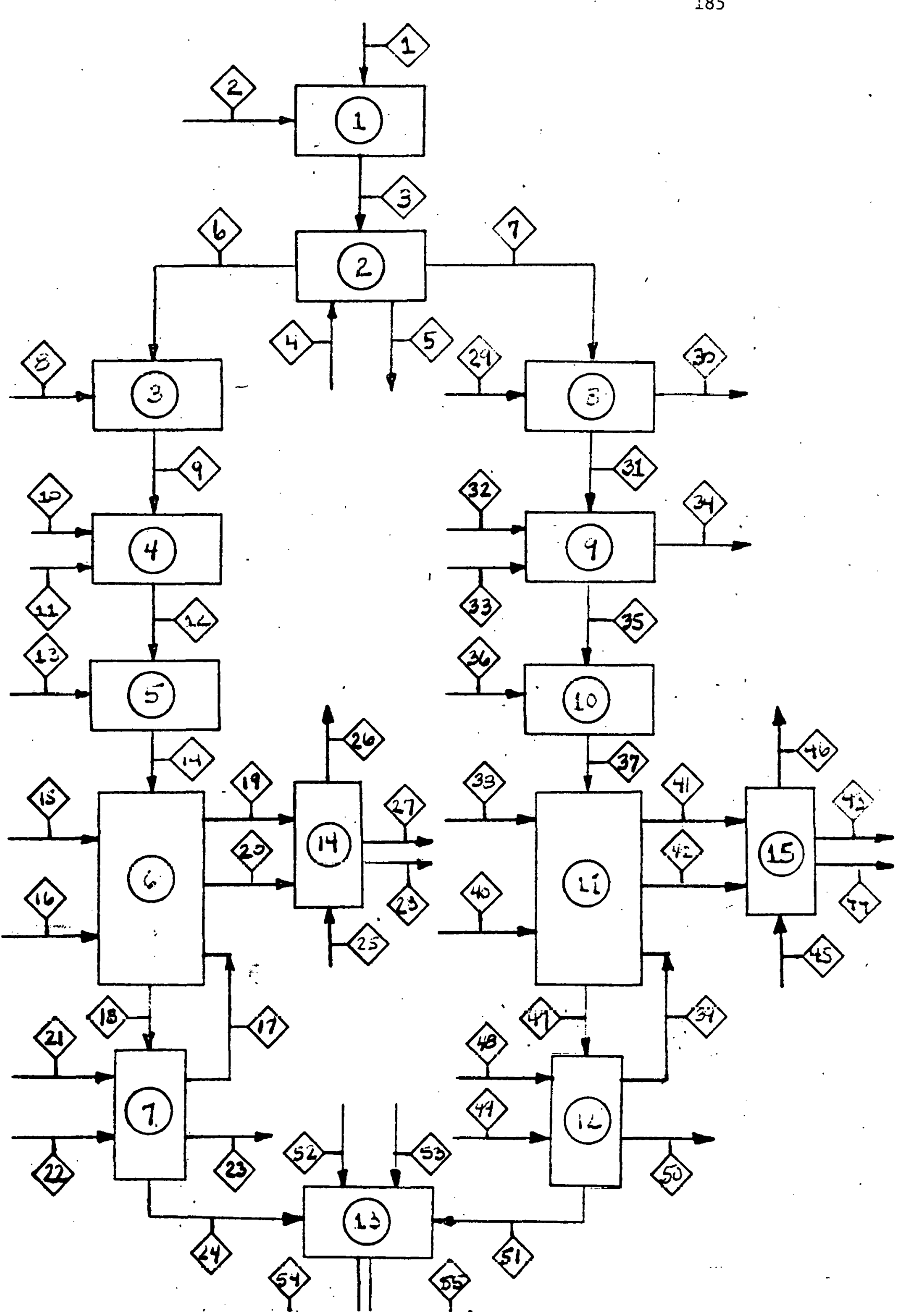




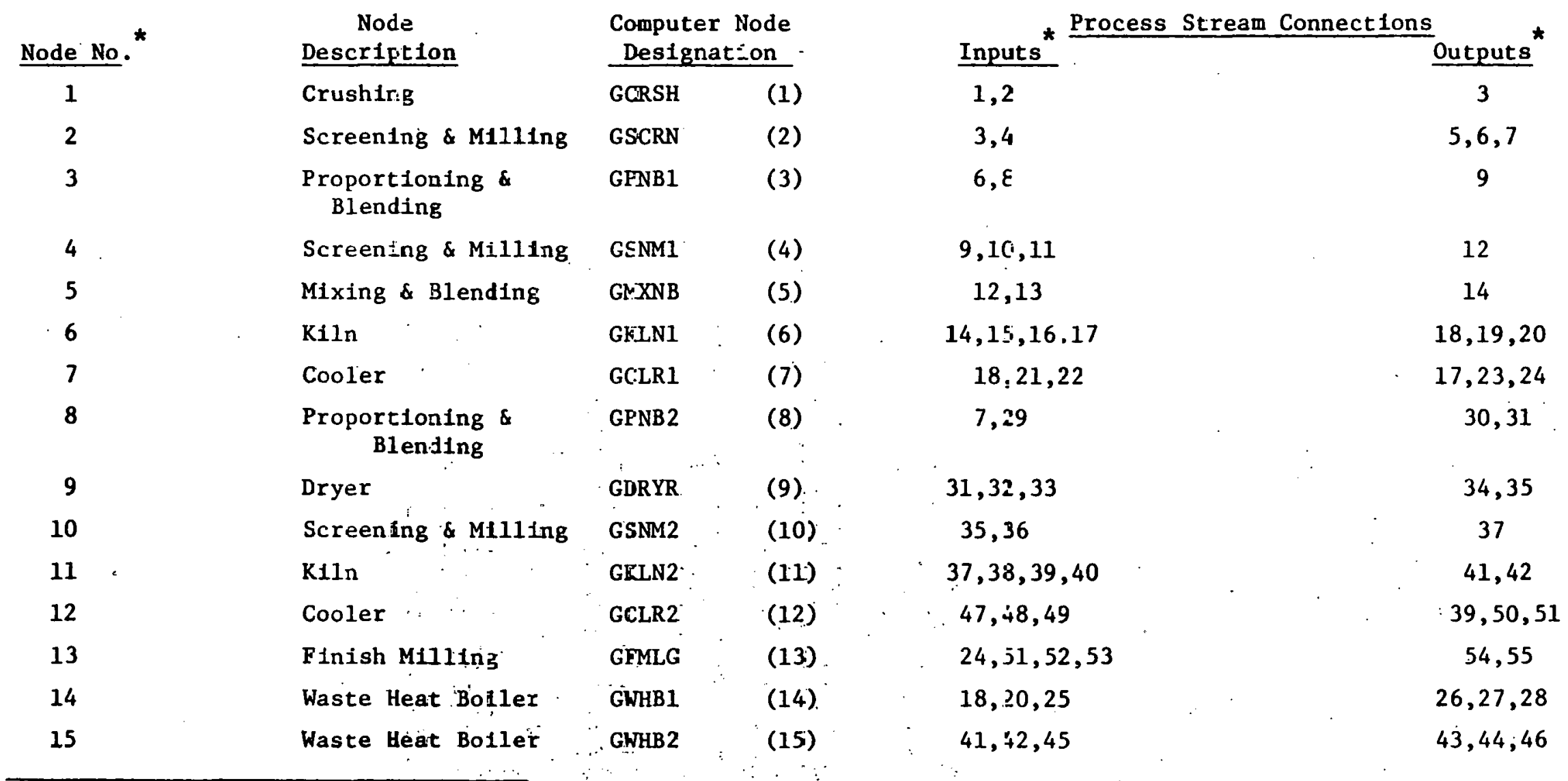

* These numbers refer to those shown on the Cement Process Directed Graph. 


\begin{tabular}{|c|c|c|c|c|c|c|c|c|}
\hline GPNBI & 8.81 & 8.01 & & & & & & \\
\hline GSNMI & 11.21 & 11.21 & & & & & & \\
\hline GHXXAU" & $13.7 \mathrm{i}^{-1}$ & $13 . \mathrm{Cl}^{\circ}$ & & & & & & \\
\hline GKLNI & 14.02 & -18.02 & 17.02 & -19.02 & -20.02 & 15.05 & -16.72 & 16.05 \\
\hline GCLR] & 21.52 & -17.02 & 21.51 & -23.01 & 18.06 & -24.06 & -22.72 & 22.05 \\
\hline$G P N G$ & 29.81 & 23.01 & & & & & & \\
\hline CLIRYR & 33.01 & -34.01 & 31.02 & $-10.0 \%$ & 32.05 & & & \\
\hline GSNM.2 & 36.71 & $36 . c 7$ & & & & & & \\
\hline $6 K L N_{2}$ & 31.02 & $\because 41.02^{-}$ & 39.027 & $\because 45.02$ & $-=42.02$ & -38.05 & -40.72 & 40.05 \\
\hline GCLLRZ & 49.42 & -39.02 & 49.61 & $->0.0 .1$ & 47.06 & -51.00 & -48.72 & 48.05 \\
\hline GF MLG & 52.71 & 52.07 & & & & & & \\
\hline - Gülig1 & -25.02 & $-2 \epsilon .02$ & $17: 00$ & $=27.06$ & .20 .00 & -28.06 & & \\
\hline GWHB2 & 45.02 & -46.02 & 41.06 & -43.06 & 42.06 & -44.06 & & \\
\hline
\end{tabular}


AVAILAHILIIY ANALYSIS HASED ON DEAD STATE IENPERATURE 75.0 OEG.F AND ATMOSPHERIC PRESSURE 14.696 PSIA

* * sinñotro nudal tanalysis

(LOST HORK ANALYSIS AND GAGGIOLI EFFICIENCIES)

PROCESS PARAMEIEIIS:

(1) IWEAL ISOTHEFMAI WCRK OF SEPARÄTION

0.7600000000 .08 BIUS/HR

(2) TIEEAL ACTUAL hCRK CF PRONUCTIOK

0.942400000D 08. BTUS/HR

(3) TIINL PROCESS I.OST HORK

0.193162337009 BTUS/HR

PROCFSS FFFICIENCY:

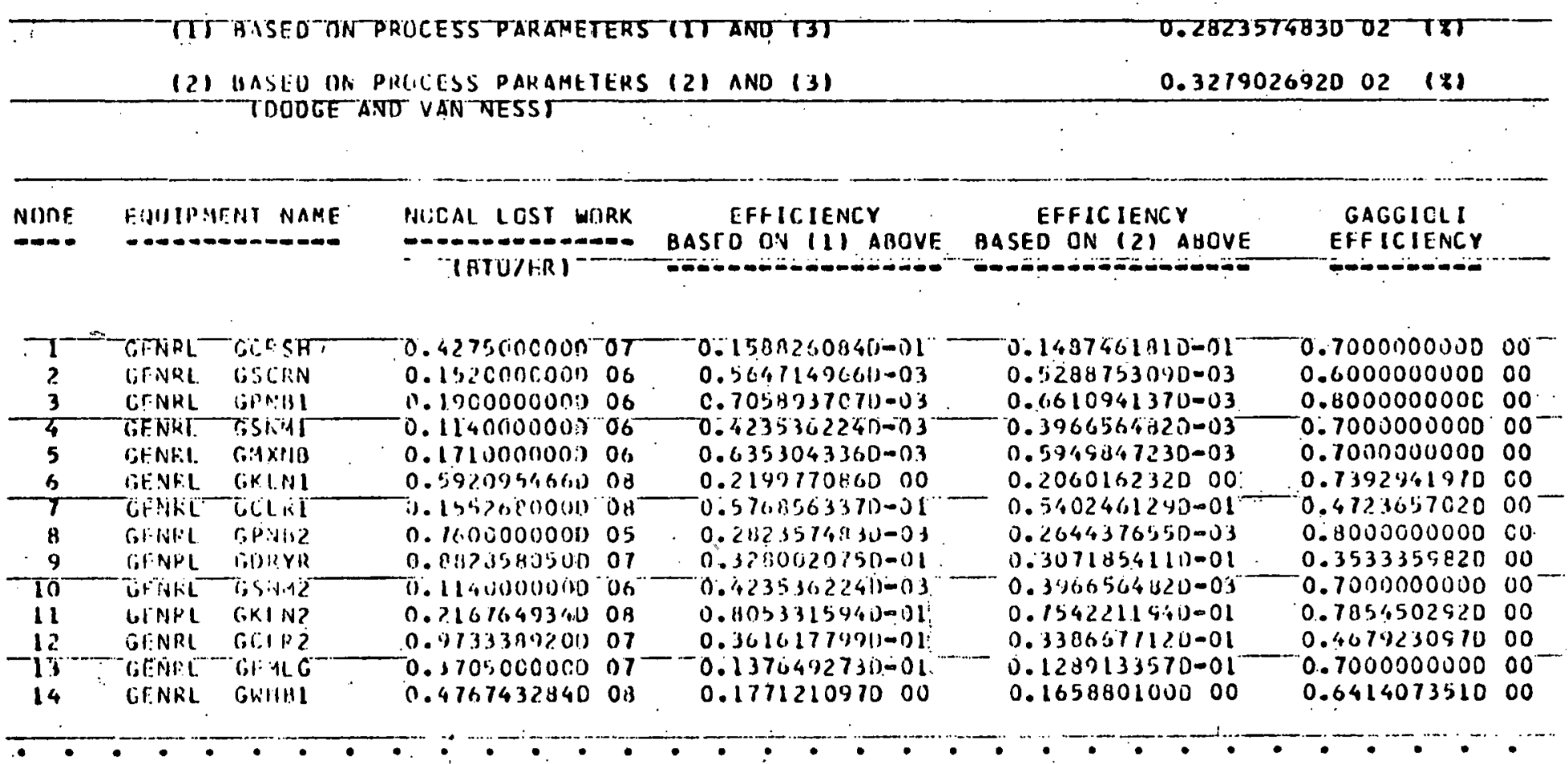


उ2दा - CENENT. HYOR GUCTC

AVAILAHILITY ANALYSIS BASEO OH DEAD STATE TEMPERATURE 75.0 DEg of ANO ATMOSPHERIC PRESSURE 14-696 PSIA

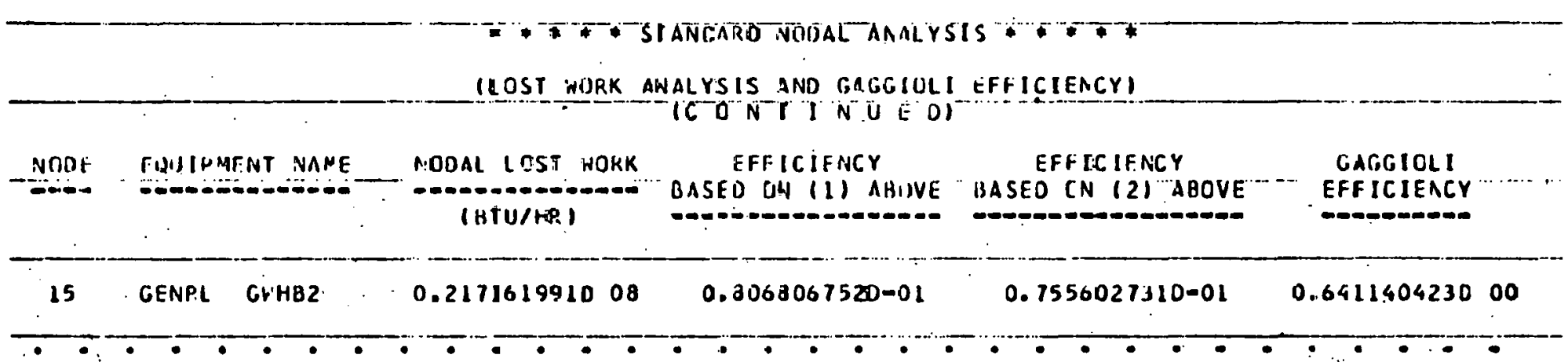




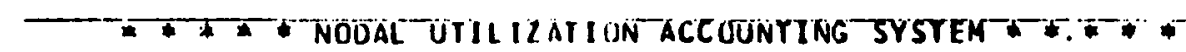

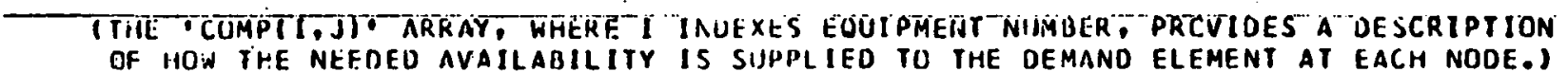

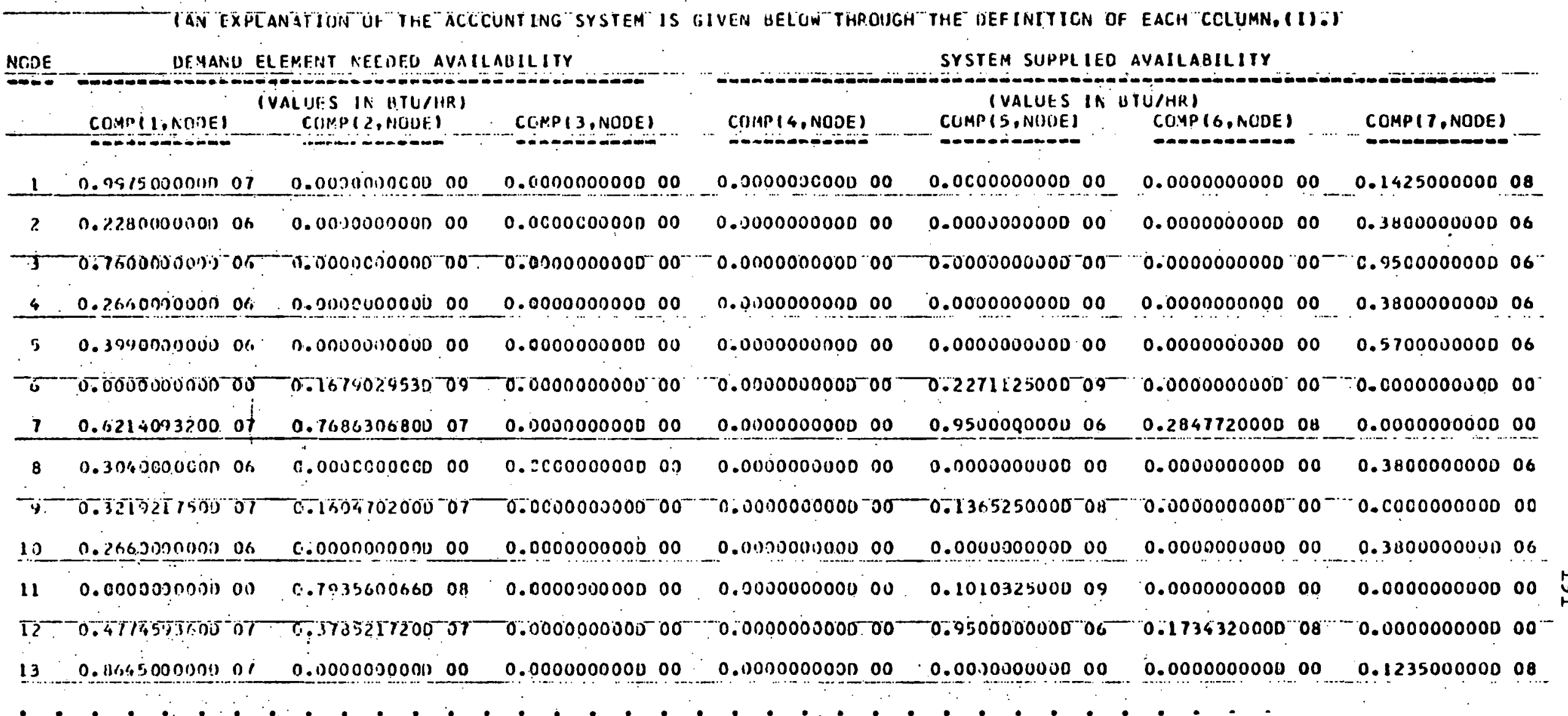




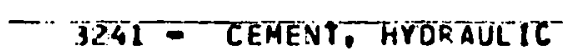

AVALLABILITY ANALYSIS BASFD ON DEAD STATE TEMPERATURE 75.0 DEG.F. AND ATMOSPHERIC PRESSURE I4.696 PSIA

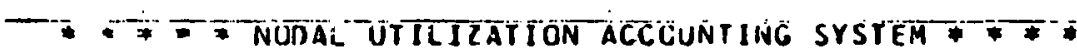

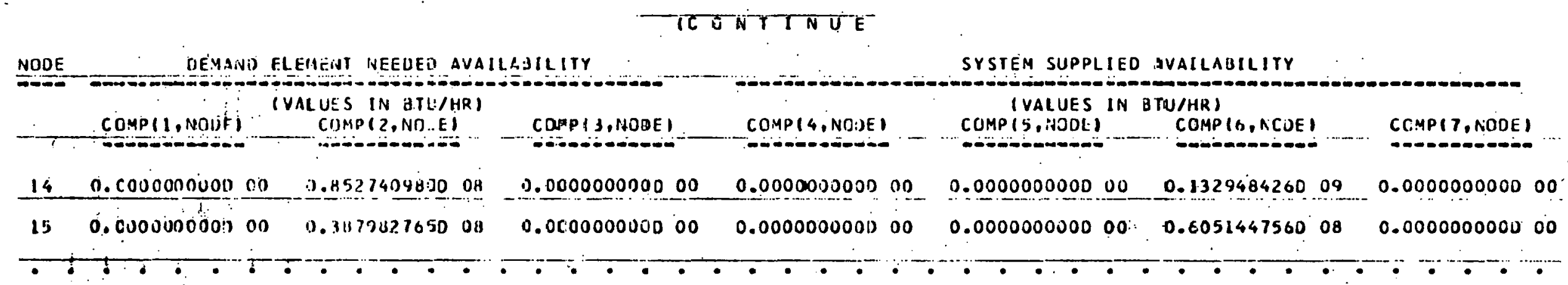


$3241-$ CEMENT, HYTORAULTC

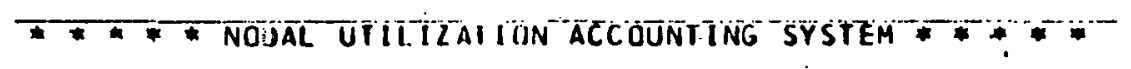

DEFINITIONOOF COLUUMN HEADINGS

TN THE PRIICESS, IT IS ESSENTIAL TO KEEP TRACK OF THE AVATCABILITY WHTCA TS

- FXCIIANCFD AT EACH AUDF, ACEORDINL TO TIE PARIICULAR NDDE OPERAIION. THE TRANSFER

OF AVAILAOII.tTY CICCURS AT THE NCUE IJR STKEAM INTERCONNECTION SITE AND THE RESULTS

UF THIS TKAKSFER ARE APPARENT IN THE STATE CIANGES WHICH OCCUR IN THE AVALLAILITV

THANSPORT MEOIA, IOIL,AIR, ANO WATFRI,RFAOILY OISTINGUISHABLE THROUGH COMPARISONS CF

TIIE INLFT NONG CUTLET NCDE IERMIAALS. II URUER TO QUANTILE AVAILABILITY IRANSFER AI

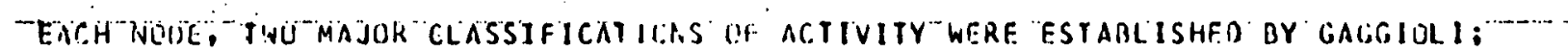

(L) AVAILABILITY NEEDFO BY NRIUE TIJ PERFOKM ITS SPECIFIC SYSIEM FUACTION

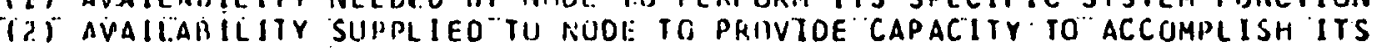
SPECIFIC UPERATICN

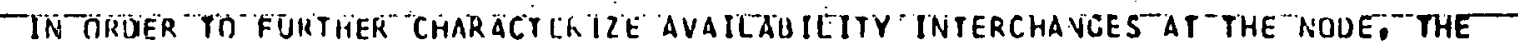

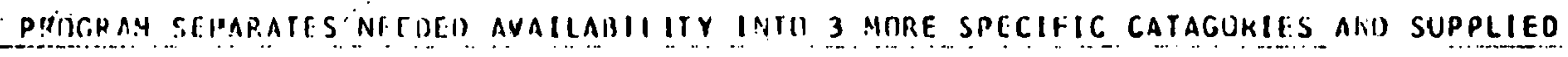

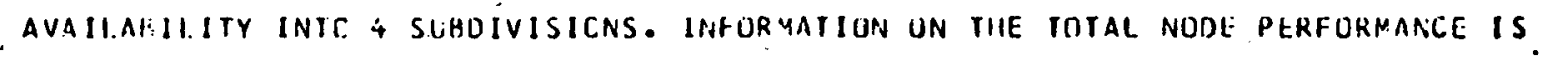

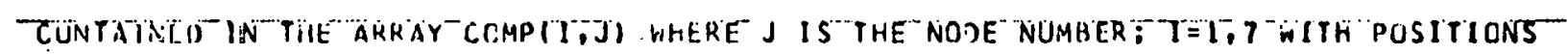
1.2:3 HEING NEEDEO AVAILAUILIIY CLASSES ANO 4 THROUGH 7 SUPPLY GROUPS.

MLiRE SPEC.IFICALLY, EXACT CCI.UNN DEFINITIUNS FULLUW ON THE NEXT PAGE. 
$324 T=$ CEMERT, HYORAULTTC

AVAILABILITY ANALYSIS BASEO TN DEAD STATE TEMPERATURE

75.0 DEG .F

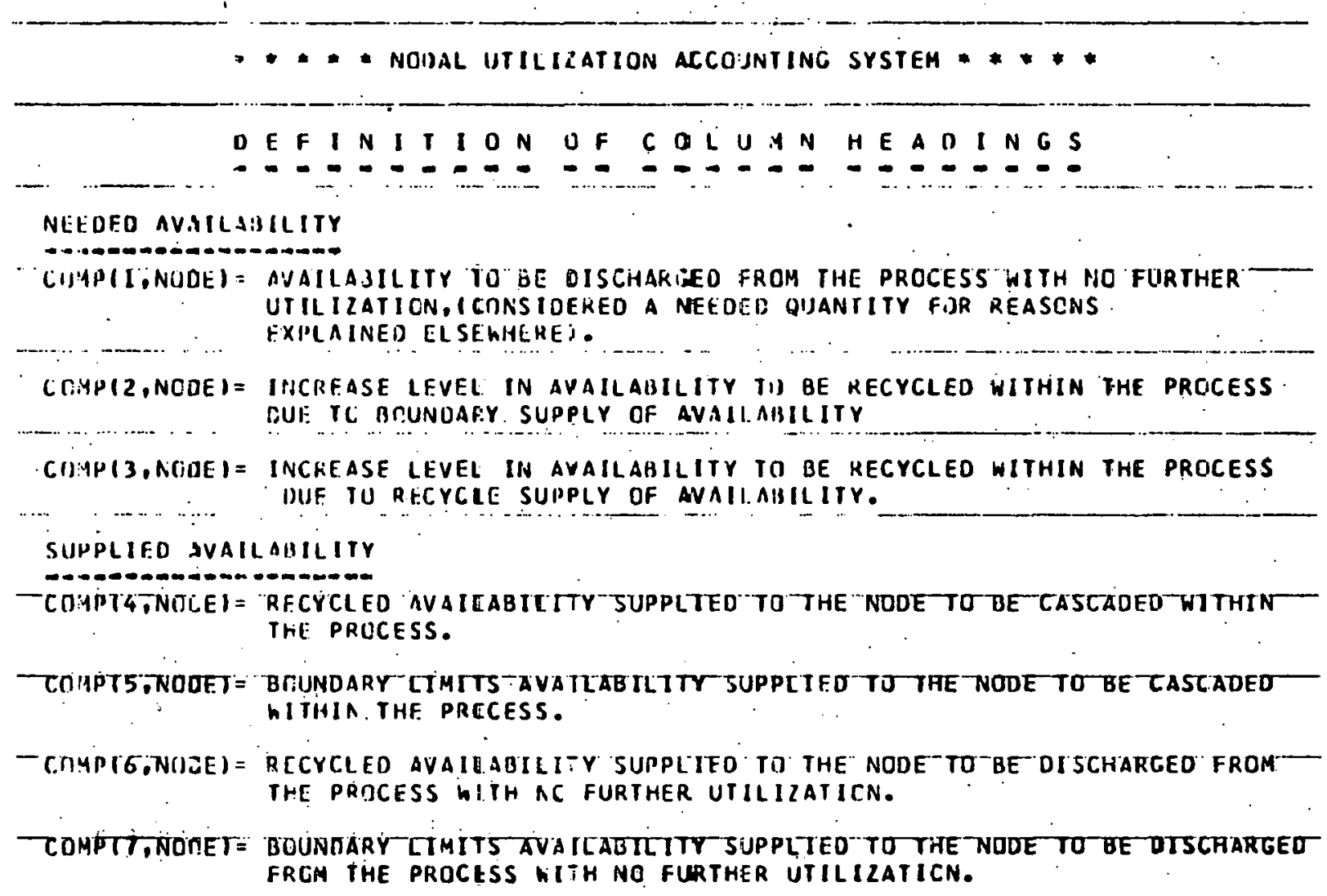




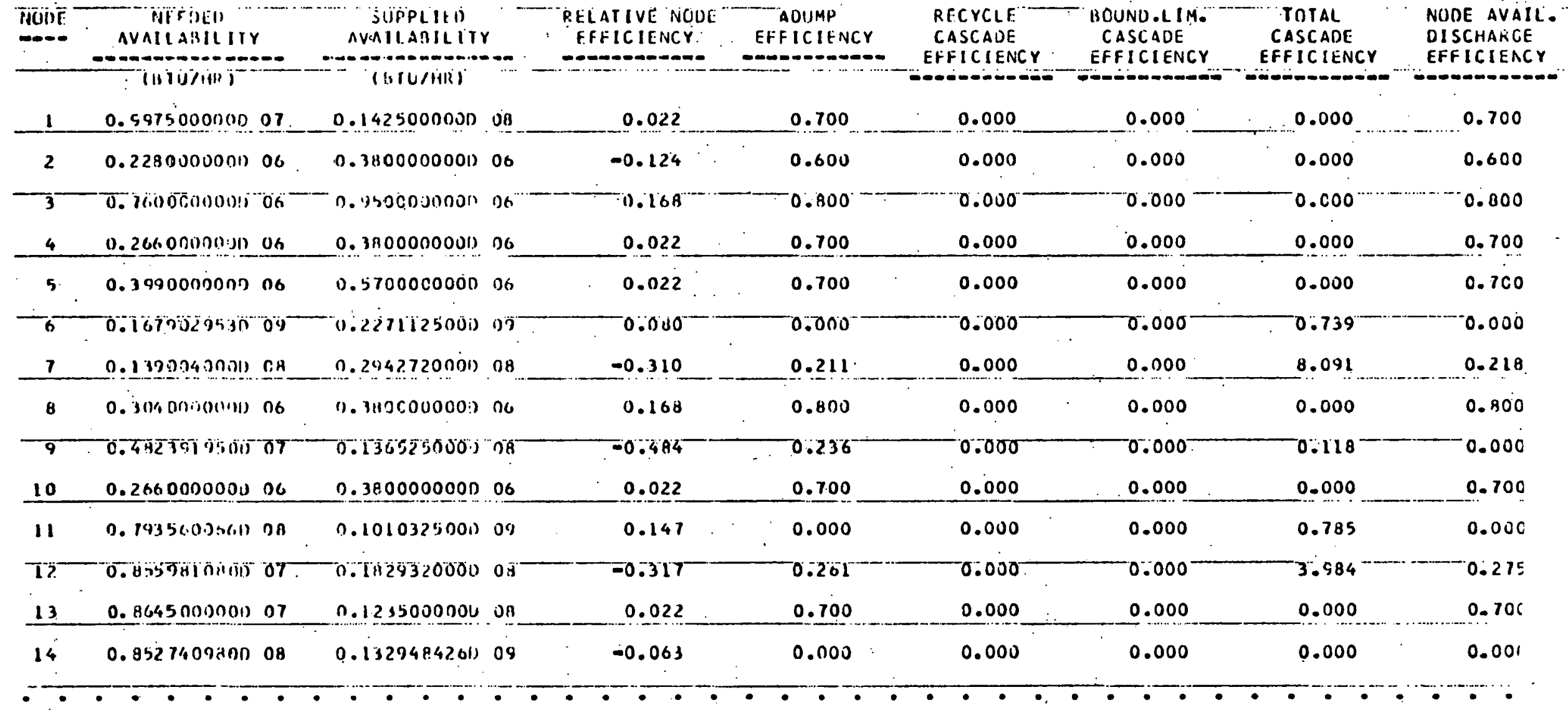




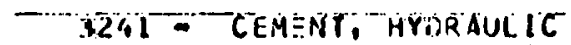

AVAILAHILITY ANALYSIS BASLD ON DEAD STITE TEMPERATURE TS.0 OEG .F ANI ATMUSPHERIC PRESSURE 14.696 PSIA

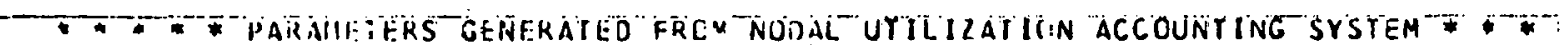

IC $\approx N \cdot T \mid N \|$ III)

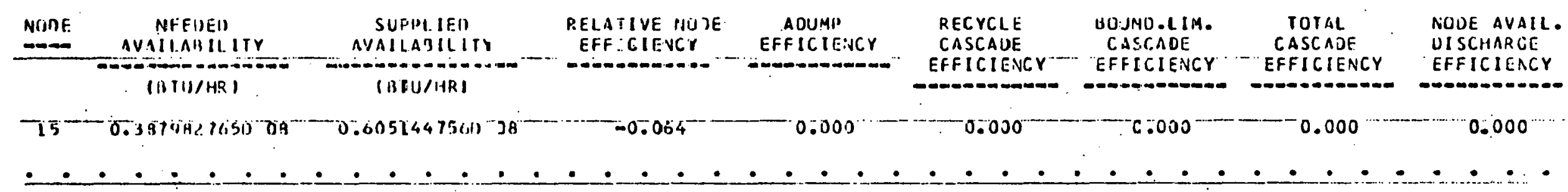


32दा - CERENT, HYORAUIC

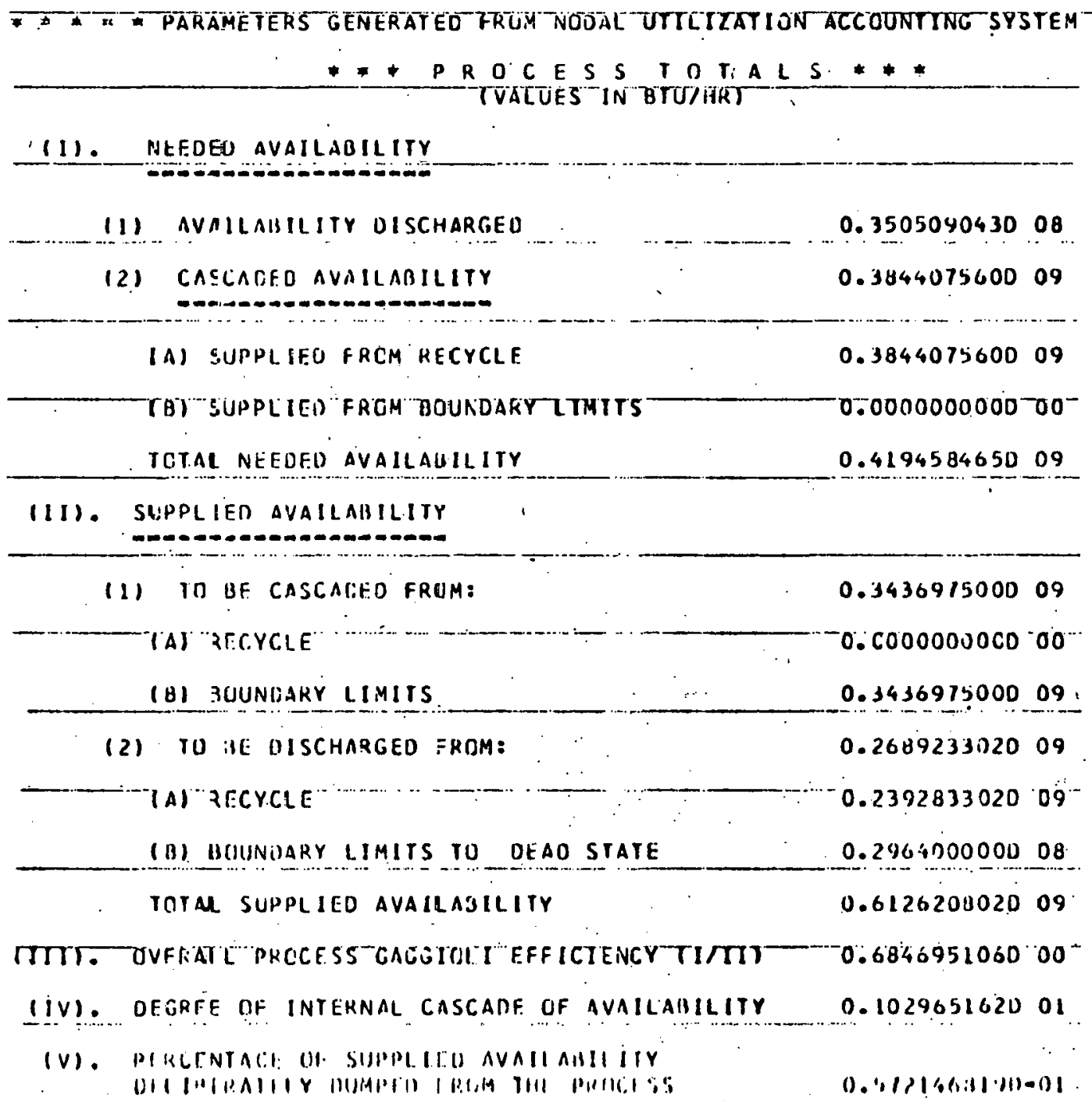




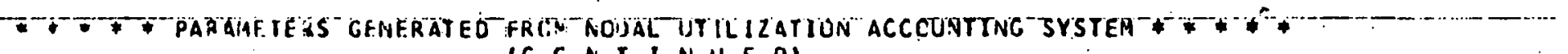
(C C N T I N.II E D)

CI:LUMN HF ADIAG"DFFIAT I ICMS:-

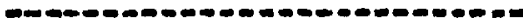

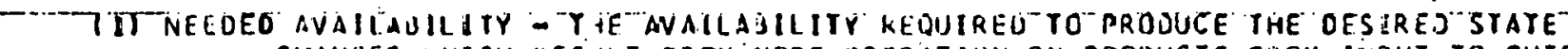

CHANGES WHICH KESJLT FROM NCRE UPFRATIUN ON PROUUCTS FROM INPUT TO CUTPUT TERMINALS.

- DUALIFILATIENS

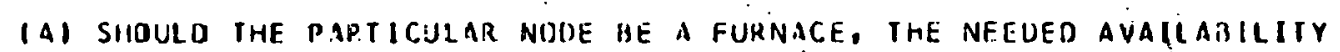
(CGNP(A,NOUE)I WILL IACLUDE AIR STATE CHANGES" STACK GAT IS OALY CISCHAHGED CN THF. FLISWSHCE AS A CONVFNIENCE, THE HEATED GASES CAN ME UIILILEO TO INEREASE PRCCLSS CANGGIOL I EFFICIENCY AND IBCHEASE LOST WORK.

(B) SHOULU TIIE PAETICJLAR NUUE BE A TOWER CCNTAINING STEAM, WITH ACCITIONAL AVAILABILITY HE(UIF) IO PIIJVIDP. THE NICESSAKY STEAM STATE CHANGES, THE NEEDED AVEILAUILITY :CQPD(B, NIODE) WILL NCT BE THE SUY CF CCNP(L-2-3, ACOE). HAIHER, IT WILL IUY RTFLFGT THIF AMUUNT CF AVAILABILITY NECESSARY FCK THC AE[DFD I]LL STAIE GHAWGES, HRIY COLUIAN FFEDISI TO PYOUUCTS.

(2) SUPPLIED AVADLABILIIY - THE TOTAL WIRKI IIG RESCURCE OF ENFKGY FROM WHICH SUFFIC. BENI CUANIIIIES ARE REMUVIED FIR PHUVISION OF THE NEEDED AVAILABILITY.

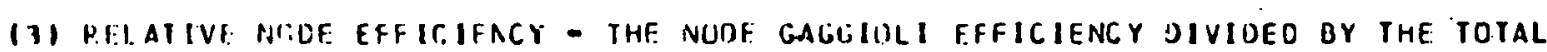
PFCCESS GACLICLI EFFICIENCY.

(1) ADUMP FIFICILIACY - THE AHCURT OFF IVAILABILITY OISCHARGEO FROM TIEE PKUCESS AI EACH NiE: DIVIDED EY THE TEIIL SUPPLY GF AVAILARILIIY IN IHAT NODE.

(5) RECYCLF CASCANE EFFICIENCY - THE AMOUVT JF NEEDEO AVAILABILITY ATERIBLIED TO RECYCLE CASIALET TPRLIUCH THE PHICESS FRJM EACH NCOE OIVIJEO BY THE LMOUNT OF

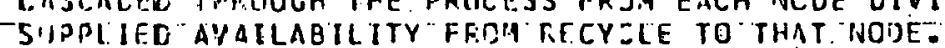

(6) BOUNOAPY LIMITS CASCACE EFHICIENCY - IHE IMIJUNT OF NEEUEO AVAILABILITY ATIRIBUTEO TO HITINDARY. LINITS CASCADEO THROUCA TIE PROCESS FROA EACH NODE DIVIOED BY THE AMLIUNT TF SUPPLIEC AVRILABILITY FRIJA BDUNUARY LIMITS TO THAT VOOE.

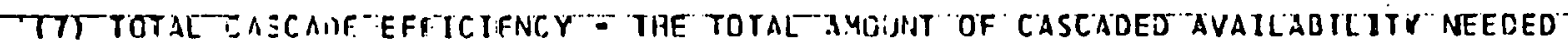
3Y FACH NIODF. DIVIDFD ISY TIIE A!UUU:NT UF SUPPLIED AVAILABILITY. TO THE NODE SAPMAP.KED EOR PROVIDING.CAST.ADE PGTENTIAL.

(8) NOOE AYILLAISILITY DISCHAZGE EFFICIFINCY - THE AVAILAOILITY DELIGERATELY DISCHARGEO HDLM EÄH MITOE TO THE EEAD STATE OIVIDED BY THAT PORTION OF BJTH RECYCLED AND "BOU DAFYY LIMTTS SUPPLIED" AVA"ILARTL"ITY." 


\section{4 - Primary Aluminum}

\section{Process Description}

Coke and binder pitch are charged to a crusher/classifiei and then mixed to the proper consistency. A mold press and subsequent baking form the graphite electrodes which are utilized in the Electrolysis step: Molten Aluminum from the electrolysis step is sent to casting and then to cooling as final process steps. The process is based on 1 million tons of aluminum per year.

\section{Process Ideal Work Basis}

The ideal reversible work for this process was developed by considering each step as an ideal reversible heat engine and calculating the minimum avallablity requirement per step based on reversible paths. The ideal actual work was calculated by adding the overall availability change from feed to products to the ideal reversible work.

\section{Process Efficiency}

The lost work efficiency of the process based on ideal reversible conditions was $48.7 \%$. The lost work efficiency of the process based on 1deal actual work was $\underline{53.3 \%}$. It can be seen that this efficiency is expected for this type of technology since electrochemical reaction is occurring together with combustion processes.

The total lost work for the process is $5 \% 62$ milition Beu/hr or abuut 22943 Btu lost work/1b aluminum produced. 
IV. Major Lost Work Unit Operations

This type of analysis allows a focus on the major lost work unit processes. For the process under study the following items were major lost work areas:

Unit

Electrolysis

Crushing and Classifying

Baking
$\%$ of Total Lost Work

86.3

6.7

2.8

Obviously, the electrolysis step must recelve the majority of attention in improving overall process efficiency.

V. Process Efficiency Parameters

The parameters generated by the nodal utilization accounting system characterize the effectiveness with which availability is interchanged and ulillzed In the process. 'The overall process Gaggioli efficiency is I3\%, a relatively low value which shows the potential for greater heal Integration between process steps. The degree of internal caocade of availahility is 2160 about $13 \%$ showilis Llal Lle process has minor interconncctedness. 
333-

POOCESS FROA

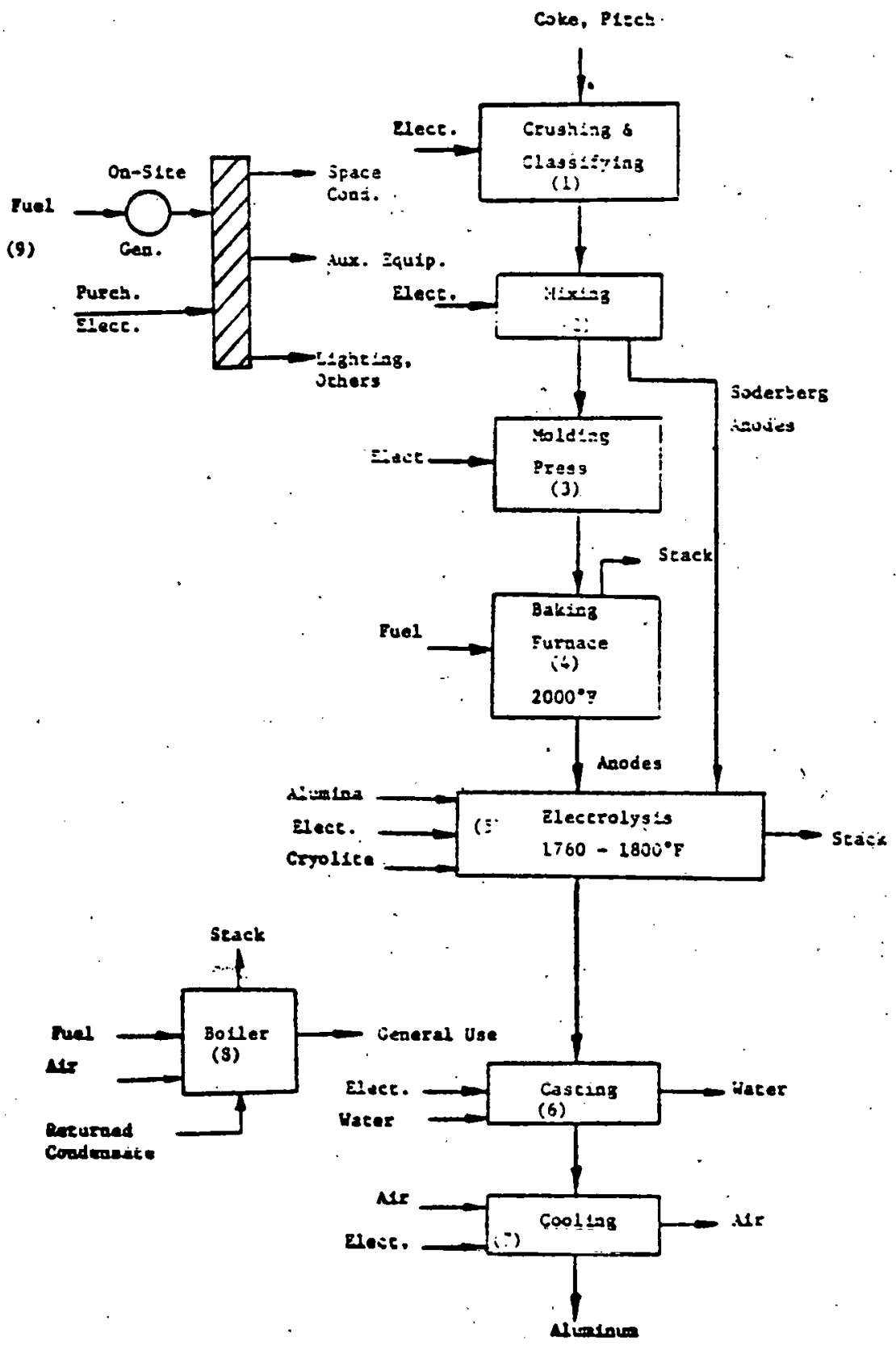

Rev1s100 2 


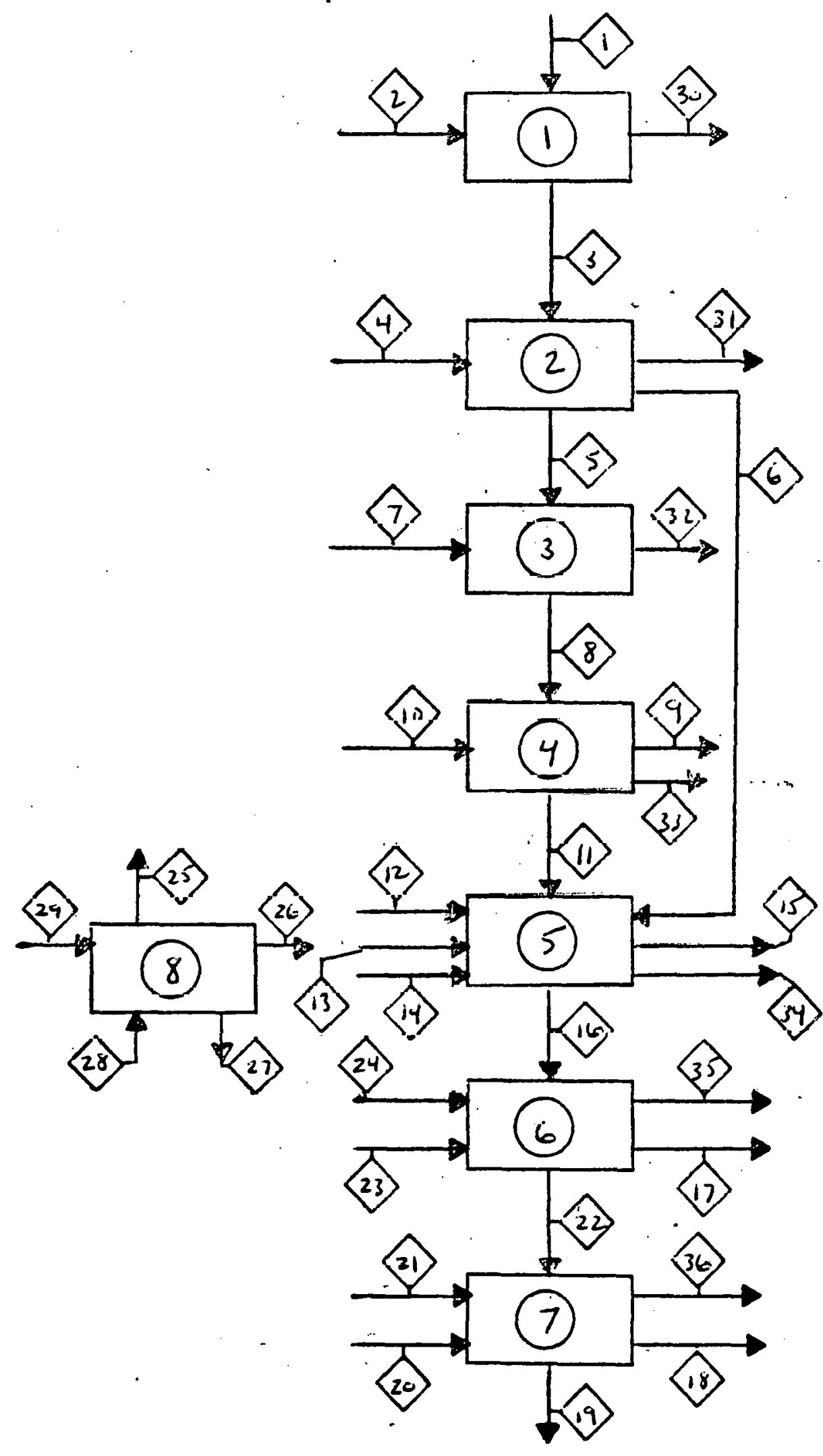




\section{4 - Primary Aluminum}

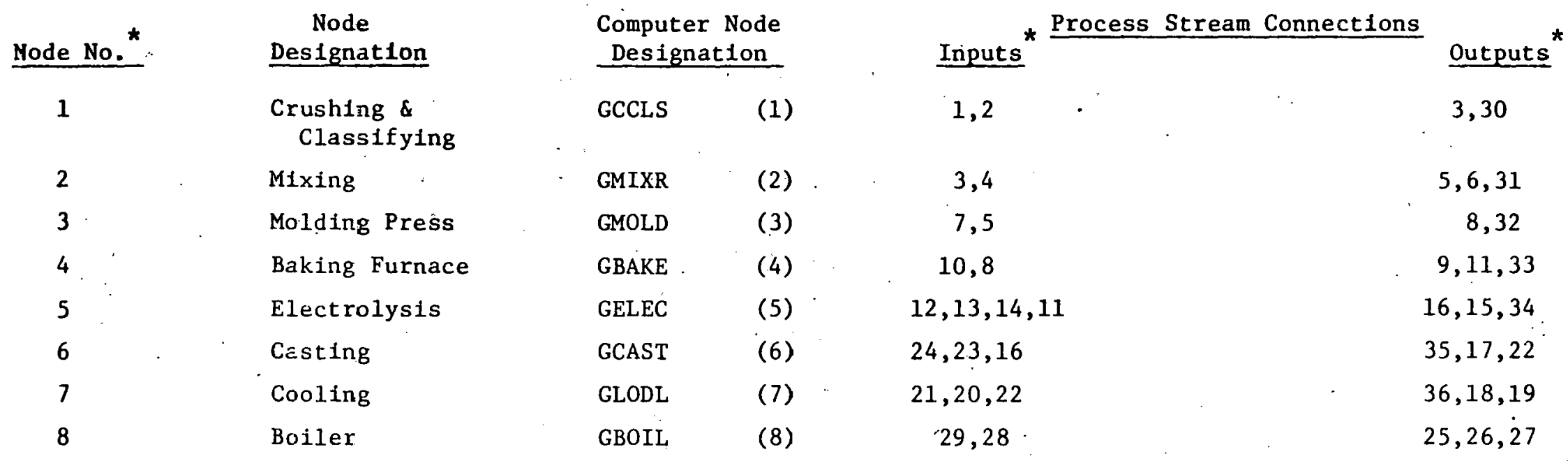

\footnotetext{
${ }^{\star}$ These numbers refer to those shown in the Aluminum- Process Directed. Graph.
} 
3334 - PRI PIARY ALUMINUM

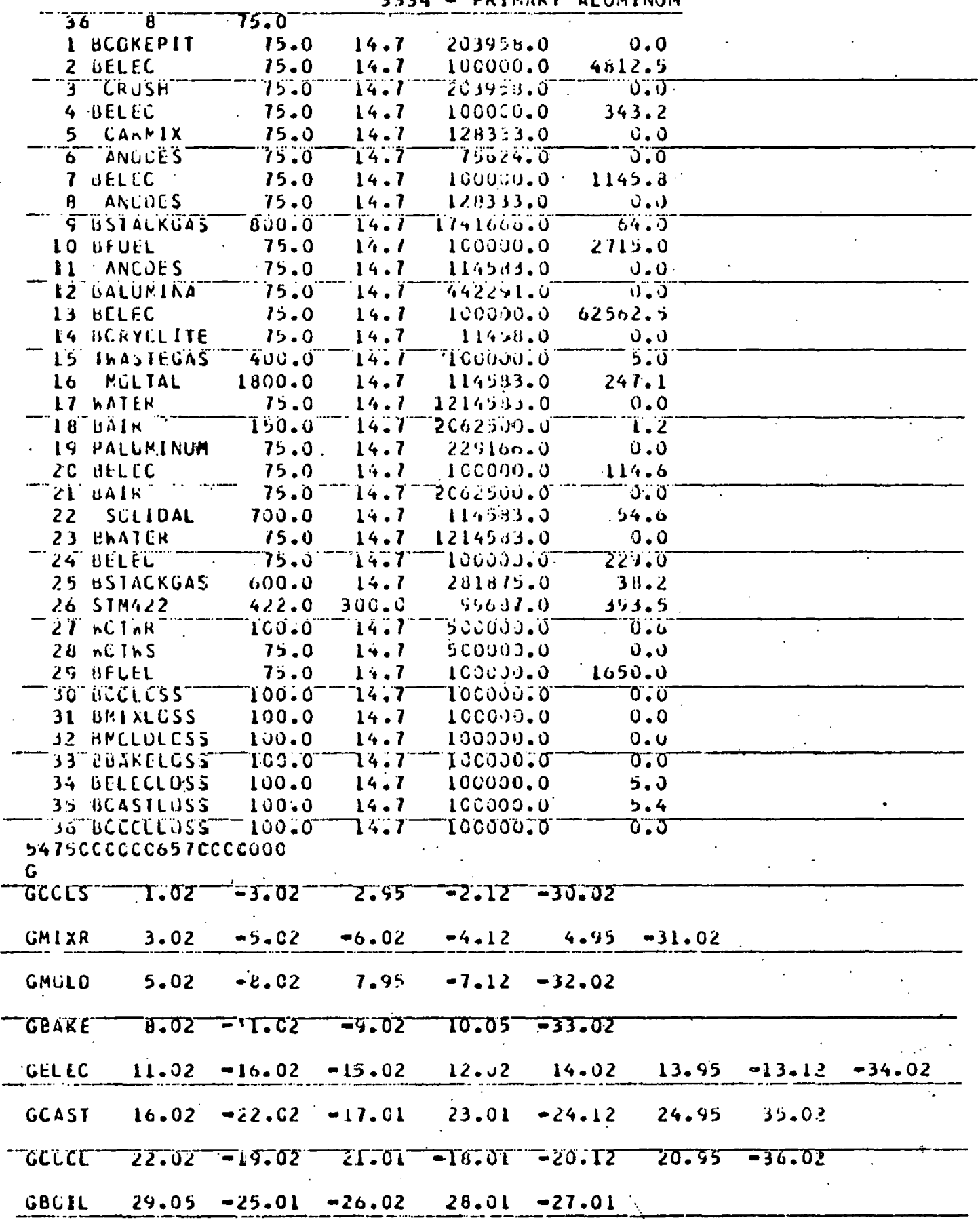


$3334-$ PRIMARY ALUMLNUIA

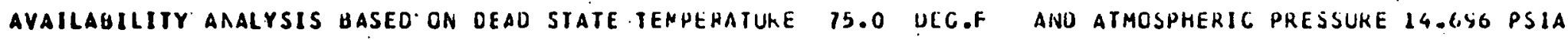

* * * stancarc noual analysis ****

ILGST hURK ANALYSIS AAO GAUGICLI EFFICIENCIESI

PROCESS PARAMETERS:

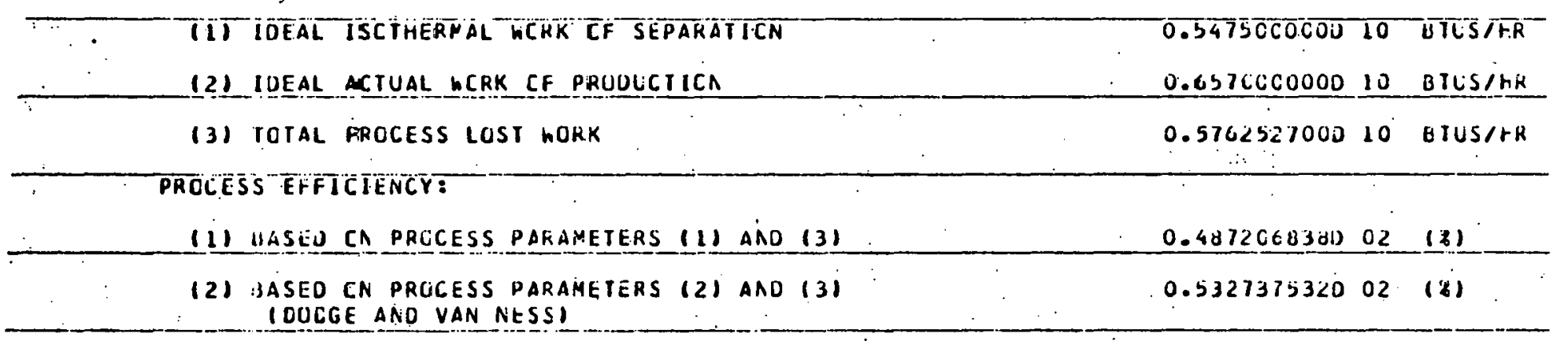

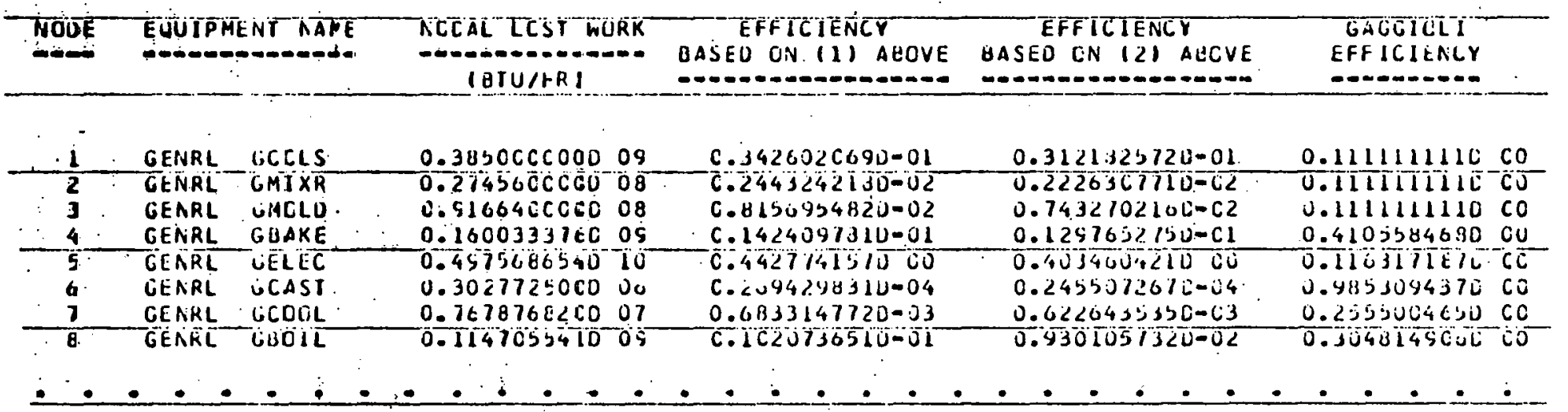




\section{4- PRIMARY ALUMINUM}

AVAILABILITY ANALYSIS GASED ON CEAD STATE TEMPERATURE 75.0 DEG.F ANO ATMOSPMERIC PRESSURE I4.G9G PSIA

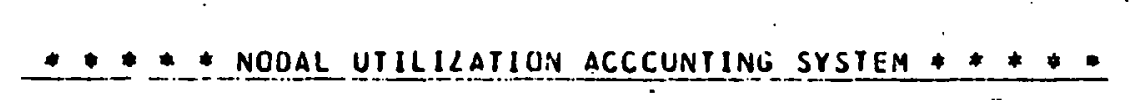

(1) AVAILABILITY AEELEC EY NCCE IC PERFCHM.ITS SPECIFIC SYSTEM FUNCTION 121 AVAILABILITY. SUPPLIED TO ACOE IO PRUVIOE CAPACITY TL ACCCIAPLISH ITS STECIFIC COPERTICN

IN CRUER IO FURTHER CHARACTERILE AVAILABILITY INTERGHAiGges at THE ACUE, THF:

prolran separates neEcec avallability into 3 muke specific catagukits anu suppliec

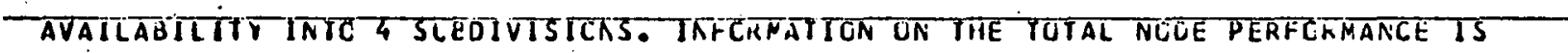
CONTAINED IN THE ARRAY CCMP(I,J) WHEN-J IS THE NCOE NUITOER: $1=1,7$ WITH PCIITICNS

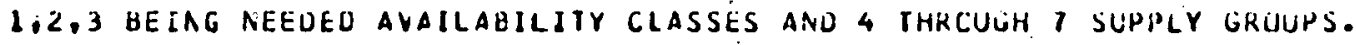

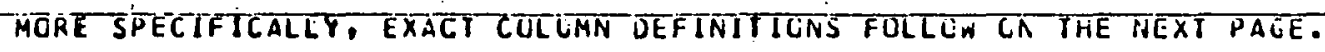


3334 - PRIMAARY ALUGINUMH

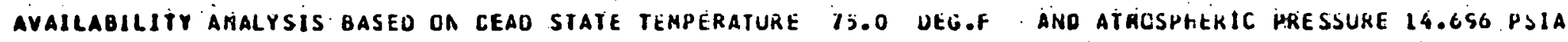

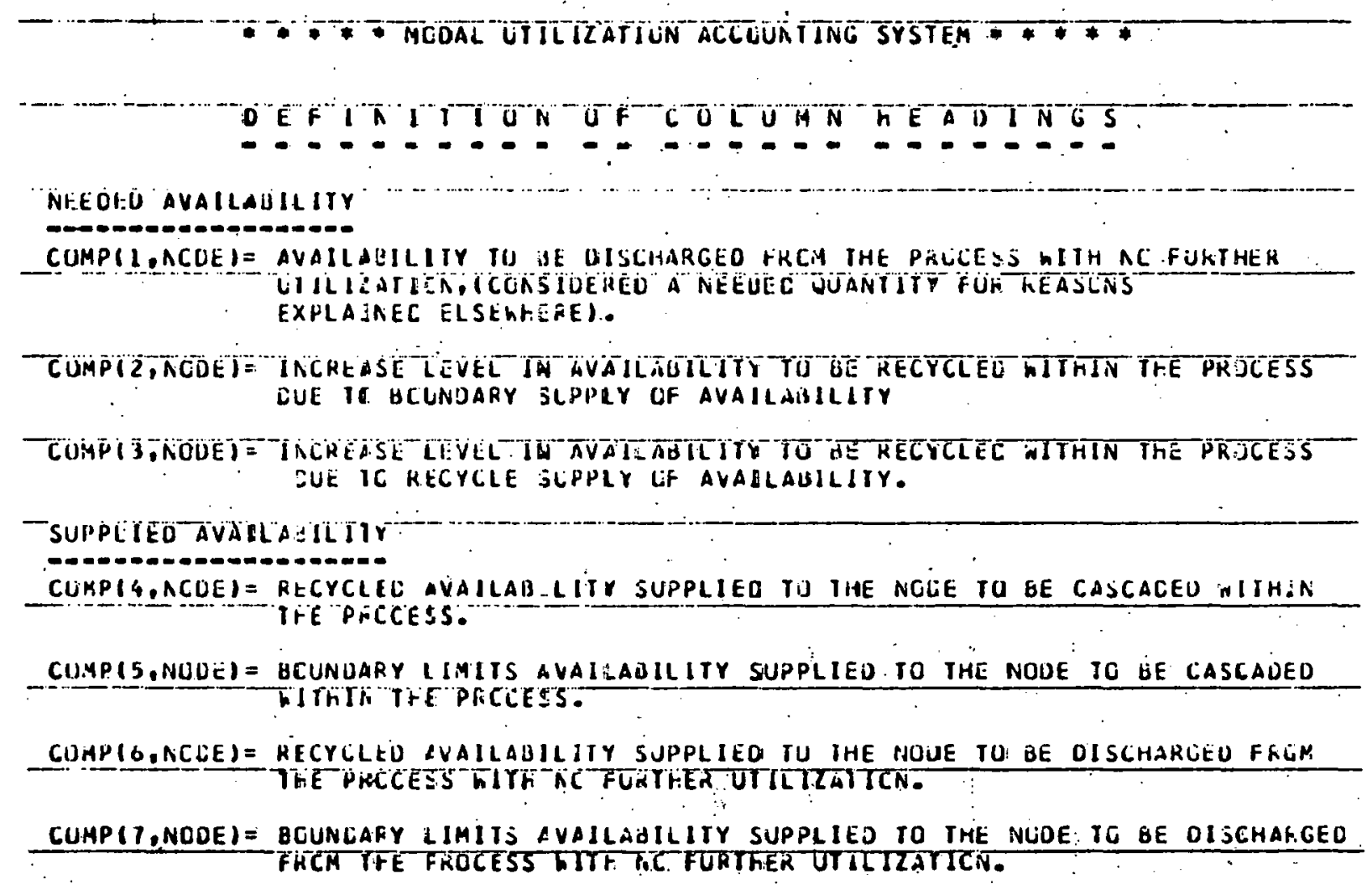


3334 - PRIMARY ALUMINUM

AVAILABILITY anALYSIS UASEO ON DEAU STATE TEMPERATUKE 75.0 UEG.F ANO ATMUSPHEKIC PRESSURE 14.696 PSIA

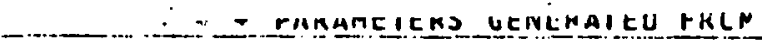

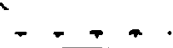

IAN EXPLAADI ICN CF CCLUMN HEACIMGS IS GIVEN BELGW THROUGH OEFINITICN UF PARTICLLA PARAMEIERS AS DERIVEC FRCM IAFCANAIICV CQNIAINEO IN THE CO.AP AKRAY.)

\begin{tabular}{|c|c|c|c|c|c|c|c|c|}
\hline NOOE & $\begin{array}{c}\text { NEEUEU } \\
\text { AVAILABILITY } \\
\text { (UIUYHK) }\end{array}$ & 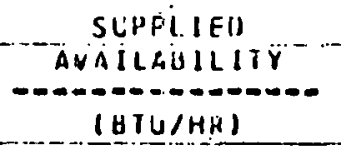 & $\begin{array}{l}\text { RELAIIVE NCDE } \\
\text { EFFICIIẼEY }\end{array}$ & $\begin{array}{c}\text { AUUMP } \\
\text { EFFICIENCY }\end{array}$ & $\begin{array}{l}\text { RECYCLE } \\
\text { CASCNJE } \\
\text { EFFICIENCY } \\
\end{array}$ & $\begin{array}{l}\text { ULUAU.LIM. } \\
\text { CAAOCOAOE } \\
\text { EFFICILUCY } \\
-\infty\end{array}$ & $\begin{array}{l}\text { JIAL } \\
\text { EASCBIiE } \\
\text { EFICIEALY }\end{array}$ & 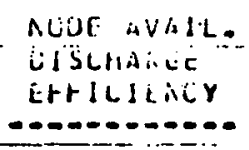 \\
\hline 1 & 0.481250000008 & 0.433125000009 & -0.180 & 0.000 & 0.000 & 0.000 & 0.111 & $0 . c c c$ \\
\hline 2 & 0.343200000007 & $0.30 \mathrm{e} 8600000 \mathrm{CO}$ & $=0.180$ & 0.000 & 0.000 & 0.000 & 0.171 & c.0.0 \\
\hline 3 & 0.114500000000 & $0.10312 \leq 0000 \mathrm{CS}$ & -0.180 & 0.000 & 0.000 & 0.000 & 0.111 & c.ecc \\
\hline 4 & 0.111466624009 & $0.271 ; \mathrm{cc0} 0000.09$ & 2.032 & 0.000 & 0.000 & 0.000 & 0.411 & c.c.ci \\
\hline 5 & 0.654938459009 & 0.563662506010 & -0.141. & 0.000 & 0.000 & 0.000 & 0.110 & $\mathrm{C} . \mathrm{C} \mathrm{CC}^{-}$ \\
\hline 6 & 0.203012275008 & $0.20 \in 200000008$ & 6.215 & 0.000 & 0.000 & C.cos & 0.965 & $c .0 c c$ \\
\hline 7 & $0.2635231800 \quad 07$ & $0.1631400000 \mathrm{Cg}$ & 0.887 & 0.240 & 0.000 & 0.000 & 0.493 & $c \cdot c c c$ \\
\hline 8 & 0.502944545008 & $0.165 \mathrm{CCC} \mathrm{COOD} C 9$ & $1 .<51$ & 0.067 & c. $\mathrm{COO}$ & 0.000 & 0.233 & $C \cdot C: C$ \\
\hline$\therefore$ & $\because \because \div \div \div$ & $-\div \quad \cdot \quad \cdot$ & 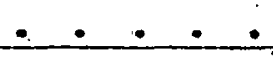 & - & - & 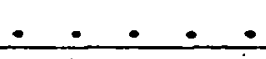 & $\bullet$ & $\therefore$ \\
\hline
\end{tabular}




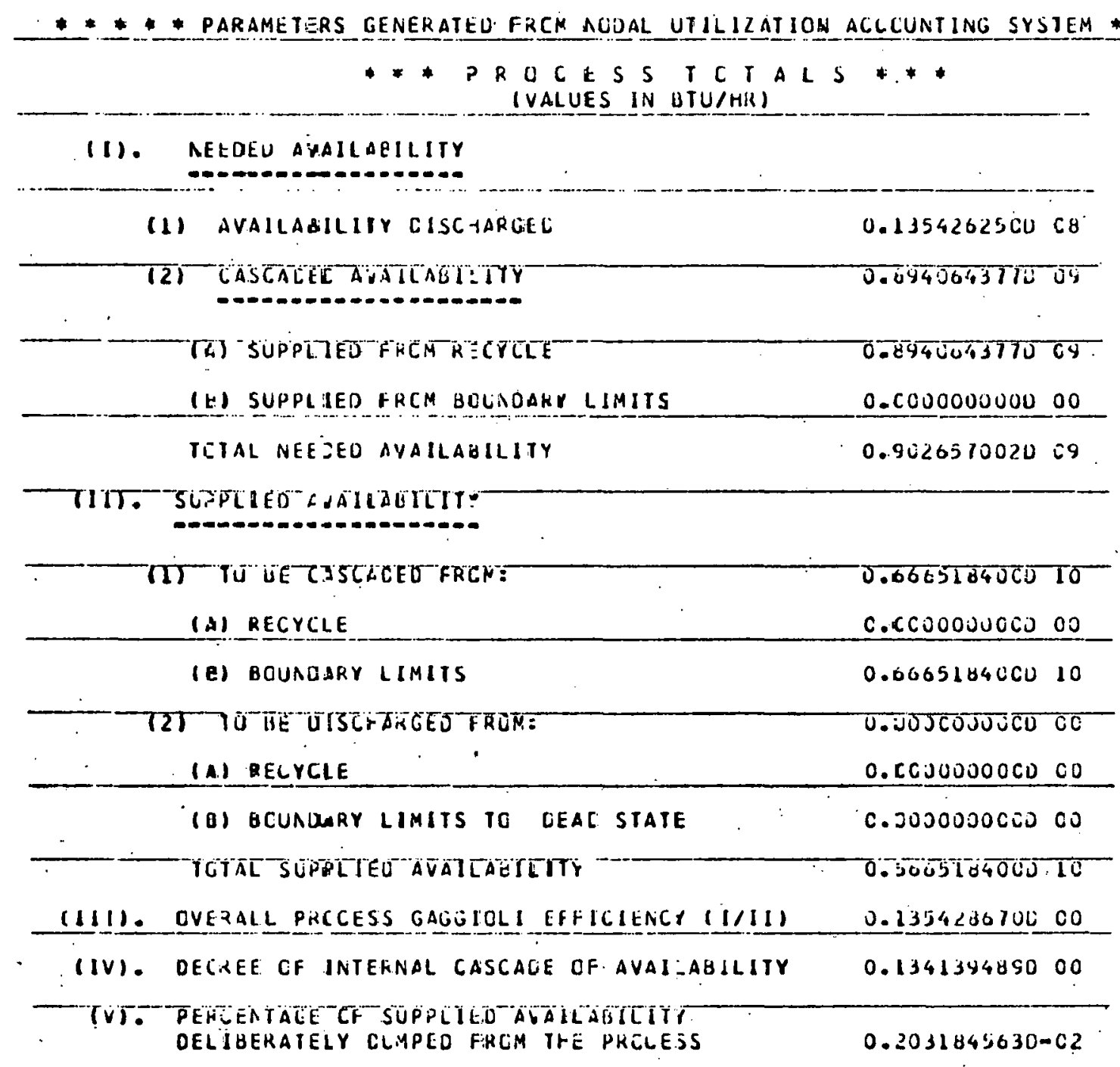


(1) NEEUED AVAILAEILITY - THE AVAILAUILITY REUUIREO TC PRUUUCE THE DESIRED STATE

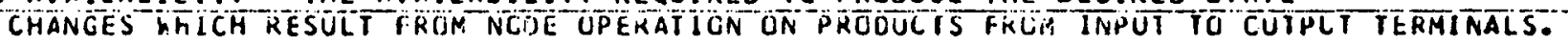

\section{* cualificaileas * *}

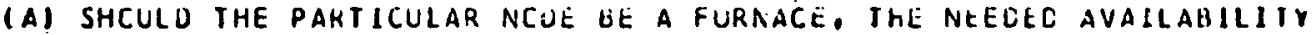
ICCMFI8,NCUEI) WILL INCLUUE AII SIAIE CRANGES. JTACK GAS IS OALY

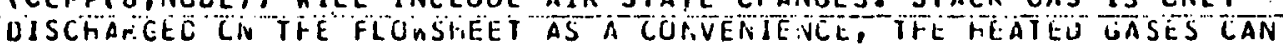

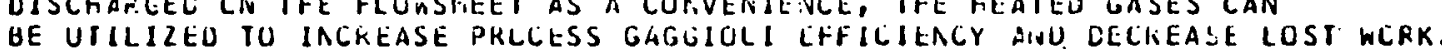

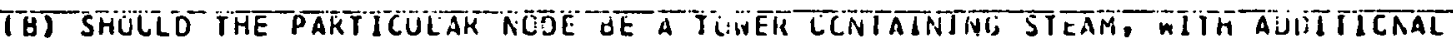
AVAILALILIIY NEELEO TO PRLVIUE THE GELESSARY SItAM SIAIE CHANGLS, ITE NLEUEO AVAILAYILITY ICCNPIY,NODEJI WILL. NOT HE IHE SUM CF CCHP(1-2-3,NCDE).

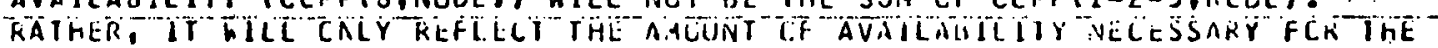

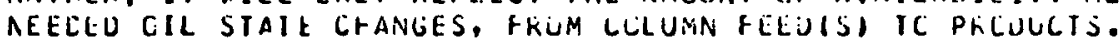

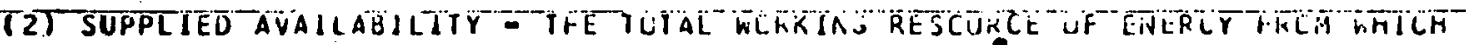

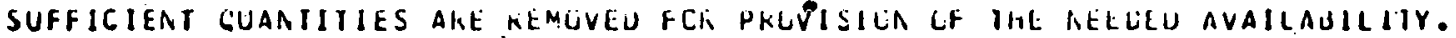

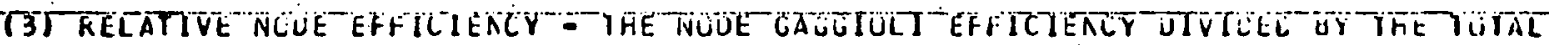
PP.OCESS GACGICLI EHFICIEACY.

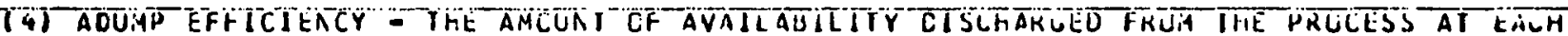
NOCE CIVIUEL HY THE TCTAL SUPPLY CF AVALLAUILITY IC THAT NUDL.

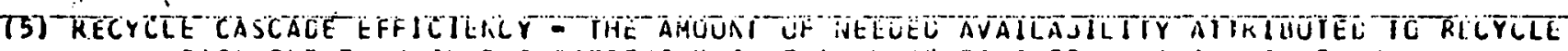

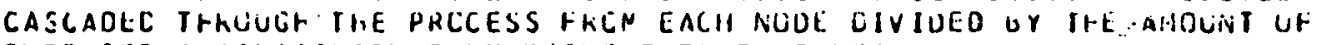
SUPPLIED AVAILAEILITY FHUM RLCYCLE TU THAT NCUE.

(6) BCUNDAKY: LIHIIS CASCAUE EFFICIENCY - THE AIUJNAT UF NLEDEN AVAILAJILITY ATIRIULTEU TO

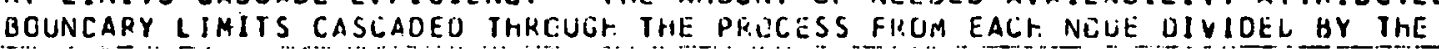

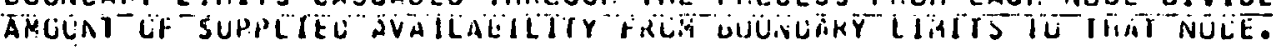

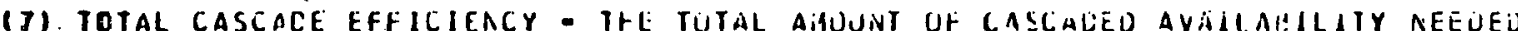

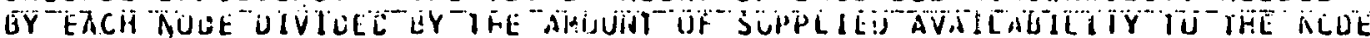
EARMAKKEC FCK PRUVICING CASCAUE PUTriltial.

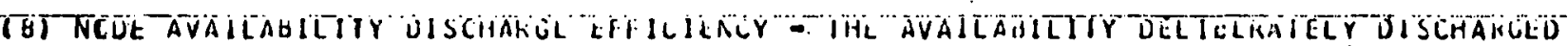

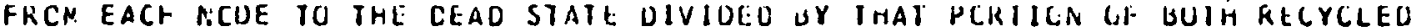
ANC UCUNCARY LIMITS SUPPLIEU AVAILAUILIIY. 
1. Ross, M.H. and Socolow, R.H., et al., "More Effictent Use of Energy: A Physics Perspective," Report of American Physics Association Summer Workshop, 1974.

2. Reistod, G., "Availability, Concepts and Applications', Ph.D. Thesis, University of Wisconsin, 1970.

3. Gaggiol1, R.A. "Proper Evaluation and Pricing of Energy", Proceedings of the International Conferance on Energy Use Management, Vo1. 2, 1977.

4. Reistad, G.M., et al., "Avallable Energy and Economic Analysis of Total Energy Systems", Private Communication Report, 1971.

5. Gyftopoulos, E.P., et al. "Potential for Effective use of fuel in Industry", Thermoelectron report TE5357-71-74.

6. Appelbaum, Lannus, "Avallble Energy Analysis of Dry Process Cement", 13th Intersociety Energy Conversion Enineering Conference, 1978.

7. Hal1, E.H., et a1., "Evaluation of the Theoretical Potential for Energy Conservation in Seven Basic Industrles", Report by Battelle Columbus Laboratories' to the Federal Energy Administration, July 1975.

8. Hamel, B., Brown, H., "Ut1lization Analysis of Energy Systems, Part I, Fundamentals of Energy Utilization, "Intersociety Energy Conversion Engineering Conference, 1972.

9. Hamel, B., Brown, H., et. al., "Utilization Analysis of Energy Systems, Part III, Application of Utilization Criteria to House Energy Systems," Intersociety Energy Conversion Engineering Conference, 1972.

10. Lee, P., McCulloch, E., "A New Parameter for Evaluating Energy Systems," 8 th IEC ECS, 1973.

11. Reistad, G.M., "Avallable Energy Conyersion and Utilization in the United Stateo, AEME, 1974.

12. Gaggioli, R., "The Concepts of Thermodynamic Available Energy. Chemical Avallable Energy and Thermal Energy," Chem. Eng. Sc1. 1962.

13. Evans, R.B., "A Proof that Essergy is the only Consistent Measure of Potential Work". Ph.D. Thesis, Dartmouth College, 1970

14. Berg, C., "Conservation in Industry," Sclence 1974; "A Technical Basis for Emergy Conservation," Technology Review, Mechanical Engineering, 1974.

15. Sweeney, J., Smith, S., et. al., "A Fundamental Approach to the Thermodynamic Configuration Analysis of Process Flowsheets as applied to a Refinery Unit," Drexel Energy Inst1tute Report, 1975. 
16: Smith, S., Sweeney, J., et. al., "A Thermodynamic Analysis of a Refinery Process," Drexel Energy Institute Report, 1975.

17. Nwude, J., Brown, H., Hamel, B., "Ut1lization Analysis of Energy Systems - Food Processing Industry. Campbell Sout Plant," Drexel Energy Institute Report, 1975.

18. Denb1gh, K. G., "The Second Law Efficiency of Chemical Processes", Chem. Eng. Science, Oct. 1956.

19. Retfert, L., "The Efficiency of Energy - Ut1lization in Chemical Processes", Chem. Eng. Science, Fol 29, 1974.

20. Urdaneta, A., Schmidt, P.S., "Evaluation of Energy Utilization A Analysis Methods for Industrial Processes", Proc. of the Int. Conference on Energy Use Mangement. 1977, Perganon Press.

21. Wepfer, W.J., Gagg1ol:, R.A., Obert, E.F., "Proper Evaluation of Ava1lable Energy for HVAC", ASHRAE, 1979.

22. Gyftopoulos, E.P., Widmer, T.F., "Availability Analysis: The Combined Energy and Entropy Balance", American Chem. Society, 1978.

23. Berg, C.A., "Process Integration and the Second Law of Thermodynamic". Workshop on the Second Law of Thermodynamics, George Wash. Univ.; 1979.

24. Hedman, B.A., Brown, H.L., Hamel, B.B., "Second Law Analysis of Industrlal Process", Workshop on the Second Law of Thermodynamico.

25. Streb, A.J., "Prfority Listing of Idustrial Processes by Total Energy Consumption and Potential for Savings", Report to Division of Industrial Energy Conservation, ERDA.

26. Fehring, T.H., Gaggiol:, R.A., "Economics of Eeedwater Replacement", ASME 76-JPCC-PWR-7, 1976. 
214

APPENDIX A

PROCESS FLOW PROGRAMS 


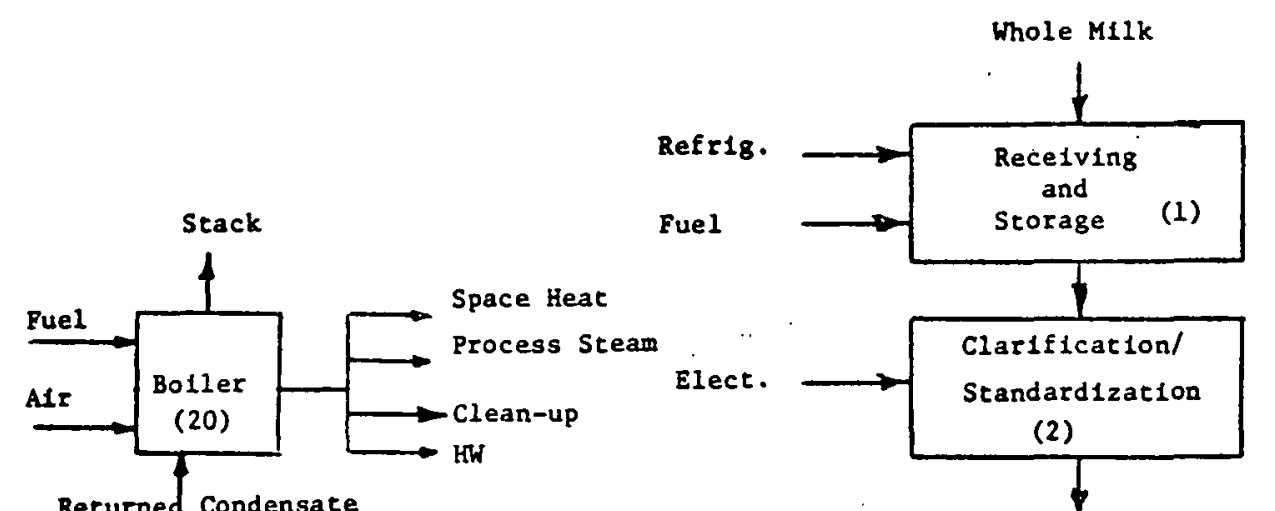

Returned Condensate
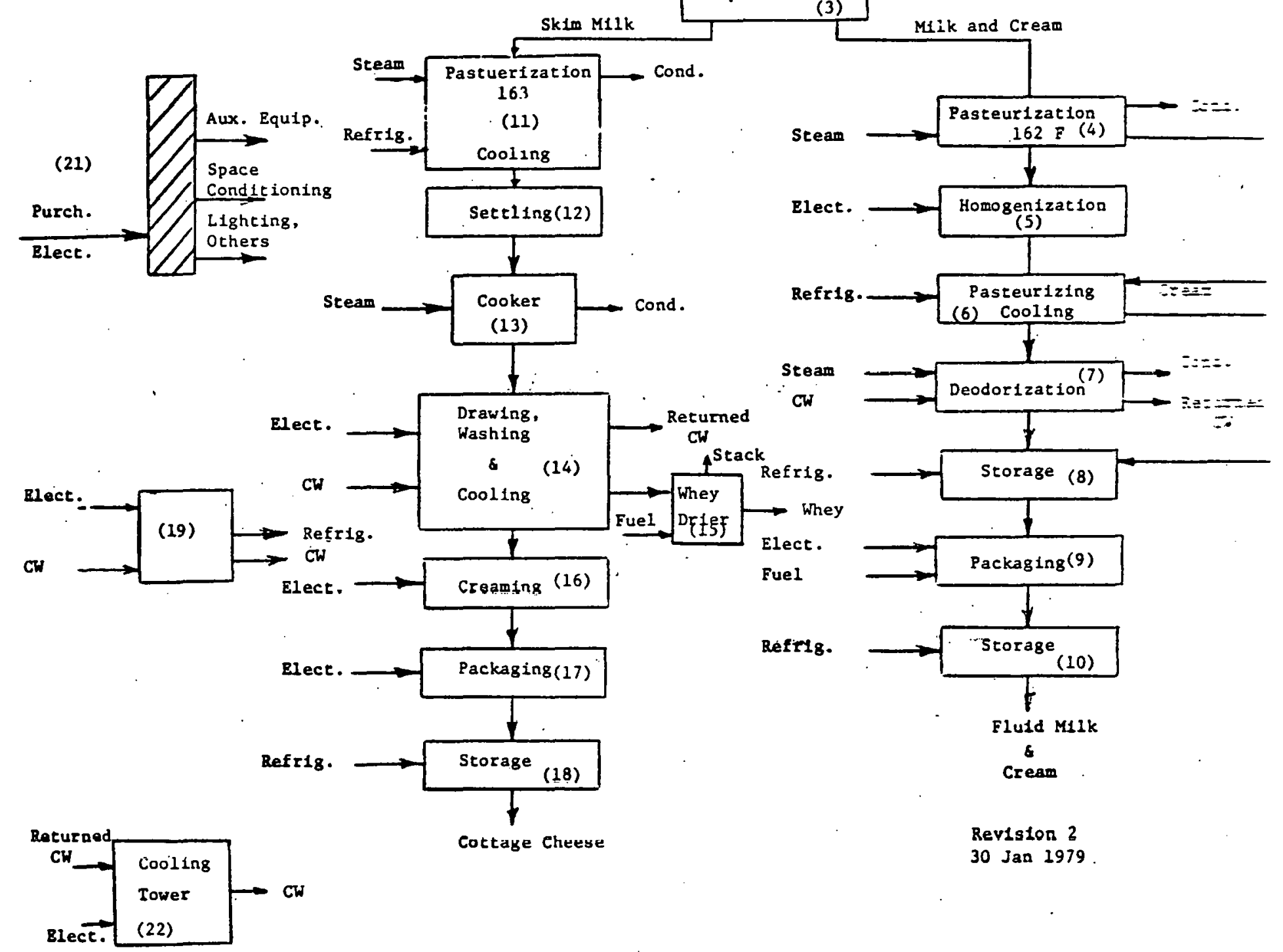

Cottage Cheese

Reviston 3

30 Jan 1979. 


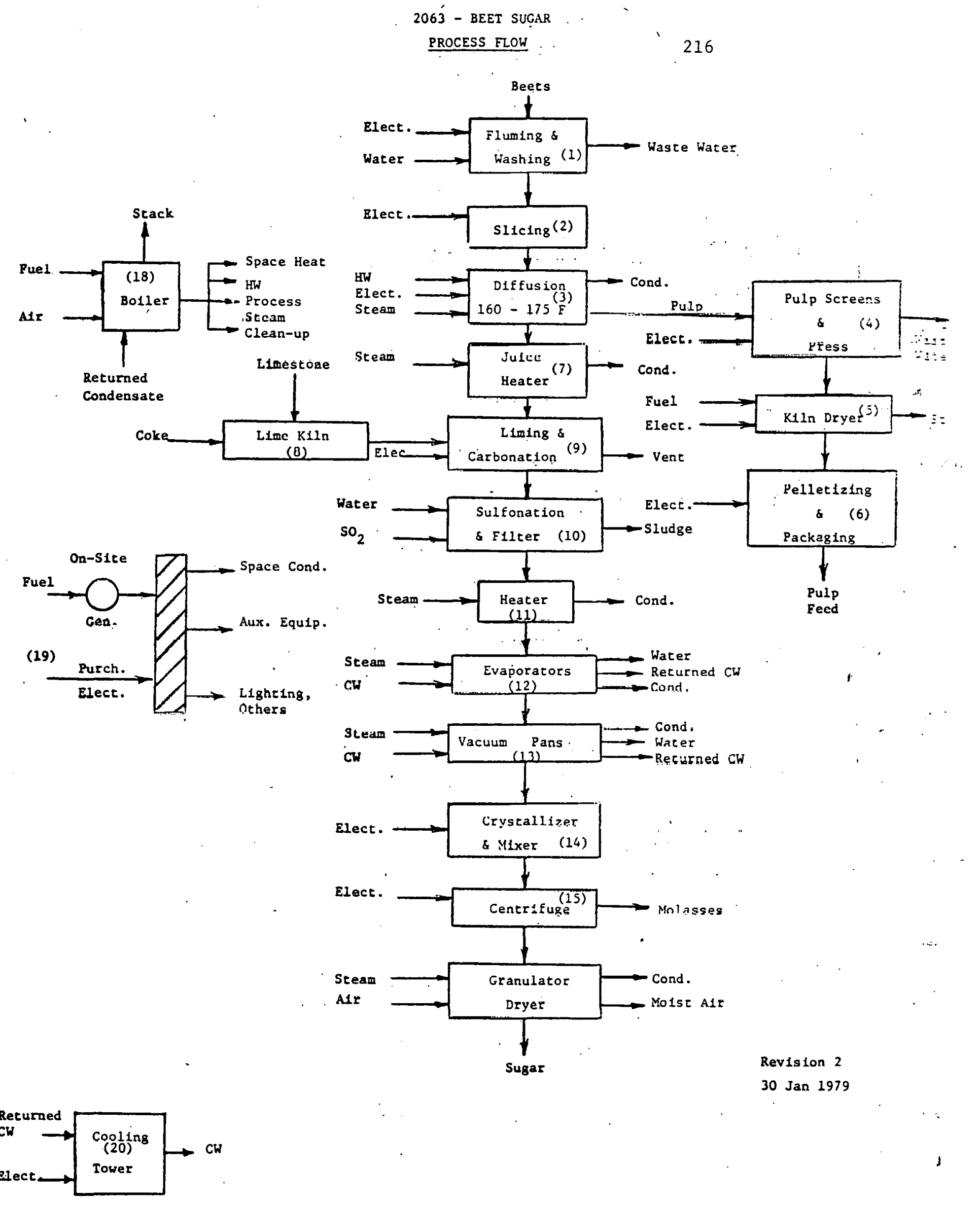




\section{PROCESS FLOW}
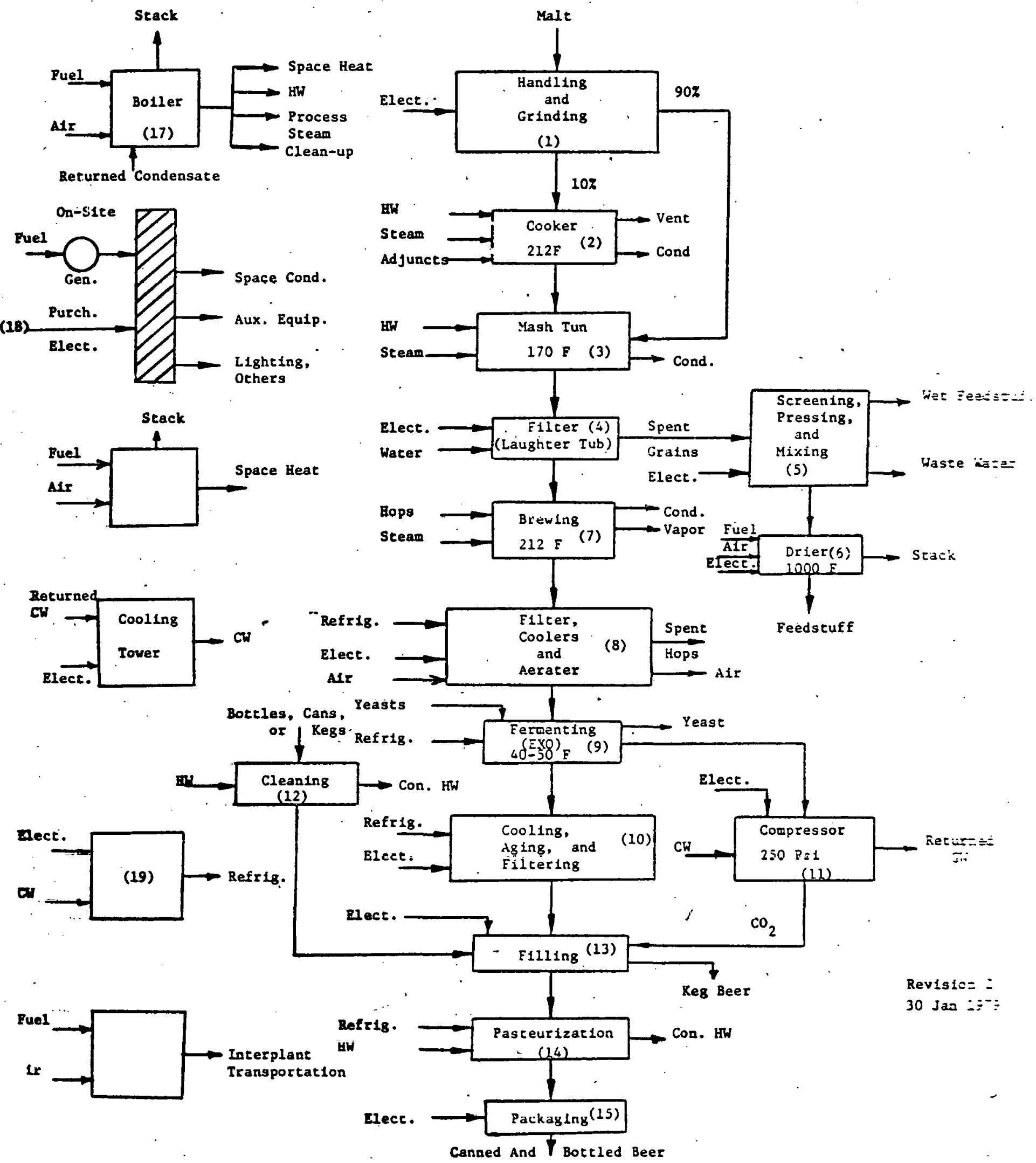
PROCESS FLOW
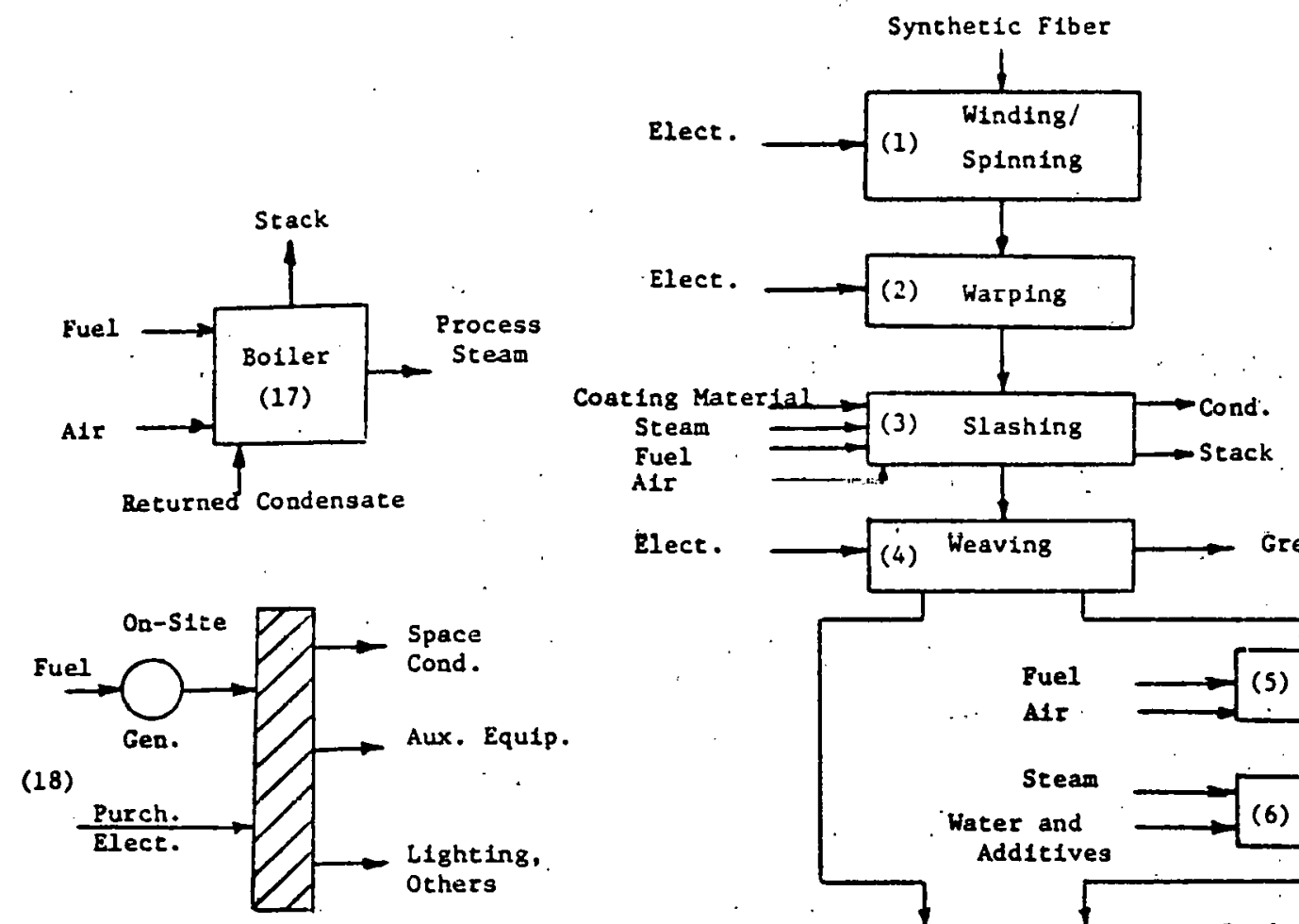

Elect.

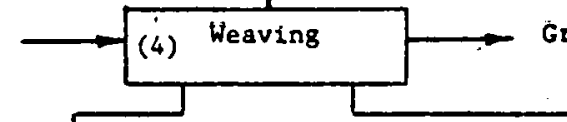

Grey Goods

Water
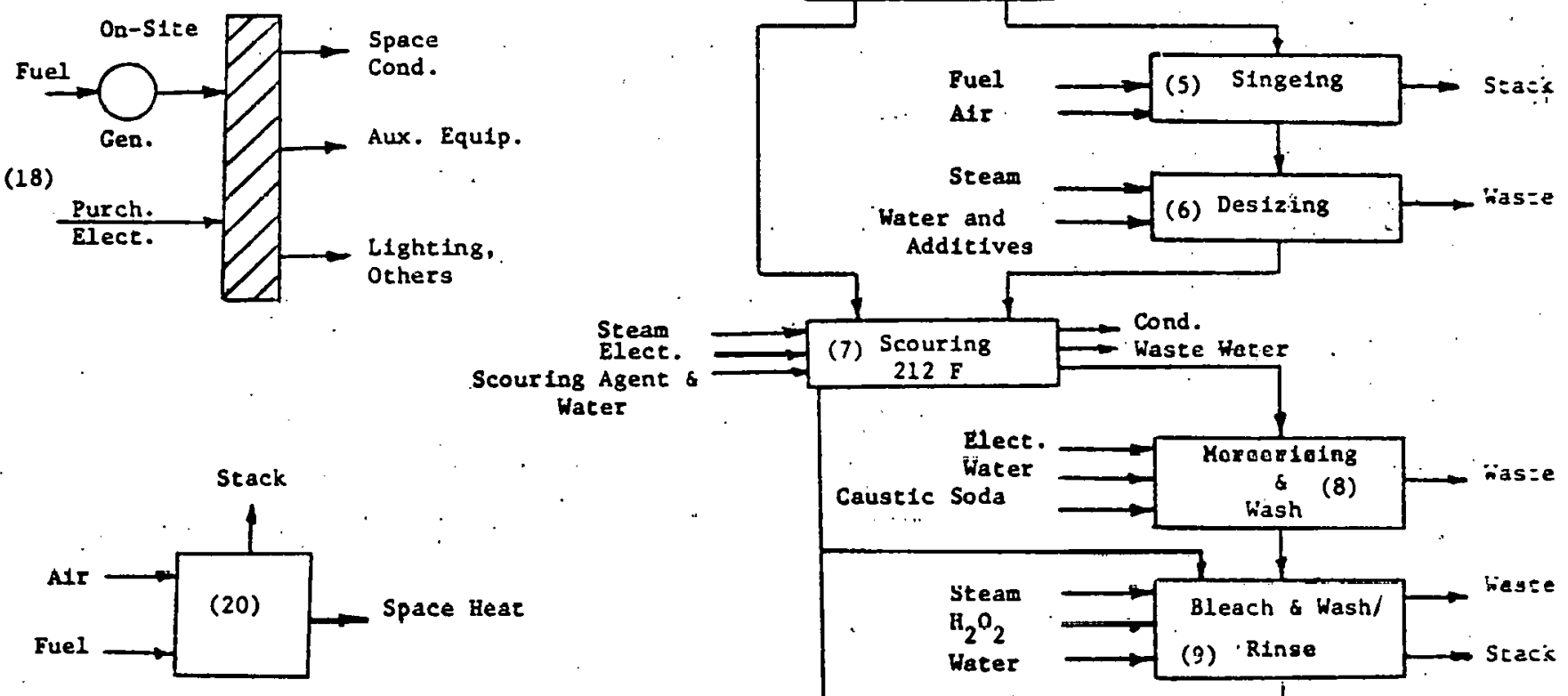

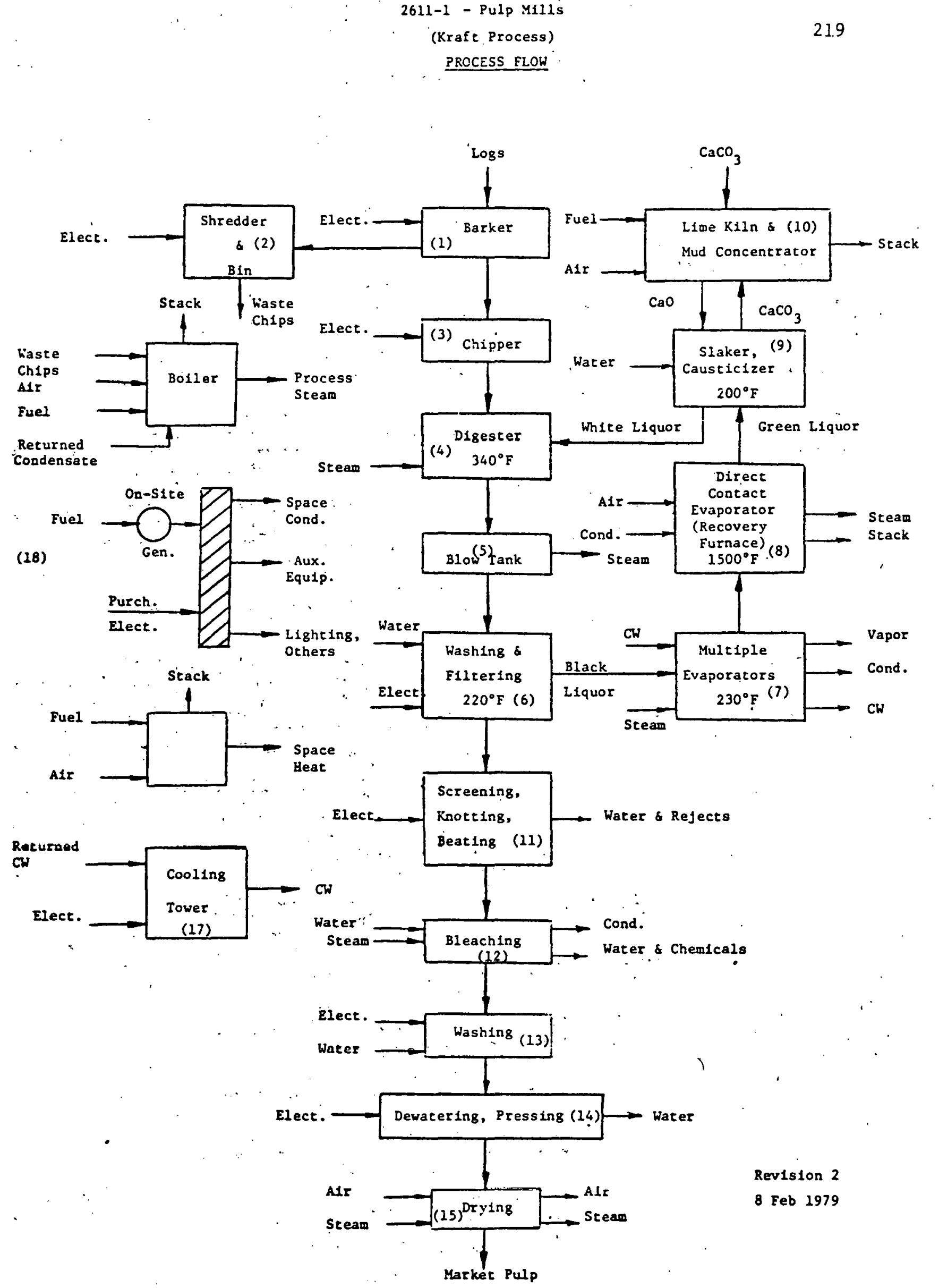


$$
\begin{gathered}
\text { 2621-1 - Paper Mills } \\
\text { (Fintshing Plant) } \\
\text { PROCESS ELOW }
\end{gathered}
$$
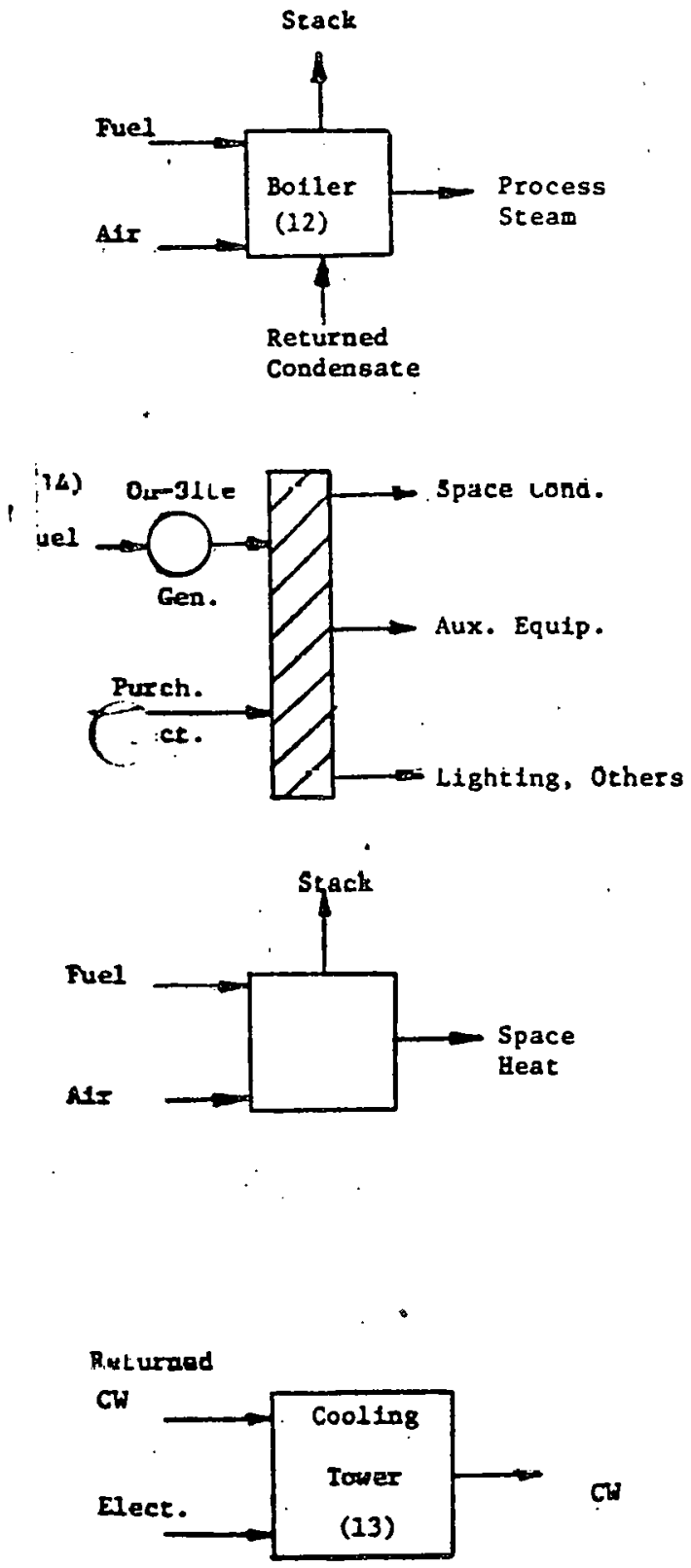

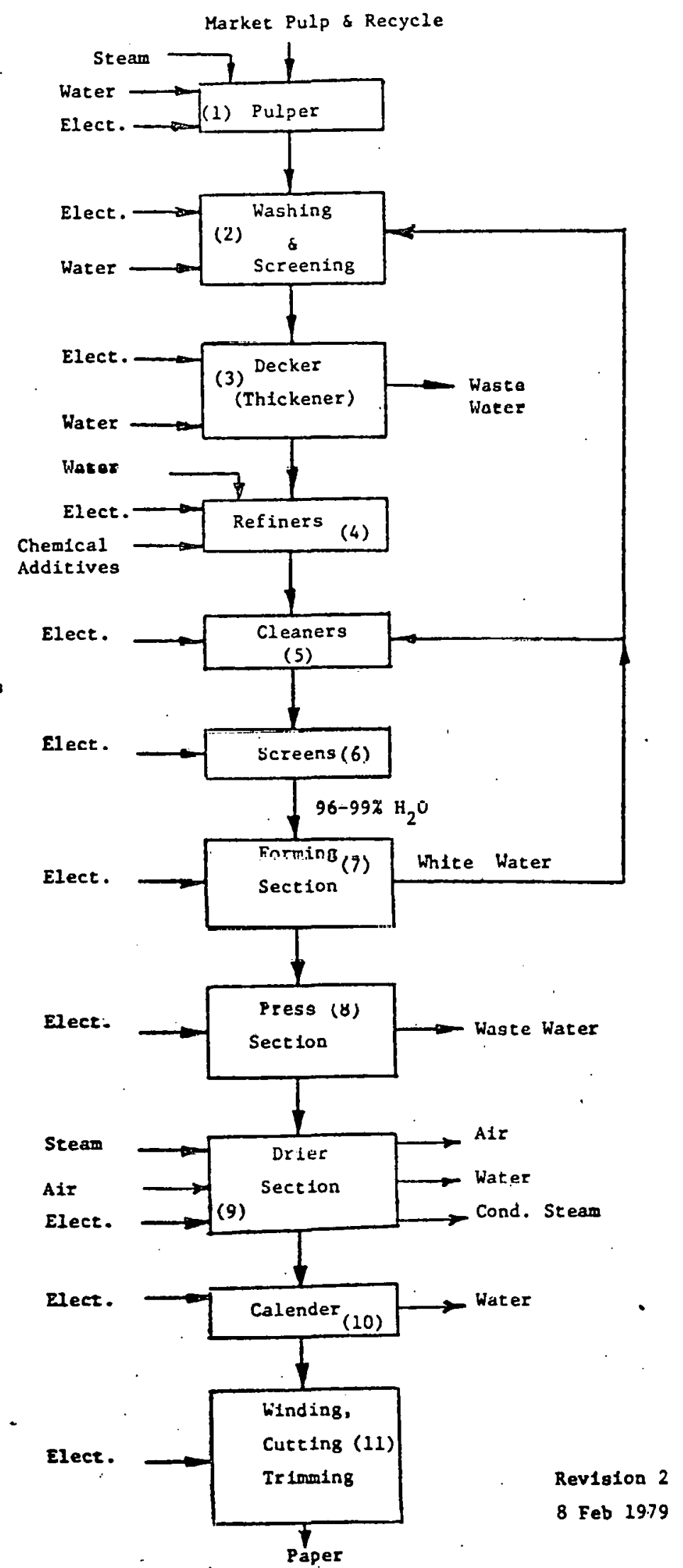




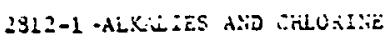

(NaOH, Cl:- zlapiragm Call

Proseys Elou
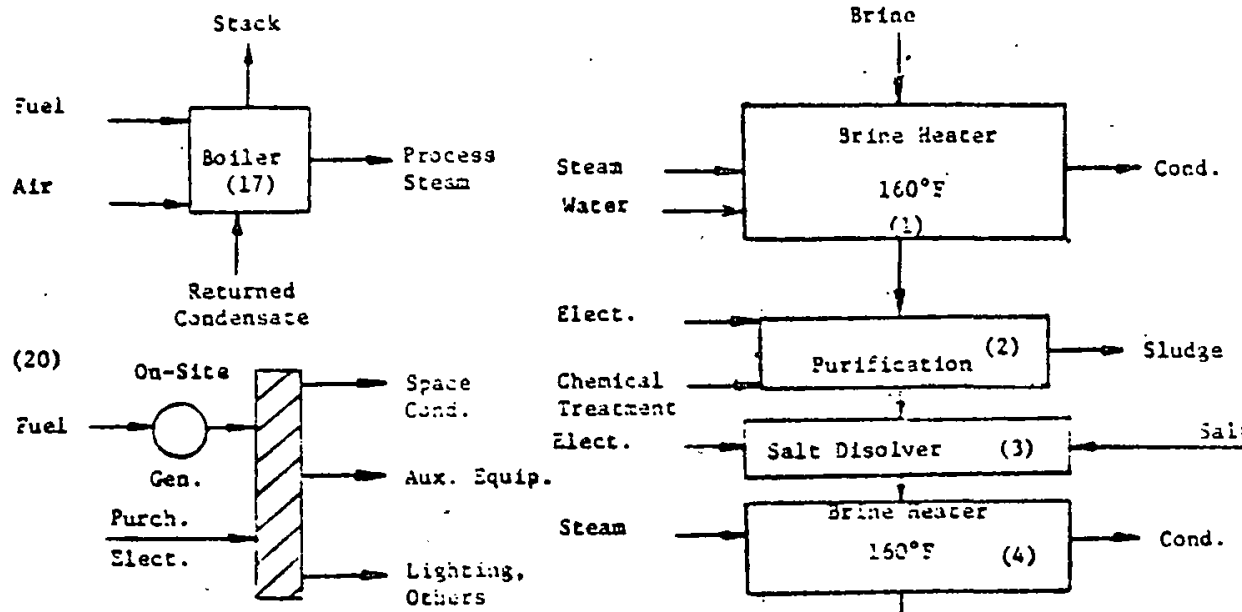

.
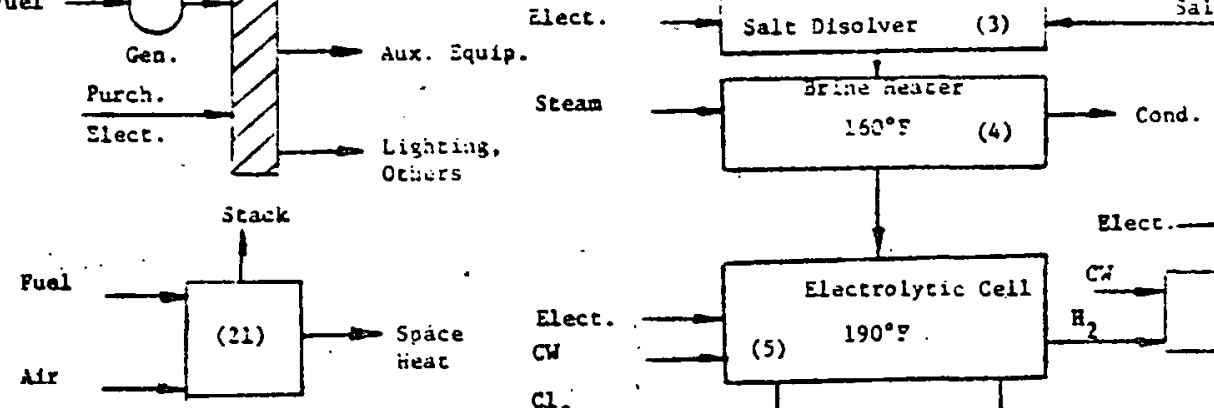

Stear

Stean
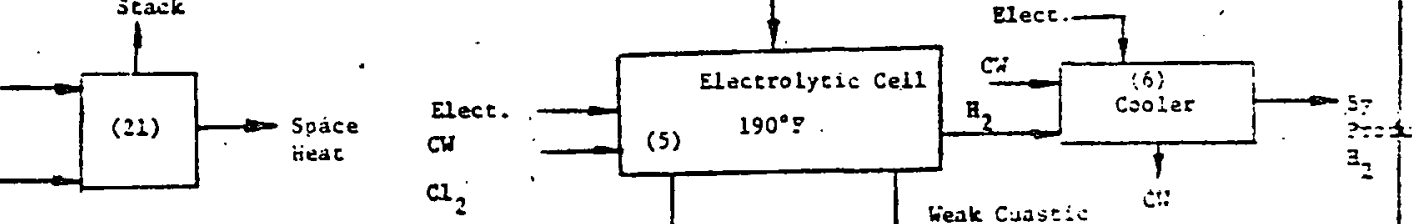

2
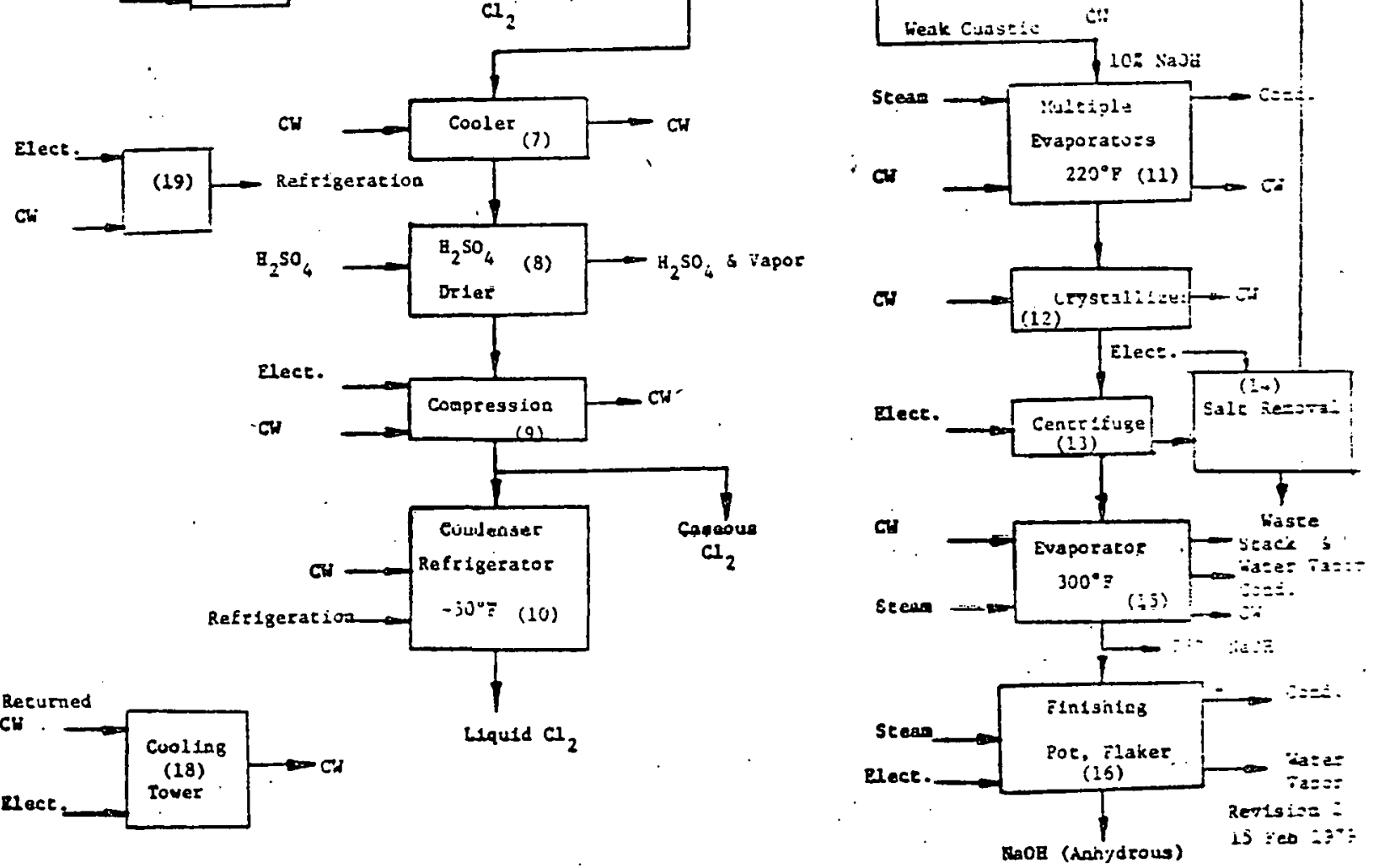


$$
\left(\mathrm{N}_{2}, \mathrm{O}_{2}\right)
$$

PROCESS FLOW

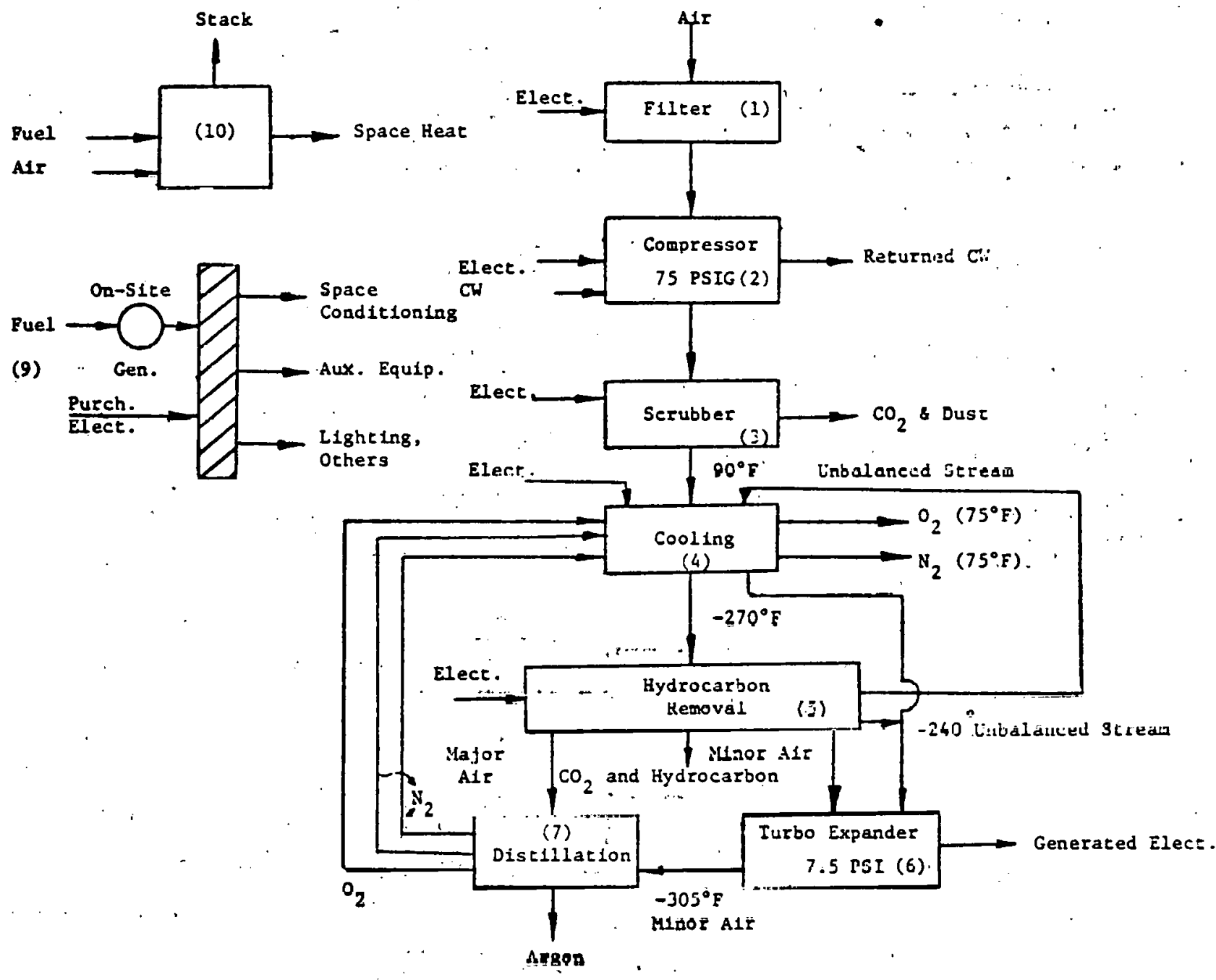

Revision $2, \cdots$

26 March 1979

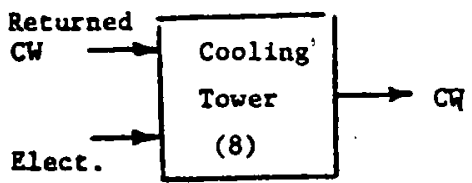




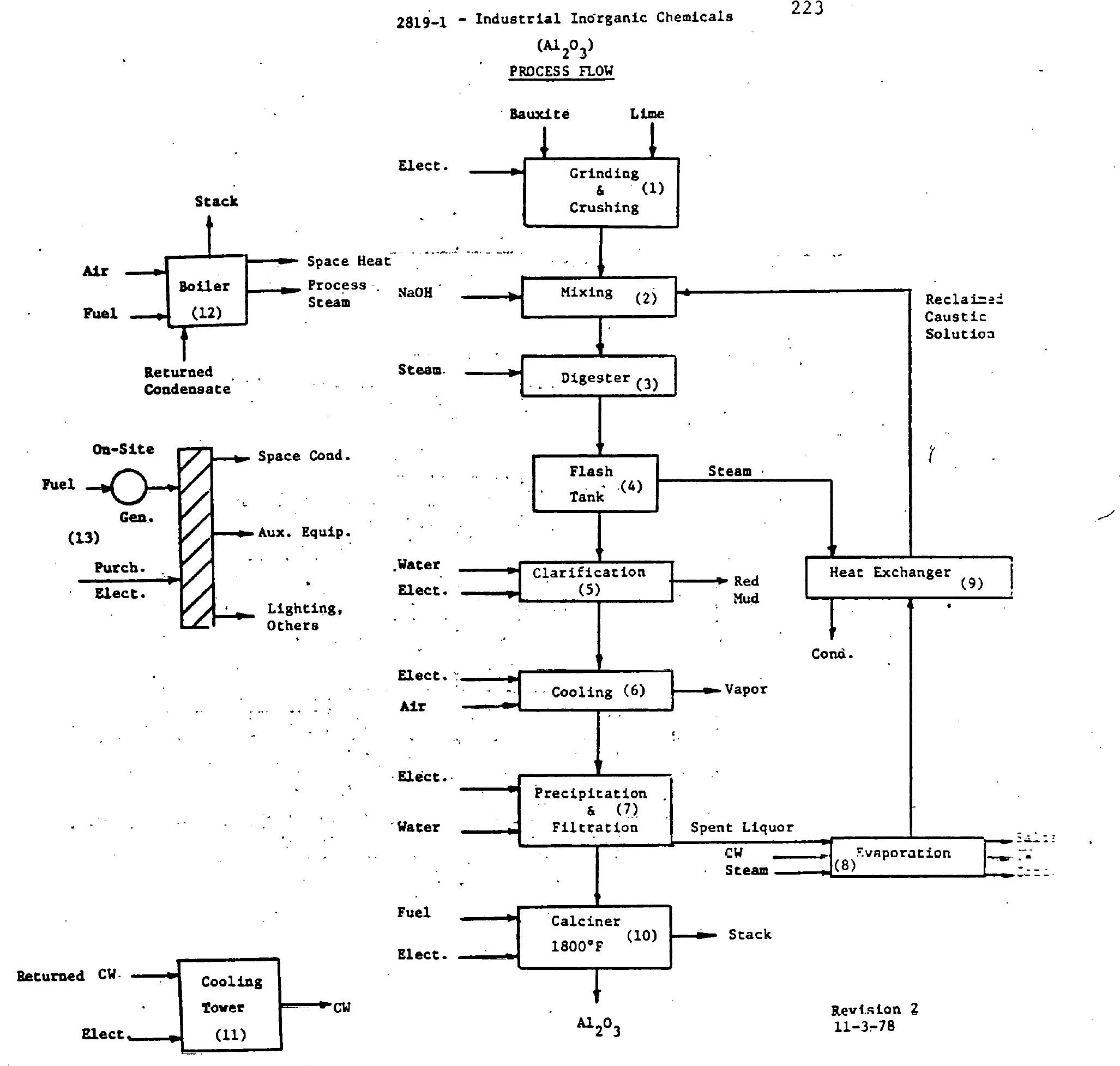


Procens Flon

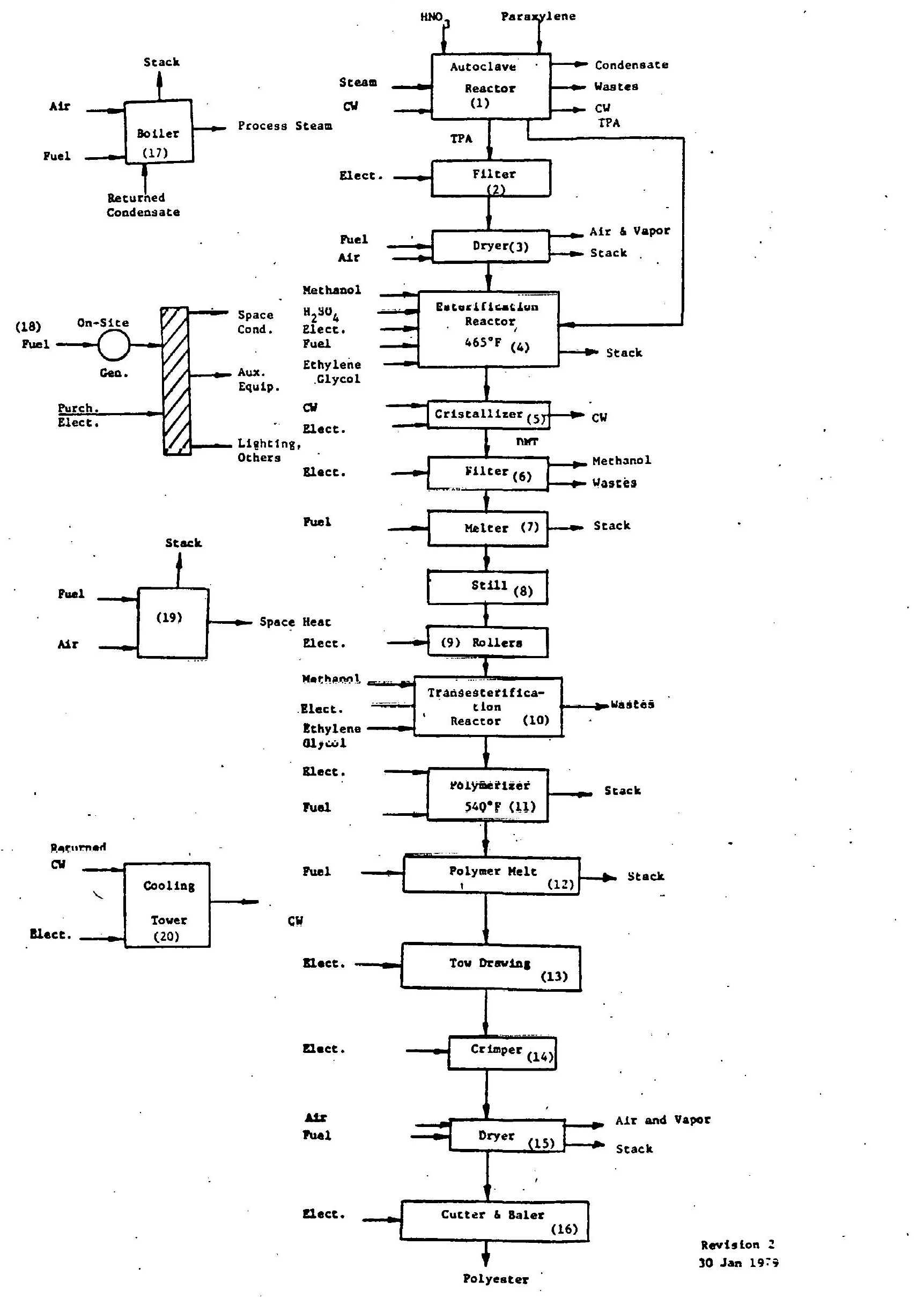


2911 Petroleum Reflning

Process Elow

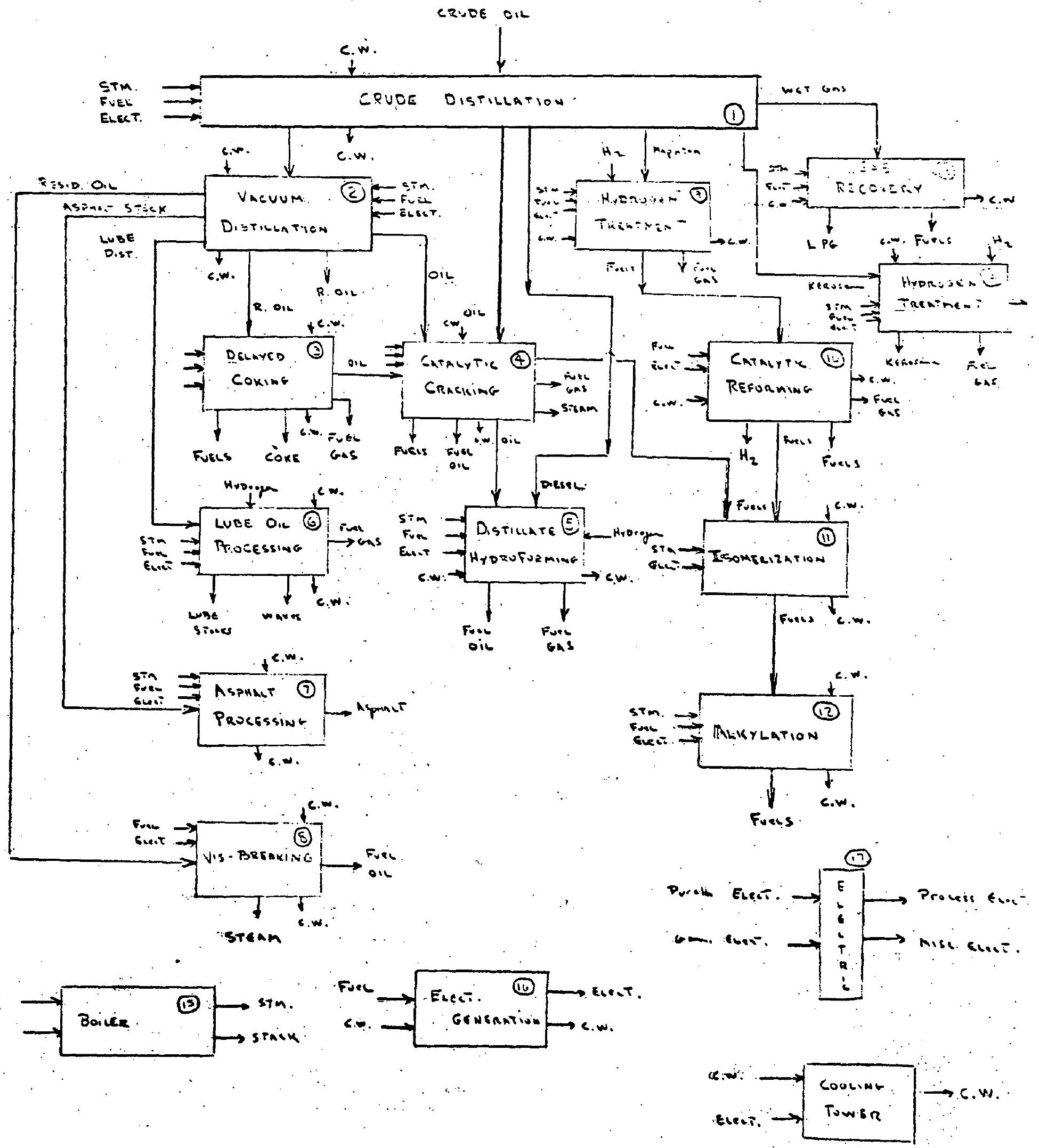




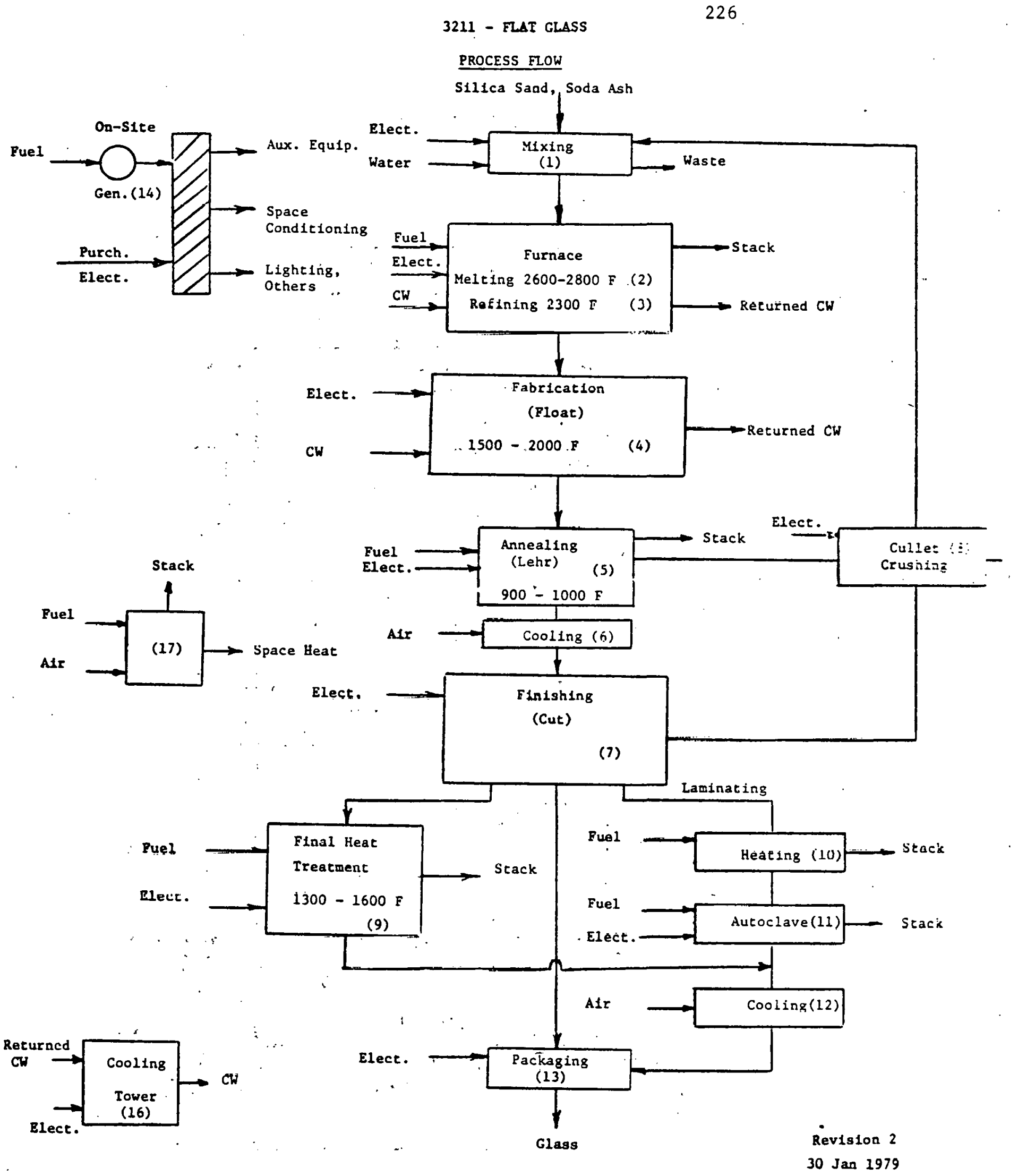


3241- CERENT, EYDRAULIC

PROCESS FLOW

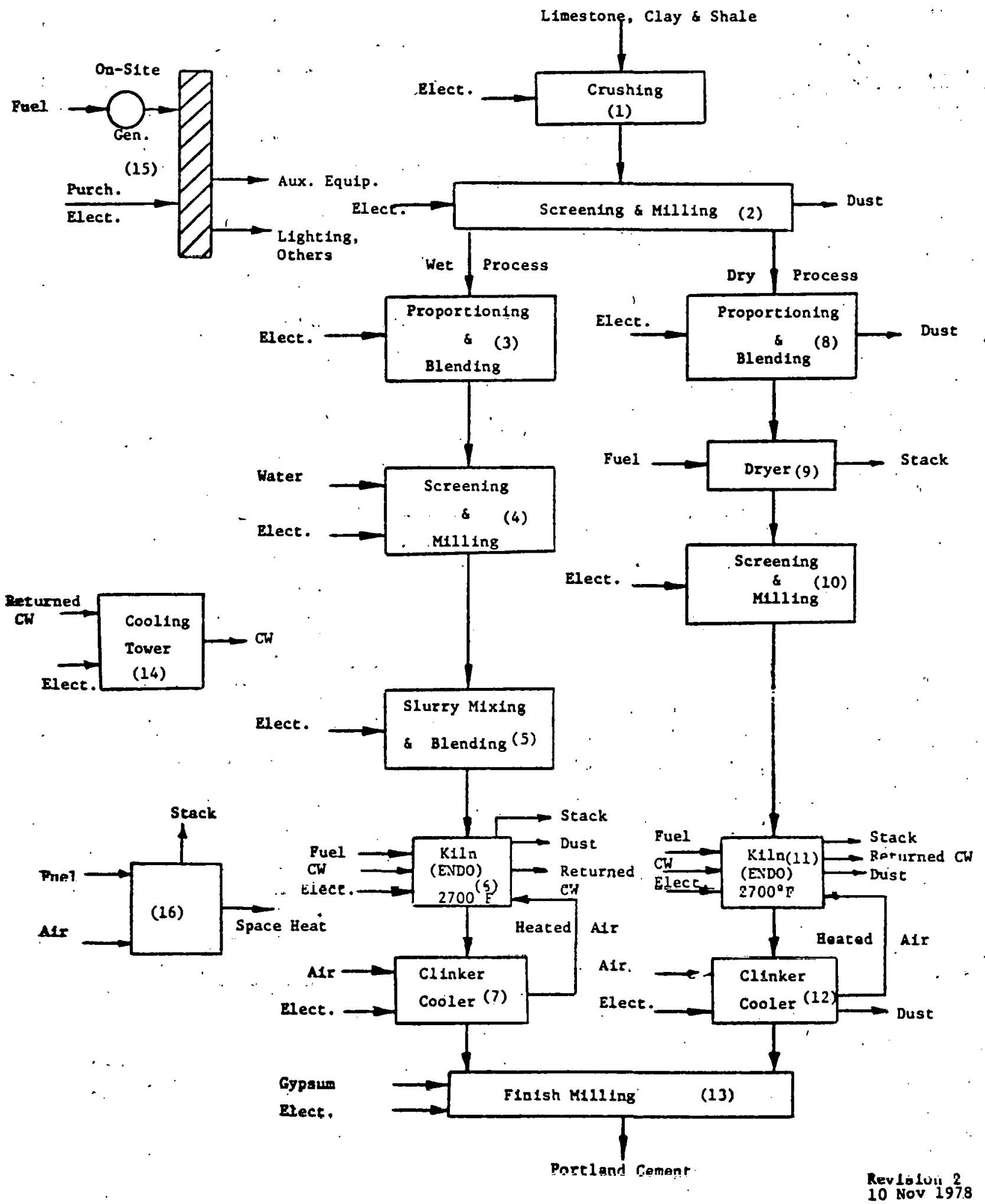


3274 - LIME

PROCESS FLOW

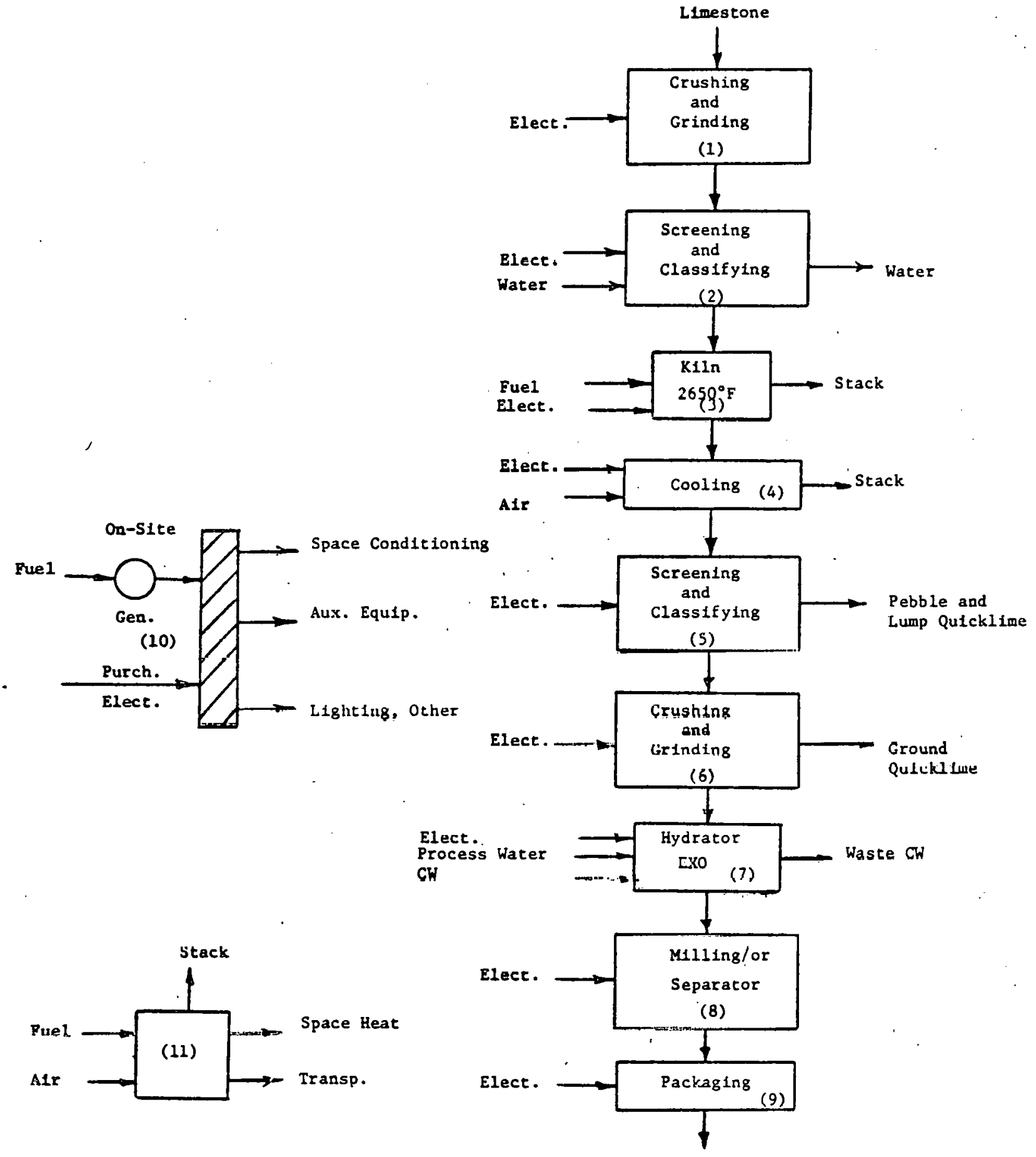

Bydrated Ilme

Revision 2

10 Nov 1978 

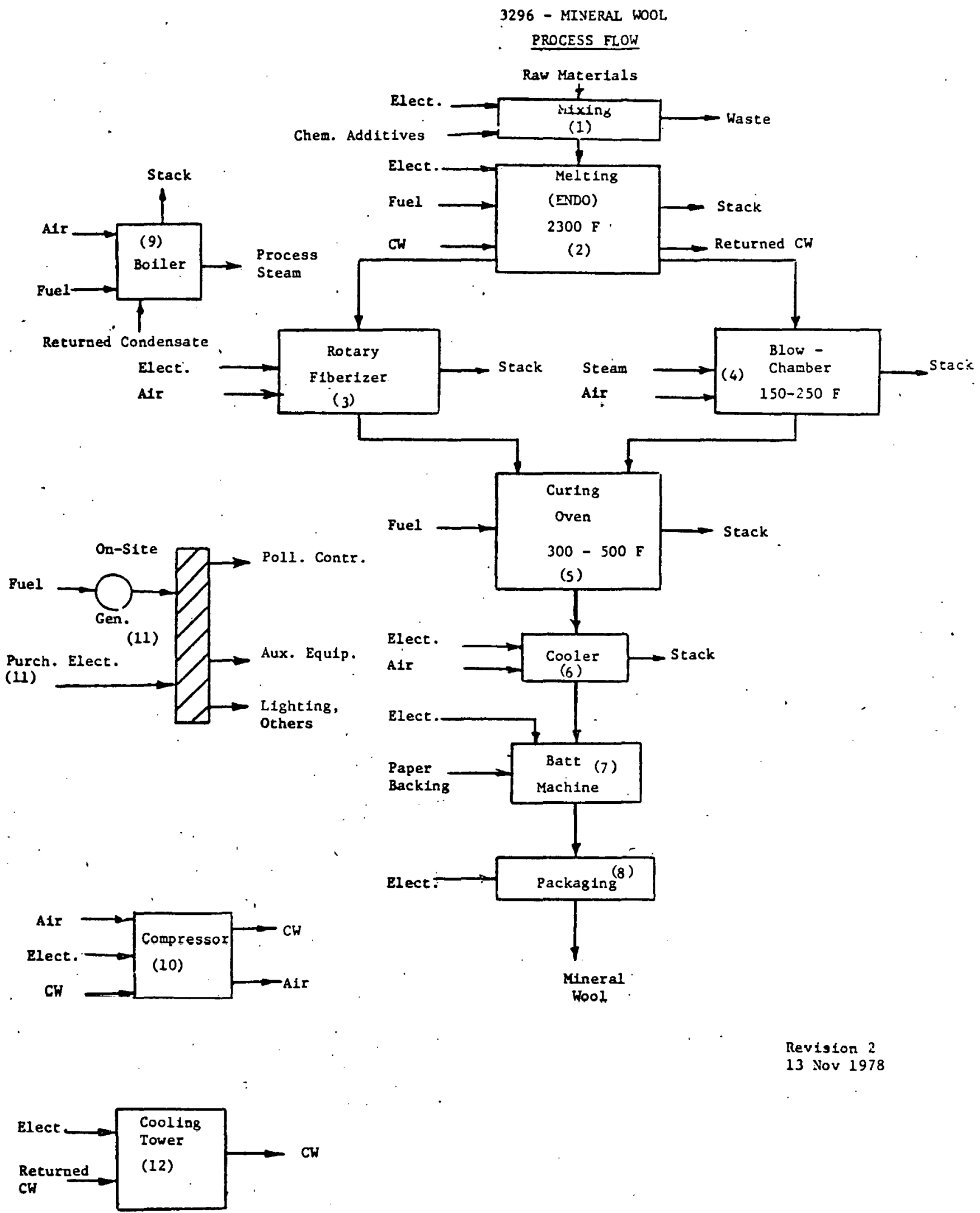
3312 - BLAST FURNACES AND STEEI MILLS

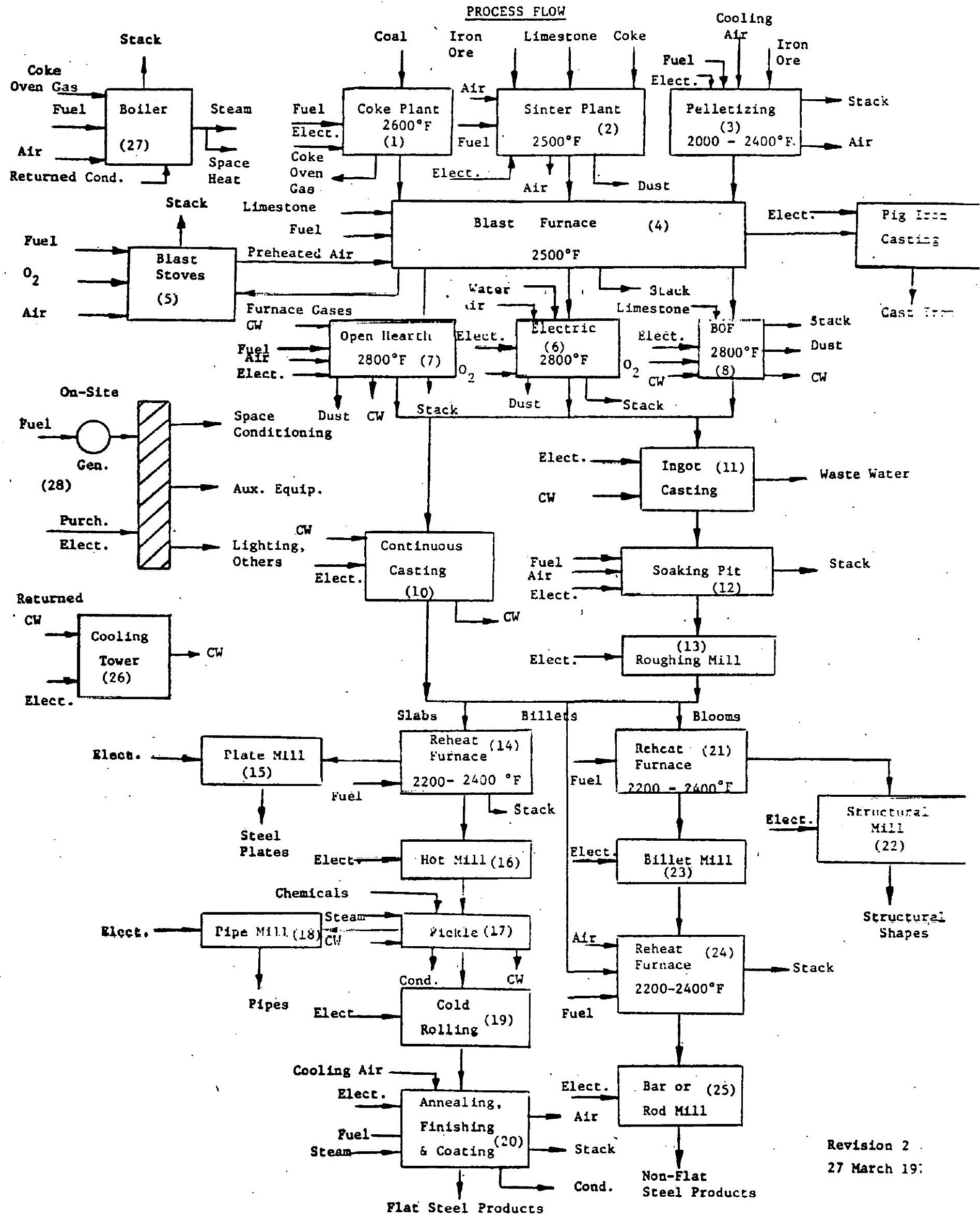



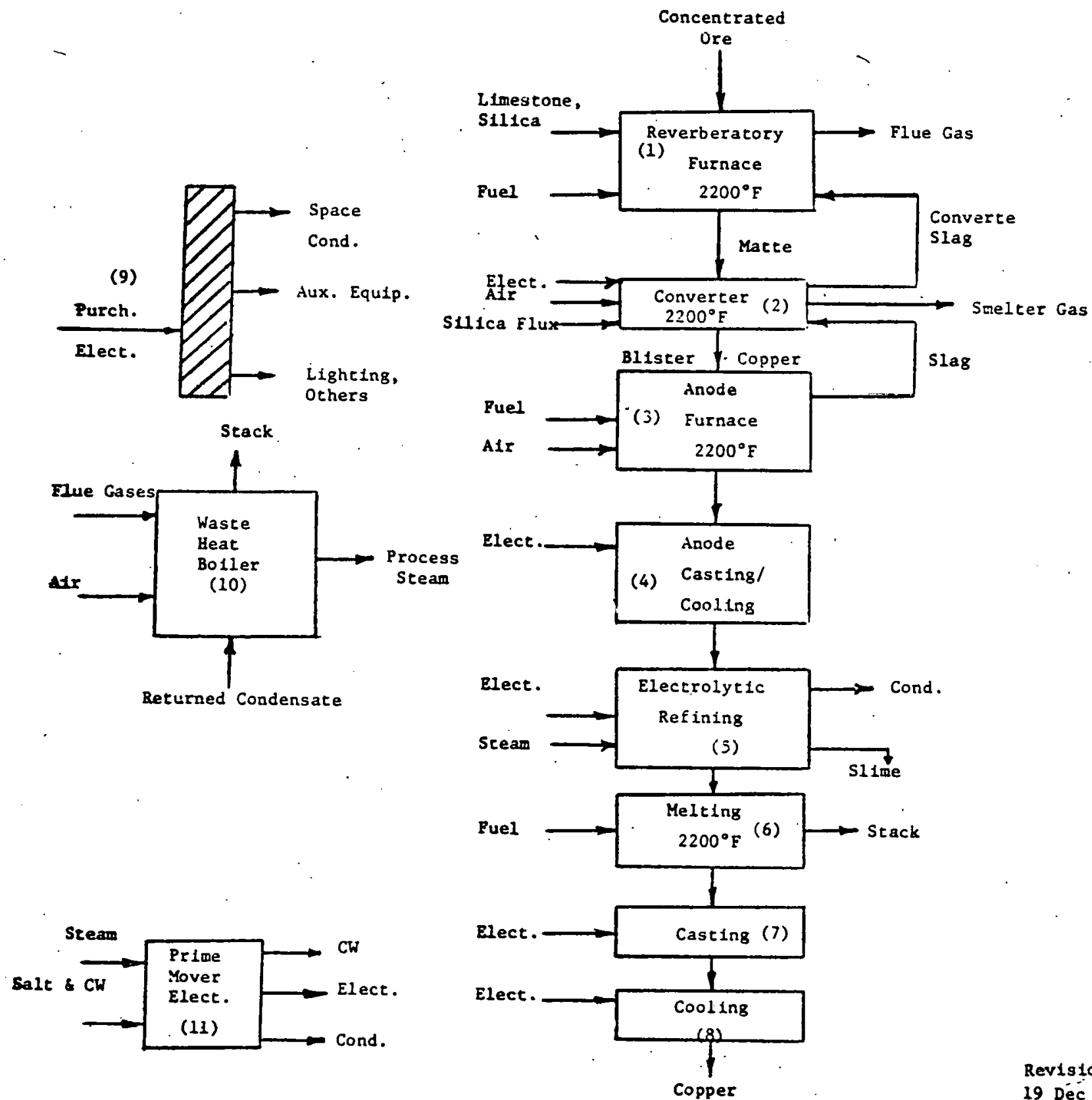


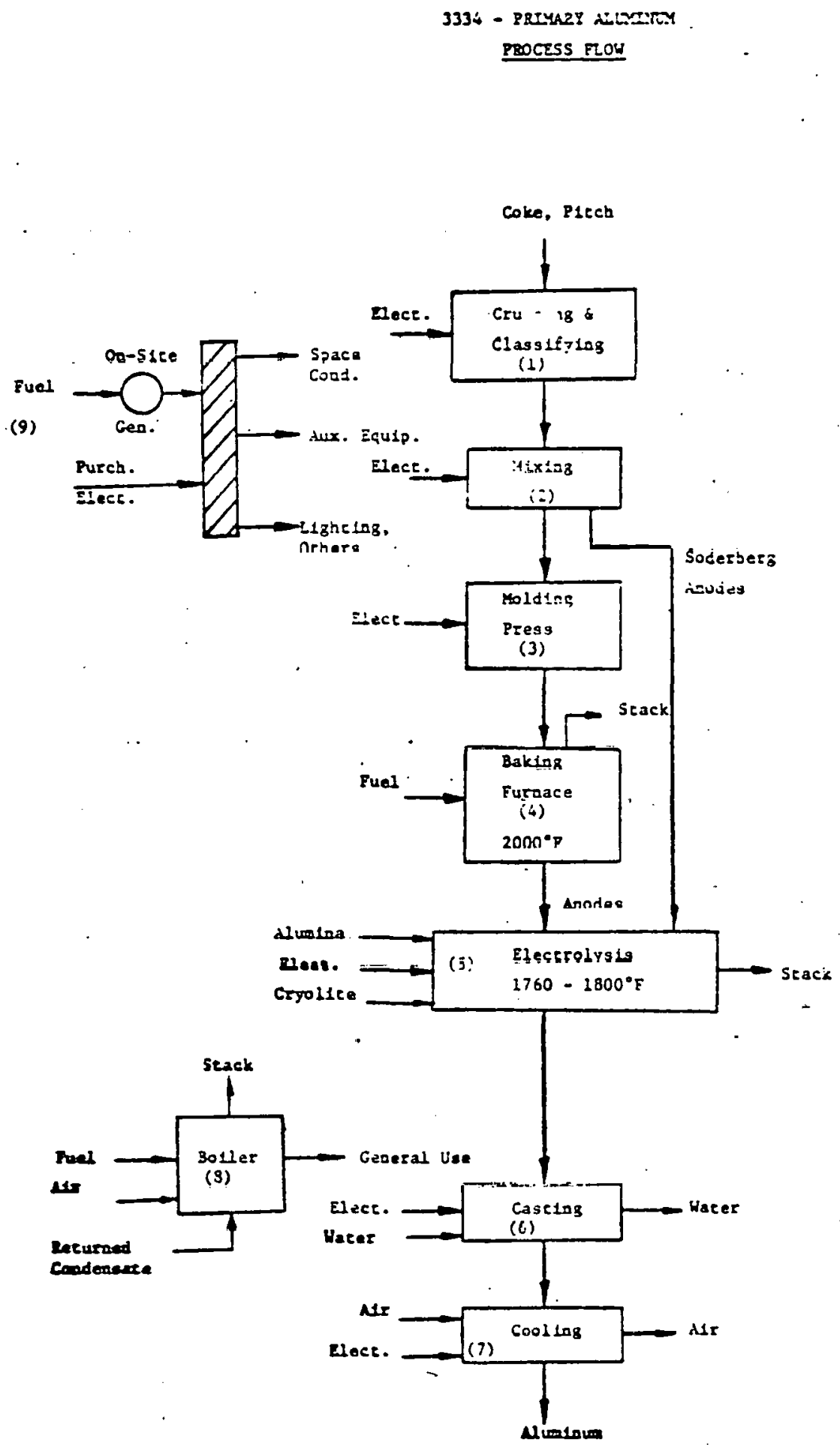

Rev1s1002 
3462 - IRON AVD STEEL FORGING PROCESS FLOW
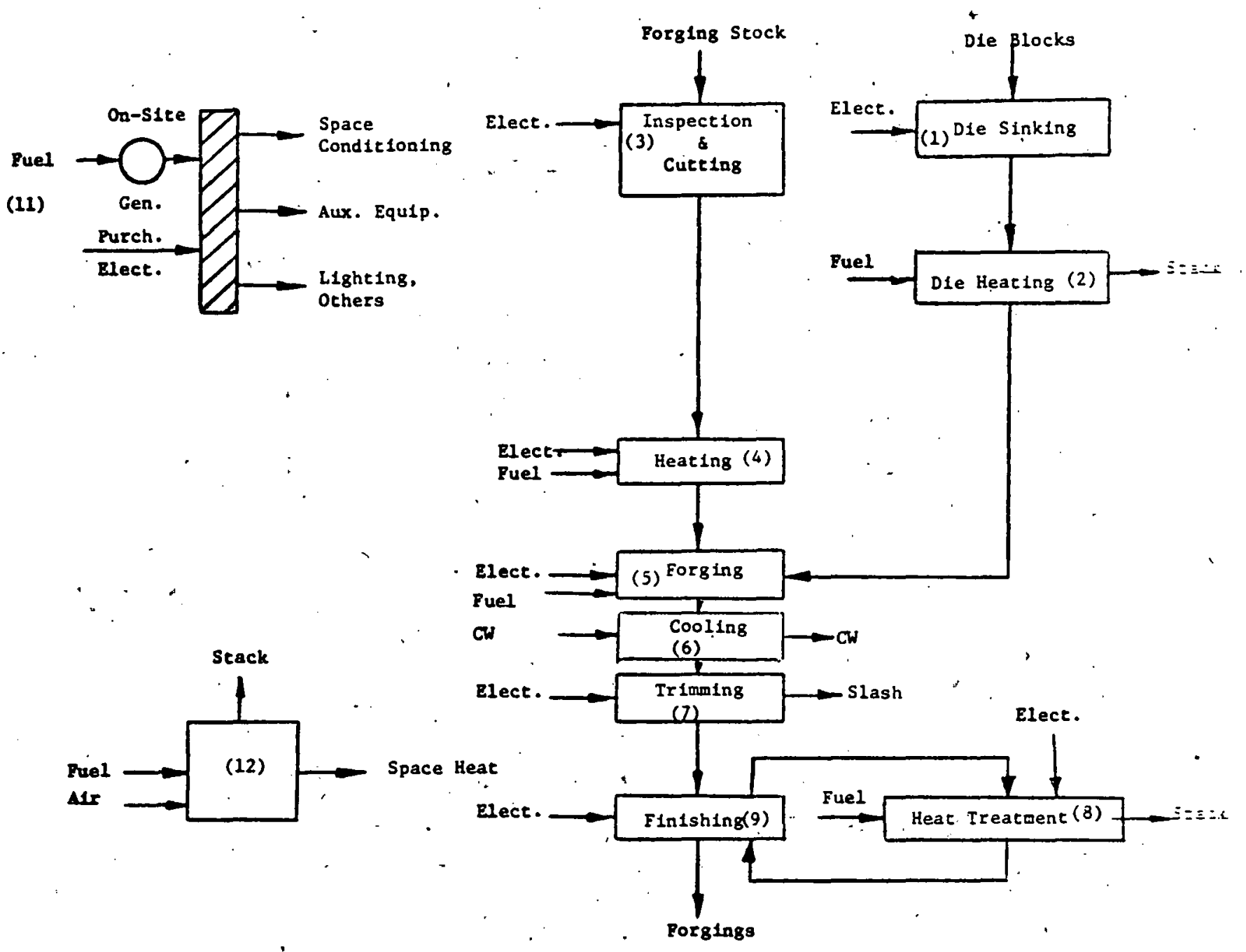

Detnroed

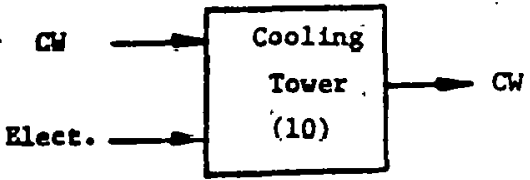

Revision 2

27 March 1979 

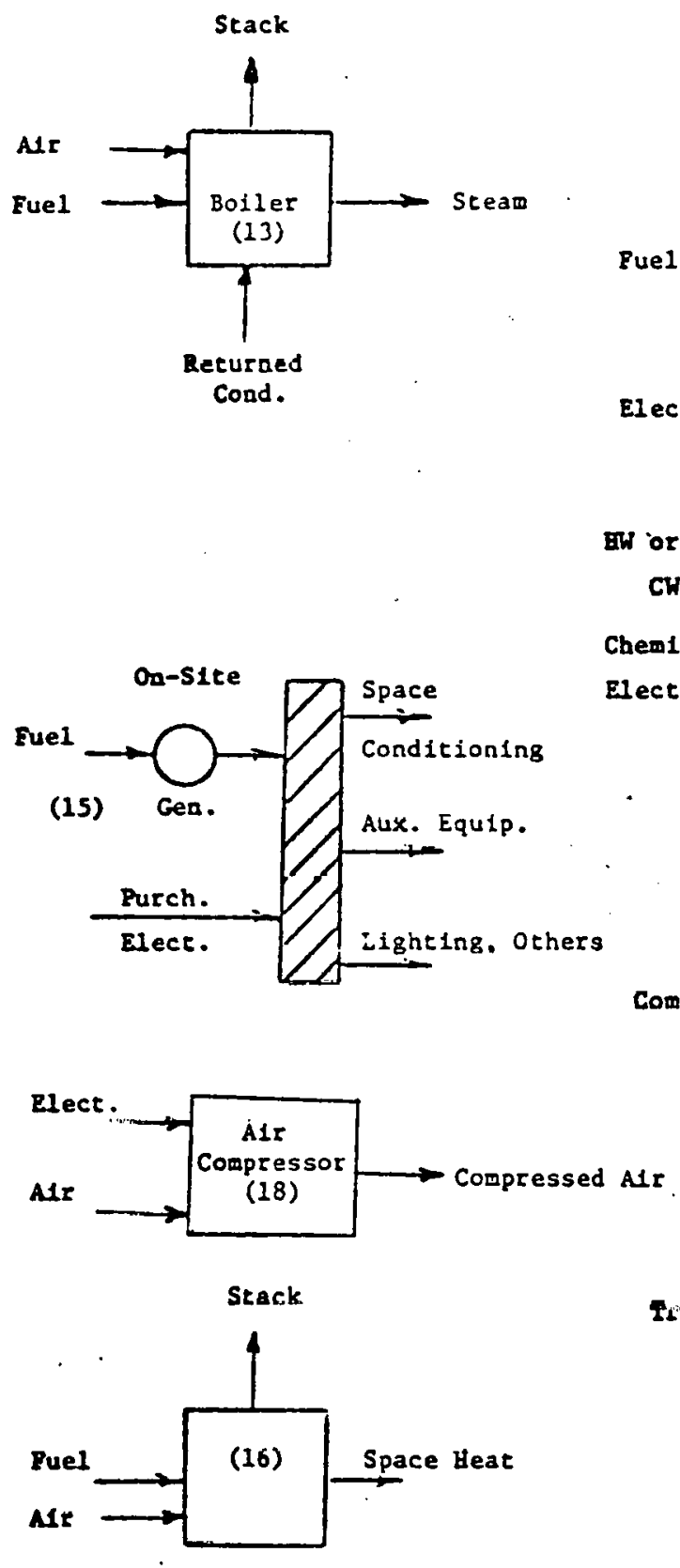

Returaed

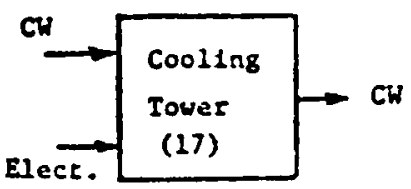

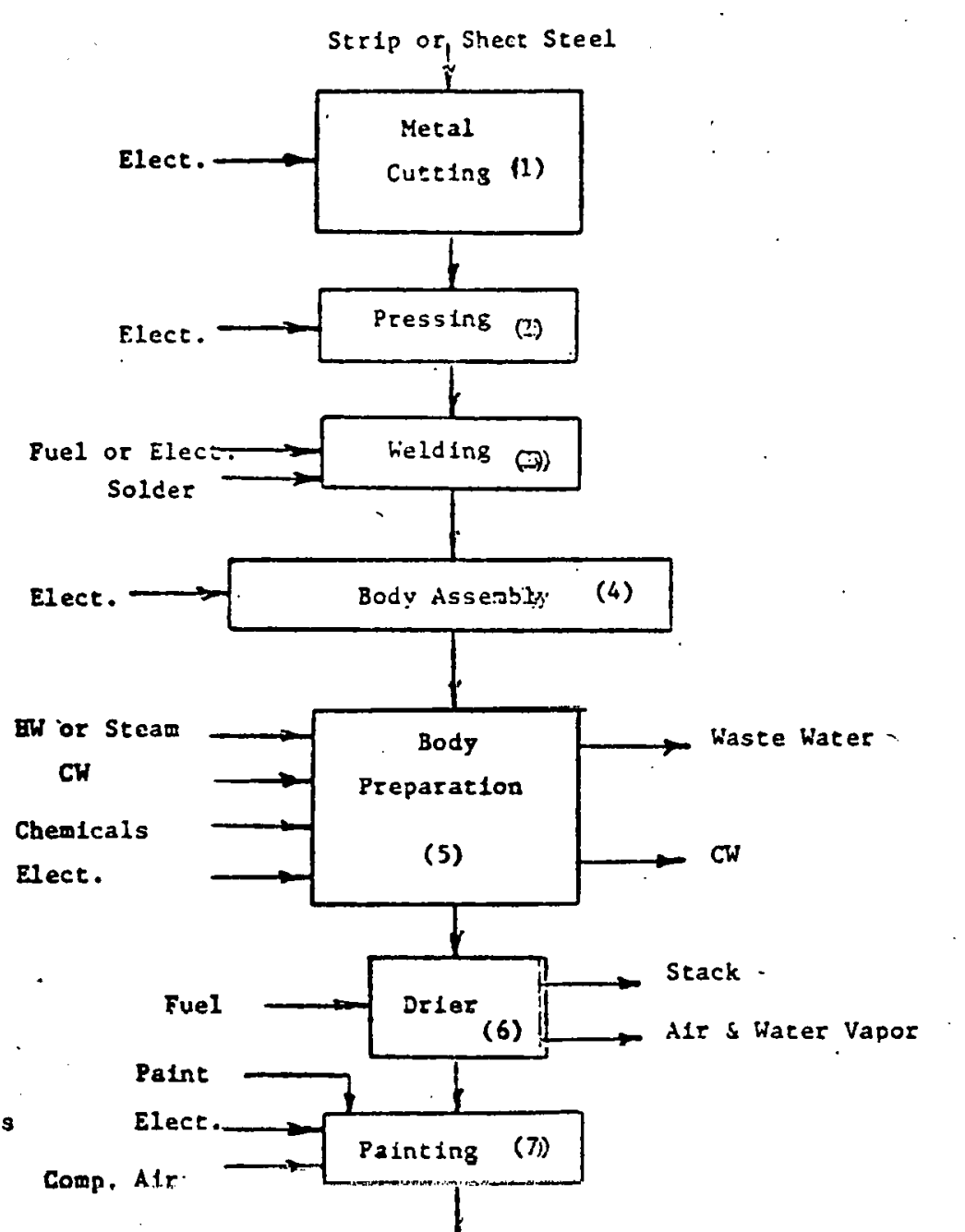


APPENDIX B

AVAILABLE ENEPGY ANALYSIS FOR HVAC

I. Inefficiencies in a Dual-Duct System

R. A. Gaggiol 1

Marquette University

Milwaukee, Wisconsin

Member, ASME

W. J. Wepfer

University of Wisconsin - Madison

Madison, Wisconsin

Associate Member, ASME

A. F. Elkouh

Marquatte University

Milwaukee, Wisconsin

Member. ASME

\section{ABSTRACT}

Available-energy is based on the Second Law, and goes back to Maxwell and Gibbs. Unfortunately, it has not yet caught on in engineering practice, or in managerial decision-making.

It is the available-energy content of a substance, not its energy content, wich truly represents the potential of the substance to cause change. Available-energy is the only rational basis for evaluating (1) fuels and resources, (2) process, device, and system efficiencies, (3) dissipations and their costs, (4) the value and cost of system outputs.

The paper presents a brief overview of Thermodynamics and a description of the methodology of second law analysis. Results from a case study are given which illustrate the efficiency analysis of a dual-duct HVAC system and components.

While exposing many misconceptions resulting from energy analyses, the results of the efficiency analyses pinpoint the opportunities for improving energy systems, showing griat potintial for alleviating "the energy problem" via conservation. This potential for conservation lies not in the usual, negative concept of austerity ("belt-tightening"), but in a positive approach: the reduction of very large dissipations in the processes which convert the resource to the desired form of "energy." In turn, the analyses show how economic-analysis decisions regarding "energy" systemis can be greatly facilitated, while avoiding the misappropriations (often gross) which result from enérgy analyses.

The efficiency analysis.evaluates the inefficiencies in and the effluent losses frow the varinus rommnents making up the system: (j.) at surmer design operating conditions, (ii) at winter design, (iii) for an entire cooling season, and (iv) for an entire heating season.

A sequel paper considers several modifications, which are deduced from the results of the efficiency analysis. The effects of these improvements upon fuel economy are systematically studied in that paper. 


\section{MOMENCLATURE}

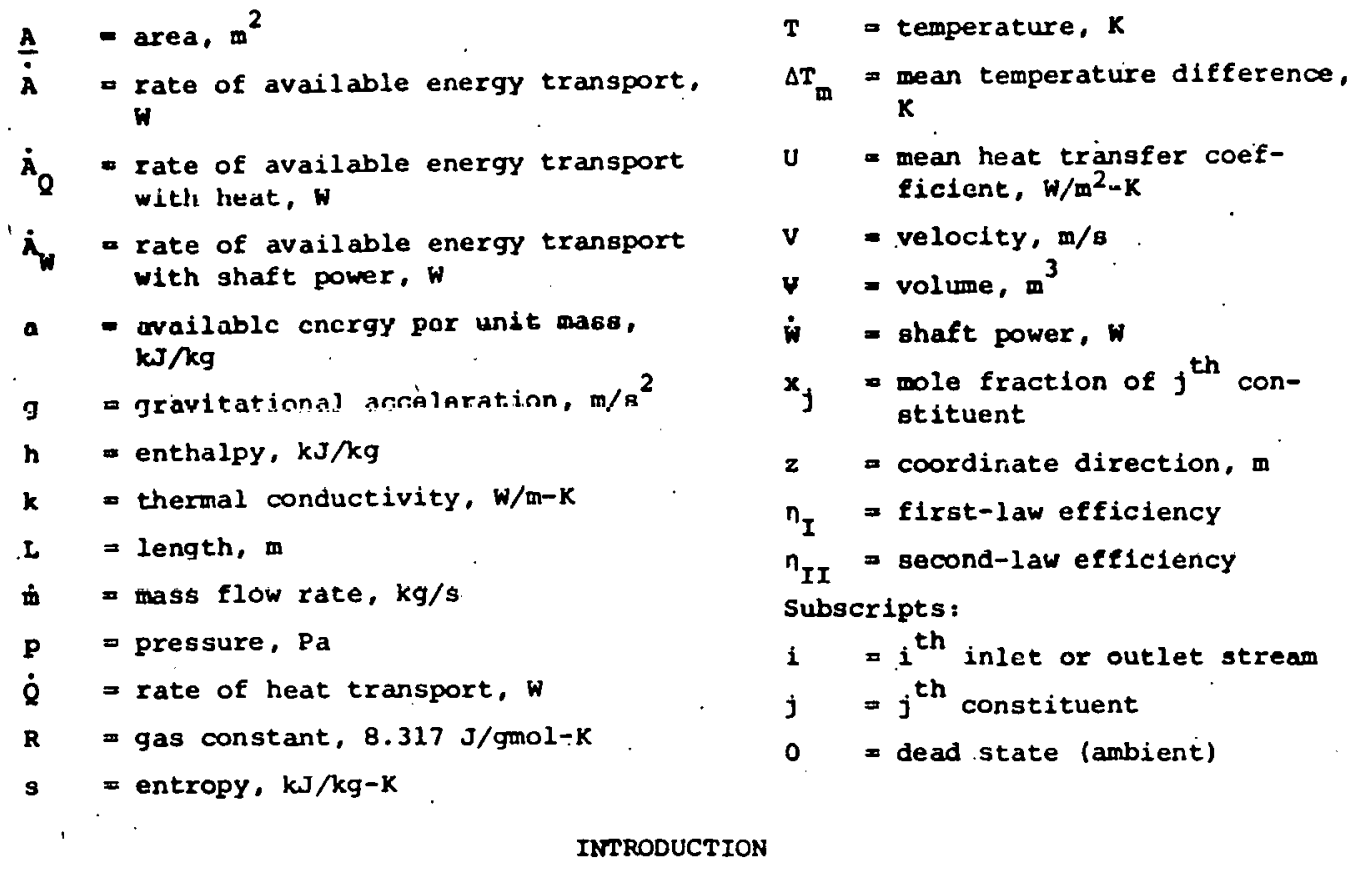

Preocnted in this paper are the results for the fundamental therwodynamic analysis of a dual-duct HVAC system. Such an analysis accurately pinpoints and evaluates the dissipations and losses in the system, as well as the efficiency of each component. Being a second-law analysis it is based, not on the firstlaw concept of energy but on the second-Iaw concept of available energy ${ }^{1}$--deFined as the useful energy derivable by bringing the substance into complete stable equilibriun whth the surroundings (the dead statel.

The results are not simply of academic interest; they are of real practical value in many ways. Engineering, administrative, and executive decisions often are made under the misimpressions given by energy analyses. For snme tima, prominent thermodynamicists $(1-8)^{2}$ have stressed the necessity to apply available energy in lieu of energy--in order to measure rationally the effectiveness with which fuels and resources are utilized--and have pointed out numerous examples of mismanagement resulting from the above-mentioned misimpressions. In fact the Federal Government recently has supported several studies based on the availableenergy concept $(9-11)$.

The results of second law analyses are much more enlightening than first-law (energy) analyses because the dissipations and efficiencies measured with available energy are the true ones, whereas those measured with energy are not.

What the scientist and engineer call "energy" is not the resource society

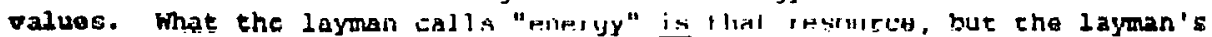
"energy" is symorymous with "available energy." When does the layman ascribe "energy" to a material? When it has a potential to cause change for him. But

${ }^{1}$ Several authors have presented the concept of available energy under a variety of names including: availability, available work, exergy, energy, utilizable, essergy, potential, energy, and useful energy. Regardless of the derivation or the name, the basic concept is the same, contentions to the contrary notwithstanding.

'Underlined numbers in parentheses designate references at end of paper. 
that. which is called energy by the engineer is not this potential. arr energy cannot be produced or destroyed; therefore, if it were truly a resource it would be non-depletable. We cannot resolve this paradox by saying that it is conserved, but it is degradable." Because, if energy loses potential to cause change for us, then energy cannot be the measure of that potential. The only resolution of the paradox is to realize that it is available energy which is the rational measure of potential to cause change for us.

It is available energy which drives processes; in 80 doing, it is literally used up--not degraded, but destroyed (consumed). "Energy converters" such as engines, power plants, or HVAC systems, take avallable energy in one form and convert it, in part, to another form, the part which is not coniverted is used up to accomplish the conversion. We could say that the consumed portion sustains ("fuelg") the conversion process.

biscussions of available energy and the evaluation of avallable energy for general systems whether open, closed, steady, or unsteady have been given in detail (12-15) and will not be repeated here. Reference. (16) developg the fundamental principles for practical evaluation of the available energy of psychrometric mixtures. The current paper presents the results of applying these principles to a typical. HVAC system. After a brief description of the methodology of available-energy analysis; results are given for a dual-duct HVAC system at sumer and winter design conditions and for annual heating and cooling, followed by a discussion of the results, and some conclusions and recomendations. A sequel paper, Part II, contains a survey of the quantitative effects on operating economy, resulting from several of the improvements recomended in Part $I$.

\section{THE METHODOLOGY OF AVAILABLE ENERGY ANALYSIS}

To date, practically all investigations that are made with the intention of locating and evaluating inefficiencies in energy-conversion systems are energy analyses. Energy analyses do not account for the consumptions that serve to drive the different processes and devices. The energy that does not leave in the product must go out with the effluents. As a consequence, the importance of losses associated with effluents are generally overestimated. The upshot is that energy analyses not only misconstrue the importance of effluents but, neglecting the all-important consumptions, greatly miscalculate the comparative efficiencies of different processes and energy systems $(17,18)$.

To improve the operating "fuel" economy of an "energy" system means to lessen the available energy consumed within the system and lost in effluent streams, so that, for a specified amount of product, the amount of available energy that needs to be supplied ("fuel"). is thereby reduced. Therefore, the evaluation of the available-energy content of fuels, products, and effluents is important, as well as the available energy consumed to drive the processes which accomplish the mnversion from fuel to product. The key relationships for making these evaluations are (i) balances for each independent commodity including available energy that is transported into or out of the system, (ii) transport relations between different commodities, (iii) kinetic relations (like $\bar{Q}=$ $-\mathrm{kA}[\mathrm{dT} / \mathrm{dL}]$ or $\dot{Q}=U \underline{\mathrm{A}}[\Delta \mathrm{T}]_{\mathrm{m}}$ ) which relate transports or reaction rates to driving forces, or device performance characteristics--which relate outputs to inputs, and (iv) invariably, property relations of materials (such as those for $\mathrm{H}_{2} \mathrm{O}$ embodied in the steam tables, or $\mathrm{pV}=\mathrm{RT}$ for perfect gases).

The steady-flow available energy balance which enables the consumptions to be evaluated is $(\underline{14}, \underline{16})$

$\left[\begin{array}{l}\text { Net available energy } \\ \text { supplied to system }\end{array}\right]=$

$$
\left[\begin{array}{l}
\text { Net available energy } \\
\text { transport out of system }
\end{array}\right]
$$

$+\left[\begin{array}{l}\text { Available energy consump- } \\ \text { tion within system }\end{array}\right]$

or

$$
\sum \dot{\mathrm{A}}_{\text {in }}=\Sigma \dot{\mathrm{A}}_{\text {out }}+\dot{\mathrm{A}}_{\text {consumed }}
$$


That 1s, the available energy steadily supplied is in part destroyed inside in order to sustain the desired process, whlle the remainder is dellvered in the outputs. (F'or the steady case there can be no accumulation of the input, nor any diminution of the content.)

The transport relations for available energy inputs to or outputs from a system are

$$
\dot{A}_{Q}=\left[1-\frac{T_{0}}{T_{Q}}\right] \dot{Q}
$$

for heat transfers or

$$
\dot{A}_{w}-\dot{w}_{\text {shaft }}
$$

For shaft power or

$$
\dot{A}_{i}=\dot{\mathrm{m}}_{i} a_{i}=\dot{\mathrm{m}}_{i}\left[h_{i}+v^{2} / 2+g z_{1}-T_{0} s_{i}-\sum x_{j i}\left[h_{j 0}-T_{0} s_{j 0}\right]\right]
$$

with flows of matter. Referencis (14) and (16) present relationships for practical evaluation. of these available energy transfers for HVAC applications.

A measure of the operating "Euel" economy of an encrgy system is provided by the second-law efficiency (effectiveness ${ }^{3}$ ):

$$
n_{I I}=\dot{A}_{\text {product }} / \dot{A}_{\text {fuel }}
$$

The denominator of $n_{\text {II }}$ exceeds the numerator by the amount of availability consumed plus the amount lost in effluents.

$$
n_{\text {II }}=\frac{\dot{A}_{\text {product }}}{\dot{A}_{\text {product }}+\dot{A}_{\text {consumed }}+\dot{A}_{\text {lost }}}=\frac{\dot{A}_{\text {supplied }}-\dot{A}_{\text {consumed }}-\dot{A}_{\text {lost }}}{\dot{A}_{\text {supplied }}}
$$

For any conversion process, the theoretical upper limit of $n_{I I}$ is 100 percent, . which corresponds to the ideal case with no dissipations or losses.

Not only is an overall analysis of an "energy" system valuable, hut sn is a detailed analysis which pinpoints the location and magnitude of the available energy consumptions within the system. The procedures for making a more detailed analysis are identical to those for the overall system. Thus, as is done in this paper, a dual-duct HVAC system can be broken down into its components

- (fans, ducts, compressors, heat exchangers,....), and each can be analyzed for its own efficiency and for the amount of availability it consumes, say as a fraction of the total used by the.overall system. Furthermore, components (e.g., a boiler) can be analyzed process by process (a.g., combustion, heat transfer, stack loss,...,.

\section{TECHNICAL ANALYSIS}

The HVAC system analyzed in this paper is illustrated in Figure 1. Air is distributed by a dual-duct low-pressure system. Temperature control is maintained in each zone with mixing-boxes. Return air flows through zone 14 (described below) betore it is mixed with frcsh air. Whenever atuantageous, the system utilizes fresh-air cooling by exhausting larger quantities of air from zone 14 and inducting a larger quantity of fresh air. During unoccupied. hours all return air is recirculated--that is, no air is exhausted.

On the equipment side cooling is provided by direct expansion, with an air-cooled, unloading reciprocating compressor; fresh-air cooling is employed whenever the outdoor temperature, $T_{0}$, is.less than $60 \mathrm{~F}$ or when $T_{0}$ is $g r e a t e r$ than $60 \mathrm{~F}$ and the enthalpy of the return air is greater than that of outdoor air.

"This use of the word "effectiveness" $(2,3)$ should not be confused with the more puhlicized "heat-exchanger effectiveness" $;$ hence, the name "Sccond-Law.. efficiency" is preferable. 


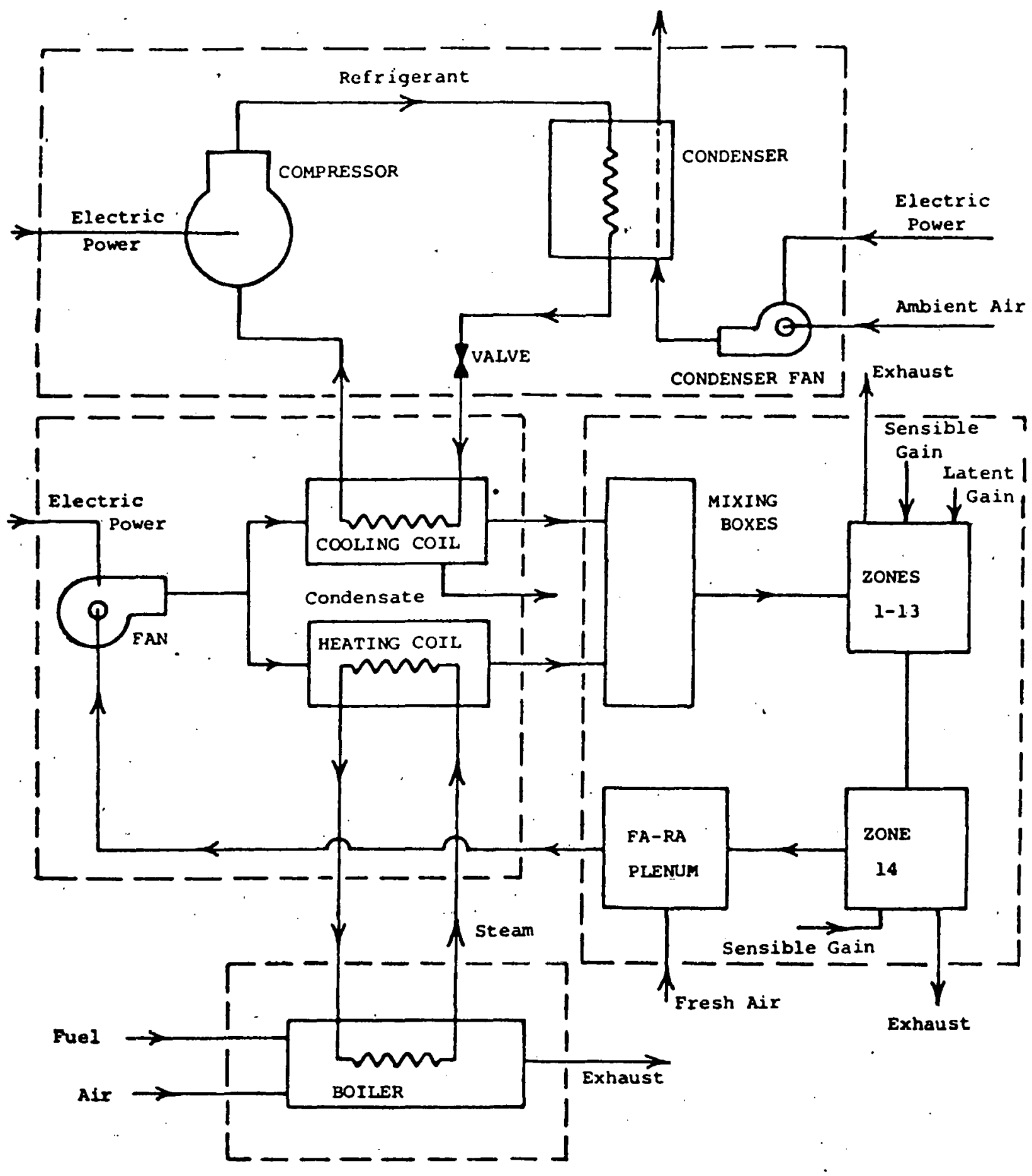

Fig. I Schematic diagram of the dual-duct heating and air-conditioning system.

Two alternative heating systems are considered. Figure 1 illustrates the first case, where the hot deck is supplied with steam delivered from a 100 psig gas-fired boiler. The secund case has the boiler replaced by a heat pump with supplementary resistance heating. During times when the building is occupied, the heat pump extracts heat from the ventilation exhaust air--which provides all of the required heat except under the coldest of outdoor conditions. During unoccupied hours, outdoor air is the heat source for the heat pump.

This syster is very similar to one installed in a school in the upper-

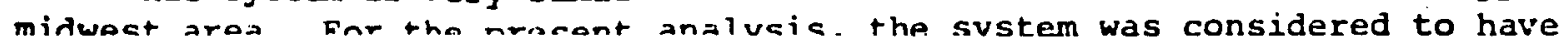


Lourteen zones, comblning some of the actual zones for simplicity. In the school the.vast majority of the return air flows through the lighting troffers, for the purposes of this study it was found convenient to combine the resultant heat gain, along with the other heat transalssions to or from the apace above the celilings, into a zone--zone 14.

The design loads (hoth heating and cooling) were abtained with the ald of one of the well-known computer simulation prograns (19), taking into account pertinent bullding information, weather data, thermophysical property data, solar data, ventilation and Infiltration requirements, occupancy information, lighting loads and so on. Computer results were obtalned for numerous systems Including (i) the ones described above, and (1i) the type actually installed-a heat pump system with water storage (20). The results from the computer model correlated quite well with extensive data collected over many yoars $\mathrm{frcm}$ the actual system and other similar systems. Therefore the computer results were considered to be reliable.

Som of the operating conditions of this gyoter exes a deaign cooling load of just over $227 \mathrm{~kW}(775000 \mathrm{Btu} / \mathrm{hr})$ at $-25.8 \mathrm{C}(-15 \mathrm{~F})$, the ventilation lasd is 199kW (680000 Btu/hr). While the heat gains axceed the tranemisgion 10s8s. iuring unoccupled hours, with no ventilation load, the design heating load is nearly $116 \mathrm{~kW}(395,000 \mathrm{Btu} / \mathrm{hr})$.

Once the energy loads and system performance characteristics are known the onergy states and flows follow as a result of mass and energy balances, and property and kinetic relations. The available energy flows are then computed from relationships like Eqs. (1)-(4) and special forms thereof (16). Figures 2, 3 and 4 show the design energy loads as well as the corresponding available energy loads and flows.

Several off=design conaleions lor bôth heating and cooling were studled. The off-design loads were determined from the results of the conputer simulatIon. Power and fuel inputg to the equipment were based upon performance characteristics obtained from manufacturer's data. The avallable ehergy loads and flows are calculated in the same manner as for the design cases.

Seasonal available energy. flows and consumptions were determined by summing the flows and consumptions at each off-design condition, weighting each appropriately for the number of hours of operation near that condition. Figures 5-9 ll lustrate the annualized available energy flowg and consumptions for the various cases considered in this paper.

\section{DISCUSSION OF THE RESULTS OF AVAITABLE EMERGX MNMYSES}

In this section the results of the yarlous analyses will we prasanten and dscussed, including several important general observations regranding system modifications for improving performance. Consequent recomendations, along wth the results that such modifications have on the system operating econoury. will be alscubodd in Part Ir.

Sumer Design (Comling)

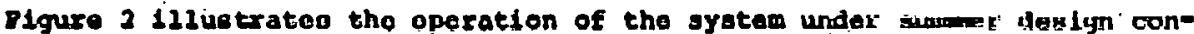
ditlons, showing available energy flow rates into, between and cout of the major components, as well as the available energy consumptions in the various. processes. The energy flows are also shown, in parentheses; a negative value weans that energy is flowing in the opposite direction from the arrowhead--in the opposite alrection of the available energy.

The true loads being met by the overall cooling system--tine true useful outputs of the system; 1.e.. the system's reason-for-being--are ithe $2.3 \mathrm{kw}$ and $0.30 \mathrm{kH}$ available energy outputs for picking up the sensible am latent loads In 20 es 1-13. The inputs, which "drive!" the overall system, arre the $65.1 \mathrm{kw}$, $6.7 \mathrm{~kW}$, and $8.5 \mathrm{~kW}$ electrical inputs to the compressor, condenser $f$ an and alr-distribution fan. Thus the second-law efficiency of the gyorem is

$$
n_{I}=\frac{2.3+0.30}{65.1+6.7+8.5}=0.032
$$

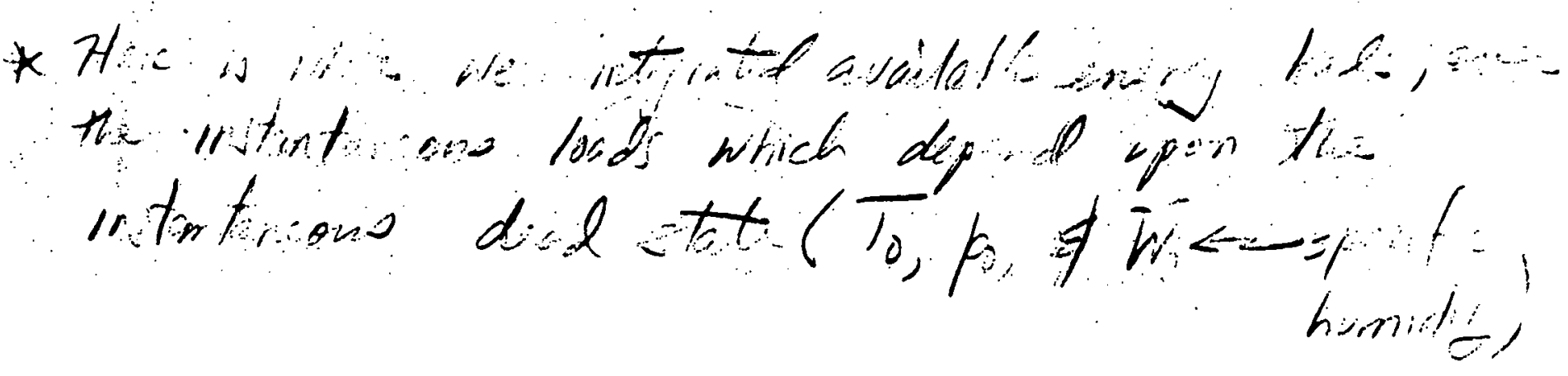




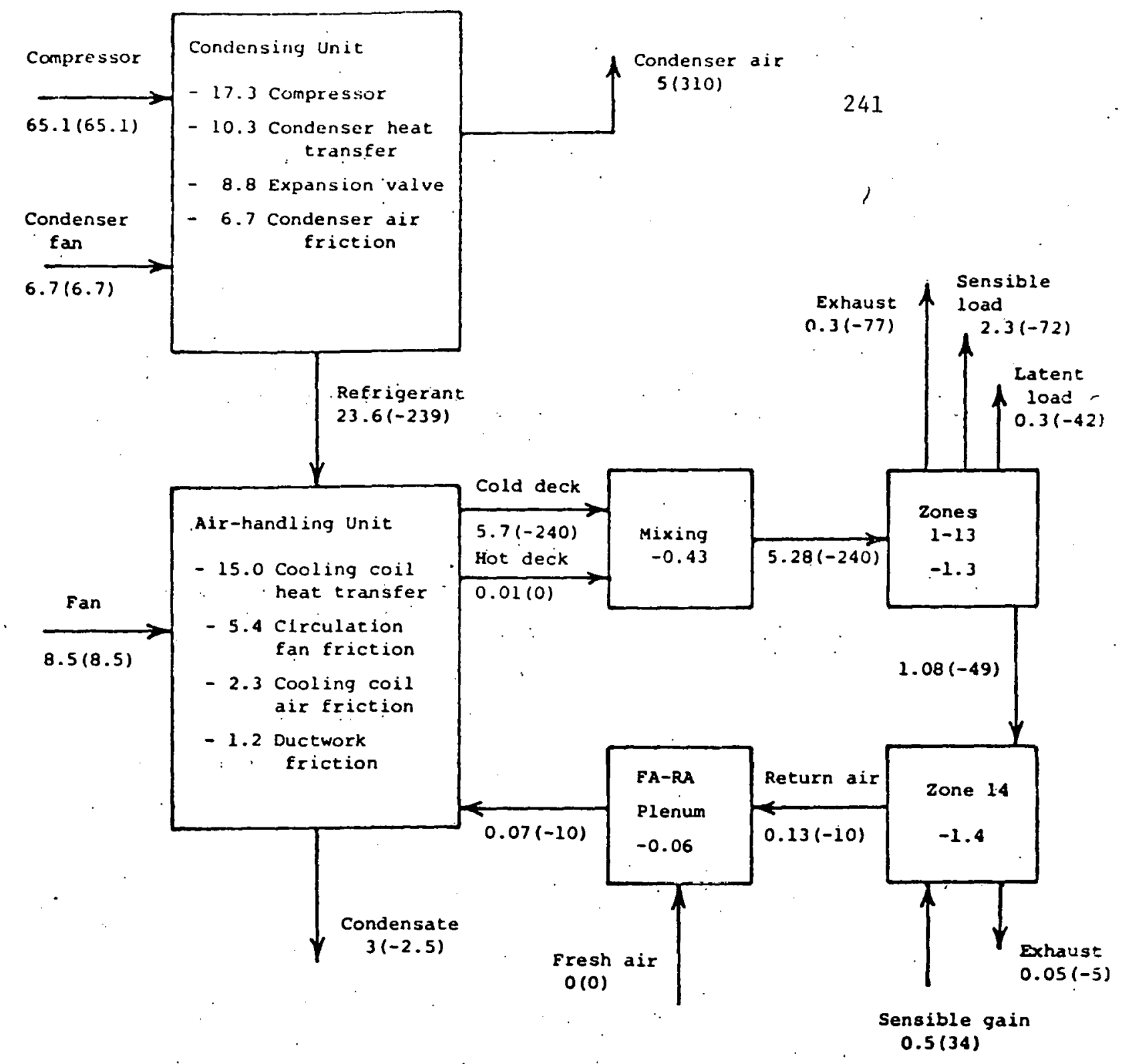

Fig.2 Summer design available energy flows, consumptions, and energy flows in kw. Negative numbers represent available energy consumptions. Energy flows are shown in parentheses and are positive in direction of arrow.

In other words, electricity of an amourt 30 times the minimum is being used to accomplish the desired task!. However this reveals the true potential for conservation; there is significant room for improvement by reducing the large consumptions of available energy.

The difference between the $80.3 \mathrm{~kW}$ supplied and the $2.6 \mathrm{~kW}$ product (useful output) is in part consumed (destroyed) in the various components, while aooomplishing the proces3es that oceur therein, and in part it is lost in the effluent streams. As shown in Fig. 2, the consumptions predominate, although there are at least two significant losses--warm air off the condenser (5 kW) and cold condensate off the cooling coil ( $3 \mathrm{~kW})$. The largest consumptions are (i) In the compressor $(17.3 \mathrm{~kW})$, as a result of mechanical- and flow-friction, 


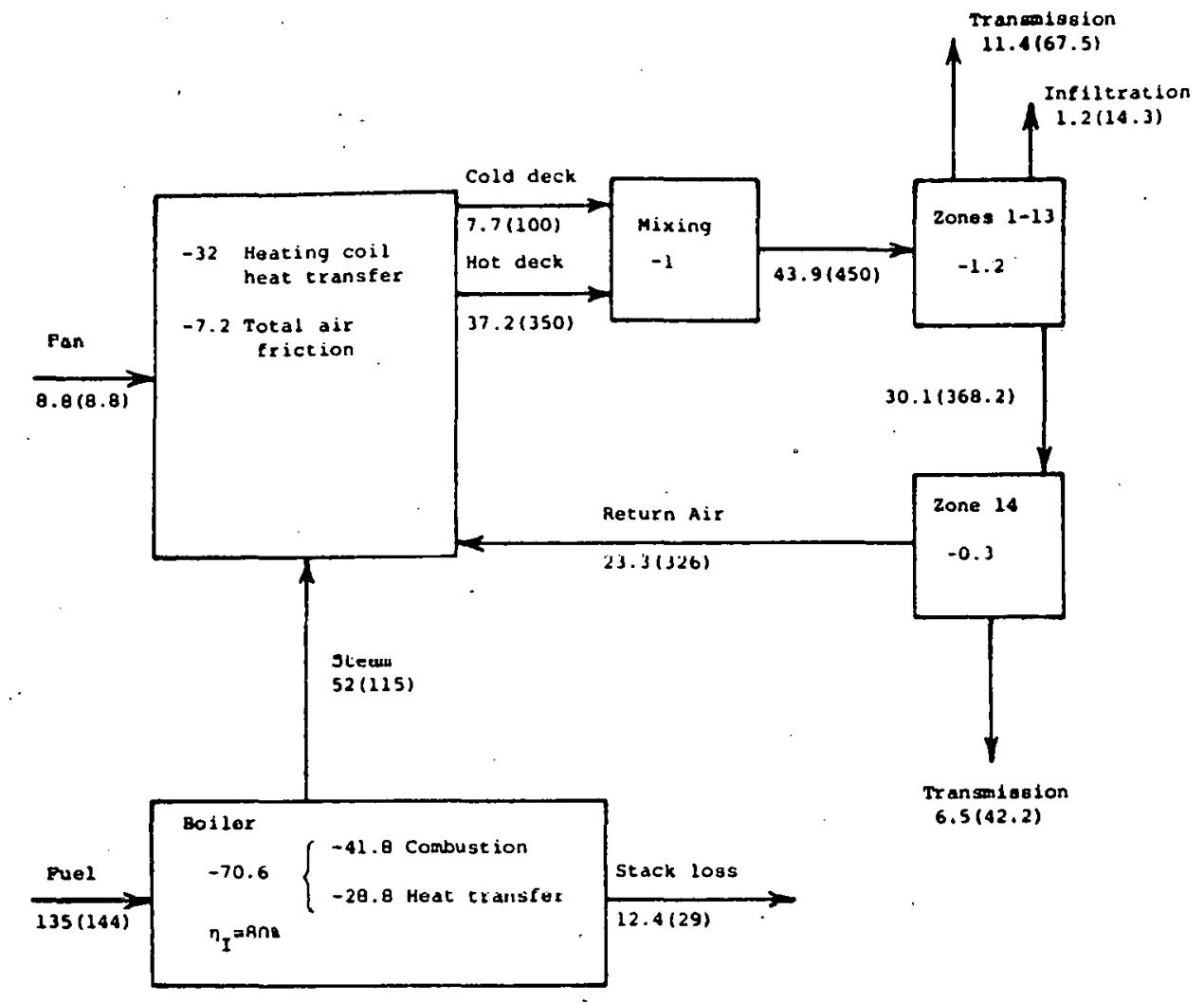

Fig.3 Winter design (unoccupied) available energy flows, consumptions, and enesyy fluws ln kï. Negarive numbers represent available energy consumptions. Energy flows are shown in parentheses and are positive in direction of arrow.

and (ii) in the two main heat-transfer processes, at the condenser $(10.3 \mathrm{~kW})$ and the evaporator ( $15 \mathrm{~kW}$ ), as a result of the sizable temperature differences between the heated and cooled media. Over half of the $80.3 \mathrm{~kW}$ input is used up in these three processes. Fan and air-flow friction, in the condenser $(6.7 \mathrm{~kW})$ as well as throughout the air-distribution system $(5.4 \mathrm{~kW}$ and $2.3 \mathrm{~kW})$, are very sizeable consumptions, as is the throttling friction in the expansion valve $(8.8 \mathrm{~kW})$.

Each of the aforementioned losses and consumptions is considerably larger than the $2.6 \mathrm{~kW}$ system output.

Minor consumptions include the $0.43 \mathrm{~kW}$ of the mixing boxes, which does not include flow friction due to the pressure drop in the mixing boxes t that friction is included in the $1.2 \mathrm{~kW}$ consumption shown schematically in the air-handling unit (where all of the circulating air-flow friction is shown, for convenielicel. The $0.43 \mathrm{~kW}$ loss is a consequence of mixing. Similarly the $0.06 \mathrm{~kW}$ consumption is a result of the mixing of return air with fresh air. The $1.3 \mathrm{~kW}$ consumption in zones $1-13$ is a consequence of the mixing of 


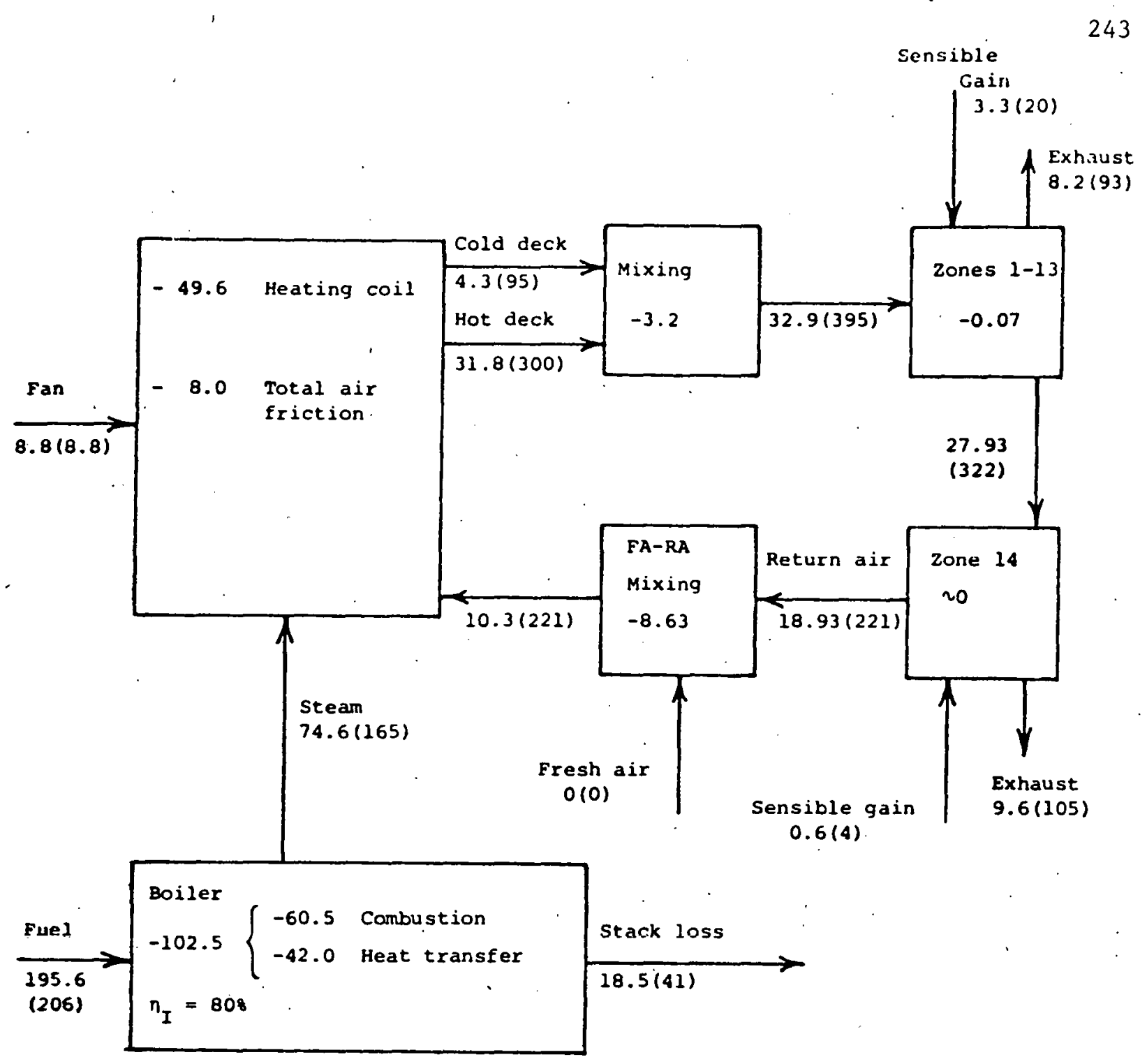

Fig.4 Winter design (occupied) available energy flows, consumptions, and energy flows in $\mathrm{kW}$. Negative numbers represent available energy"consumptions. Energy flows are shown in parentheses and are positive in direction of arrow.

conditioned supply air with the room air, while the $1.4 \mathrm{~kW}$ loss in zone 14 results primarily from mixing the air going to zone 14 from zones $1-13$ at $24.2 \mathrm{C} .(75 \mathrm{~F})$ with the air in Zone 14 , which is considerably warmer at $37 \mathrm{C}$. (Incidentally, 0.5 of the $1.4 \mathrm{~kW}$ dissipated in Zone 14 is available energy supplied at $37 \mathrm{C}(98 \mathrm{~F})$ with heat from the lights; supplied, inasmuch as the heat is at a temperature greater than $T_{0}=35.3 \mathrm{C}(95 \mathrm{~F})$. This heat could be collected with outdoor air. No doubt, the reason it is collected with return air is that it is considered less expensive than other schemes--especially since that heat is a desired commodity during the heating season.)

Annual Cooling

Figure 5 presents the accumulated available-energy flows, consumptions, losses, and outputs for one year of cooling operation. The true system. 


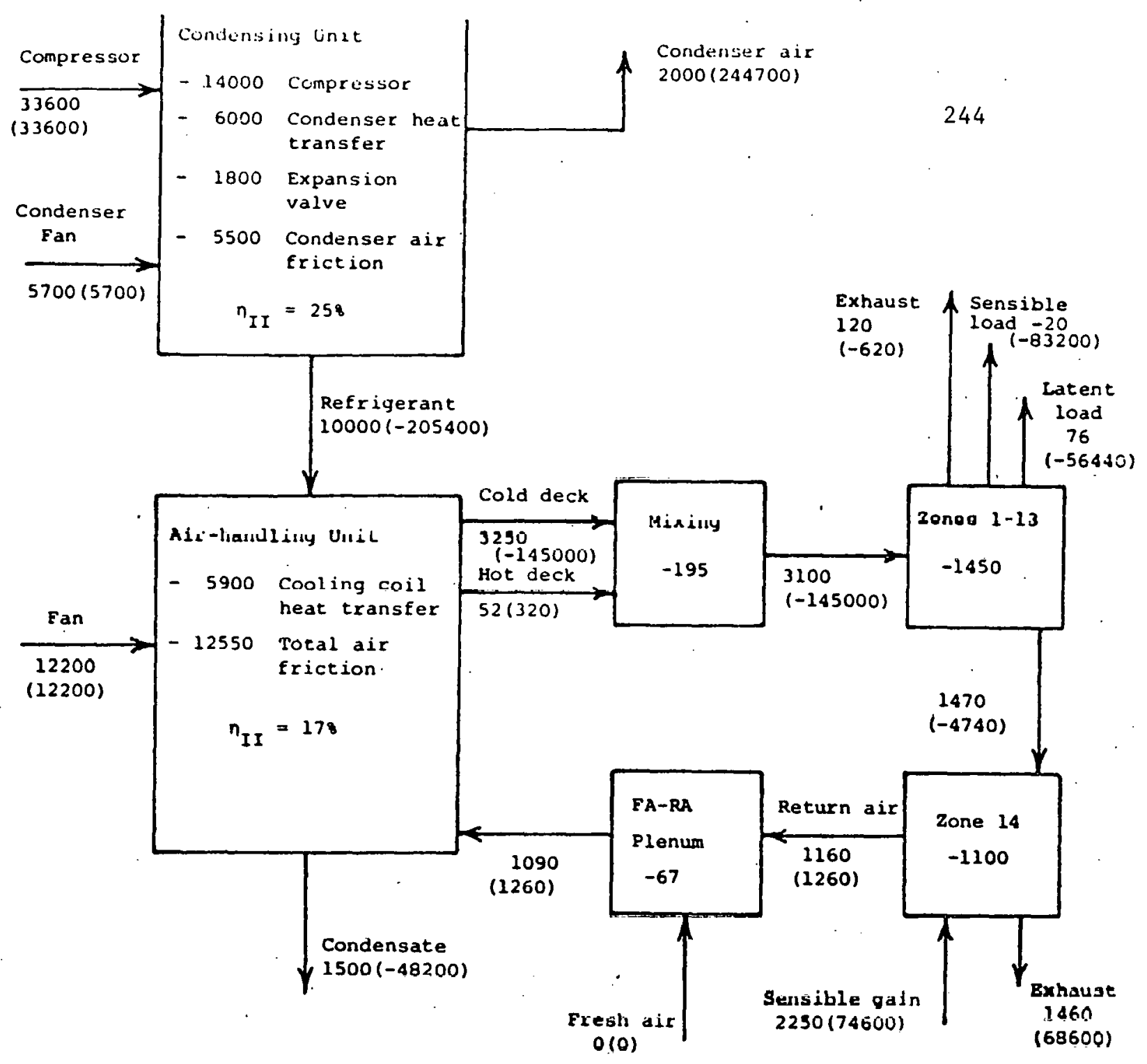

Fig. 5 Annual cooling (1300 hours) available energy flows, consumptions and energy flows in $\mathrm{kWh}$. Negative numbers represent available energy consumptions. Energy flows are shown in parentheses and are positive in direction of arrow.

efficiency is 4

$$
n_{I I}=\frac{-20+76}{33600+5700+12200}=0.001
$$

${ }^{4}$ Recall that, for summer design (Figure 2), the sensible available energy load is positive $(2.3 \mathrm{~kW})$ and the sensible energy load is negative $(-72 \mathrm{~kW})$ : The reason for this is that $T_{0}>T_{r o o m}$, and it follows from Eq. (2) that available energy and energy flow in opposite directions. However, for annual cooling (Figure 5 ), the majority of heat gains ( $\dot{Q})$ occur when $T_{0}>T_{r o o m}$ whereas the bulk of the sensible available energy transports occur during hours when 


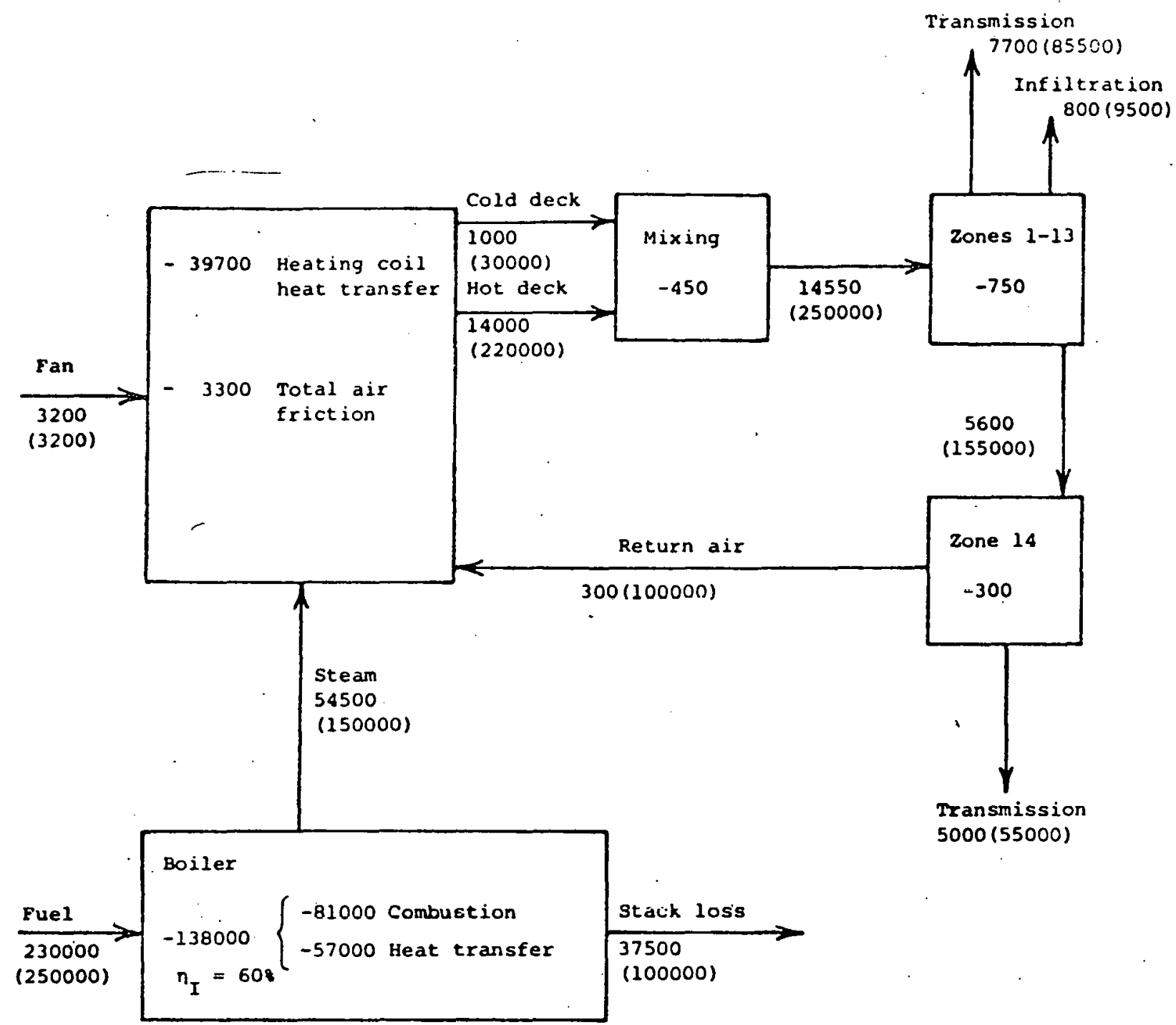

Fig.6 Annual heating (unoccupied, 3400 hours) available energy flows, consumptions, and energy flows in $\mathrm{kWh}$. Negative numbers represent available energy consumptions. Energy flows are shown in parentheses and are positive in direction of flow.

If the efficiency at which electricity is produced, ${ }^{5} n_{I I}=0.33$, is considered! then the amount of conling availablc energy divided by the available energy of the "energy" resource from which it was derived is

$$
n_{I I}=0.001(0.33)=0.00033
$$

$T_{\text {room }}>T_{0^{--t h a t ~}}$ is, the annual cooling available energy gains exceed the available enerqy loads.

${ }^{5}$ The first- and second-law efficiencies at which electricity is produced are approximately the same inasmuch as the energy content of power plant fuels ihudrnnartion finlal is nearlv eoual to the available energy content (21). 


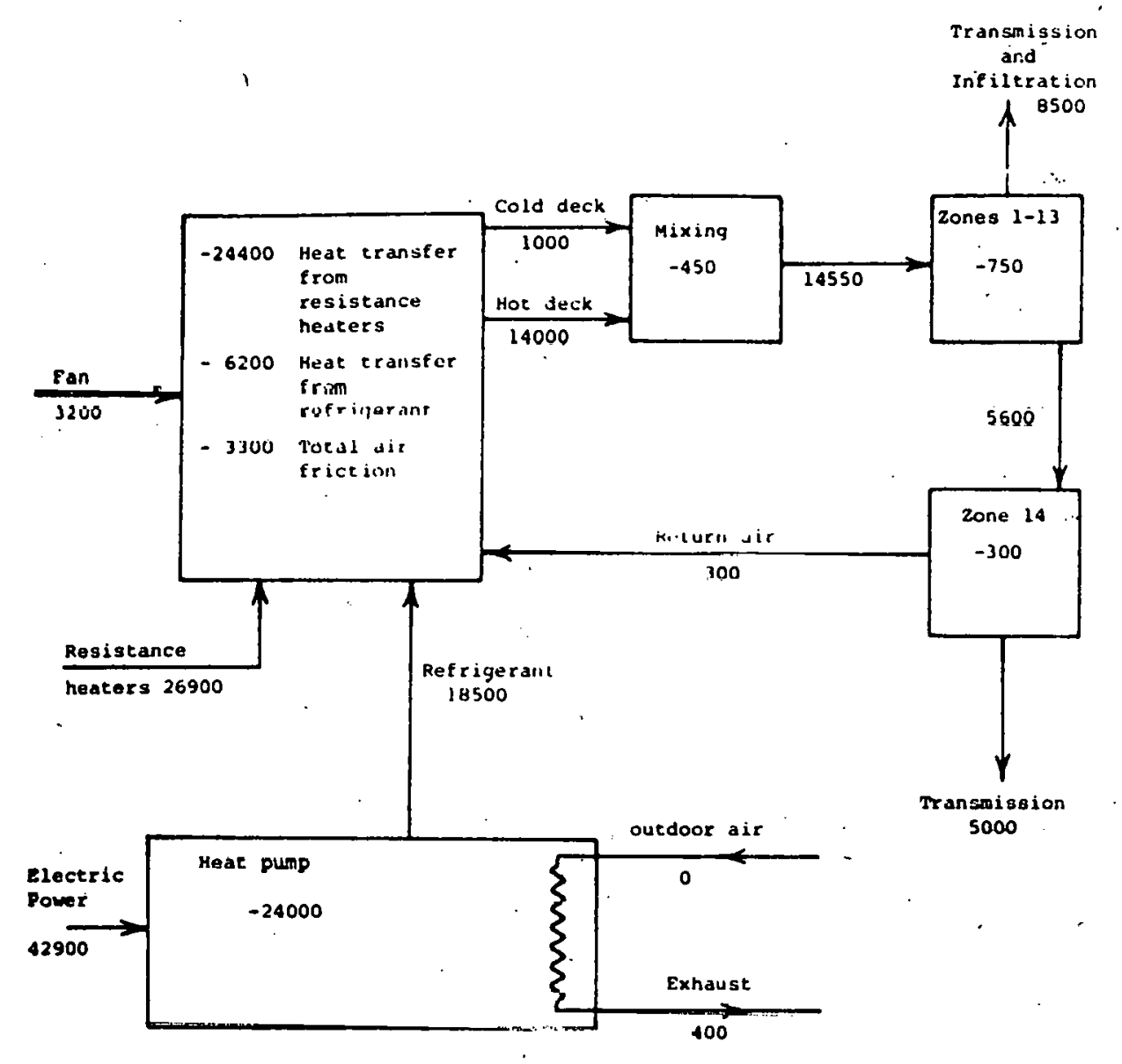

Pig. 8 Annual heating with heat pump (unoccupied, 3400 hours) available energy flows and consumptions in $\mathrm{kWh}$. Negative numbers represent available eneryy cuisumptions.

Tine efflclency of the aif adistribution dyetem excluting frtetion is

$$
n_{I I}=\frac{76}{3250+52-1090}=0.034
$$

Compared to design operation, there is little change in the relative significance of the various consunptions and losses. Notable differences for the annual period are (i) the decreased significance of the expansion valve losses, and (ii) the substantial increase in the relative consumption by compressor. Eriction. As would be expected, the overall annual performance, 0.001 , is much lower than that at design, 0.032 . This is due to primarily lower component efficiencies during off-design hours.

Can the various sizeable consumptions and losses shown in Figs. 2 and 5 be decreased? Invariably, yes! of course, each proposed means for improvement will in general call for added capital expenditure. However, before going into details, and before moving onto consideration of heating, the important 


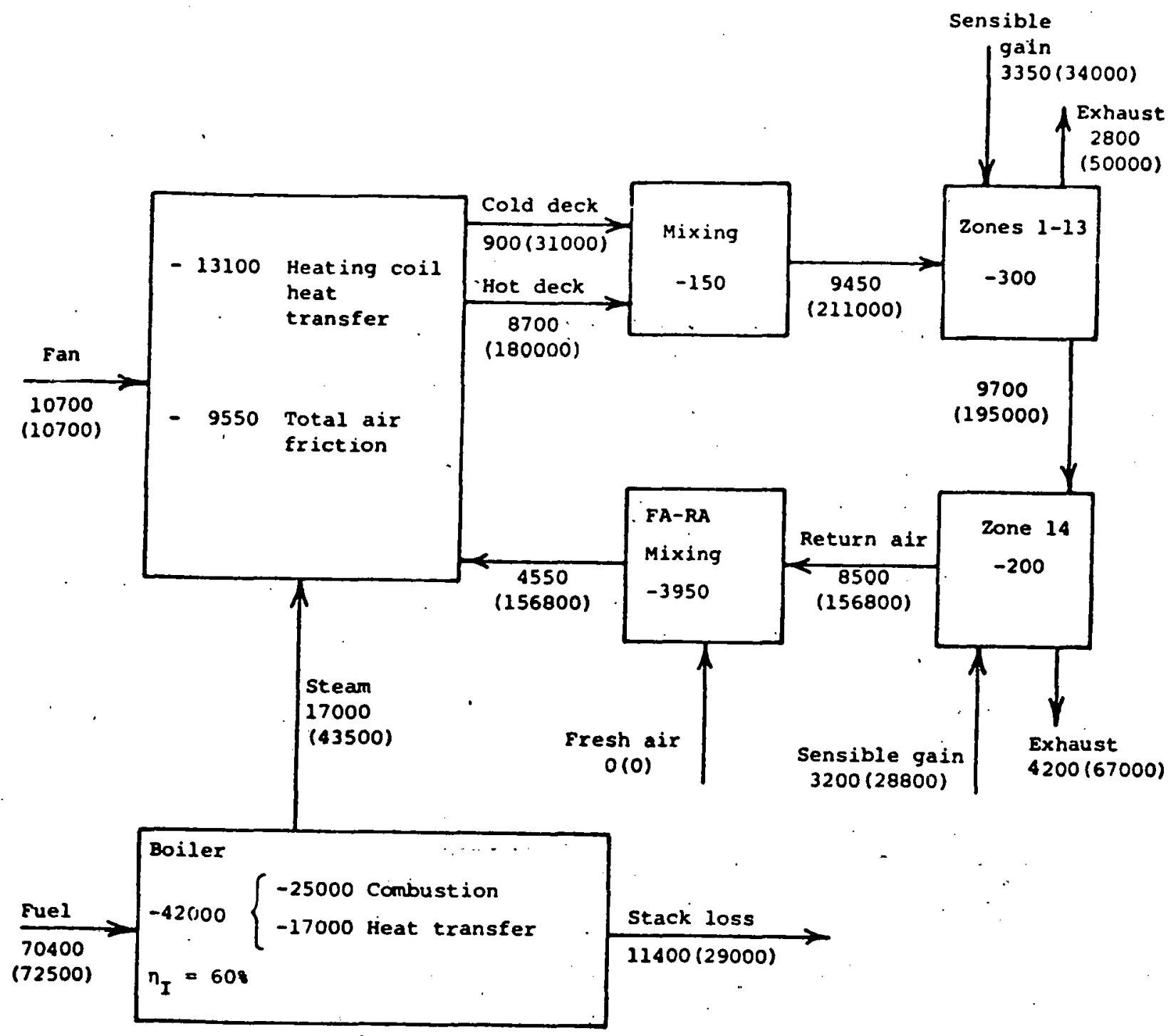

Fig.7, Annual heating (occupied, 1140 hours) available energy flows, consumptions, and eneryy flows in $\mathrm{kWh}$. Negative numbers represent available energy consumptions. Energy flows are shown in parentheses and are" positive in direction of flow.

The second-rlaw efficiency of the condensing unit, as shown, is

$$
n_{I I}=\frac{10000}{33600+5700}=0.25
$$

compared to $n_{I I}=0.33$ at design. That of the air-handing unit is

$$
n_{I I}=\frac{3250+52-1090}{10000}=0.22
$$

Actually the denominator here should include the available energy consumed in the coil pressure drop $(12200[2.3 / 8.5]$, where the 2.3 and 8.5 are from $F i g .2)$, so that

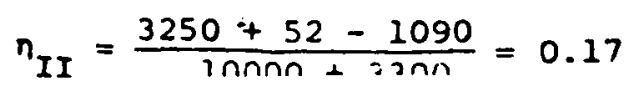




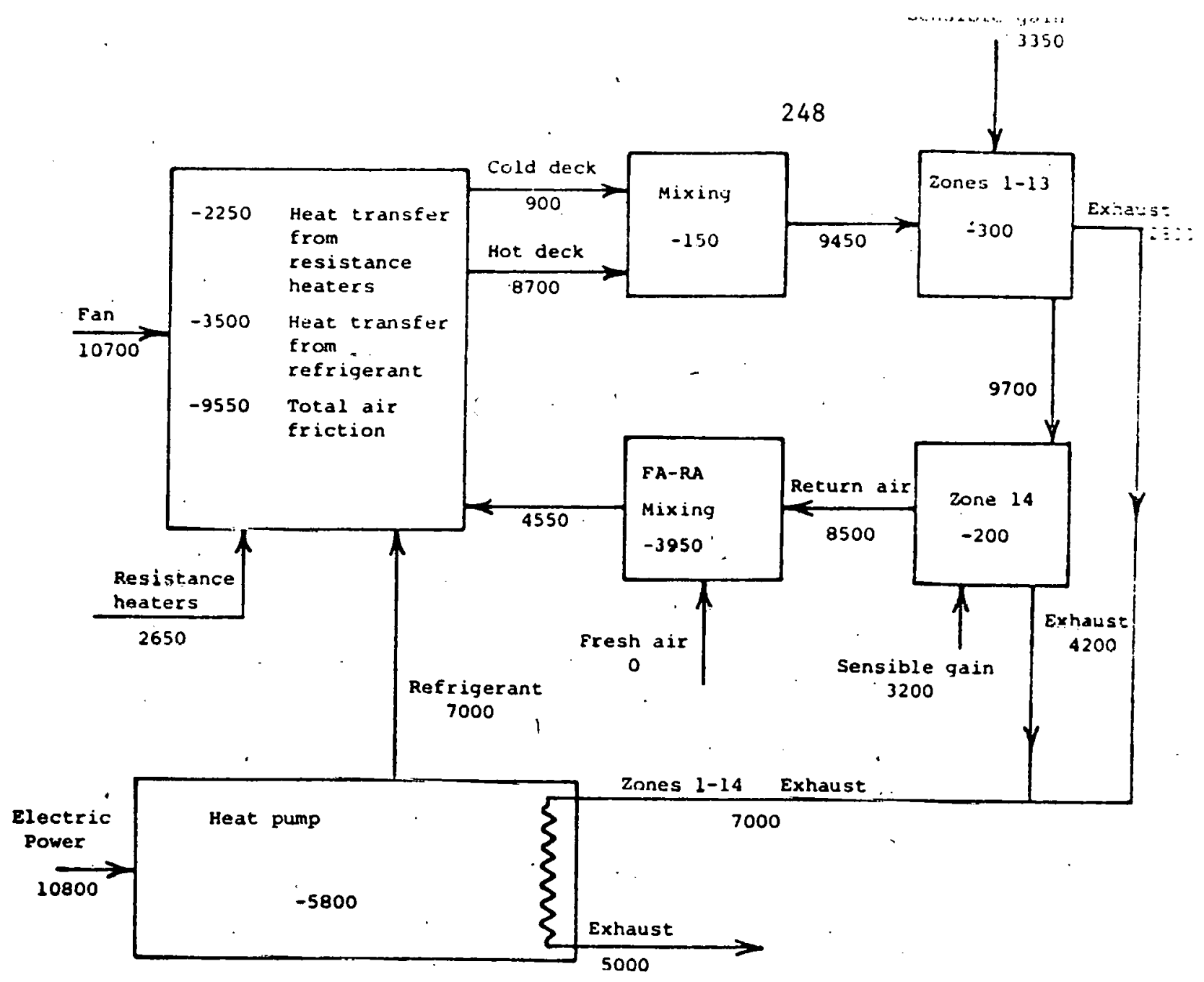

Fig.9 Annual heating with heat pump (occupied, 1140 hours) available energy flows and consumptions in $\mathrm{kWh}$. Negative numbers represent available energy consumptions.

general conclusion to be observed at this time is the extremely low efficiency of cooling systems.

\section{Winter Design (Heating)}

Next, consider Figure 3, which shows the performance of the system, during unoccupied hours, when winter design conditions prevail outdoors. The effectiveness of the entire system, including the production of electricity at $n_{I I}=0.33$ for driving the fan and assuming a furnace efficiency $\eta_{I}$ as high as 0.80 , is

$$
n_{I I}=\frac{11.4+1.2+6.5}{135+(8.8 / 0.33)}=0.118
$$

Thus, the amount of fuel resource consumed to provide the needed heating is ovez eight times the minimum; for every unit provided, over seven are consumed or lost, by inefficiencies, in the processes. 
There are very large consumptions used to accomplish the heat transfer and the chemical reaction. Heat transfer from combustion products to steam uses up $28.8 \mathrm{~kW}, 1 . e ., 28.8 \mathrm{~kW}$ for every $19.1 \mathrm{~kW}(\mathrm{a} 11.4+1.2+6.5 \mathrm{~kW})$ of system output. There is $41.8 \mathrm{~kW}$ consumed to drive the chemical reaction--uncontrolled combustion. This $41.8 \mathrm{~kW}$ plus $28.8 \mathrm{~kW}$ dwarfs the $105 \mathrm{~s}$ due to the traditional "furnace inefficiency"--the stack loss of $12.4 \mathrm{kWl}$ To transfer heat from steam to alr, $32 \mathrm{~kW}$ is consumed. (For the case with 10 psig steam, the total of consumptions and losses is the same as with 100 psig steam, if the boller ofEiclency is the same. With $10 \mathrm{psig}$ steam, the heat transfer consumptions are larger for the boiler and less for the coil, since the temperature difference between combustion products is greater while that between steam and air 13 less. Note that since that between steam and air is less, the case with less consumptian requires more coil surface area--the tradeoff between avallable energy consumption and capital cost. Similarly, for the same boller efficiency, less boller material is needed for the 10 psig boller.)

The total available energy consumption for distributing the air is $7.2 \mathrm{~kW}$. All other losses or consumptions are negligible compared to the foregoing.

Figure 4 depicts the situation when outdoor design conditions prevail during occupied hours. The circumstances are much the same as for unoccupied hours. as far as the relative size and importance of the different consumptions and losses are concerned. But there are at least two important differences. Because of the high internal gains there is really no net load on the system. The $8.2 \mathrm{~kW}$ and $9.6 \mathrm{~kW}$ leaving Zones $1-13$ and 14 are really not loads but losses--large losses--leaving in exhaust air.

Another important difference during occupied hours is that of the sizeable mixing losses, especially the mixing of cold fresh air $(-25.8 \mathrm{C}=-15 \mathrm{~F})$ with the hot return air $(24.2 \mathrm{C}=75 \mathrm{~F})$.

Annual Heating

Figures 6 and 7 show the annual available energy flows and consumptions, for heating during unoccupied hours and occupied hours, respectively, assuming a more realistic furnace efficiency of 60 percent. Even if the overall, annual furnace efficiency were 80 percent, the annual second-law efficiency of the system (and of each component) is somewhat less than under design conditions. (For exarple, the system efficiency for all the unoccupied hours turns out to be $n_{I I}=0.074$ compared to $n_{I I}=0.118$ calculated above for the design condition. With the more typical 60 percent furnace efficiency, $n_{I I}$ is 0.056$)$. The total annual load, for both occupied and unoccupied hours is $7700+$ $800+5000=13500 \mathrm{kWh}$. The total available energy supplied to carry this load is 10700 (occupied, fan) +70400 (occupied, fuel) +3200 (unoccupied, fan) + 230000 (unoccupied, fuel) $=314300 \mathrm{kWh}$, which yields $n_{\text {II }}=0.043$. The total amount of resources consumed, assuming that electric power is produced and delivered at $n_{I I}=0.33$, is $10700 / 0.33+70400+3200 / 0.33+230000=343000$. The overall true efficiency. $n_{I I}=13500 / 343000=0.039$ shows the effectiveness of resource utilization for heating.

For annual operation, the rulative sizes of consumptions and losses are similar to those under design conditions, except that those associated with the boiler--especially the stack loss--are larger as a result of the lower furnace efficiency.

An analysis was also made for a system with heating supplied by a heat pump instead of a boiler. Figure 9 shows the year-round operation for occupied hours. Aside from electricity supplied for air-distribution, the available energy supplied is $10800+2650=13450 \mathrm{kWh}$; if this electricity is produced with $n_{I I}=0.33$, the resource consumption is $13450 / 0.33=40800 \mathrm{kWh}$. This $40800 \mathrm{kWh}$ can be compared with the $70400 \mathrm{kWh}$ boiler input (Figure 7). During the occupied hours, exhaust air from zones $1-13$ and 14 is employed as the heat source for the heat pump, which suffices except at the extremes of cold weather.

During unoccupied hours, Figure 8 , outdoor air has been takepn as the source of heat and substantial supplementary resistance heating is needed: $26900 \mathrm{kWh}$ compared to the $42900 \mathrm{kWh}$ used by the heat pump. The total resource consumption for supplying these two is $(26900+42900) / 0.33=212000 \mathrm{kWh}$. Adding this to the $40800 \mathrm{kWh}$ for occupied hours, the total is $252800 \mathrm{kWh}$, which 
can be compared to $300000 \mathrm{kWh}$ for the boller. Note, too, that the resource which would be used for electricity production (coal) is generally less valuable than boller fuel (oil or natural gas).

Compare the effectiveness of the heat pump (PIgure 9) per se--compressor, condenser and exparision valve--with that of the bollex (Figure 7), for exanple. Although there is not a great difference between the two second-law efficiencles, it must be recognized that (1) the $3500 \mathrm{kWh}$ available energy consumption with heat transfer from refrigerant to distributed air 18 much less than the $13100 \mathrm{kWh}$ for heat transfer from steam to air--even when the $2250 \mathrm{kWh}$ resistance heat transfer consumption is added to the $3500 \mathrm{kWh}$. of course the lower consumption with heat transfer from refrigerant is accompanied by higher coll costs, since more heat transfer surface is needed (and usually by higher air friction costs since more alr is generally distributed, with a heat punp sysreal). The comparative flgures for both occupied and unoccupied hours are $35 n n+225 n+62 n n+2 \Delta \Delta n n$ - $3635 n \mathrm{kWh}$ (hast mump heat tranofor) veroue 13200 I

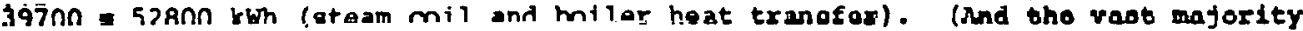
of the $36350 \mathrm{kWh}$ is the $24400 \mathrm{kWh}$ association with resistance heating during unoccupied hours, to be commented upon in Part II.)

Thus, when all of the consumptions associated with the use of a heat pump are compared with all those asscciated with a boiler, the heat pump has a higher efficiency. On the other hand, the available energy supplied to the heat pump (electrical) is more expensive than that supplied to a boller. Overall, though, the heat pung uses less resource--the aforementioned $252800 \mathrm{kWh}$ versus $300000 \mathrm{kWh}$ for the boiler.

\section{Conclusions}

A primary purpose of this study is to show how to ascertain how inefficientiy today's systems perform, and how to pinpoint and evaluate the true losses and consumptions. In turn, needs and opportunities for tmprovement can be accurately assessed; the real prospective savings of "energy" that could accrue from proposed improvements--whatever they might be--can be rationally determined. Then, decisions and investments of time or money can be made judiciously. Whereas, analyses made from an energy-efficiency viewpolnt can be very misleading.

For example, is there any hope for saving substantial amounts of energy by conservation? Some have scoffed at conservation, as a significant means for relieving our energy problems--at least over the long term. Others have reoognized the importance of conselvatiun, Lut have placed most all of the emphasis on better "end-use." Thus in the HVAC sector the stress is on belt-tightening--the prevent in nif Insses (and gaing) with bottar inaulation, fenestration, exhaust-air heat recovery, etc., as well as by reduced system use. Nelther group is aware of how great the potential savings really are, with conservation, because they do not realize how ineffictent the conversion. processes are. The biggest prospective sayings are in the converatinn procasses. not In end-use. And that is not to minimize the importance of end-use conservation. The important point is that energy analyses recognize losses only, they do not correctly evaluate the relative importance of different lostes, and they fail to recognize consumptions--which are generally much more important than the losses!

Cooling consumes nearly 1000 times the electricity than that which would be required if all the conversion processes were 100 percent efficient. Heating consumes about 25 times the minimum conceivable resource consumption.

The analysis assumes year-around use of a school in the upper midwest. Under such circumstances the annual consumption of electricity for cooling would be the total of the inputs shown in Figure 5, namely 51,500 kWh--corresponding to $156.000 \mathrm{kWh}$ of energy resources. The annual consumption for conventional heating is $300,000 \mathrm{kWh}$ of hoiler fuel plus $14000 \mathrm{kWh}$ of eleotrioity, totalling $343000 \mathrm{kWh}$ of resources--which is about 2.2 times that consumed for cooling. That puts the relative importance of inefficiencies in heating and cooling in porspective, for the upper midwest.

The analysis of the dual-duct system shows significant consumptions associated with air friction--pressure drops through ductwork, colls, etc.--even 
though the system is a low-pressure system $\left(2.0 \mathrm{in.}-\mathrm{H}_{2} \mathrm{O}\right.$ overall). Of course, In engineering practice this has been recognized implicitly if not explicitly. and hence we see a reversion back to low-pressure systems and more use of variable-volume systems. Also, the reduction of alr friction is one reason, among other more important ones to be mentioned later, that in the future we might well find ourselves employing more localized equipment rather than central equipment.

Perhaps this is an appropriate juncture to mention that the consumptions associated with the purping of water in systems employing chilled water and hot water--whether for distribution, or simply for transporting heat between central coils and "boiler" or chiller--are very large. And, in spite uf the conveniences of water systems, in design and operation, we will be seeirg mcre use of direct expansion and of stean boilers.

As shown in figure 5, for year-around cooling, the condensing unit is about 25 percent efficient; the heat transfer in the "air-handling unit" is. 22 percent efficient. The overall efficiency of the air-handling unit, including air flow friction attributable to $1 t$, is about 17 percent. The distribution system has $n_{I I}=3.4$ percent, exclusive of air flow friction; with friction, $n_{\text {II }}=0.5$ percent.

Obviously, there is considerable room for improvement, and as "energy" costs go up improved second-law efficlencies will follow. Even with no technological developtrents, additional capital will be spent for better, fefined equipment employing today's technology. We are already seeing more use of vari-pitch fans, to reduce air-friction losses, and of larger cooling coils to reduce the sizeable consumptions associated with heat transfer as well. Each unit of the heat transfer consumption saved realizes a sawings of

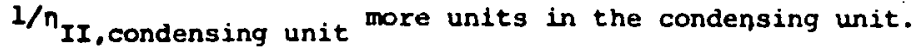

However, new technology with significantly improved efficiency will also be developed--novel hardware, and systems. (Variable-volume systems, no lónger novel, are a recent example.) Perhaps we will see completely new methods of refrigeration, which can inherentily achieve much higher efficiencies, or which are better suited to local systems in contrast to central systems. Meanwhile, more condenser heat transfer surface may be employed, and a return to slower compressors with less flow friction is conceivable.

In any case, the relatively low efficiencies of distribution systems, air-handling units and condensing units indicate, happily, that there is a significant margin for improvement, when economics dictateg such a need. Although the compressor efficiency at full capacity is not much better than at part-load, the inefficiencies of part load operation are significant. That is one more reason that local, in contrast to central, systems may become desirable--so that loads can be pinpointed better in space and time. Among the modifications to be described, one shows that central use of several smaller compressors rather than one large, unloading compressor does improve power utilization, but not extensively. Local systems would also help to reduce mixing losseg (suoh as the $1100 \mathrm{kWh}$ consumption in zone 14 तiring annual cooling), as well as enhance exhaust air "cold" and heat recovery.

Just as the relative inefficiencies of air-conditioning systems provide big opportunities for improvement, heating systems present a great potential for savings. The modes of capitalizing on the opportunities are the same as for cooling: refined equipment and systems, and new technology.

$\leftarrow$

At least for the school application at hand, it is evident that there are important prospective savings by reduction of the exhaust air losses during occupied hours, or by taking care of them more wisely. In fact, by and large, the yains in zones $1-13$ and 14 exeecd tho exhauot losega and could, by themselves, carry these losses; they would, if it were not for the large consumption associated with mixing fresh air with the return air.

As mentioned earlier, the combustion, and the furnace and coll heat transfer, are by far the biggest consumers of available energy during heating. The large available energy consumptions associated with heat transfer, to steam and from steam provide a clear--the only clear--quantitative measure of how inefficient it really is to burn fuels for low-temperature heating applications. For the cooling system, the heat transfer consumptions can be reduced considerably with increased heat transfer surface. For heating, the savings 
are miniscule, because the overall average temperature difference between combustion products and heated air cannot be influenced much. However, the conoumptions could be reduced somewhat by lowering the distribution-air flow rate-which would have an even blgger payoff in savings of air-flow friction consumption.

Larger than either of the heat transfer consumptions is that of combustion. Buming is extremely dissipative. As fuel costs increase, the use of "modernday" furnaces and "boilers" for comfort heating, will become out. of the question.

For high-temperature heating the heat transfer losses are considerably less--for example, in coal-fired power plant bollers (21) 6 . However, stack losses are inclined to be much greater, calling for exhaust heat recovery equlpwent. That equipment is expensive, and hence smaller high-temperature applicationg are apt to use resistance or induction hoating, even though very consumptive. Even when the application is at high temperatures with exhaugt heat recovery--such as the power plant boiler (21)--the very large combustion diogipationo aro inovitable, with buming. 7 Therefore, at some stare, $x$ loling fuel costs are going to preclude such uncontrolled chemical reaction--are going to lead to technological developments which will reduce the consumptions assoclated with chemical reaction kinetics.

At an intermediate stage, fuel costs will drive out low-temperature heating furnaces and boilers. The results presented here for heat pumps show the substantial savings--in amount and guality--of resources that can be accrued with them, with greater capital costs of course. Also, there is substantial room for improvement of heat pumps--as mentioned earlier for refrigeration cycles. The true efficiency of these cycles is much less than those of large power plants $\left(n_{I I}=0.33\right)$. Even though the capital invested in a refrigeration cycle per $\mathrm{kW}$ of available energy output will never approach that of large power plants, nevertheless one can expect their efficiencies to improve. In fact, large cryogenic cycles are approaching second-law efficiencles of 50 percent.

\section{CLOSURE}

The results of this study are for a particular type of system (dual-duct, etc.) with a particular application (a school) in a particular locale (the upper midwest), but the general conclusions are valid for HVAC systems in general. The true efficiencies of these systems are extremely low; hence there is great margin for improvement. These improvements will follow, as consequences of the inevitable increases in "energy" cost.s. Avaliahle energy analyses are of orucial importance, as guides for determining where and how large the inefficiencies and wastes are--and hence for determining the opportunities. They are also the first step in evaluating the monetary costs of different inefficiencies, the knowledge of which is valuable in regards to both optimal system design and operation (8, $15,18,22,23,24$; pp. 281-283).

The potential impact of improved second-law efficiencies in the HVAC sector is great, indsmuch as over 15 percent of the national energy consumption is devoted thereto.

It is evident from this study that the processes which are by far the qreatest consumers of avallable energy are compugtion and hoat tranofor. Research, motivated by economic need, will develop new technology for overcoming these waster--directly, with more efficient heat production, transport and transformation proçesses, and with more efficlent chemical

6 The heat-transfer consumptions in power plant boilers are considerably less yet large. It is these consumptions that topping cycles and dual cycles hope to reduce and thereby capitalize on. Likewise for MHD.

7 Efforts to enhance fuel utilization by improving "furnace efficiency," reducing the stack losses, are worthwhile, of course. But they miss the point 1 The really important "losses" in a furnace are the consumptions, in burning and heat trangfer. 
processes. 8 The more efficient chemical processes will also save heat transfer consumptions, either by eliminating the heat transfer or, as a consequence of lower reaction temperatures. . Indirect improvements will come from the development of new systems combining processes--old and new--in novel ways.

As mentioned earlier, energy analyses cannot locate or evaluate consunptions of "energy," because energy is consarved--energy cannot be cansumed or produced. At best, energy analyses can only determine energy losseg; in so doing, however, the importance of losses is generally misevaluated-often badly, as in the case of a power plant (21). The foregolng avallable energy methods for analyzing "energy" sygtens are the key to pinpointing the losses and consumptions, for measuring their magnitudes and resultant inefficiencies, in order to determine where opportunities for improvement and conservation lie, for the purposes of decision-making for allocation of resources--capital, RED effort, and so on. Available energy methods, which involve exactly the same kinds of calculations as energy analyses, show that

(1) There is need for new technology in energy conversion processes and systems.

(2) There is a great margin for improvement, which augurs well for the development of new technology.

(3) The motivation for acquiring and developing more efficient energyconservation equiprent and systems will be economic--responding to rising fuel costs.

\section{REFERENCES}

1 Gibbs, J. W. , 1875, Collected Works - Vol. I, Yale University Press, New Haven, 1948, pp. 77ff.

2 Keenan, J. H., "A Steam Chart for Second Law Analysis," Trans. ASME, Vol. 54, 1932, Pp. 195-204.

3 Keenan, J. H. , Thermodymamics, Wiley, New York, 1941.

4 Hatsopoulos, G. N. and Keenan, J. H. , Principles of General Thermodynamics, Wiley, New York, 1965.

5 Gyftopoulos, E. P., Keenan, J. H., Hat sopoulos, G. N. , "Thermodynamics," Encyclopedia Brittanica, 1975, pp. 290-315.

6 Obert, E. F., Thermodynamics, MCGraw-Hill, New York, 1948.

7 Obert, E. F., Concepts of Thermodynamics, MoGraw-Hill, New York, 1960.

8 Tribus, M. and Evans, R., Thermoecononics, UCLA Report No. 52-63, 1962.

9 Gyftopoulos, E. P., Lazardis, L. J., and widmer, T. F., "Potential Fuel Effectiveness in Industry--A Report to the Energy Policy Project of the Ford Foundation," Ballinger, 1974.

10 Hall, E. H., et al., "Evaluation of the Theoretical Potential for Energy Conservation in Seven Basic Industries," Report by Battelle Columbus Labriatolies to the Federal Energy Administration. Report No. FEA/D-75/CEl, July 1975.

11 Ross, M. H., and Socolow, R. H., et al., "Efficient Use of Energy: A Physics Perspective," ERDA Authorization - Part I, "Hearings before the Subcommittee on Energy Research . . . of the U. S. House of Representatives," Feb. 18, 1975, pp. 397-659.

12 Gaggioli, R. A., "The Concept of Available Energy," Chem. Eng. Sci..

vol. 16, 1961, Pp. 87-95. -...

13 Gaggioli, R. A. " The Concepts of Thermodynamic Friction Thermal Available Energy, Cheinical Available Eneryy and Therial Eneryy," Chem. Eng. Eci., Vol. 17; 1962, pp. 523-530.

14 Gaggioli, R. A. and Petit, P. J., "Second Law Analysis for Pinpointing the True Inefficiencies in Fuel Conversion Systems," ACS Sumposium Series, Vol. 21, No. 2, 1976, pp. 56-75. This article also appears in Chem Tech, Vol 1, No. 8, 1977, pp. 496-506.

${ }^{8}$ puel aelle strive to accompish this. 
15 Gaggioli, R. A. and Wepfer, w. J., "Avallable-Energy Costing--A Cogeneration Case Study," submitted to A.I.Ch.E. Journal (presented at the $85 \mathrm{th}$ national Meeting of A.I.Ch.E., Philadelphia, June B, 1978).

16 Wepfer, W. J., Gaggioli, R. A., Cbert, E. F., "Proper Evaluation of Available Energy for HVAC," submitted to ASHRAE, 1978.

17 Reistad, G. , "Avallable Energy Conversion and Utilization In the United States," Trans. A.S.M.E., J. Eng. for Power, Vol. 97, No. 3, 1975.

18 Gaggioli, R.A., "Proper Evaluation and Pricling of Energy." Proc. Int. Conf. on Energy Use Management, Vol. 2, Pergamon Press, 1977, pp. 31-43. 1970. 19 Bullding Energy Estimating Program (BEEP), American Electric Power,

20 Ratal, W.. "Heat Pump/Recovery System . . Cuts Costs," Actual Speclfying Engineer, April 1972, Pp. 71-76.

21 Gaggloli, R. A., at. Al., "Pinpointing tho Raal Inefflelencles In Powar Plants and Energy Systems," Proc. Aner. Power Conf., Vol. 37, 1975, pp. 656fe.

22 Gyftopoulos, E. P., and Widmer, T. P.. "Ef fective Energy End-Use-Opportunities and Barriers," Proc. Int. Conf. On Energy Use Management, II, Pergamon Press, 1977, pp. 45-55.

23 Fehring, T., and Gaggioli, R. A., "Economica of Feedwater Heater Replacement," Trans. A.S.M.E. J. Fing. Power, Vol. 99, 1977, pp. 482-489.

24 Obert, E. F.., and Gaggiozi, R. A., Thermodynamics, 2nd ed. , MoGrawHill, New York, 1962. 


\section{APPENDIX C. \\ Transportation System Analysis}

\section{a) The Automobile Efficiency}

The use of energy in connection with automobiles can be described by a number of figures of merit such as miles per gallon, indirect fuel use relative to direct fuel use, and various efficiencies. The question here is what in particular can be learned from efficiency measures?

The efficiency of the engine plus drive train (or transmission) of a car has been discussed in an Americal Physical Society Study. ${ }^{2}$ Given a particular car, with its air drag and weight and tires, the energy output at the drive wheels which will propel the vehicle through a particular driving cycle can be determined. This output can be evaluated as the energy to overcome three kinds of resistance: air drag, rolling resistance and braking resistance:

$$
E_{\text {out }}=E_{A}+E_{R}+E_{B}
$$

We w11 return to these terms below.

This output of rotational energy at the drive wheels is created through a series of transformation from input fuel energy. An ideal engine-drive train could transform the available work in fuel into an equal amount of energy at the drive wheels. For the engine-drive train of an actual car we show, in Table VIII, an analysis of the lost work. This early 1970's mid-weight car has an engine-drive train efficiency of $8 \%$ in the Federal Urban Driving Cycle and $14 \%$ in 60 m.p.h. * steady driving, where the efficiency is the ratio:

\footnotetext{
* Note how efficiency depends on the task variation here. For a discussion of energy requirements and speed, see T. VonKarman,...
} 
rotational energy output to drive wheels over the cycle fuel energy consumed over the cycle

The $14 \%$ highway efficiency means that, in principle, the engine and drive train could be improved for that purpose more than 7 fold. Any change even beginning to approach this degree of improvement would require radical changes in the engine - drive train. But there's a problem here. It is undesirable to devule too many resources to the engine-drive train; there may be more cosc elfecțve improvements.

We need a more general figure of merit. What other efficiencies might be defined for this car? This is a question we would like to explore in some detail because of its relevance to use of efficiency for monitoring purposes. Some notion of the various approaches to task definition was presented in the previous section. For purposes of illustration, we remain narrowly focused on automotive travel with a particular driving cycle. Instead of the task being to provide energy at the drive wheels, however, we extend the efficiency concept to the car as a whole. Recall that the general (second-law) efficiency is the ratio

input energy required by an ideal reference system actual energy input to perform the same task

The task will now he tn propel a car, ac required, with certaiu speclflcarlons about the three kinds of resistance mentioned above.

The numerator in the efficiency ratio, the 1deal energy requirement, is equal to the energy output made up of the three resistances. But now rather than having these resistances given, we allow for the fact they can be reduced. Consider the resistances in term.

The aerodynamic drag term, $E_{A}$, is the product of the air drag coefficient, $C_{0}$, which is small for highly streamlined vehicles, the square of the velocity (v) and the frontal area of the vehicle. The minimum 
frontal area can be approximated in terms of the vehicle weight (W) to the two-thirds power (to reduce the number of variables under discussion). We then have

$$
E_{A}=k_{o} w^{2 / 3} v^{2}
$$

where $k$ is a known constant. The inpact of a reduced drag coefficiont on the energy requirements of a car (e.g. ${ }^{-}$on $\mathrm{E}_{\text {out }}$ ) is shown in Figure 3. A series of points shows what has been achieved with a few existing vehicles and with aerodynamic models.

The rolling resistance term, $E_{R}$, is essentially determined by the Internal properties of the tire (or whatever will play the role of the tire in the future). The design of a tire is, in turn, adapted to safety (e.g. holding the road under various conditions) and comfort. A steel wheel rolling on a smooth steel rail has very low rolling resistance, but under present conditions such a technique cannor be used for cars. The rolling resistance can be written

$$
\mathrm{E}_{\mathrm{R}}=\overline{\mathrm{RW}}
$$

where the coefficient $\bar{R}$ is little influenced by the vehicle's velocity (except for very high speeds). The impact of creating a harder, more elastic, tire is shown in Figure 7. How this could be done retaining traction and anti-skid qualities is a major research issue. (see, e.g. Chapter 10, Vol. 2, O.T.A., "Change in the Future Use and Characteristics of the Automobile Transportation System, Feb. 1979). In the figure the Impact is simply that of over inflating the tire (a practice which reduces safety). 
The braking term $\sim$ the energy loss when the car is slowed by use of the brakes. This term can be neglected in evaluating highway driving but is comparable to the others in urban driving. The braking term can be written

$$
\mathrm{E}_{\mathrm{B}}=\mathrm{BW}
$$

where the coefficient $B$ depends on the decellerations occurring in the driving cycle under consideration. In principle B could also depend sensitively on design of the vehicle because the latter could incorporate a regenerative system depending, e.g., on a fly wheal or clectrical storage. We will neglect this possibility below.

If we are to define an efficiency for the whole vehicle, the task of moving the automobile through a driving cycle has to be supplemented by some specification of ultimate limits to which the resistances could be reduced. The energy output at the wheels now has the form

$$
E_{\text {out }}=\mathrm{kC}_{\mathrm{o}} \mathrm{W}^{2 / 3} \mathrm{v}^{\overline{2}}+\overline{\mathrm{RW}}+\mathrm{BW}
$$

where air drag coefficient, $C_{0}$, rolling coefficient, $\vec{B}$, and weight, $W$, are parameters strongly dependent on vehicle design. Any specification is somewhat arbitrary, which is an important fact about definition of effictency. Let us, for purposes of illustration, seleçt drag coefficient reduction by a factor of $1 / 3$, and weight and rolling coefficient reductions by $1 / 2$ each, as ultimate goals (all reductions are with respert to an average car in a . given weight class).

The 1deal level of energy output defined by these ultimate goals is indicated on Figure 7. Relative to an Ideal vehicle, which achieved these goals, the efficiency of present average cars in urban driving is $2.8 \%$ (for highway driving the corresponding figure is $3.1 \%$ ). 
What can be conclude from this exercise? An absolute measure of vehicular efficiency is highly arbitrary. Although one might be able to specify an ideal air drag coefficient, minimum weight and minimum rolling resistance are not fundamental quantities. Thus, although ultimate goals can be set for these characteristics these goals cannot be based on simple principles, This means that in an absolute sense a particular efficiency such as $3 \%$ has only a very crude quantitative significance. The relative performance of different vehicles in a given driving cycle, is a much more meaningful index. But such relative performance does not require defining an efficiency as such. The figure of merit miles per gallon provides the same relative information that vehicular efficiency sould. . We conclude that calculation of vehicular efficiencies would not add to the information already available from the figure of merit: miles per gallon.

b) Other Passenger Transportation Modes

The conclusion reached about energy monitoring on the basis of a vehicular efficiency in the case of the automobile also holds for other powered modes of paesenger travel euch as train, bus and airplare. An absolute efficiency would for any of these vehicles be highly arbitrary. Relative improvements and comparisons can be made using standard figures of merit for eneergy intensity such as fuel energy per vehicle mile and fuel energy per passenger mile. Such use of these figures of merit is shown by figures and tables from D. B. Shonker, Ed., "Transportation Energy Convervation Data Book, Edition 3; ORNL, Feb., 1979. Some of these for bus transport are attached for purposes of illustration as Figures 9, 10 and 11; and for air transportation as Figures 12, 13 and 14 . *For purposes of illustration one such use of the energy intensity measure is shown in Figure 8. 


\section{c) Freight Transportation (Truck)}

The conclusion reached about the usefulness of an efficiency measure for automobiles also applies to freight transportation. Efficiency measures would not provide more information than comparitive use of specific energy intensity measures already in use. Such applications are illustrated by Figures 11 and 12 taken from D. B. Shonker, cp cit.

Tab1eVII.

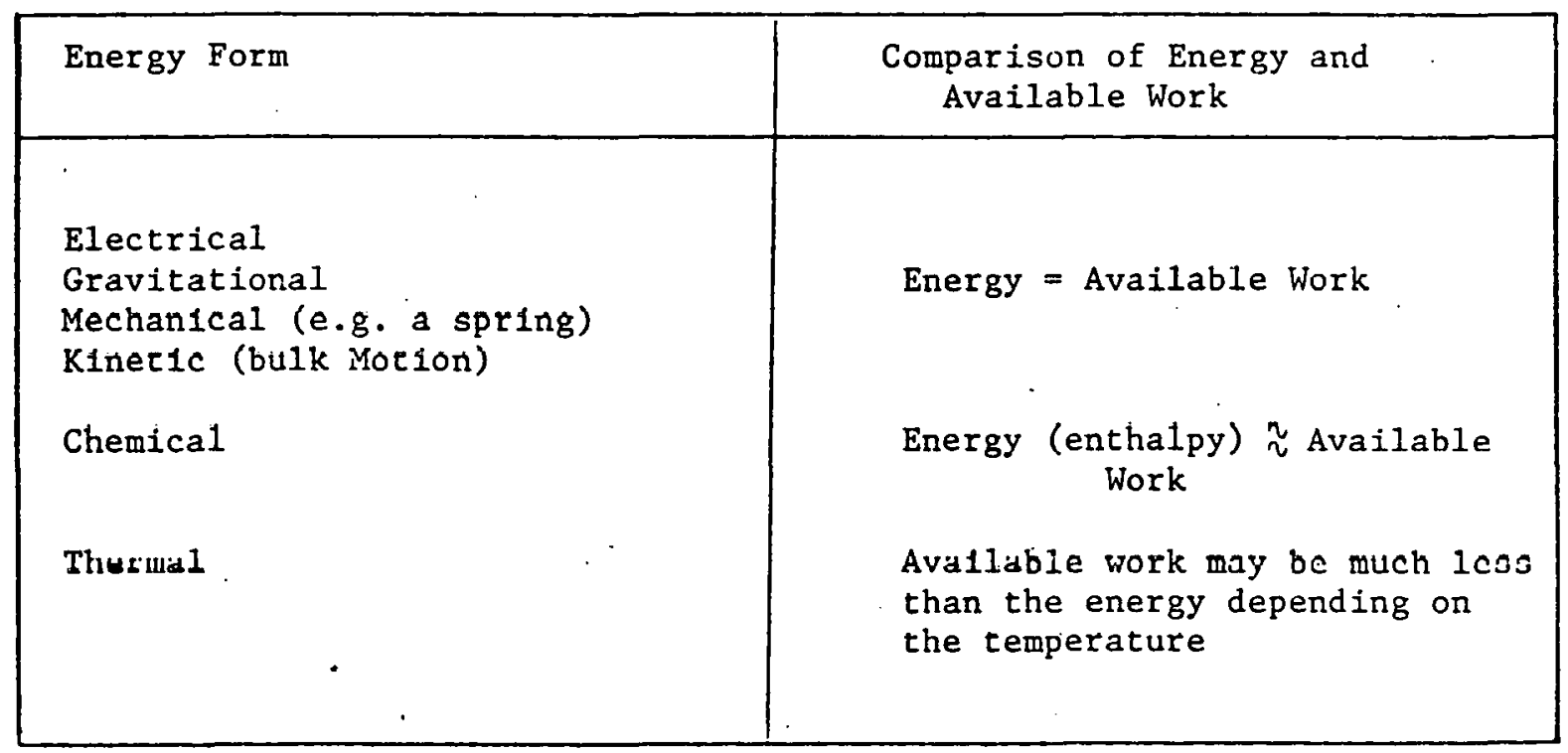


Tab? e VIII.

Consumption of available work and calculation of second-law efficiency for an "average" 3600-1b domestic automobile in two driving patterns $100 \times 10^{6} \mathrm{~J}$ of gasoline will power this vehicle for about 1900 seconds of the Federal Urban Driving Cycle for an average fuel consumption of $13 \mathrm{mpg}$, or for about 700 seconds at a constant $60 \mathrm{mph}$ on a level road for an average fuel consumption of $16.5 \mathrm{ml} g(7 \mathrm{~km} / 1)$. FUDC time and mpg are calculated using an additional 7.5 percent fuel for $1 d$ ling, which reduces $\varepsilon$ from 0.093 to 0.086 .

\begin{tabular}{|c|c|c|c|c|}
\hline \multicolumn{3}{|c|}{ Energy paths } & \multicolumn{2}{|c|}{$\begin{array}{l}\text { Net efficiency at } \\
\text { successive stages }\end{array}$} \\
\hline \multicolumn{2}{|c|}{$\begin{array}{l}\text { Fuel avallable } \\
\text { Commonly used lower heating value } \\
\text { Practical fuel-air otto cycle } \\
\text { Frictional losses }\end{array}$} & 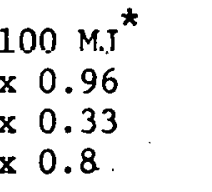 & & $\begin{array}{l}1.0 \\
9.96 \\
0.32 \\
0.26\end{array}$ \\
\hline$\cdot$ & $\begin{array}{l}\text { Federal urban } \\
\text { driving cycle }\end{array}$ & $\begin{array}{l}\text { Constant } \\
60 \mathrm{mph}\end{array}$ & FUDC & $60 \mathrm{mph}$ \\
\hline $\begin{array}{l}\text { Part-load losses } \\
\text { Accessories } \\
\text { Automatic transmission } \\
\text { losses }\end{array}$ & $\begin{array}{l}\mathbf{x} 0.75 \\
-3.5 \mathrm{~kW} \\
\mathbf{x} 0.75\end{array}$ & $\begin{array}{l}x \quad 0.7 \\
-4 \mathrm{~kW} \\
\mathrm{x} 0.9\end{array}$ & $\begin{array}{l}0.19 \\
0.12 \\
0.09\end{array}$ & $\begin{array}{l}0.18 \\
0.15 \\
0.14\end{array}$ \\
\hline $\begin{array}{l}\text { Work available at rear } \\
\text { wheels }\end{array}$ & $9 \mathrm{MJ}$ & $14 \mathrm{MJ}$ & $\varepsilon=0.09$ & $\varepsilon=0.14$ \\
\hline
\end{tabular}




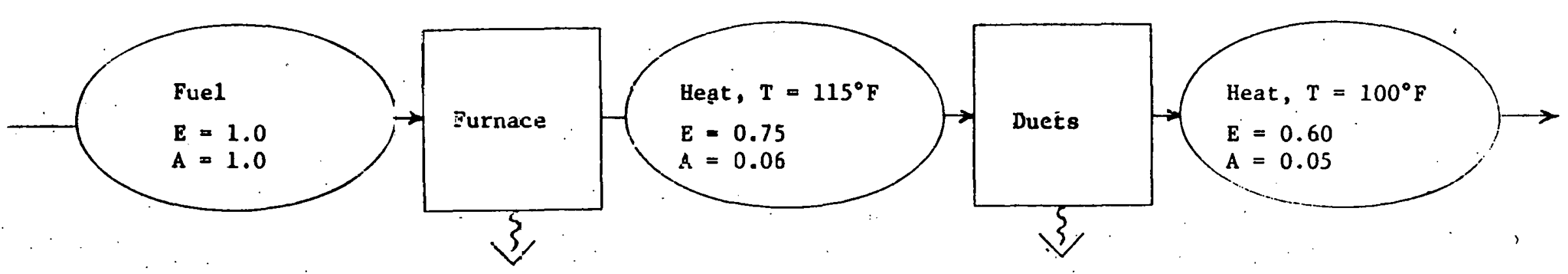

Lost Work $=0.94$

Lost Work $=0.01$

Figure 1. A household heating system, lost work analysis. Energies are evaluated as energy (E) and avallable vork ( $A$ ).

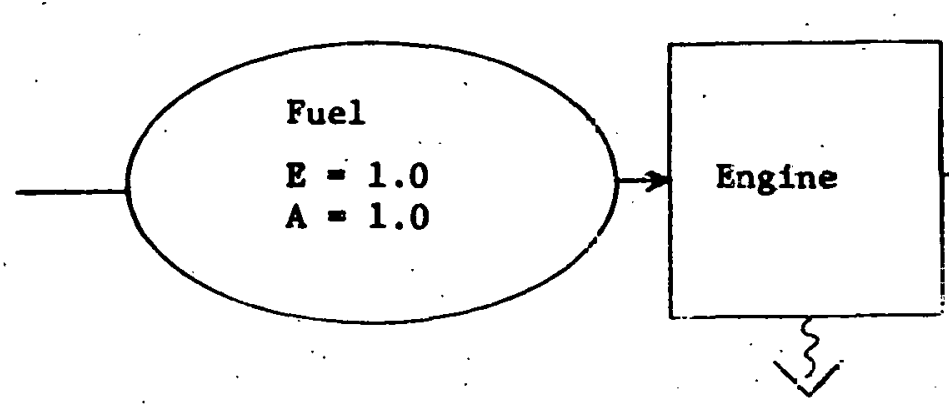

Lost Dork $=0.75$

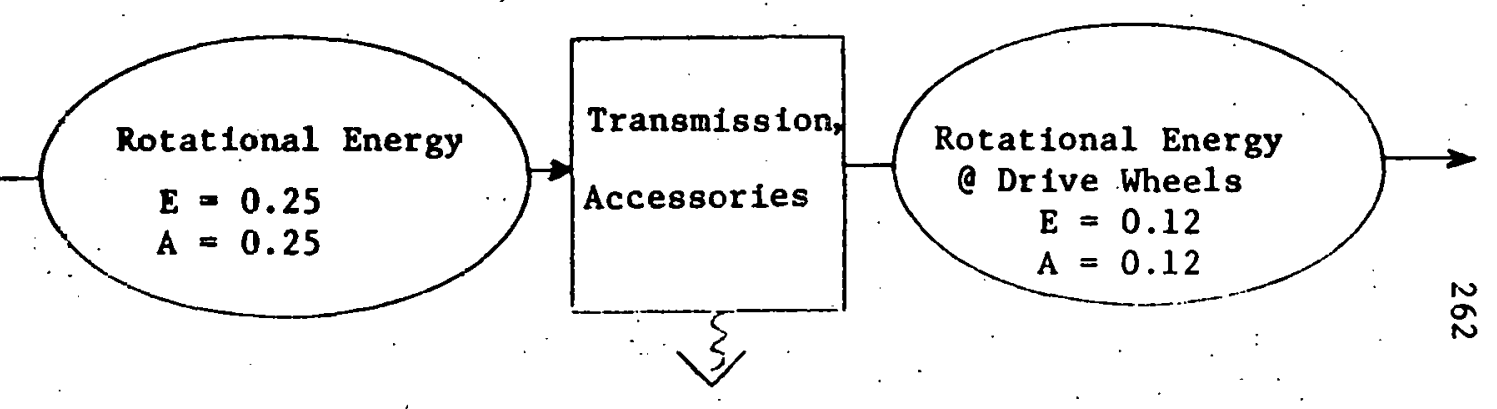

Lost Work $=0.13$

Figure 6, An automobile, loat work analyete. 
Figure 7. The energy requirement at drive wheels relative to a typical $2500 \mathrm{lb}$ compact car, in urban driving, as it depends on design parameters.

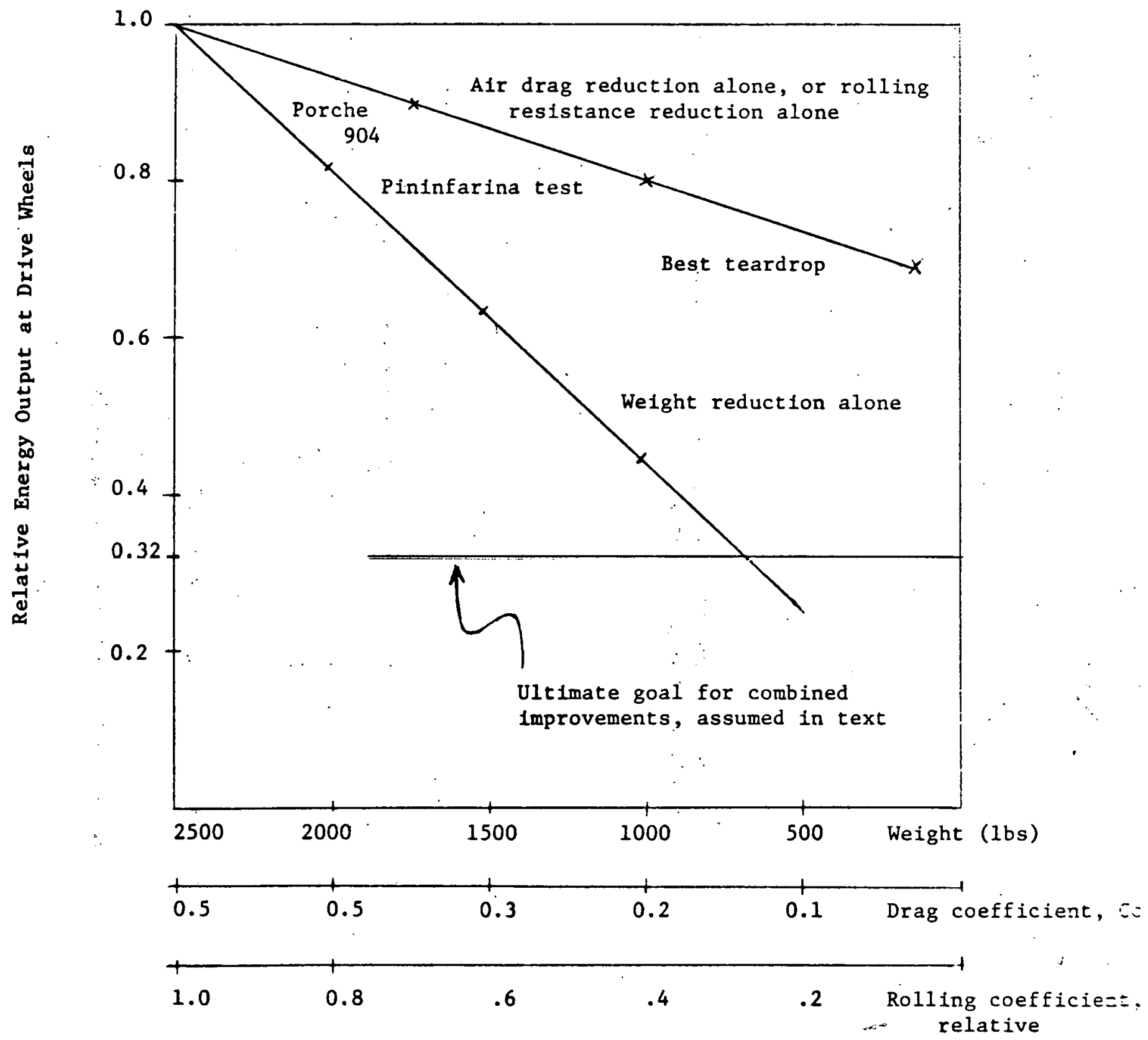


Figure 8 . The proportsonality relating energy performance and weigt.t of new autombiles

Energy Intensity

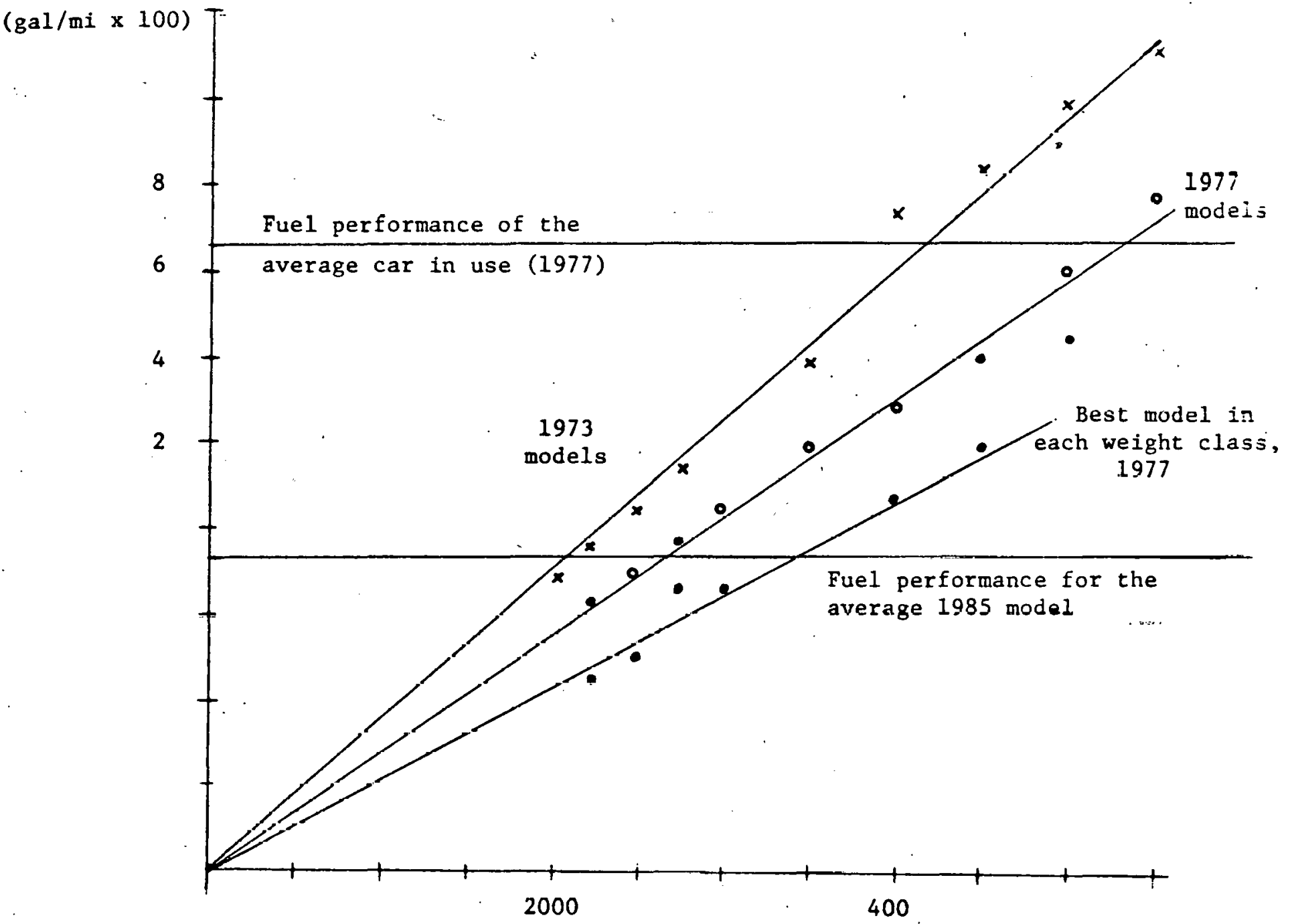

Inertial Welght (1bo)

Note: Inertial weight is curb weight pks 300 lbs.

Source: J.D. Nurrell et al and D.B. Shonka, Ed., Transportation Energy Consumption Data Bank, Edition 2, ORNL. 
Figure 9. 1976 Estimates of Passenger Transportation Energy Intensity. (Btu/route-passengermile).

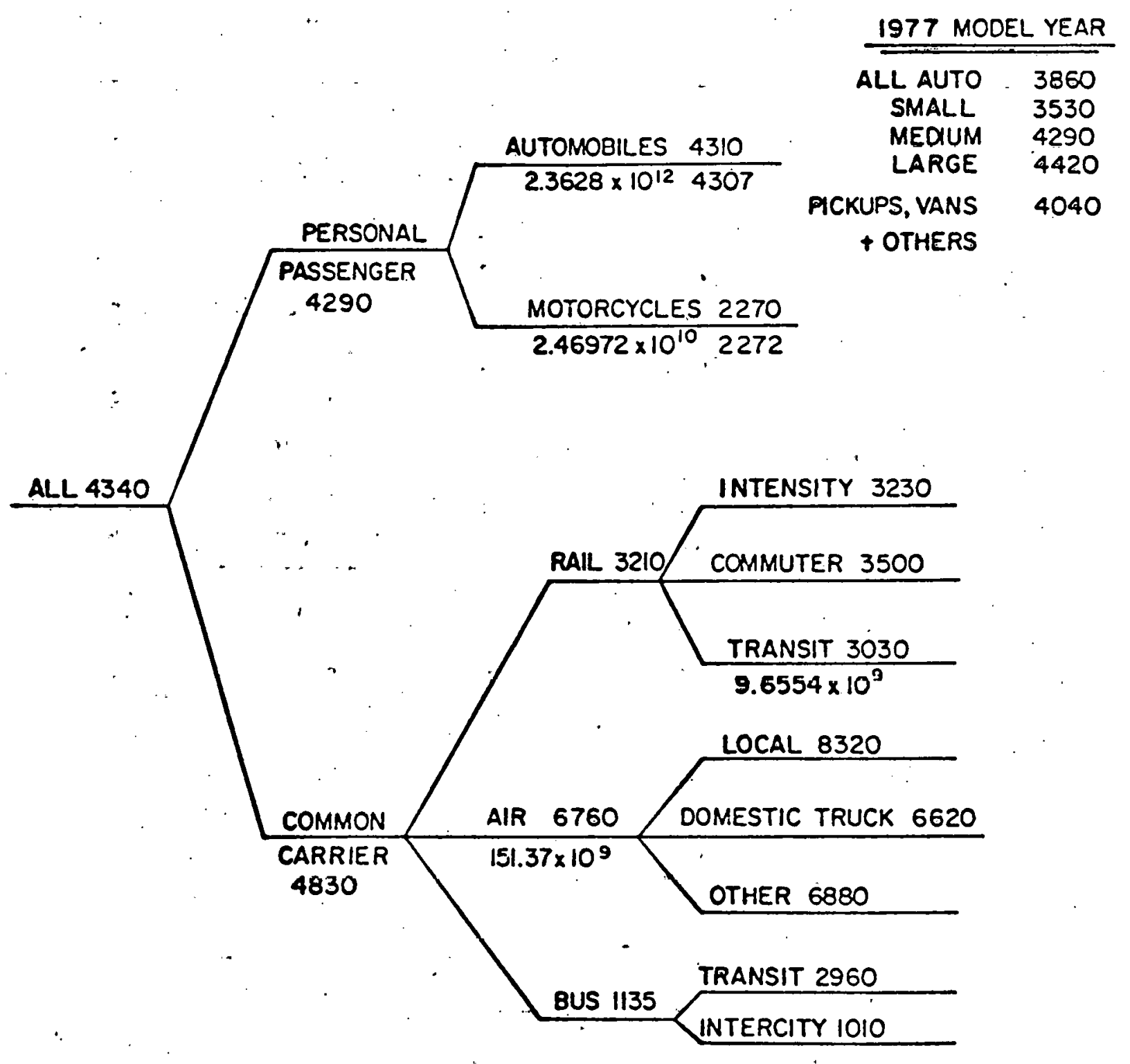


Figure 10. Buses serve a large variety of transportation needs. The intercity bus is the most energy efficient of the public passenger transportation modes.

Summary of Bus Energy Intensities, 1970 through 1977

\begin{tabular}{|c|c|c|c|c|c|}
\hline \multirow[b]{2}{*}{ ( } & \multirow{2}{*}{$\begin{array}{l}\text { Trolley } \\
\text { coaches } \\
\text { (Btu/VIT) }\end{array}$} & \multirow{2}{*}{$\begin{array}{c}\text { Transit. } \\
\text { buses } \\
(\text { Btu/VNT })^{a}\end{array}$} & \multirow{2}{*}{$\begin{array}{l}\text { School } \\
\text { buses } \\
\text { (Btu/MIT) }\end{array}$} & \multicolumn{2}{|c|}{ Intercity buses } \\
\hline & & & & $(B t u / V M T)^{\alpha}$ & $(B t u / P M)^{b}$ \\
\hline 1970 & 49,300 & 32,500 & 17,710 & NA & NA \\
\hline 1971 & 52,100 & 30,420 & 17,710 & NA & NA \\
\hline 1972 & 50,800 & 30,540 & 16,820 & 22,850 & 1,050 \\
\hline 1973 & 41,200 & 30,800 & 16,820 & 22,840 & 1,020 \\
\hline 1974 & $\mathrm{NA}$ & 31,520 & 16,850 & 22,300 & 960 \\
\hline 1975 & 44,300 & 33,750 & 16,960 & 22,280 & 990 \\
\hline 1976 & NA & 34,600 & 16,890 & 22,620 & 1,010 \\
\hline 1977 & NA & 35,100 & & 22,890 & 980 \\
\hline
\end{tabular}

alarge system-to-system variations exist within this category.

$b$ These values are calculated on a route-m1le basis. For purposes of intermodal comparisons they should be nultiplied by a circuity factor of 1.114 to convert them to a great-circle-mile basis.

NA - Not available.

Note: VNT - vehicle-miles traveled.

PM - passenger-mile.

Sources: American Bus Association, America's Number 1 Passenger Transportation Service, Washington, D.C., 1977, supplemented with private communications with the American Bus Association; American Public Transit Association, Transit Eact Book, '76-'77 ed., Washington, D.C., June 1977. 
Since the number of passenger-miles traveled on bus transit systems is not known, one must calculate all passenger energy intensities parametrically by assuming a trip length.*

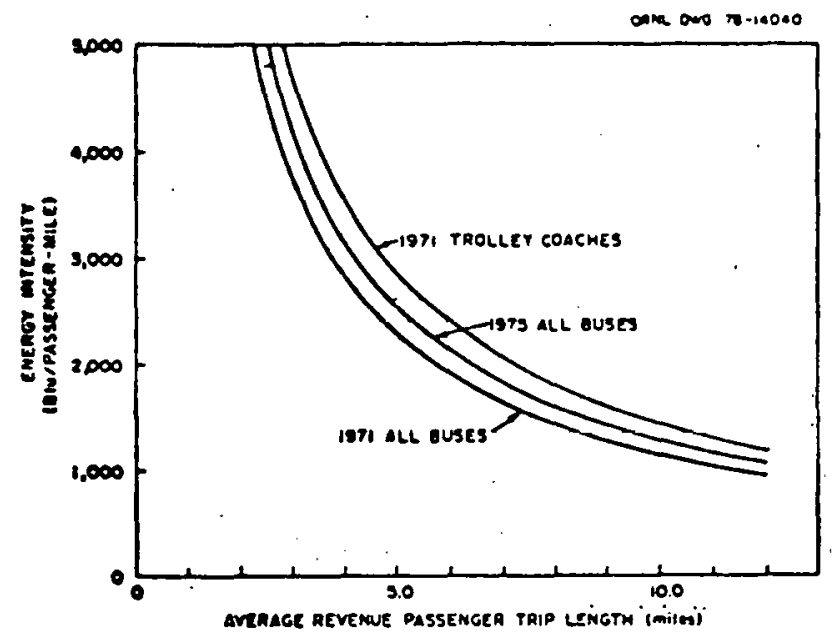

Figure 11. Variation of Transit Bus Enery Intensity with Passenger Trip Length.

-Calculated given that the energy intensity = total energy used (number of passengers $x$ trip length). The mean trip length in 1971 was 4.38 miles. Base data for other years: $1974,45.11 \times 10^{12}$ Btu, $4057.1 \times$ $10^{6}$ trips; $1975,51.51 \times 10^{12}$ Btu, $4150.9 \times 10^{6}$ trips; $1976,54.72 \times$ $10^{12}$ Btu, $4221.9 \times 10^{6}$ trips.

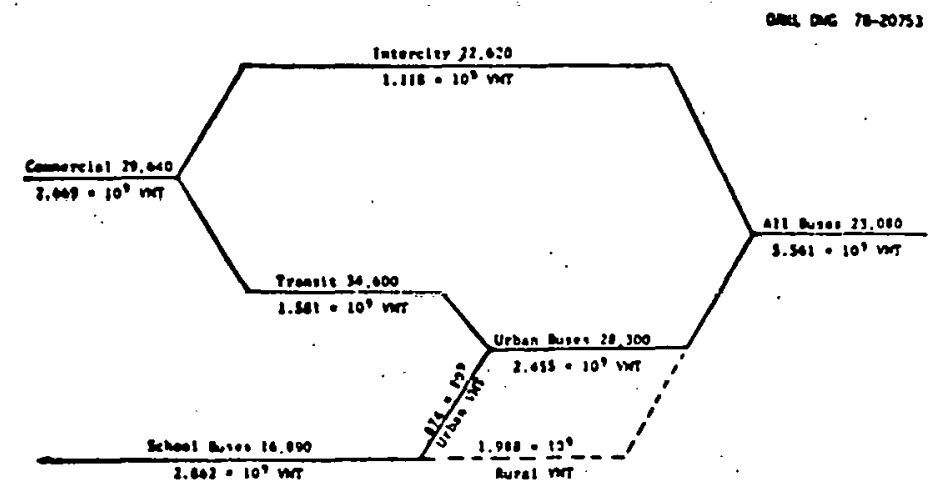

Bus Energy Intensity and VIT Summary. 1976.

(Btu per route vehicle-mile)

Source: A. B. Rose, The Energy Intensity and Related Paraneters of Selected Passenger Tronsportation Modes, ORNL-5506, Oak Ridge, Tenn., 1979. 
The energy intensity of the certificated route air carrier passenger service has shown marked improvements since 1971.

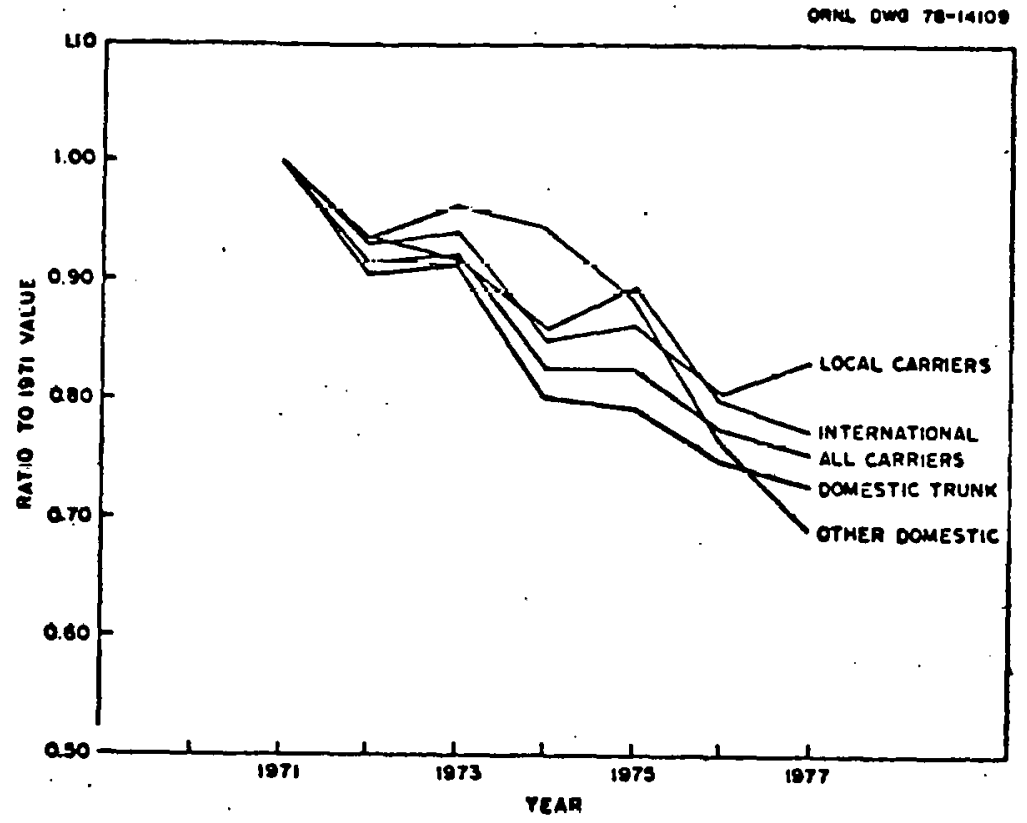

Figure 12. Certificated Route Air Carrier Energy Intensity in Btu Per Passenger-üile, 1971-1977, hormalized to 1971 values.

Certificated Air Carrier Passenger Energy Intensity, 1971 through 1977

\begin{tabular}{|c|c|c|c|c|c|c|}
\hline & \multicolumn{2}{|c|}{ Domestic } & \multicolumn{2}{|c|}{ International } & \multicolumn{2}{|c|}{ Total } \\
\hline & Btu/PM & $\begin{array}{l}\text { \% load } \\
\text { factor }\end{array}$ & Btu/PM & $\begin{array}{l}\text { load } \\
\text { factor }\end{array}$ & Btu/PM & $\begin{array}{l}\text { y luad } \\
\text { factor }\end{array}$ \\
\hline $\begin{array}{l}1971 \\
1972 \\
1973 \\
1974 \\
1975 \\
1976 \\
1977^{a}\end{array}$ & $\begin{array}{l}8920 \\
8130 \\
8200 \\
7240 \\
7180 \\
6760 \\
6580\end{array}$ & $\begin{array}{l}48.6 \\
52.6 \\
52.2 \\
55.9 \\
55.0 \\
56.2 \\
56.6\end{array}$ & $\begin{array}{r}6510 \\
6080 \\
6020 \\
5630 \\
5860 \\
5230 \\
5070\end{array}$ & $\begin{array}{l}56.6 \\
60.3 \\
58.4 \\
56.8 \\
54.4 \\
58.6 \\
59.9\end{array}$ & $\begin{array}{l}8290 \\
7590 \\
7650 \\
6870 \\
6870 \\
6440 \\
6260\end{array}$ & $\begin{array}{l}50.5 \\
54.5 \\
53.6 \\
56.1 \\
54.9 \\
56.7 \\
57.2\end{array}$ \\
\hline
\end{tabular}

a Based on data for first three quarters.

Note: $P M$ - passenger-mile.

Source: National Archives and Records Service, Machine Readable Archives Division, CAB Form 41 Schedule $T-2$, Washington, D.C., 1970-1977. 
These large improvements in energy intensity are due to a combination of improved load factors and a series of operational improvements such as reduced cruising speeds, improved maintenance, use of cruise climb, reduced holding, and grounding of inefficient aircraft. It is possible to differentiate between these effects in an analytical fashion at the aircraft class level.

ORNL OWG 78.20741

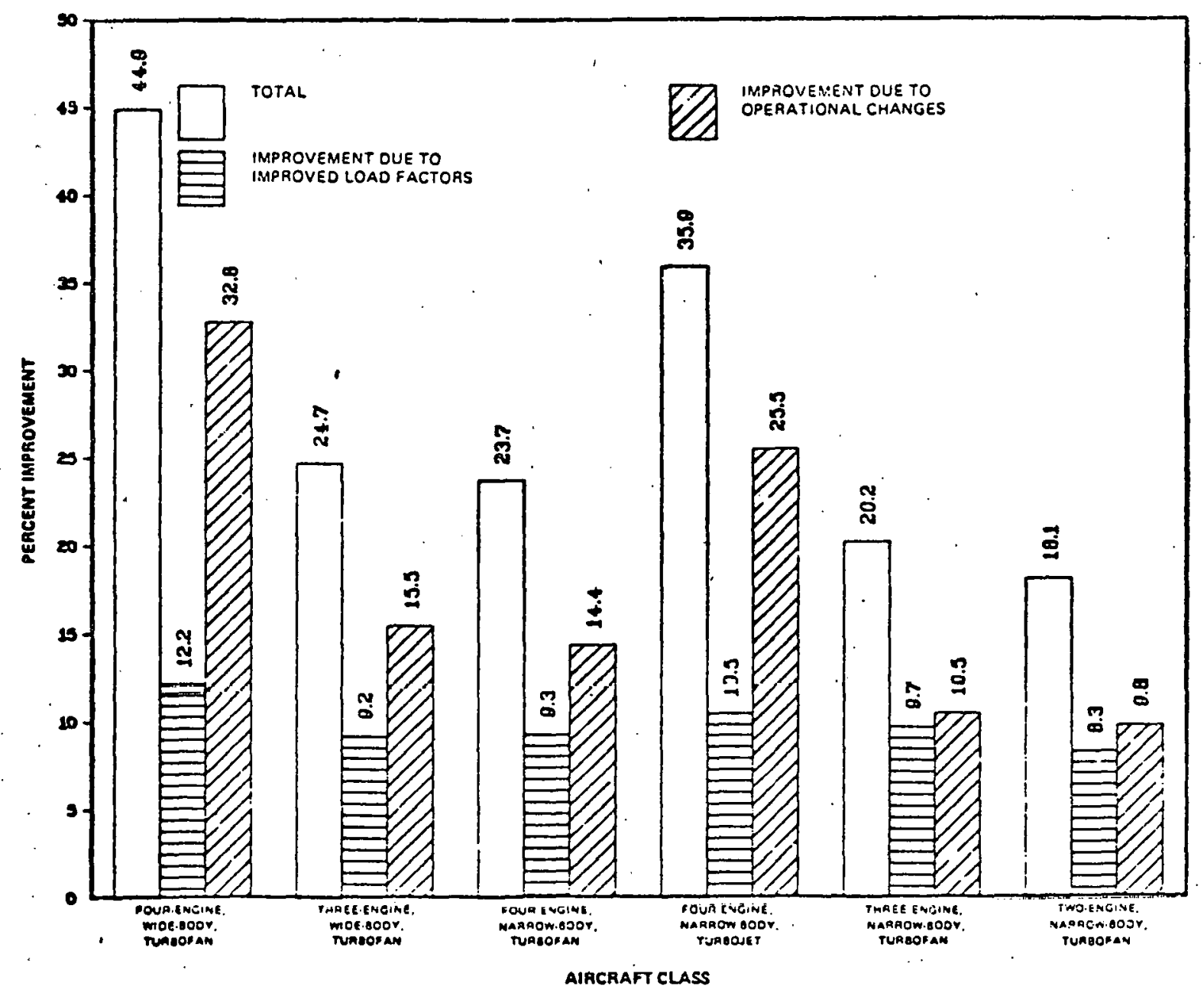

Figure 13. Summary Breakdown of Aircraft Efficiency Improvement, 1971-1976.

Source: A. B. Rose, The Energy Intensity and Related Parameters of Selected Passenger Transportation l'odes, ORVL-5506, 0ak Ridge, Tenn., 1979. 
RNL DWG 78-20747

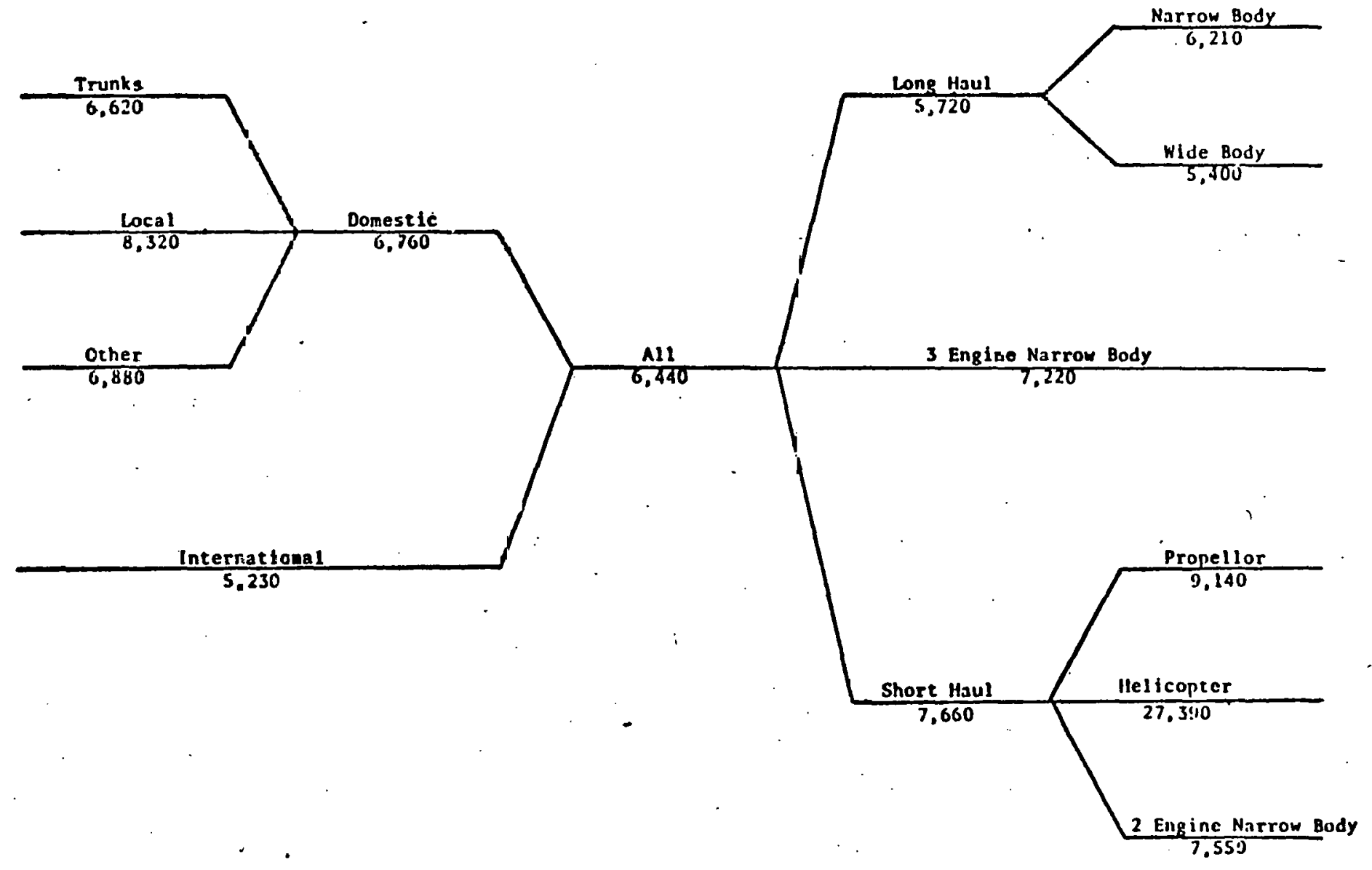

Figure 14. Summary of Certificated Route Air Carrier Energy Intensity, 1976.

Source: National Archives and Records Service, Machine Readable Archives Division, CAB Form 42 Scheduze $r-2$, Washington, D.C., 1970-1977. 


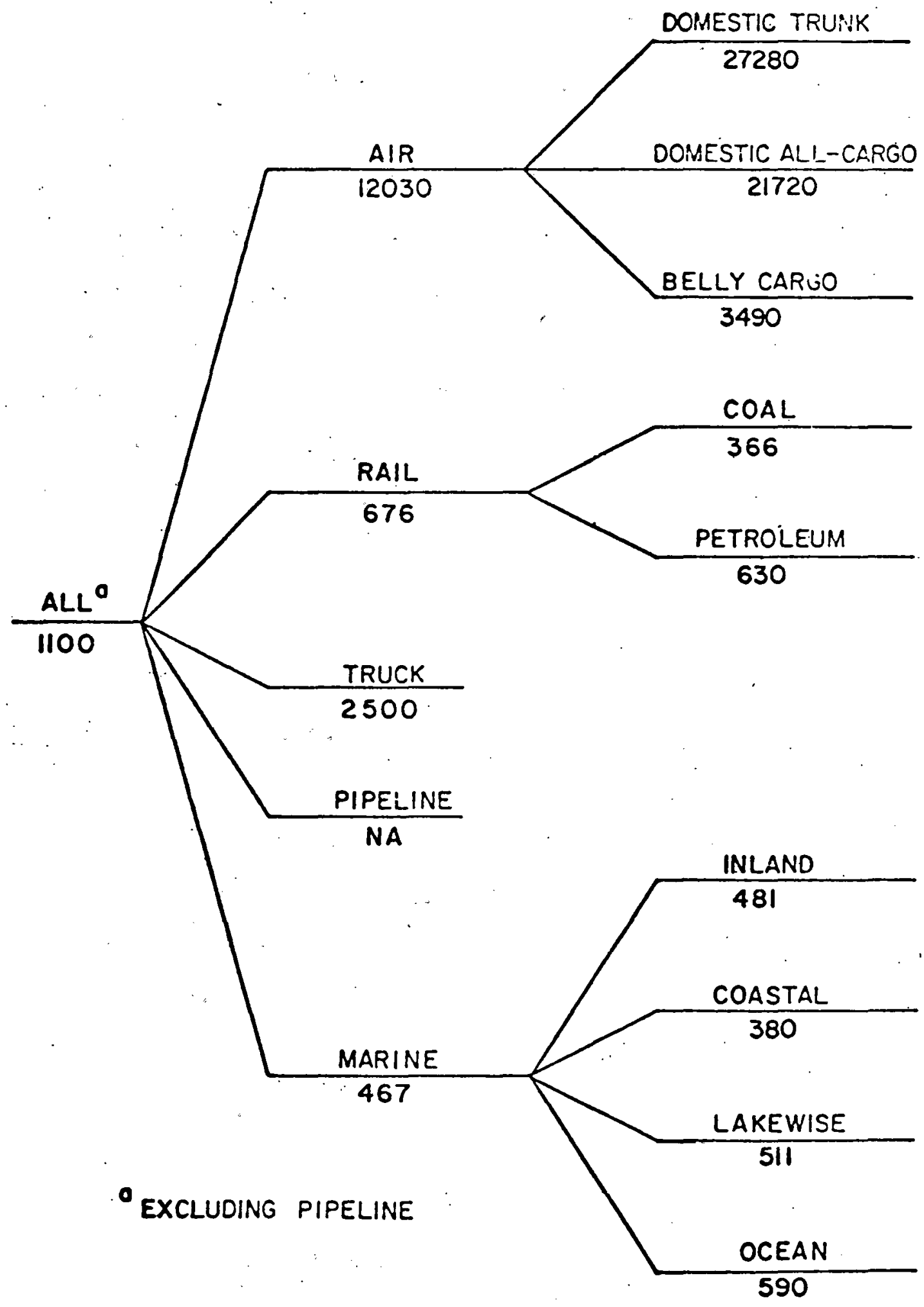

Figure 15. Domestic, Freight Energy Intensity, 1976. (Btu/route-ton-mile) 
The large intercity trucks, with gross vehicle weights over $5,0001 \mathrm{~b}$, should be singled out because they account for the overwhelming majority of all truck cargo ton-miles. Their energy intensity under actual operating conditions is approximately 2500 Btu/Route-Ton-Mile. However, many of the new trucks entering the fleet are equipped with a series of energy-saving options which will decrease this value substantially in the near future. The savings potent1al from these options, outlined in Figure 12, are based on the actual operating experience from the trucks already so equipped.

Figure 16. Energy Efficlency Improvements Possible Through Selected Options.

\begin{tabular}{|c|c|}
\hline Option & $q$ efficiency improvement \\
\hline $\begin{array}{l}\text { Aerodynamic aids (wind } \\
\text { deflector, fairings) }\end{array}$ & $\begin{array}{c}5 \% \\
\text { (mostly around 3\%) }\end{array}$ \\
\hline Demand actuated fans & 68 \\
\hline Radial tires & $10 \%$ \\
\hline Fuel economy engines & 208 \\
\hline \multicolumn{2}{|l|}{ Maltiple trailers } \\
\hline $\begin{array}{l}\text { Doubles } \\
\text { Triples }\end{array}$ & $\begin{array}{r}5 \% \\
28 \%\end{array}$ \\
\hline
\end{tabular}

Source: Jack Faucett Associates Inc., Truck Fleet Experience with Fuel Economy Improvement Measures, Chevy Chase, Md., 1976. 


\section{United States}

\section{Department of Energy}

Washington, DC 20585

PENALTY FOR PRIVATE
USE TO AVOID PAYMENT
OF POSTAGE, \$300
DOE 350

Official Business

Penalty for Private Use, $\$ 300$

THIRD CLASS MAIL 